\title{
DRAFT
}

MLM-3719

\section{Health Physics Manual of Good Practices for Tritium Facilities}

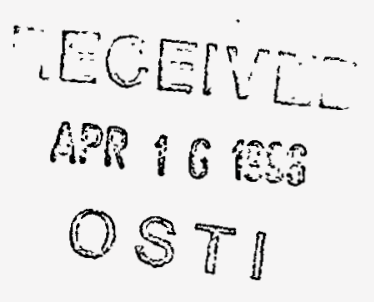

DSTRIBUTION OF THS DOCUMENT IS UNLHMTA

\section{December 1991}

\author{
U.S. Department of Energy
}

Assistant Secretary for Environment, Safety, and Health

Office of Health

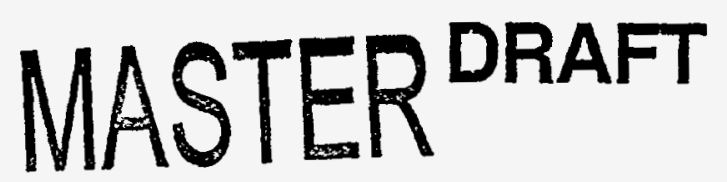





\section{Foreword}

[To be written by the DOE] 


\section{Preface}

This guide was prepared at the request of the Radiological Controls Division, Office of Nuclear Safety, Department of Energy, Germantown, Maryland. The lead contractor in preparing the document was EG\&G Mound Applied Technologies, which operates the Mound facility in Miamisburg, Ohio. The following DOE sites contributed to this document:

- General Electric/Pinellas

- Idaho National Engineering Laboratory

- Sandia National Laboratories, Livermore

- Los Alamos National Laboratory

- Lawrence Livermore National Laboratory

- Battelle Pacific Northwest Laboratory

- Savannah River Site

Input was also obtained from the following non-DOE facilities: Atomic Energy of Canada Limited - Chalk River National Laboratory, the Canadian Fusion Fuels

- Technology Project, and KMS Fusion, Incorporated.

The document was revised to incorporate the contributions and comments from each site following a review of the original draft. It is presented as a consensus document, although it is recognized that there are valid differences in operations, inventories, design criteria, and operating philosophies among the various facilities.

The "good practices" described in the document directly contribute to good radiological safety performance at tritium facilities. It will also enhance existing programs designed to protect the health and safety of the public and the environment. This document can be used as a reference by DOE and contractor personnel. It is not a regulatory standard. It is not intended to establish performance standards or design criteria. 
 


\section{Acknowledgments}

The Mound authors would like to thank the following for their valuable input:

- John Bartlit

Los Alamos National Laboratory

- Robert Burkhart

General Electric/Pinellas

- Ray Cooperstein

U.S. Department of Energy

- Lisa Gordon

Lawrence Livermore National Laboratory

- Jose Gutierrez

- Los Alamos National Laboratory

- Ron Hafner

Lawrence Livermore National Laboratory

- Jim Hentges

Savannah River Site

- Doug Holland

Idaho National Engineering Laboratory

- Bill Holtzlander

Chalk River National Laboratory

- Roland Jalbert

Los Alamos National Laboratory

- Jerry Martin

Battelle Pacific Northwest Laboratory

- DeVaughn Nelson

U.S. Department of Energy

- Don Putz

Sandia National Laboratories, Livermore

- Dan Slack

General Electric/Pinellas

- Clark Souers

Lawrence Livermore National Laboratory

- James Stafford

Savannah River Site

- George Stephens

Savannah River Site

- Vincent Vis

KMS Fusion, Inc.

- William Wall

Sandia National Laboratories, Livermore

- John Widman

KMS Fusion, Inc.

- Kam Wong

Canadian Fusion Fuels Technology Project 


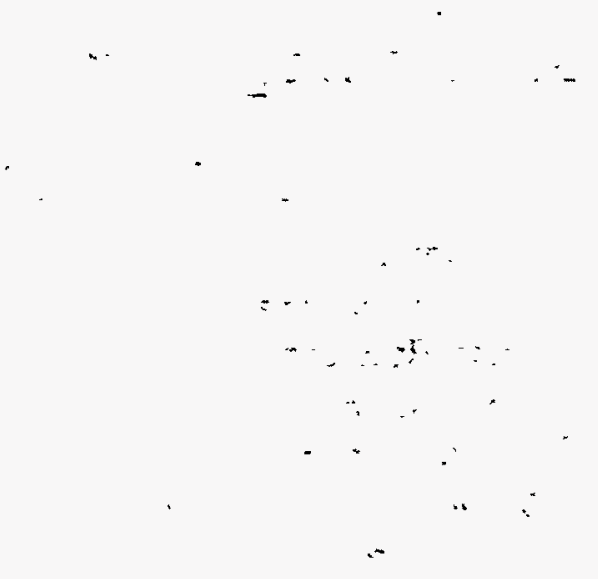

,

[This page intentionally left blank.]

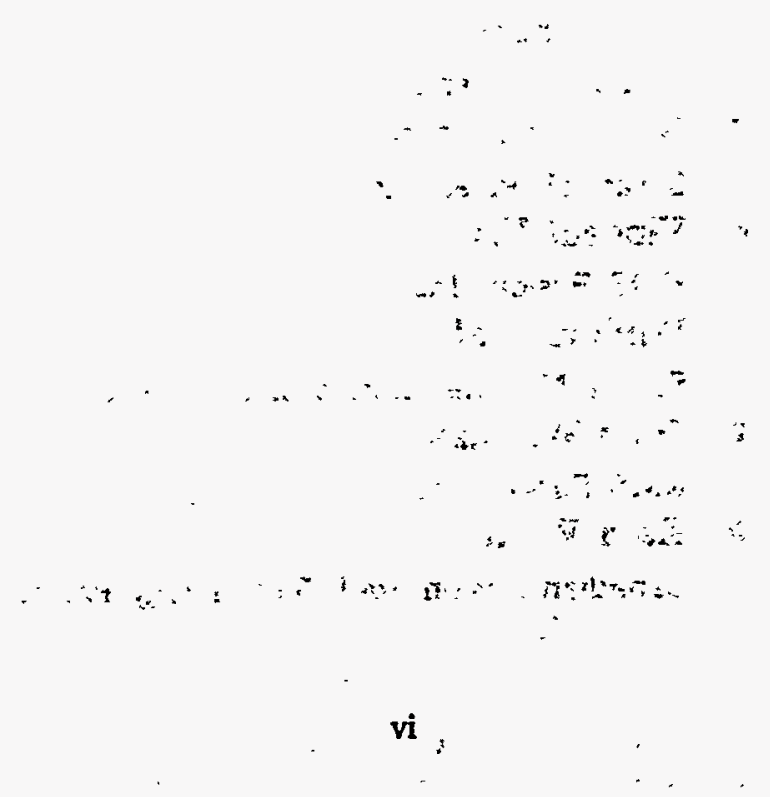




\section{Contents}

\section{List of Abbreviations}

\section{Chapters}

\section{Page}

1. Introduction .

Harold F. Anderson

1.1. Purpose

1.2. Scope

$1-1$

1.3. Depth of Detail

1-1

1.4. Limitations of This Guide

1-2

1.5. Intended Use of This Guide

2. Basic Principles and Philosophies

Harold F. Anderson

2.1. ALARA 2-1

2.1.1. Meaning . 2-1

2.1.2. Application 2-1

2.1.3. Potential Problems in Applying ALARA 2-2

2.2. Risk Assessment 2-2

2.2.1. Purpose 2-2

2.2.2. Techniques 2-3

2.2.3. Quantifying Risk 2-3

2.2.4. In-House Guidelines 2-6

2.2.5. Determining Actions 2-6

2.3. Containment 2-6

2.3.1. Degrees 2-6

2.3.2. Reliability $2-7$

2.3.3. Safety 2-7

2.3.4. Management Philosophy 2-8

2.3.5. Maintenance Operations - 2-8

2.4. Quality Assurance 2-8

2.4.1. Facilities 2-8

2.4.2. Operating Procedures 2-9

2.4.3. Personnel Training 2-9

2.5.' References 2-9

3. Properties of Tritium

John T. Gill

3.1. Sources of Tritium

3.1.1. Environmental Source 3-1

3.1.2. Sources of Tritium Production . . . $3-1$

3.2. Chemical Properties 3-2 
3.2.1. Atomic Weight/Hydrogen Isotopes 3-2

3.2.2. Chemical Reactions - 3-2

3.2.3. Compatibility 3-4

3.3. Nuclear and Radiative Properties $\quad \ldots \quad \ldots \ldots . \cdots$

3.3.1. Disintegration 3-5

3.3.2. Range and Energy Absorption of Beta Particles 3-7

3.4. Physical Properties of Tritium Gas 3-9

3.4.1. Solubility 3-9

3.4.1.1. Endothermic and Exothermic Solutions $\quad 3-9$

3.4.1.2. Solubility in Polymers, Glasses, and Ceramics . 3-9

3.4.1.3. Solubility in Metals 3-10

3.4.2. Diffusion $3-10$

3.4.3. Permeability 3-20

3.5. Biological Properties of Tritium 3-27

$\begin{array}{ll}\text { 3.5.1. General 3-27 } & 3-27\end{array}$

$\begin{array}{ll}\text { 3.5.2. Metabolism of Gaseous Tritium } & 3-27\end{array}$

3.5.3. Metabolism of Tritiated Water 3-27

3.5.4. Metabolism of Other Tritiated Species 3-28

3.5.4.1. Tritiated Surfaces 3-28

3.5.4.2. Metallic Tritides 3-28

3.5.4.3. Other Tritiated Solids - 3-29

3.5.4.4. Tritiated Liquids 3-29

3.5.4.5. Other Tritiated Gases 3-30

3.5.5. Single Compartment Modeling of HTO Retention 3-30

3.5.6. Multi-Compartment Modeling 3-32

3.6. References 3-32

\section{Operational Health Physics}

Thomas M. Flanagan, Jerome B. Martin, Ronald S. Hafner,

Roland A. Jalbert, John H. Stafford

4.1. Purpose and Scope 4-1

4.2. Administration 4-1

4.3. - Bioassay and Internal Dosimetry 4-2

4.3.1. Sampling Schedule and Technique * 4-3

4.3.2. Dose Reduction 4-5

4.4. Measurement Techniques 4-6

4.4.1. Air Monitoring 4-7

4.4.2. Differential Monitoring 4-7

4.4.3. Discrete Sampling 4-8

4.4.4. Process Monitoring 4-9

4.4.5. Surface Monitoring ‘ ‘ : 4-9

4.4.6. Liquid Monitoring 4-10

4.5. Instrument Types and Calibration 4-10

4.5.1. Air Monitors $4-10$

4.5.2. Surface Monitors $\quad \therefore \quad \therefore * 4.4 \%$

4.5.3. Tritium Sample Counters $\$$ 
4.6. Contamination Control and Protective Measures $\cdots \quad \cdots, \ldots \ldots, \quad \ldots \quad 4-13$

4.6.1. Methods of Contamination Control

4.6.1.1. Smear Surveys .......... 4-13

4.6.1.2. Off-Gassing Measurements - 4-14

4.6.2. Protection Against Airborne Contaminants $\quad$.. 4-16

4.6.2.1. Differential Room Pressure Zones : . 4-16

4.6.2.2. Dilution Ventilation " * . .

$\therefore \quad$ 4.6.2.3. Room Air Detritiation Systems $\therefore$ 4-17

4.6.2.4. Local Exhaust Ventilation 4-17

$\therefore \quad 4.6 .2 .4 .1$. Fumehoods $\quad$ 4-18

4.6.2.4.2. Canopy Hoods 4-18

4.6.2.5. Air-Supplied Respirators 4-19

4.6.2.6. Air-Supplied Suits . 4-19

4.6.2.7. Temporary Enclosures 4-20

4.6.3. Protection Against Surface Containmination $\quad 4-20$

4.6.3.1. Glovebox Housekeeping 4-20

4.6.3.2. Gloves 4-21

4.6.3.2.1. Selection of Box Gloves for Varying

Box Environments 4-22

4.6.3.2.2. Protective Measures for Glovebox Work 4-23

4.6.3.3. Lab Coats and Coveralls 4-24

4.6.3.4. Shoe Covers . 4-25

4.7. Decontamination 4-25

4.8. Maintenance 4-26

4.9. References 4-26

5. Facility Design

Rodney P. Bowser, Michael L. Rogers

5.1. Design Objectives 5-1

5.2. Building Criteria $5-2$

5.2.1. Structure $\quad 5-2$

5.2.2. Location and Layout $\quad 5-3$

5.2.3. Services and Utility Systems . . . . . $5-5$

5.2.3.1. Ventilation 5-5

5.2.3.2. Electrical System $5-7$

5.2.3.3. Fire Protection, . . . . . 5-7

5.2.3.4. Cooling Water 5-8

5.2.3.5. Breathing Air , 5-8

5.2.3.6. Process Gases $5-8$

5.3. Special Systems $\quad \therefore \quad \therefore 5-9$

5.3.1. Primary Tritium Handling Systems $5-9$

5.3.1.1. Design Principle 5-9

5.3.1.2. Piping Systems $5-9$

5.3.1.3. Pressure Protection $\therefore \therefore-5-10^{\circ}, \ldots$

5.3.1.4. Gas Movers … T. $5-11$

5.3.1.5. Gas Storage $5-12$

5.3.1.6. Maintenance $\quad \because \because: \div ; \ldots \div 5-12$

5.3.1.7. Instrumentation $\quad \therefore \quad \therefore 5-13 \ldots$

5.3.1.8. Glovebox Layout $\quad 5-15$ 
5.3.2. Secondary Protection _. . . . . . $\quad 5-15$

5.3.2.1. Strategy : $5-15$

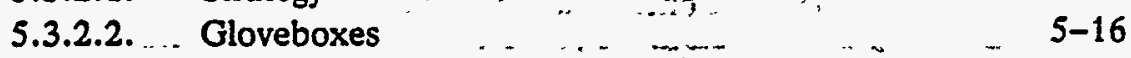

5.3.2.3. Transfer Lines $\quad \ldots-17$

5.3.2.4. Special Secondary Containment Systems , 5-18

5.3.2.5. Purge Systems . . . . 5-19

5.3.2.6. Secondary Cleanup Systems $\quad \therefore \quad 5-22$

5.3.2.7. Room Containment - . $5-22$

5.4. Quality Control . . . 5-22

5.5. Quality Assurance . . : 5-23

5.6. Emergency Signals 5-23

5.7. Decontamination $\quad$ 5-24

5.8. Security . ... . 5-24

5.9. Accountability $\quad 5-24$

5.10. References $\quad \therefore-24$

6. Tritium Waste Manàgement

Richard,K. Blauvelt

6.1. Gaseous Effluents 6-1

6.1.1. Description of Waste Streams 6-1

6.1.2. Applicable Regulations 6-1

6.1.3. Treatment 6-2

6.1.4. Packaging and Transportation 6-3

6.1.5. Disposal 6-4

6.2. Liquid Wastes 6-4

6.2.1. Description of Waste Streams 6-4

6.2.2. Applicable Regulations 6-4

6.2.3. Treatment 6-5

6.2.4. Packaging and Transportation 6-7

6.2.5. Disposal 6-8

6.3. Solid Wastes ‥ . 6-9

6.3.1. Description of Waste Streams 6-9

6.3.2. Applicable Regulations . . . 6-9

6.3.3. Treatment 6-9

6.3.4. Packaging and Transportation 6-10

6.3.5. Disposal $6-10$

6.4. References 6-10

6.5. ... Additional Reading 6-11

Appendices

A. Material Compatibility

Harold F. Anderson

A.1... Nonhydriding Metals

A.2. - : Hydriding Metals

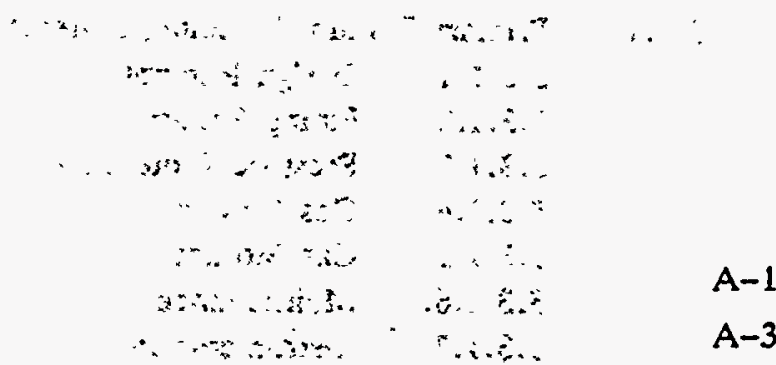

$\therefore$.

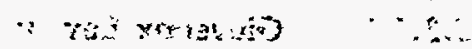

$A-3$ 
A.3. Graphite

A.4. Glasses

A.5. Ceramics

A-5

A.6. Plastics, Elastomers, and Oils

A-5

A.7. References

A-11

A.8. Additional Reading

$A-13$

B. Procedures

Michael R. Deaton, William R. Wood

B.1. Operating Procedures

B-1

B.1.1. General Operating Procedures

B-1

B.1.1.1. Environment

B-1

B.1.1.2. Quality and Efficiency

B-1

B.1.1.3. Technology

B-2

B.1.1:4. Hazards

B-2

B.1.1.5. Unacceptable Actions

B-2

B.1.1.6. Responsibilities

B-2

B.1.1.7. Health Physics

B-2

B.1.1.8. Emergencies

B-3

B.1.1.9. Service Functions

B-3

B.1.2. Detailed Operating Procedures

B-3

B.2. Health Physics Procedures

B-4

B.2.1. General Information

B-4

B.2.2. Purpose and Scope

B-4

B.2.3. Responsibilities

B-4

B.2.4. Building or Facility Description

B-4

B.2.5. Orientation and Training

B-4

B.2.6. Monitoring

B-5

B.2.7. Protective Clothing and Equipment B-5

B.2.8. Tritium Monitors

B-5

B.2.9. Tritium Counters

B-5

B.2.10. Breaching Operations

B-5

B-6

B.3. Maintenance Procedures

B-7

B.4. Emergency Procedures

B-7

B.4.1. General

B-7

B.4.2. Types of Emergencies

$\mathrm{B}-7$

B.4.3. Personnel Contamination or Injury .

B-8

... - B.4.4. Special Emergency Teams

B.4.5. Emergency Alarms

B-8

B.5. References

B-8

\section{Training}

\section{John L. Hehmeyer}

C.1. Introduction

C.1.1. Development Methods

C-1

C.1.2. Needs Assessment

C-1 
C.1.3. Job and Task Analysis C-2

C.1.3.1. General Training Programs - C-2

C.1.3.2. Specific On-The-Job Training $\quad \cdots \quad \mathrm{C}-3$

C.1.4. Course Design and Development _ . . _ $\because \mathrm{C}-3$

C.1.5. Instructors $\mathrm{C}-3$

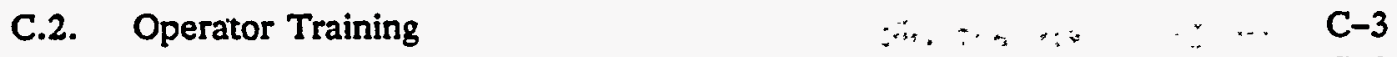

C.2.1. Operator Example $\quad$ C-3

C.3. Evaluation

C.4. Support Staff Training C-6

C.5. Documentation $\quad \cdots, C-6$

C.5.1. Location of Documentation on Training C C-6 -

C.5.2. Documentation for Historical Purposes C-7

C.6. References $\mathrm{C}-7$

D. Inventory Control

Paul H. Lamberger

D.1. Measurements ' ' D-1

D.2. Measurement Control . ? D-2

D.3. Holdup in Systems D-3

D.4. Predictors D D-3

D.5. Accounting Practices D-5

D.5.1. Materials Accounting D-5

D.5.2. Accountability Practices - D-5

D.5.3. Tritium Decay - . $\quad$ D-7

$\begin{array}{ll}\text { D.6. References } & \text { D }-7\end{array}$

D.7. Additional Reading D-7

E. Measurement Techniques

Robert E. Ellefson

E.1. Introduction E-1

E.2. Calorimetry E-1

E.2.1. Calorimeter Operation E-I

E.2.1.1. Heater Replacement Method E-3

E.2.1.2. Servo-Control Method E-4

E.2.2. Calibration $\quad$ E $E-4$

E.2.3. Watts-Per-Gram Value for Tritium $\quad \cdots \quad \therefore$ E-5

E.2.4. Sample Preparation $\quad \ldots=$ E-5

E.2.5. Measurement Control Methods and Expected Performance E-5

E.3. Mole Measurement and Compositional Analysis $\quad \because \therefore \%$ E-6

E.3.1. Mole Determination by pressure, Volume, and
Temperature Measurement

xii 
E.3.2. Gas Composition Measurements

E-10

E.3.2.1. Expected Composition of Tritium Process Gas

E-10

E.3.2.2. Composition Measuring Instruments

E-11

E.3.2.3. Sampling Techniques

$E-12$

E.3.2.4. Measurement Control Methods

E-14

E-15

E-15

E-16

E-16

E.4.3. Gas Flow Rate Measurements

E-16

E.4.4. Process Impurity Measurements

E-17

E.5. Measurement of Tritium Diffused into Solids

E-18

E.6. Process Glovebox Atmosphere Measurements

E-18

E.8. Additional Reading

E-19

Glossary

Glossary-1 


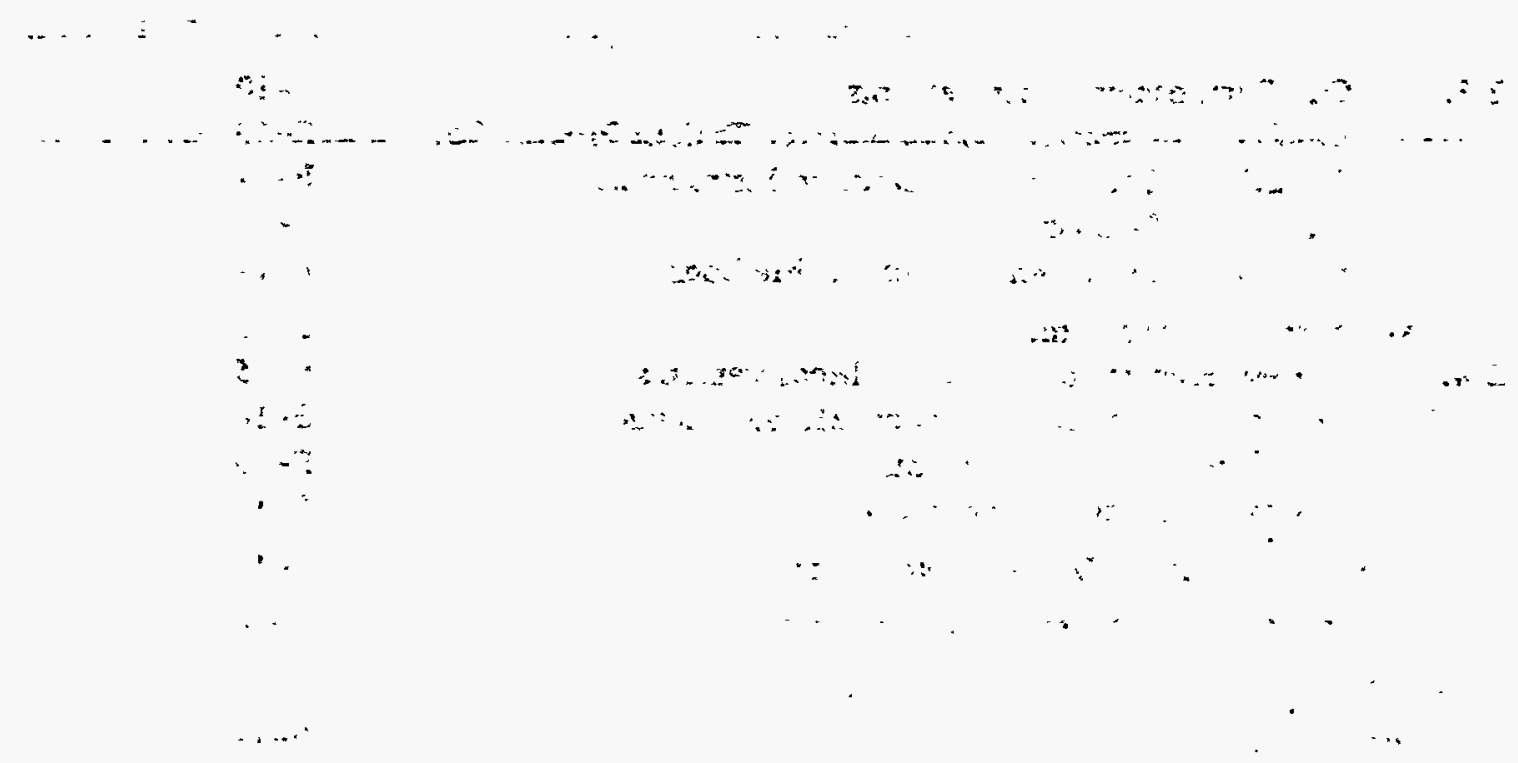




\section{List of Abbreviations}

ALARA - As Low As Reasonably Achievable

Ar - Argon

Atm. - atmosphere

Atmosphere - a unit of pressure equal to the air at sea level or approximately 14.7 pounda to the square inch

Bat - Best Available Technology

$\mathrm{Bq}$ - becqueral which means 1 disintegration per second

cfm - cubic feet per minute

CFR - Code of Federal Regulations

$\mathrm{Ci}$ - Curies

DA\&C - Data Acquisition and Control

DAC - Derived Air Concentration

DCGs - Derived Concentration Guides

dpm - disintegrations per minute

dps - disintegrations per second

De minimis value - smallest value of any significance

EPDM - Ethylene Propylene Diene Terpolymer

EPR - Ethylene Propylene Rubber

GI - gastrointestinal

GM - Geiger Muller

$\mathrm{H}$ - protium

HAT - High-Activity Tritium

$\mathrm{He}$ - heliulm

HTO - Tritium oxide (liquid tritium) 
ICRP - International Commission on Radiological Protection

ID - inventory difference

$\mathrm{K}$ - Kelvin

k - kilo $(1,000)$

$\mathrm{keV}-1,000$ electron volts

lfpm - linear feet per minute

$\mathrm{Li}$ - lithium

LSA - Low Specific Activity

$\mathrm{m}-$ milli- $\left(10^{-3}\right)$

MAOP - maximum allowable operating pressure

MAWP - maximum allowable working pressure (the design pressure for individual components)

Mole - molecule

$\mu$ - micro- $\left(10^{-6}\right)$

$\mathrm{N}_{2}$ - nitrogen

NCRP - National Committee on Radiation Protection

NESHAP - National Emissions Standards for Hazardous Air Pollutants

${ }^{63} \mathrm{Ni}$ - an isotope of nickel

NOP - normal operating pressure

NTS - Nevada Test Site

ppm - parts per million

psia - pounds per square inch absolute

PVT - pressure/volume/temperature

$R\left(t_{0}\right)$ - dose equivalent rate

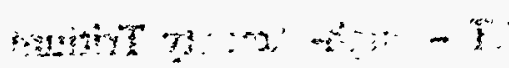

RAC - Respirator Advisory Committee

RCRA - Resource Conservation and Recovery Act $\operatorname{Ac}_{1}, i^{3}$ 
rem - roentgen equivalent man

RMA - radioactive materials area

SBR - Styrene-butadiene

STP - Standard temperature and pressure

$\mathrm{T}_{2} \mathrm{O}$ - the oxide form of tritium (liquid form)

TAM - Tritium Activity Meter

TERS - Tritium Effluent Removal System 


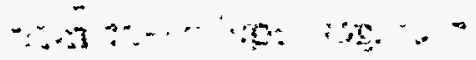

$$
\vdots \because \ldots
$$




\section{Chapter 1 \\ Introduction}

\subsection{Purpose}

The purpose of this document is to provide written guidance defining the generally accepted good practices in use at Department of Energy (DOE) tritium facilities. A "good practice" is an action, policy, or procedure that enhances the radiation protection program at a DOE site. The information selected for inclusion in this document should help readers achieve an understanding of the key radiation protection issues at tritium facilities and provide guidance as to what characterizes excellence from a radiation protection point of view. The ALARA (As Low as Reasonable Achievable) program at DOE sites should be based, in part, on following the good practices that apply to their operations.

\subsection{Scope}

This document focuses on radiation protection and also presents many good practices related to design and operations because they directly affect the effectiveness of the radiation protection program at a DOE site. The principal chapters cover philosophies, properties of tritium, health physics operations, design considerations, and waste treatment. Additional information on tritium compatibility, training, procedures, inventory control, and measurement techniques is presented in the appendices.

\subsection{Depth of Detail}

The chapters on physical properties, health physics, and design make up the core of this document. They contain considerable detail on some subjects.

The other chapters and the appendices cover a variety of topics, but, in general, an effort was made to limit the detail in these sections. The areas of emphasis and the depth of detail are based on the comments received on the initial draft of this document.

The material presented is that which the authors consider to be of prime importance, or it is background information needed to familiarize the reader with the key elements of tritium facilities. In selecting the good practices to be discussed, the authors give primary consideration to the health physics aspects: the protection of the worker, the public, and the environment. "Consideration is also given to the quality of the process, process wastes, quality of facility design and installation, future decommissioning and decontamination, accountability, and cost-effectiveness. 


\subsection{Limitations of This Guide}

Although this document is a consensus document based on review by and input from personnel at many tritium facilities, the reader must recognize that consensus is a broad term. There are differences among sites in terms of management philosophies, design criteria, and control methods and limits. These differences arise out of site-specific considerations.

The current DOE regulations adequately control the various site contractors. It would be improper to use this guide as a direct measure of performance or adequacy of a radiation protection program at any individual site. However, it can serve as a useful source of information and as a reference for DOE and contractor personnel in assessing tritium operations.

Another limitation of this guide is that most topics are covered generally. The intention is to make the reader aware of certain information and issues, not to provide definitive operating instructions or design details. The reader is encouraged to pursue topics of interest further. The references at the end of several chapters provide additional sources of information. It would be improper to try to apply any good practices described in this document without considering site-specific restrictions and practices.

\subsection{Intended Use of This Guide}

The DOE's modern tritium facilities are characterized by high productivity, minimal effluents, and low personnel exposures. The common attributes of these facilities and their generally excellent radiation protection programs are:

- Well-designed and well-constructed facilities.

- Carefully prepared procedures.

- Adequate personnel training.

- Effective radiation monitoring and controls.

This guide should provide insight into the reasons these attributes are important and should also assist DOE and contractor personnel in assessing the balance among these attributes at any site.

This guide will probably be most useful as a reference document for perșons who are new to the field of tritium technology. Basic and applied information of interest to persons in health physics, operations, and engineering disciplines is presented, and the reader is directed to other references for additional information. Although this document was sponsored by the DOE for use at DOE facilities, the information it contains and the good practices it cites will be useful to non-DOE operations in the United States as well as in other countries. 


\section{Chapter 2 \\ Basic Principles and Philosophies}

\subsection{ALARA}

\subsubsection{Meaning}

ALARA is an acronym for "As Low As Reasonably Achievable." The objective of ALARA is to "reduce personnel and environmental radiation exposures to the lowest levels commensurate with sound economics and operating practices" $[2.1,2.2]$. It is important not to lose sight of the latter part of the definition. Economic and sociopolitical factors are useful criteria that can help establish what the good practices should be at a specific site.

There is always a limit to the time and money that can be spent on this program at any site. Therefore, every site must prioritize the funds to be allocated to fix deficiencies or provide enhancements. Because all projects cannot be funded, some repairs and improvements will be delayed or may never be made. This fact must be recognized, and the projects that offer the greatest reduction in risk must be the first to receive support.

A complementary concept to ALARA is the principle of "optimization of radiation protection." This concept is discussed in detail in Publication 37 of the International Commission on Radiological Protection (ICRP) [2.3]. Optimization frequently involves cost-benefit analyses of various aspects of a radiation protection program. Careful application of this principle can help health physicists specify the amount of radiation protection that is necessary and feasible in relation to the hazards involved in an operation.

From a practical point of view, inhalation and absorption through the skin are the only significant exposure pathways for tritium. As will be explained in Chapter 4, the risk of radiation exposure depends on the form of the tritium. As a dry gas, there is little risk of uptake; however, the risk of uptake is much higher when the tritium is oxidized (tritiated water). The principle of optimization points out that the radiation protection program should be more stringent when the potential for exposure to tritium in the oxide form exists.

\subsubsection{Application}

ALARA is most effective when it is the operating philosophy behind a radiation protection program. ALARA should be apparent in the policy and procedure documents that implement a radiation protection program at a site, and it should also be incorporated into facility design. Additional corporate or site-specific 
philosophies and principles may be used in establishing a health, safety, and environmental control program, but they should be integrated with ALARA into a consistent, meaningful approach. Establishing good practices for tritium operations is easier when the site has a policy that incorporates ALARA.

Performance goals can be helpful tools in an ALARA-based program. By meeting specific annual targets for improved radiation safety performance or reduced environmental releases, a site can demonstrate its commitment to ALARA. To monitor progress toward these goals and to indicate the possible need for corrective actions, a chart that displays monthly and/or year-to-date status can be generated. Such charts help keep the concept of ALARA in perspective and focus management attention on performance. They also allow a site to plan improvements phased over a reasonable time span.

\subsubsection{Potential Problems in Applying ALARA}

By definition, ALARA is open to interpretation. What is "reasonable" and in whose opinion? For this reason, it is difficult to interpret how ALARA is to be applied. It is tempting to expect faster progress, iess risk, less exposure, and lower effluents than observed. The best way to avoid this problem is to have a well-established program with reasonable goals. A method for measuring performance should be incorporated, and a time period for reaching the goals should be set. Periodic internal or self audits should be conducted regarding the ALARA performance of a site.

If a site establishes internal goals for exposures and environmental releases, these must have some significance and relate to generally recognized external standards. Internal goals may lead to reduced exposures, but they may also impact operations and costs. If internal goals are too ambitious, they may not be reached and may not be cost effective. If the goals are too easily achieved, the site may not be perceived as being serious about ALARA. It is important to recognize that ALARA does not necessarily require a reduction in exposures or effluents, nor does it imply that current levels of exposures and effluents are not acceptable. Notwithstanding the potential problems in applying ALARA, the credibility and effectiveness of a site's overall health and safety program is strengthened with its use. This can benefit the site if it is called upon to defend itself against critics:

\subsection{Risk Assessment}

2.2.1. Purpose

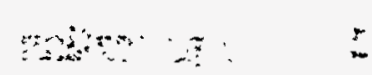

The purpose of conducting a risk assessment is to obtain an understanding of the hazards involved in an operation and to plan ways to cope with them. The results of

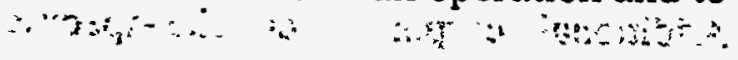


the assessment should be the basis for determining actions to be taken. The emphasis should be on avoiding problems.

\subsubsection{Techniques}

Two techniques are used to assess risk: consultation with experienced personnel and rigorous application of logic diagrams and modeling with their associated mathematics. Both techniques are valid and are frequently used in combination.

\subsubsection{Quantifying_Risk}

Risk is quantified for many reasons. The "quantification of risk" may be part of a planned maintenance operation, or it may be incorporated into a formal document such as a safety analysis report (SAR). The requirements for a formal SAR are given in DOE Order 5481.1B, "Safety Analysis and Review System" [2.4]. A SAR contains a thorough analysis of the risks associated with the start-up and operation of a DOE facility or process, along with documentation of the results of the analysis. SARs are required for existing facilities if they contain hazards or pose risks that are not commonly accepted by the general public as "day-to-day" hazards. SARs contain detailed descriptions of facilities, process operations, and engineered safety systems in place to prevent an accident or to mitigate the consequences of an accident. The current emphasis in SARs is the design of process equipment and the inherent factors that are important to safety. The reliability and availability of items important to safety must be addressed.

Quantifying risk usually involves estimating the probability of an event occurring. This estimate can be a simple "low-medium-high," or it can be an occurrence rate derived through statistical calculation. If probabilities of failure are used to quantify risk, the user must be careful to obtain statistical information that is truly representative of the components or equipment being evaluated. Large data bases used for probability calculations exist, but site-specific failure data are usually a better source of information.

One source of failure rate data used to quantify a model of a tritium system is the WASH 1400 Reactor Safety Study [2.5]. Some of the failure rate data are presented below. (WASH 1400 discusses the bases for the data.)

\section{Equipment Failure Rates:}

- Pipe rupture per section (section is the average length between major discontinuities such as valves and pumps; approximately $10 \mathrm{ft}$ )

Pipes greater than 3 in. $=10^{-8 / y r}$

Pipes less than 3 in. $=10^{-4} / \mathrm{yr}$ 
- Valve external leak/rupture $=10^{-5 / y r}$

- Weld leak $=3 \times 10^{-5 / y r}$

Human Failure Rates:

- Operator error $=10^{-2}$ (Example used in WASH 1400: After a routine operation, a manual valve will be left in an incorrect position 1 out of every 100 times.)

- Human error/two valves $=10^{-3}$ (One person incorrectly positioning two redundant valves.)

- Human failure/procedure error $=10^{-4}$ (One person following a written procedure or checklist.)

- Redundant personnel error $=10^{-5}$ (Two-man rule being followed.)

The probability of a failure in a tritium system can be estimated by applying failure rate data to a model (fault tree, event tree, etc.) of a system configuration. These failure rate data assume that the quality of the tritium system equipment and the quality (training and experience) of the system operators are similar to the quality of equipment and operators found in a U.S. nuclear power plant.

Consider a tritium system consisting of $100 \mathrm{ft}$ of line (less than $3 \mathrm{in}$. in diameter), 10 valves, and 33 welds. This system would be expected to fail (leak) twice every 1,000 years as a result of mechanical failure.

$$
\begin{aligned}
& \text { pipe valves welds } \\
& (100 / 10) \times 10^{-4 / y r}+(10) \times 10^{-5 / y r}+(33) \times 3 \times 10^{-5 / y r} \\
& 10^{-3} / \mathrm{yr}+10^{-4} / \mathrm{yr}+0.99 \times 10^{-3} / \mathrm{yr}=2.09 \times 10^{-3} / \mathrm{yr}
\end{aligned}
$$

If each of the 10 valves in the system is manipulated by a trained operator 10 times per year, and if the improper operation of any 1 of the 10 valves would result in a tritium release, then the probability of a release can be approximated by Equation 2-2. (Note: This method provides only an approximation and works only when $\mathrm{nx} \ll$ 1 , where $\mathrm{n}$ is the number of trials and $\mathrm{x}$ is the failure probability for one trial.)

$$
\begin{aligned}
& \begin{array}{ccc}
\text { operations } & \text { failures } & \text { failures } \\
\text { per } & \text { per } & \text { per } \\
\text { year } & \text { operation } & \text { year } \cdots
\end{array} \\
& \therefore \quad \therefore \quad 10^{2} \quad x^{: 10-2}=10^{0}=1
\end{aligned}
$$

If another valve that is redundant to the critical valve is added to the system, the probability of release as a result of human failure will be reduced by a factor of 10 . 
Adding this valve will increase the mechanical rate of failure by a factor of two. If one trained operator is following a written procedure, the chance of turning the wrong valve and releasing material will be reduced by two orders of magnitude. If a second trained operator working with the first is checking for errors, the risk of a release will be reduced by three orders of magnitude. The designer should minimize the potential for both mechanical and human error when planning a tritium system.

Unfortunately, the use of rigorous analytical techniques such as fault trees can be time-consuming and costly. The results can have wide margins of uncertainty, depending on the appropriateness of the failure rate data used in the analysis.

A less rigorous method of estimating the probability of a tritium release is to review historical data on the failures of entire systems or failures within general components such as gloveboxes. This approach ignores the exact cause of a release and only considers the results, such as "release from primary containment." This approach is beneficial in the early decision-making regarding major design issues. For example, the results can help determine what containment systems will be required.

This approach also helps identify the systems or subsystems that are major contributors to the risk associated with a facility. After these are identified, a decision can be made as to whether a more rigorous analysis of the systems is needed. The data published in WASH 1400 suggest that in systems with multigram tritium inventories, a 1,000-Ci leak (approximately $750 \mathrm{~cm}^{3}$ of DT) from the primary occurs in a standard $2.5-\mathrm{m}^{3}$ glovebox once every 100 years $[2.5 \mid$. A $10,000-\mathrm{Ci}$ release occurs once in 1,000 glovebox-years. If the tritium facility contains 100 gloveboxes, then a 1,000-Ci release to a glovebox from primary piping will occur an average of once per year. A 10,000-Ci release will occur once in 10 years. Again, this method yields only approximations and should be used cautiously.

Each facility has its own base of failure data for various pieces of equipment used in tritium service. Usually, these data are available from maintenance records kept as part of a preventive maintenance program. Unfortunately, such records may not include all the important operating data, such as the operating time of a pump. Although such information is not often available in a neat, organized fashion, the designer and operator should seek it out and use it to their advantage.

In addition to estimating the probability of leaks, another part of quantifying risk is evaluating the consequences of a failure. This usually involves evaluating the amount of tritium that can be released, the form the tritium is in, and any protective features in place to minimize personinel exposures and releases to the environment. Again, this aspect of quantifying risk can range in complexity from estimates based on experience to detailed atmospheric diffusion and dose assessment calculations.

$$
2-5
$$


Differences exist among sites in terms of the material forms, topography, geography, and climate.

\subsubsection{In-House Guidelines}

It is generally considered good management practice to have a site policy or procedure that gives guidance on when and how risk assessments will be conducted. Further, internal criteria regarding what is, or is not, an acceptable risk should be established. Although many sites have similar policies, the specifics of implementation and internal criteria regarding risk vary for many reasons, including corporate policies, physical characteristics of the facilities, nature of operations, inventories, and geographic location. A useful reference for evaluating risk criteria is A Guide to Radiological Accident Considerations for Siting and Design of DOE Non-Reactor Nuclear Facilities [2.6].

\subsubsection{Determining_Actions}

On the basis of the risk assessment, the appropriate actions must be determined. This is a particularly visible decision when the risk assessment involves a formal review or study, such as a SAR. Usually, these large-scale risk assessments involve many experts at a site, as well as DOE personnel at the area office and operations office levels. Gradually, the decisions become less visible as the formality of the review process becomes less rigorous. The foundation for making good decisions then becomes the experience and training of the first-line supervisor; the written policies, procedures, and in-house directives; and the quality of the health physics advice and support provided to operations.

\subsection{Containment}

\subsubsection{Degrees}

In a tritium facility, it is a common practice to think in terms of containment. In its simplest terms, primary containment surrounds the tritium. Secondary containment surrounds the primary. Tertiary containment surrounds the secondary, and so forth. Although individual containers are usually referred to as "primaries," "secondaries," etc., they can range in complexity from a section of process plumbing to a multigauge high pressure vessel. Because containers can only provide a passive containment method, active containment methods must be added to remove the tritium that does escape.

Gloveboxes are the most commonly used active containment systems. While gloveboxes are sometimes thought of as secondary containers, this view can be misleading because gloveboxes are most often used to trap localized tritium releases for subsequent tritium removal. 
Temporary vented enclosures (tents) are often used to control releases locally during maintenance operations. In these situations, the tent serves the same function as a glovebox in that the tritium released into the enclosure is sent to an active cleanup system.

Fumehoods and vented enclosures provide little in the way of containment, as their primary purpose is personnel protection. They are generally used to minimize tritium releases into a room, and they provide localized high air velocities to sweep tritium out into the environment. When the multiple containment system is being designed or evaluated, the complete "envelope" of the configuration should be examined.

\subsubsection{Reliability}

Philosophies vary as to how much reliability should be built into containment systems. At one extreme, the primary containment is designed, built, inspected, and certified to have an extremely high level of reliability. Historically, this approach has proved to be less than satisfactory and, in some cases, much more expensive than using secondary containment.

Depending only on primary containment assumes that there will be no human error: perfect equipment will ensure perfect operation. This philosophy of containment is largely out of favor because no equipment is ever perfect and, more importantly, because human error is a more frequent cause of tritium releases. However, it should be noted that early work on improving' tritium containment equipment resulted in an improvement in quality.

All modern tritium facilities use secondary containment; i.e., placing tritiumhandling equipment inside a box tight enough to hold the tritium. The current philosophy assumes human error will cause a release of tritium with almost predictable frequency. Therefore, it is preferable to contain the tritium in a secondary enclosure so it can be held up and recovered. Providing secondary containment is almost always cheaper than using only primary containment because neither the equipment nor the box surrounding it needs to be certified at the high level of reliability required for the primary containment when it is the only form of containment used.

It is often tempting to add a tertiary cleanup system. Such a system cleans room air if tritium escapes from the secondary containment. However, tertiary systems are expensive because they must be able to process large volumes of air.

\subsubsection{Safety}

In assessing the safety of a containment system, the overall impact of a release must be examined. If tritium gas is captured in a secondary or tertiary enclosure,

$$
2-7
$$


something must be done with it. Typically, treatment systems for such containment systems convert tritium gas to the oxide form, then trap the moisture on some type of zeolite molecular sieve. This converts the tritium into a more hazardous form.

The question of what to do with the tritium oxide must then be addressed. Will it be driven off the dryer to be collected as contaminated water? What type of maintenance operations will be required for the treatment systems?

It is necessary to evaluate the potential exposures to workers and to the general public for various scenarios assuming various degrees of containment and various mechanisms for converting the tritium to the oxide form.

\subsubsection{Management Philosophy}

A management philosophy should recognize the complexity of the issues regarding containment, as well as the total effect of containment on the safety of personnel and the environment. Failure to distinguish the real risks as a result of equating all tritium operations regardless of tritium quantity or form can reduce the effectiveness and credibility of a site's radiation protection program. Because resources are limited, priorities are necessary. A graded, rational approach to containment will permit a wide range of tritium operations and focus the most effort and resources on the operations involving the greatest hazards.

\subsubsection{Maintenance Operations}

The most important function of containment is to protect people. The risk to personnel increases as the layers of containment are breached. Because of this, maintenance operations on tritium systems represent a high potential for tritium exposures.

Because of the potential for exposure during maintenance operations involving a containment breach, a prejob review of the maintenance operation should be conducted. The formality of this review varies from site to site. The most important aspects to be covered in prejob reviews are risk assessments, and plans to minimize the exposure risk to the workers and the chance of a release to the environment.

\subsection{Quality Assurance}

\subsubsection{Facilities}

Quality assurance programs are essential to DOE tritium facilities. They ensure that facilities, equipment, and instruments meet design specifications. DOE Order 5700.6B, "Quality Assurance," [2.7] and site-specific quality plans give details on quality assurance programs. The DOE places special emphasis on the quality 
requirements for those design features that relate to personnel safety and environmental protection. Because certain equipment and protective features must be highly reliable, quality assurance measures should exist to achieve and maintain the degree of reliability desired.

\subsubsection{Qperating_Procedures}

DOE tritium facilities follow a wide variety of operating procedures. They vary in detail according to the nature of the work (e.g., production or research) and according to local administrative policies and practices concerning documentation. The important quality assurance aspects of these procedures are that they provide for the quality control measures applicable to the process and can be audited for compliance.

The operating practice of a facility, as detailed in its operating procedures, is an equal partner of good facility design. Normally, the operating procedures are developed, reviewed, and revised over a period of time. The time period depends on the rate of process and equipment improvements. At all facilities, effort is expended to develop and ensure compliance with operating procedures that are safe and that minimize the risk of exposures and environmental releases. Additional information on procedures is found in Appendix B.

\subsubsection{Personnel Training}

Because of the importance of personnel training in radiation safety and environmental protection, the DOE and its contractors require comprehensive training of tritium workers and the radiation safety staff. Again, differences in content and scope exist among facilities, but all should have active training programs. As a general rule, personnel receive training in the facilities and equipment they will operate, the use of radiation protection monitoring instrumentation, detailed operating procedures (including emergency procedures), and general support procedures and systems. A new employee is usually assigned to work with an experienced employee to gain competence in the tasks to be performed. In addition, the DOE requires documentation of all training conducted so it can be monitored through a quality assurance program. Additional information on training is provided in Appendix C.

\subsection{References}

2.1. R. L. Kathren, A Guide to Reducing Radiation Exposure to As Low As Reasonably Achievable (ALARA), DOE/EV/1830-T5, Battelle Pacific Northwest Laboratory, Richland, Washington (April 1980), 233 pp. 
2.2. W. N. Herrington, and D. P. Higby, Health Physics Manual of Good Practices for Reducing Radiation Exposures to Levels That Are As Low As Reasonably Achievable, PNL-6577, General Electric/Pinellas, Pinellas Park, Florida (June 1988), 169 pp.

2.3. International Commission on Radiological Protection, Publication 37: CostBenefit Analysis in the Optimization of Radiation Protection, Pergamon Press, New York, 1983.

2.4. DOE Order 5481.1B, Safety Analysis and Review System, September 23, 1986.

2.5. Nuclear Regulatory Commission, WASH 1400 Reactor Safety Study: An Assessment of Accident Risks in U.S. Commercial Nuclear Power Plants, Appendixes 3 and 4, Washington, D.C. (October 1975).

2.6. J. C. Elder, et al., A Guide to Radiological Accident Considerations for Siting and Design of DOE Non-Reactor Nuclear Facilities, LA-10294-MS, Los Alamos National Laboratory, Los Alamos; New Mexico (January 1986).

2.7. DOE Order 5700.6B, Quality Assurance, September 23, 1986.

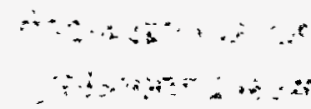




\section{Chapter 3 \\ Properties of Tritium}

\subsection{Sources of Tritium}

\subsubsection{Environmental Sources}

Tritium occurs naturally in the environment. Reactions between cosmic rays and upper atmosphere constituents produce tritium. For example,

$$
{ }_{7} \mathrm{~N}^{14}+{ }_{0} \mathrm{n}^{1} \rightarrow{ }_{1} \mathrm{H}^{3}+{ }_{6} \mathrm{C}^{12}
$$

and

$$
{ }_{1} \mathrm{H}^{2}+{ }_{1} \mathrm{H}^{2} \rightarrow{ }_{1} \mathrm{H}^{3}+{ }_{1} \mathrm{H}^{1}
$$

This tritium becomes incorporated into water and falls to earth with rain. At an estimated production rate of $4 \times 10^{\circ} \mathrm{Ci} / \mathrm{yr}$, a world steady state natural inventory of $-70 \times 10^{\circ} \mathrm{Ci}$ results [3.1].

In addition, commercial producers of radioluminescent and neutron generator devices release about $1 \times 10^{\circ} \mathrm{Ci} / \mathrm{yr}$ [3.1]. Atmospheric nuclear test explosions from 1945 to 1975 added approximately $8 \times 10^{\circ} \mathrm{Ci}$ of tritium to the environment [3.2], much of which has since decayed, but about $5 \times 10^{8} \mathrm{Ci}$ remain in the environment. Underground nuclear tests appear to add little tritium to the mobile ecosphere [3.2]. The nuclear power and defense industries currently release $1-2 \times 10^{\mathrm{B}} \mathrm{Ci} / \mathrm{yr}$, a small fraction of which derives from light-water reactors [3.3].

\subsubsection{Sources of Tritium Production}

Numerous potential and actual sources of tritium production exist in the U.S., UK, France, USSR, and other countries. They include light-water reactors, heavy-water reactors, fuel reprocessing plants, and production reactors [3.4]. Light-water and heavy-water reactors produce in their coolants approximately 500 to 1,000 and $2 \mathrm{x}$ $10^{\circ} \mathrm{Ci} / \mathrm{yr}$, respectively, for every $1,000 \mathrm{MW}(\mathrm{e})$ of power.

Tritium is a ternary fission product within nuclear fuel, generated at a rate of $1-2 \mathrm{x}$ $10^{4} \mathrm{Ci}$ per year $/ 1,000 \mathrm{MW}(\mathrm{e})$. Recovery of this tritium at fuel reprocessing plants could reach $1-10 \times 10^{\circ} \mathrm{Ci} / \mathrm{yr}$ if reprocessing were allowed, depending on the state of the power industry. U.S. DOE reactors are used to produce tritium by the neutron activation of $\mathrm{Li}^{-6}$. The Hanford $\mathrm{N}$ reactor has had a production capability of $6 \times 10^{7}$ $\mathrm{Ci} / \mathrm{yr}$, while capabilities at the Savannah River Site remain classified. Tritium is commercially available from Canada, the Soviet Union, and the U.S. DOE's Mound Plant, and is provided within the U.S. DOE by the Savannah River Site [3.4]. 


\subsection{Chemical Properties}

\subsubsection{Atomic Weight/Hydrogen Isotopes}

The atomic weights, symbols, and abundances [3.5] of the three well-known isotopes of hydrogen are given in Table 3.1. $\mathrm{H}^{4}$ and $\mathrm{H}^{5}$ are also known. However, since they decay in fractions of $1 \mathrm{~s}$, they are not extensively studied [3.6]. Unless otherwise specified in this chapter, the term "hydrogen" includes protium, deuterium, and tritium. $H$ will be used to refer to protium; confusion with elemental hydrogen will be eliminated by spelling the latter.

Table 3.1 - Hydrogen Isotopes

\begin{tabular}{|c|c|c|c|c|}
\hline \multicolumn{2}{|c|}{ Symbol } & \multirow[b]{2}{*}{ Name } & \multirow[b]{2}{*}{ Abundance (\%) } & \multirow[b]{2}{*}{ Mass (amu) } \\
\hline Physical & Common & & & \\
\hline${ }_{1} \mathrm{H}^{1}$ & $\mathrm{H}$ & Protium & 99.985 & 1.007825 \\
\hline${ }_{1} \mathrm{H}^{2}$ & D & Deuterium & 0.015 & 2.01400 \\
\hline${ }_{1} \mathrm{H}^{3}$ & $\mathrm{~T}$ & Tritium & $\begin{array}{c}\beta \text {-Emitter } \\
\text { 12.32-years half-life }\end{array}$ & 3.01605 \\
\hline
\end{tabular}

Numerous hydrogen-isotopic combinations of simple molecules can be formed. These include diatomic hydrogen molecules $\left(\mathrm{H}_{2}, \mathrm{HD}, \mathrm{HT}, \mathrm{D}_{2}, \mathrm{DT}\right.$, and $\left.\mathrm{T}_{2}\right)$, water $\left(\mathrm{H}_{2} \mathrm{O}, \mathrm{HDO}\right.$, HTO, $\mathrm{D}_{2} \mathrm{O}$, DTO, and $\left.\mathrm{T}_{2} \mathrm{O}\right)$, methane $\left(\mathrm{CH}_{4}, \mathrm{CH}_{3} \mathrm{D}, \mathrm{CH}_{2} \mathrm{D}_{2}, \mathrm{CHD}_{3}, \mathrm{CD}_{4}\right.$, $\mathrm{CH}_{3} \mathrm{~T}, \mathrm{CH}_{2} \mathrm{~T}_{2}, \mathrm{CHT}_{3}, \mathrm{CT}_{4}, \mathrm{CHDT}_{2}, \mathrm{CHD}_{2} \mathrm{~T}, \mathrm{CH}_{2} \mathrm{DT}, \mathrm{CD}_{3} \mathrm{~T}, \mathrm{CD}_{2} \mathrm{~T}_{2}$, and $\mathrm{CDT}_{3}$ ), and hydrogen fluoride (HF, DF, and TF).

\subsubsection{Chemical Reactions}

Tritium can form the same type of compounds as do protium and deuterium. For example,

$$
\begin{aligned}
& \mathrm{C}_{2} \mathrm{H}_{4}+\mathrm{T}_{2} \stackrel{\mathrm{Ni}}{\rightarrow} \mathrm{H}_{2} \mathrm{TC}-\mathrm{CH}_{2} \mathrm{~T} \\
& \mathrm{U}+3 / 2 \mathrm{~T}_{2} \rightarrow \mathrm{UT}_{3} \\
& \mathrm{SOCl}_{2}+\mathrm{T}_{2} \mathrm{O} \rightarrow \mathrm{SO}_{2}+2 \mathrm{TCl}
\end{aligned}
$$

In addition, substitution or exchange reactions, which are rapid for protium and deuterium, are also rapid for tritium: ": 


$$
\begin{gathered}
\mathrm{CH}_{3} \mathrm{COOH}+\mathrm{T}_{2} \mathrm{O} \leftrightarrow \mathrm{CH}_{3} \mathrm{COOT}+\mathrm{HTO} \\
\mathrm{FeOOH}+\mathrm{NT}_{3} \leftrightarrow \mathrm{FeOOT}+\mathrm{NHT}_{2} \\
\mathrm{C}_{6} \mathrm{H}_{12}+\mathrm{T}_{2} \stackrel{\text { PS }}{\mathrm{C}_{6} \mathrm{H}_{11} \mathrm{~T}+\mathrm{HT}}
\end{gathered}
$$

The rates and equilibrium distributions of reactions involving hydrogen tend to be isotope-dependent [3.6]. This "classical" isotope effect is especially apparent if the bond involving the hydrogen atom is broken during a reaction or is involved in the transition state. For example,

$$
\mathrm{C}_{6} \mathrm{H}_{5} \mathrm{MgX}+\mathrm{HTO} \stackrel{k}{\rightarrow} \mathrm{C}_{6} \mathrm{H}_{5} \mathrm{~T}+\mathrm{MgXOH}+\mathrm{C}_{6} \mathrm{H}_{6}+\mathrm{MgXOT}
$$

where the ratio of products $\left(\mathrm{C}_{8} \mathrm{H}_{8} / \mathrm{C}_{6} \mathrm{H}_{5} \mathrm{~T}\right)$ is -2.5 . This effect is caused by zero-point energies which are lower for the heavier isotopes. Higher activation energies are thus required in most reactions of the heavier, more "sluggish" isotope.

In contrast, the following reactions occur at approximately equal rates, since no tritium-containing chemical bonds are broken:

$$
\begin{aligned}
& \mathrm{C}_{6} \mathrm{H}_{4} \mathrm{TMgX}+\mathrm{H}_{2} \mathrm{O} \stackrel{\stackrel{k}{\rightarrow} \mathrm{C}_{6} \mathrm{H}_{5} \mathrm{~T}+\mathrm{MgXOH}}{\mathrm{C}_{6} \mathrm{H}_{5} \mathrm{MgX}+\mathrm{H}_{2} \mathrm{O} \stackrel{\mathrm{k}}{\rightarrow} \mathrm{C}_{6} \mathrm{H}_{6}+\mathrm{MgXOH}}
\end{aligned}
$$

Most classical hydrogen isotope effects are expressed as ratios of product amounts, as in the above reactions, and are between 1 and 10 to 20 for protium/tritium.

An added "isotope effect" exists for tritium. Reactions can occur at room temperature with high concentrations of tritium that would require elevated temperatures or other added energy conditions for protium or deuterium [3.6]. This is because the activation energy necessary to drive thermodynamically favored reactions involving protium or deuterium is often not present. However, this activation energy for tritium reactions is "self-provided" by beta rays (high energy, electrons) from radioactive decay. Upon collision with a molecule, a beta ray loses several electron volts and produces dissociated molecular fragments, ions, and radicals. These fragments then can open a pathway to the favored end products. To compare a kinetically slow protium reaction to a similar tritium reaction at room temperature, consider the following: 


$$
\begin{aligned}
& \mathrm{C}_{2} \mathrm{H}_{6}+\mathrm{H}_{2} \rightarrow 2 \mathrm{CH}_{4} \\
& \mathrm{C}_{2} \mathrm{H}_{6}+\mathrm{T}_{2} \rightarrow 2 \mathrm{CH}_{3} \mathrm{~T}
\end{aligned}
$$

In the first process, the heat of reaction is $-16 \mathrm{kcal} / \mathrm{mole}\left(\mathrm{CH}_{4}\right.$ is favored), but the reaction time at $25^{\circ} \mathrm{C}$ is many years. In contrast, the tritium reaction at the same temperature should proceed in a matter of minutes or hours when $T_{2}$ pressure is approximately 1 atmosphere. $T_{2}$ gas is a "self-catalyzing reducer;" $T_{2} \mathrm{O}$ is a "self-catalyzing hydrater/oxidizer." Rates of reaction involving tritiated compounds are dependent on their concentration or partial pressure [3.7, 3.8].

Other processes should take place concurrently with the reaction $\mathrm{C}_{2} \mathrm{H}_{8}+\mathrm{T}_{2} \rightarrow$ $2 \mathrm{CH}_{3} \mathrm{~T}$. depending on the relative proportions of reactants. For example, if the concentration of $\mathrm{C}_{2} \mathrm{H}_{6}$ is much greater than that of $\mathrm{T}_{2}$, then most of the beta ray energy is deposited in ethane. This leads to the formation of organic radicals, which in turn react primarily with the ethane. Higher order hydrocarbons and polymers containing some tritium should then be formed. If $\mathrm{C}_{2} \mathrm{H}_{8}$ is dominated by $\mathrm{T}_{2}$, most of the beta rav energy is deposited in the tritium, which causes tritium radicals and ions to form. These should reduce the $\mathrm{C}_{2} \mathrm{H}_{8}$ to $\mathrm{CT}_{4}$, with the protium redistributed between $\mathrm{CHT}_{3}$ and $\mathrm{HT}$. Between these two extremes, the reactions should occur in varying proportions.

Flammability/ignitability characteristics of $T_{2}$ in the presence of oxygen are substantially the same as for $\mathrm{H}_{2}$. This is because chemical ignition occurs even more quickly than "self catalysis." Approximately $1 \%$ of $\mathrm{T}_{2}$ in air or approximately $4 \%$ oxygen in the presence of $T_{2}$ represent ignitable mixtures.

\subsubsection{Compatibility}

Because of its radioactive, chemically reducing, and diffusive properties, tritium gas interacts in some way with almost all materials. In organics such as pump oils, plastics, and O-rings, it perfuses and degrades many useful polymeric materials. This causes a loss of mechanical properties within months or years.

Tritium gas diffuses through glasses, especially at elevated temperatures. The beta rays activate the reduction of $\mathrm{Si}-\mathrm{O}-\mathrm{Si}$ bonds to $\mathrm{Si}-\mathrm{OT}$ and $\mathrm{Si}-\mathrm{T}$ bonds, and mechanical properties may be lost over a period of years. Tritium gas in ceramics has a similar effect, but the diffusion is much slower, limiting damage to surfaces. Silica glass plus $\mathrm{T}_{2} \mathrm{O}$ may lead to mechanically damaging hydration of the $\mathrm{SiO}_{2}$ network.

Some metals, such as uranium, are directly hydrided by tritium gas. These form a chemical compound and their mechanical properties are altered within minutes or 
hours. On the other hand, some metals, such as stainless steels, are permeated by tritium but do not lose their mechanical properties unless the tritium pressure is hundreds of atmospheres for several years (Figure 3.1).

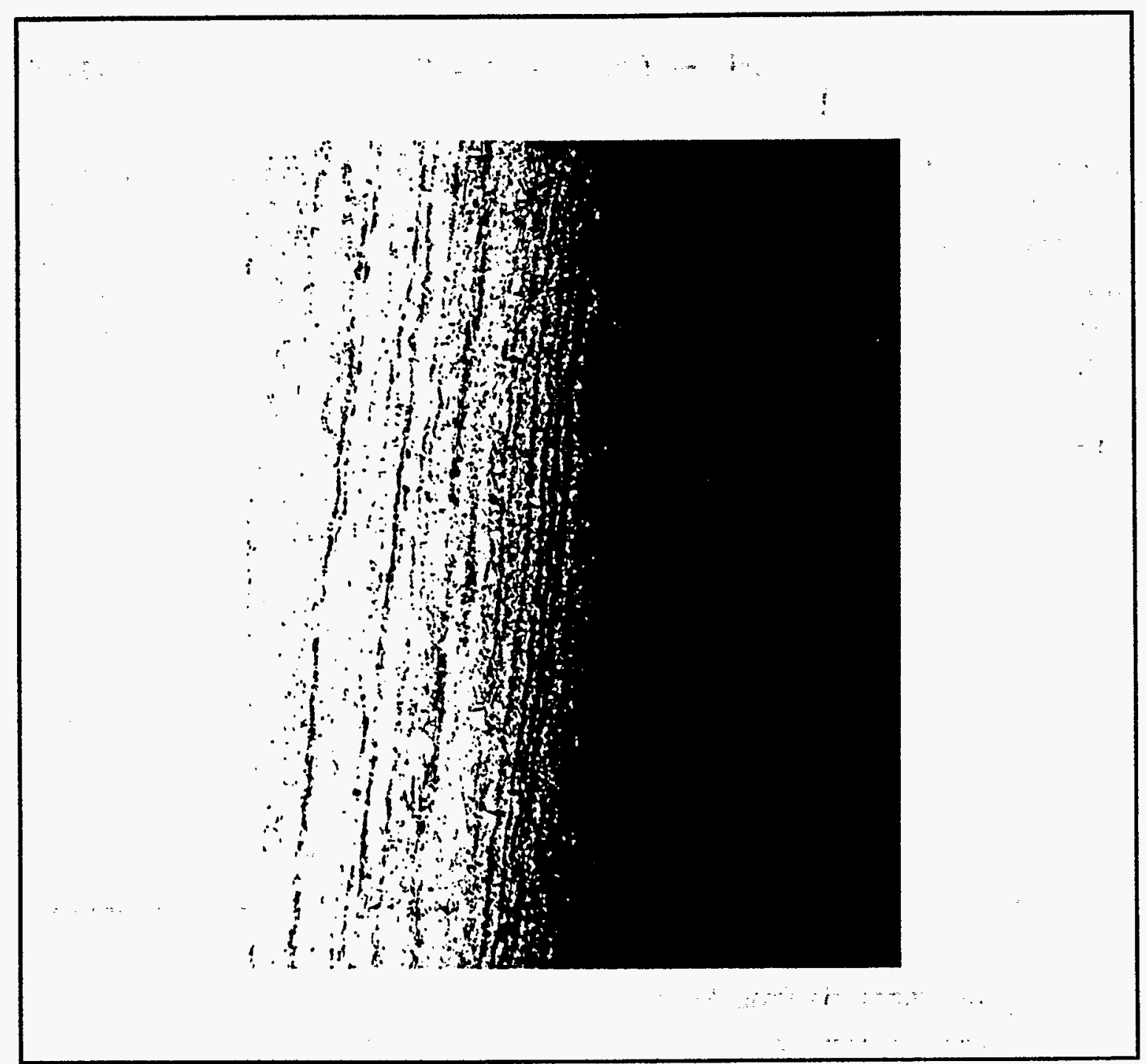

Figure 3.1 - Autoradiograph of tritium in $304 L$ stainless steel showing penetration from 0.5 atmosphere tritium gas at room temperature after 8 years (100X).

Care must be exercised when designing equipment for tritium gas to minimize the likelihood of spills, fires, or explosive gas mixtures. For a more detailed discussion of material compatibility with tritium, refer to Appendix $\mathrm{A}$.

\subsection{Nuclear and Radiative Properties}

\subsubsection{Disintegration}

Tritium decays by emitting a weak beta particle, together with an antineutrino; the daughter product is helium $-3[3.6 ; 3.9]$. Helium is a monatomic gas; therefore, the

$$
3-5
$$


decay of 1 mole of $T_{2}$ yields 2 moles of helium. This causes a pressure buildup in sealed vessels containing diatomic tritium gas (or HT or DT gas). The following is the equation for tritium disintegration:

$$
{ }_{1} \mathrm{H}^{3} \rightarrow\left({ }_{2} \mathrm{He}^{3}\right)^{+}+\beta^{-}+\bar{\nu}
$$

The $\left.{ }_{2} \mathrm{He}^{3}\right)^{+}$formed during the decay is rapidly neutralized by thermal electrons. ${ }_{2} \mathrm{He}^{3}$ is a stable isotope of helium. From the definition $1 \mathrm{Ci} \equiv 3.70 \times 10^{10}$ disintegrations/s [3.9], the atomic mass of tritium, and the tritium decay half-life of $12.3232 \mathrm{yr},{ }^{*}$ the values of some other radioactive properties of tritium can be derived by using other physical constants and conversion factors tabulated in the Handbook of Chemistry and Physics [3.5]. They are shown in Table 3.2.

Figure 3.2 shows the beta spectrum of tritium decay, with number density as a function of the energy of the beta particle [3.16-3.18]. Based on this and other information [3.15], the following beta energy parameters are accepted:

$$
\begin{aligned}
\mathrm{E}_{\max }(\beta) & =18.6 \mathrm{keV} \\
\mathrm{E}(\beta) & =5.69 \mathrm{ktV}
\end{aligned}
$$

\begin{tabular}{|c|c|c|}
\hline $\begin{array}{l}\because \\
\cdots\end{array}$ & $\begin{array}{l}\text { Half-Life } \\
\text { Disintegration Probability } \\
\text { Specific Activity } \\
\text { Power Density } \\
\text { Activity Density } \\
\quad\left(\mathrm{T}_{2} \text { gas, } 1 \text { atm, } 0^{\circ} \mathrm{C}\right) \\
\left.\quad \mathrm{T}_{2} \text { gas, } 1 \text { atm, } 25{ }^{\circ} \mathrm{C}\right) \\
\quad \mathrm{T} \text { atoms }\end{array}$ & $\begin{array}{l}12.3232 \mathrm{YR}^{*} \\
1.78241 \times 10^{-9} \mathrm{~S}^{-1} \\
9,619 \mathrm{Ci} / \mathrm{g} \\
0.324 \mathrm{~W} / \mathrm{g}\end{array} \begin{array}{l} \\
2.589 \mathrm{Ci} / \mathrm{cm}^{3} \\
2.372 \mathrm{Ci} / \mathrm{cm}^{3} \\
58,021 \mathrm{Ci} / \mathrm{g} \text {-mole } \\
29,011 \mathrm{Ci} / \mathrm{g} \text {-atom }\end{array}$ \\
\hline
\end{tabular}

Table 3.2 - Radioactive Properties of Tritium

*A tritium half-life of $12.323 \pm 0.004 \mathrm{yr}$ is the value accepted by the DOE $[3.10,3.11]$. However, the National Institute of Standards and Technology (NIST) recognizes a value of $12.43 \pm 0.05$ ì $[3,12,3.13]$. Recently, a number between these two, $12.38 \pm 0.04 \mathrm{yr}$, has been proposed and may become the new accepted half-life in the future $[3.14,3.15]$. 


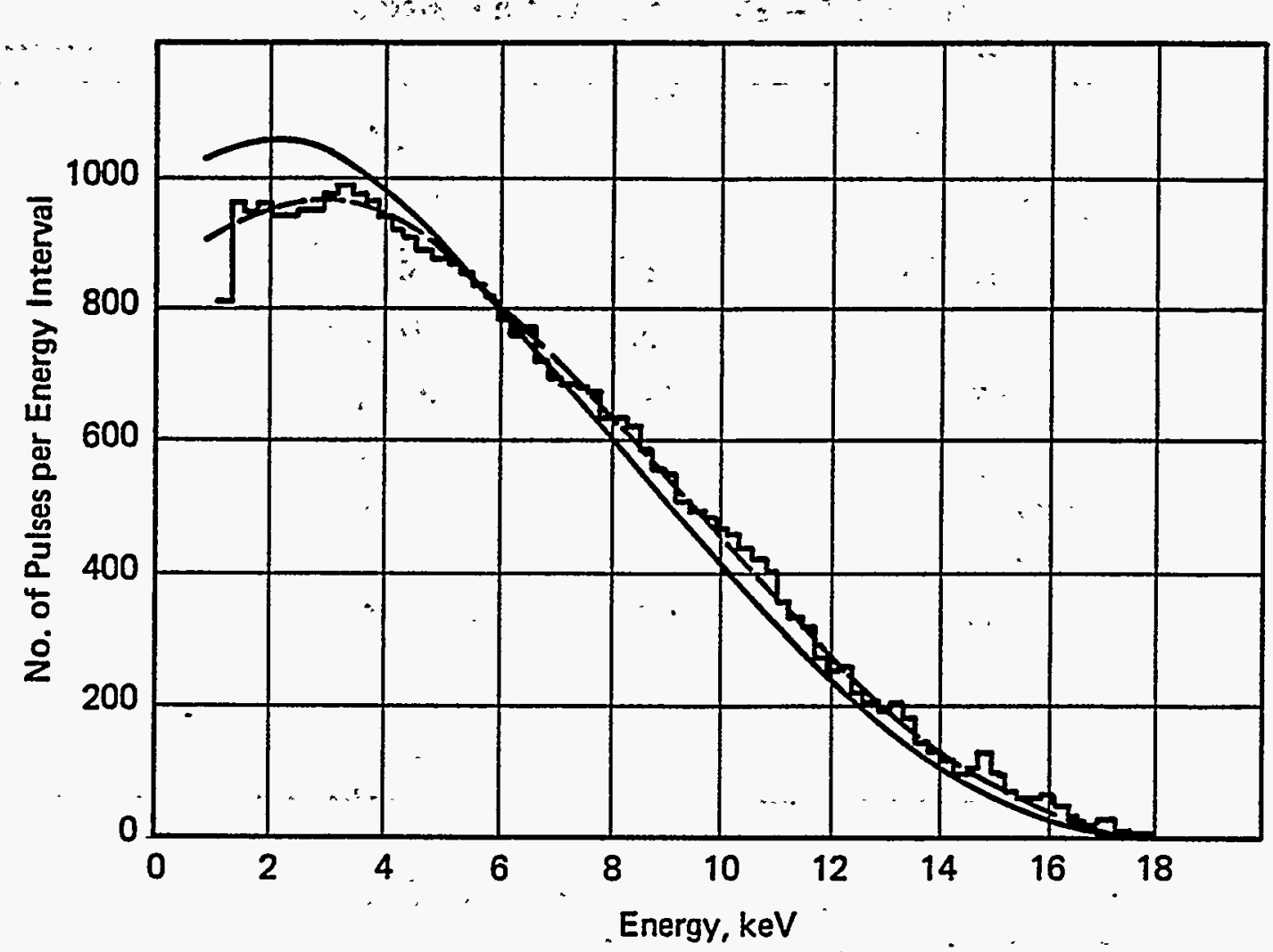

Figure 3.2 - Beta particle energy spectrum of tritium decay, showing number density as a function of energy.

\subsubsection{Range and Energy Absorption of Beta Particles}

The range and absorption of beta particles in a material are important properties when designing methods to detect tritium and in understanding the mechanisms by which tritium can degrade materials.

A beta particle interacts with matter by colliding with bound electrons in the surrounding material [3.9]. In each collision, the beta particle loses several electron volts of energy, and the electron is stripped from its molecular fragment (ionization) or promoted to an excited state. Because the rate of energy loss per unit path length (linear energy transfer, LET) increases as the beta particle slows [3.19], the beta particle has a finite range in a material. $\because, \quad \therefore$.

Ranges of tritium betas in various materials are given in Table 3.3.

Because of its low energy, the tritium beta particle is not a penetrating radiation. The maximum range in biological tissue (similar to water) is much less than the depth of the dead cell layer on human skin. 
Table 3.3 - Ranges of Tritium Bietas

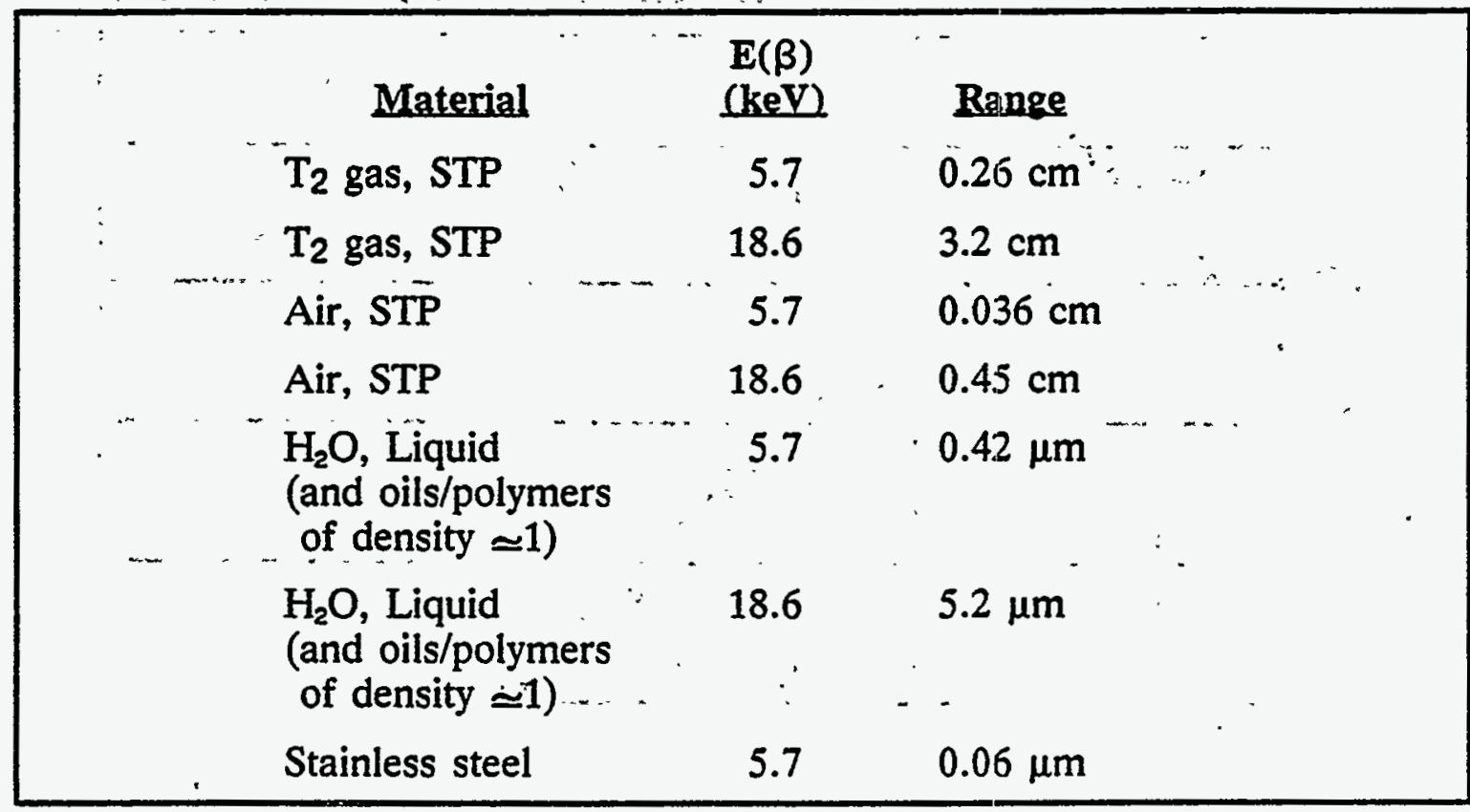

The absorption of energy from beta particles that emanate from a point source of tritium occurs nearly exponentially with distance [3.9]. This is a result of the shape of the beta particle spectrum folded into the ranges appropriate to different starting energies. Fraction of energy absorbed, F, can be expressed as

$$
\mathrm{F}=1-\exp (-\mu \mathrm{x})
$$

where $\mathrm{x}$ is distance in $\mathrm{cm}$ and

$\mu$ is the absorption coefficient for the surrounding material.

In gases at $25^{\circ} \mathrm{C}, 1 \mathrm{~atm}$ pressure, the absorption coefficient for tritium beta radiation is

$$
\begin{aligned}
\mu & =1.81 \mathrm{~cm}^{-1}\left(\mathrm{H}_{2}\right) \\
& =11.0 \mathrm{~cm}^{-1}\left(\mathrm{~N}_{2}\right) \\
& =12.9 \mathrm{~cm}^{-1} \text {.(Ar) }
\end{aligned}
$$$$
[3.20]: \because 3-18)
$$

For example, in $5 \mathrm{~mm}$ of air, $99.6 \%$ of beta particle energy is absorbed, whereas in hydrogen (or tritium) gas, only $60 \%$ is absorbed. The absorption coefficient for other media can be estimated by correcting for the relative stopping power (scattering probability: approximately the number of electrons per cubic centimeter) of the material [3.21]. 


\subsection{Physical Properties of Tritium Gas}

\subsubsection{Solubility}

Hydrogen gas (including tritium gas) dissolves to some extent in almost all materials [3.22-3.26]. Tritium and deuterium behave like protium, except for small isotopic effects. Hydrogen atoms or diatomic hydrogen molecules and some larger hydrogen-bearing molecules dissolve interstitially; that is, they diffuse into a structure and locate between atoms or molecular frameworks. As it dissolves, the hydrogen slightly disrupts the structural networks of the material and causes expansion. The extent of the disruption, along with the extent of chemical attractive/repulsive forces between the hydrogen and the material, determines the ultimate equilibrium state.

Solubility is a thermodynamic property [3.27], with associated enthalpies and free energies. The extent of tritium solubility in materials is important when considering contamination, inventory, and material degradation. Solubility with respect to a gas over a solid is generally measured as the number of atoms or molecules of that gas present within a given volume of that solid.

\subsubsection{Endothermic and Exothermic Solutions}

Solutions are endothermic when the interaction between hydrogen and the material structure is repulsive. Although solubility is low in such cases, it increases as the temperature increases. This is true for alumina [3.24], many metals [3.27], organic polymers [3.25], and perhaps glasses at temperatures below $150^{\circ} \mathrm{C}[3.24]$.

Solutions are exothermic when the interaction between hydrogen and the material structure is attractive. The solubility is higher than that for endothermic systems, but, as the temperature increases, this solubility decreases. This holds true for hydrogen atoms in glasses at temperatures greater than $150^{\circ} \mathrm{C}[3.24]$, in silicon carbide [3.24], and in metals where chemical hydride phases form [3.27]. For illustrations, see Figures 3.3 and 3.4.

\subsubsection{Solubility in Polymers. Glasses, and Ceramics}

Hydrogen gas dissolves as the molecular hydrogen species in many materials. For these systems, solubility is generally endothermic and is directly proportional to gaseous overpressure [3.26]. The materials in which hydrogen dissolves as the molecular species include organic polymers and glasses at less than $150^{\circ} \mathrm{C}$. Organic polymers generally have atomic-scale voids between the twisted polymer chain, and the hydrogen molecules seek these sites. Hydrogen dissolution in glasses is assumed to be similar [3.28]. The solubility of hydrogen in polymers is approximately $0.1 \mathrm{~cm}^{3}$ (STP) $/ \mathrm{cm}^{3}-$ atm at $300 \mathrm{~K}$, while it is $10^{1}$ to $10^{2}$ times lower in glasses. Polymers are unique in that hydrogen-bearing molecules larger than hydrogen can easily dissolve. Water and hydrocarbon vapors are known to enter and often swell 
polymeric networks [3.29]. These molecules can contain tritium. At temperatures well above ambient, hydrogen gas reacts with and "dissolves" as atoms in glasses $[3.30,3.31]$ and ceramics $[3.32,3.33]$. In the equilibrium $\mathrm{H}_{2}+\mathrm{M}=2 \mathrm{H} \cdot \mathrm{M}$, where $\mathrm{M}$ equals any material, solubility becomes proportional to the square root of pressure. In glasses at temperatures of $300^{\circ} \mathrm{C}$ or more, the equilibrium

$$
\mathrm{H}_{2}+-\mathrm{Si}-\mathrm{O}-\mathrm{Si}-\leftrightarrow-\mathrm{Si}-\mathrm{H}+\mathrm{H}-\mathrm{O}-\mathrm{Si}-
$$

becomes important. In ceramics, such as alumina and silicon carbide at or above $500^{\circ} \mathrm{C}$, hydrogen appears also to react and migrate as atoms:

$$
\mathrm{H}_{2}+-\mathrm{Al}-\mathrm{O}-\mathrm{Al}-\rightarrow-\mathrm{Al}-\mathrm{H}+\mathrm{H}-\mathrm{O}-\mathrm{Al}-
$$

The extent of molecular dissolution of hydrogen in ceramics (and crystalline materials in general) appears comparatively low.

\subsubsection{Solubility in Metals}

Hydrogen dissolves as atoms in metals [3.22, 3.34, 3.35]. These atoms occupy octahedral and tetrahedral locations within the lattice [3.36]. The hydrogen apparently exists within nonhydriding metal lattices as proton, deuteron, or triton, with the electron in a metal conduction band. Sorne metals are endothermic hydrogen absorbers and others are exothermic (see Section 3.4.1.1), and solubilities vary considerably (approximately 10 to 15 orders of magnitude) at room temperature.

Figures 3.3 and 3.4 show hydrogen solubility as a function of temperature for various metals and refractories. Note that solubilities for endothermic absorbers have a negative slope (positive enthalpy) in the inverse temperature plots, whereas exothermic systems have a positive slope (negative enthalpy). For various hydride phases, plots of decomposition overpressure as a function of inverse temperature yield negative enthalpies or heats of formation, as shown in Figure 3.5.

\subsubsection{Diffusion}

Diffusivity, a kinetic property, is a measure of the speed at which a diffusing species jumps from one solution site to another [3.37]. It is important in calculating the rate at which tritium migrates through a structure. The migration of hydrogen in most materials is orders of magnitude faster than the migration of other elements, as demonstrated in Figure 3.6. Again, isotopic differences are small.

Consider polymers, for example. Diffusion is a function of the potential energy barrier between site 1 and site 2 in Figure 3.7. The potential energy contours are 


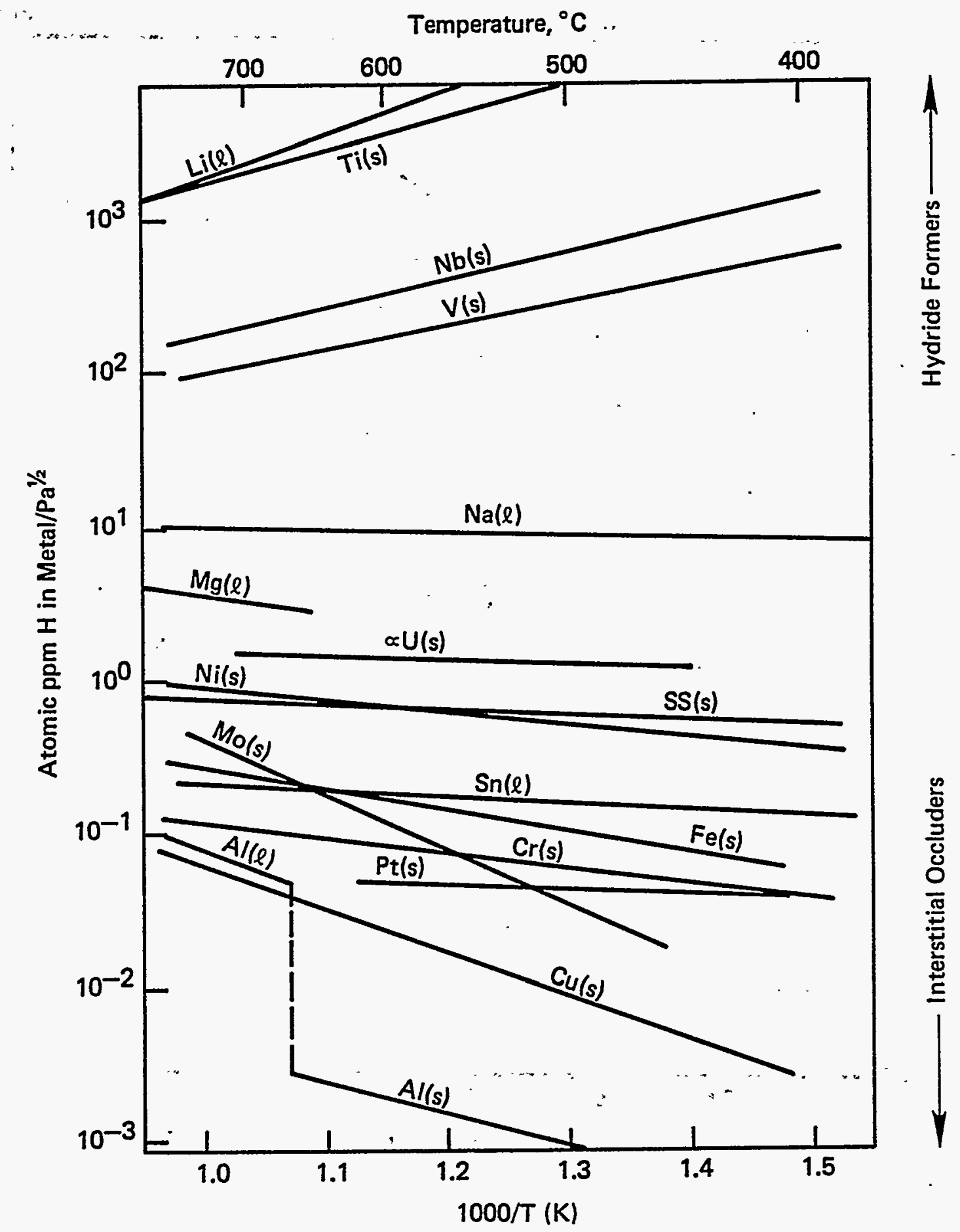

Figure 3.3 - Hydrogen solubility as a finction of temperature for selected metals and alloys ( $s=$ solid, $l=$ liquid) [3.38]. 


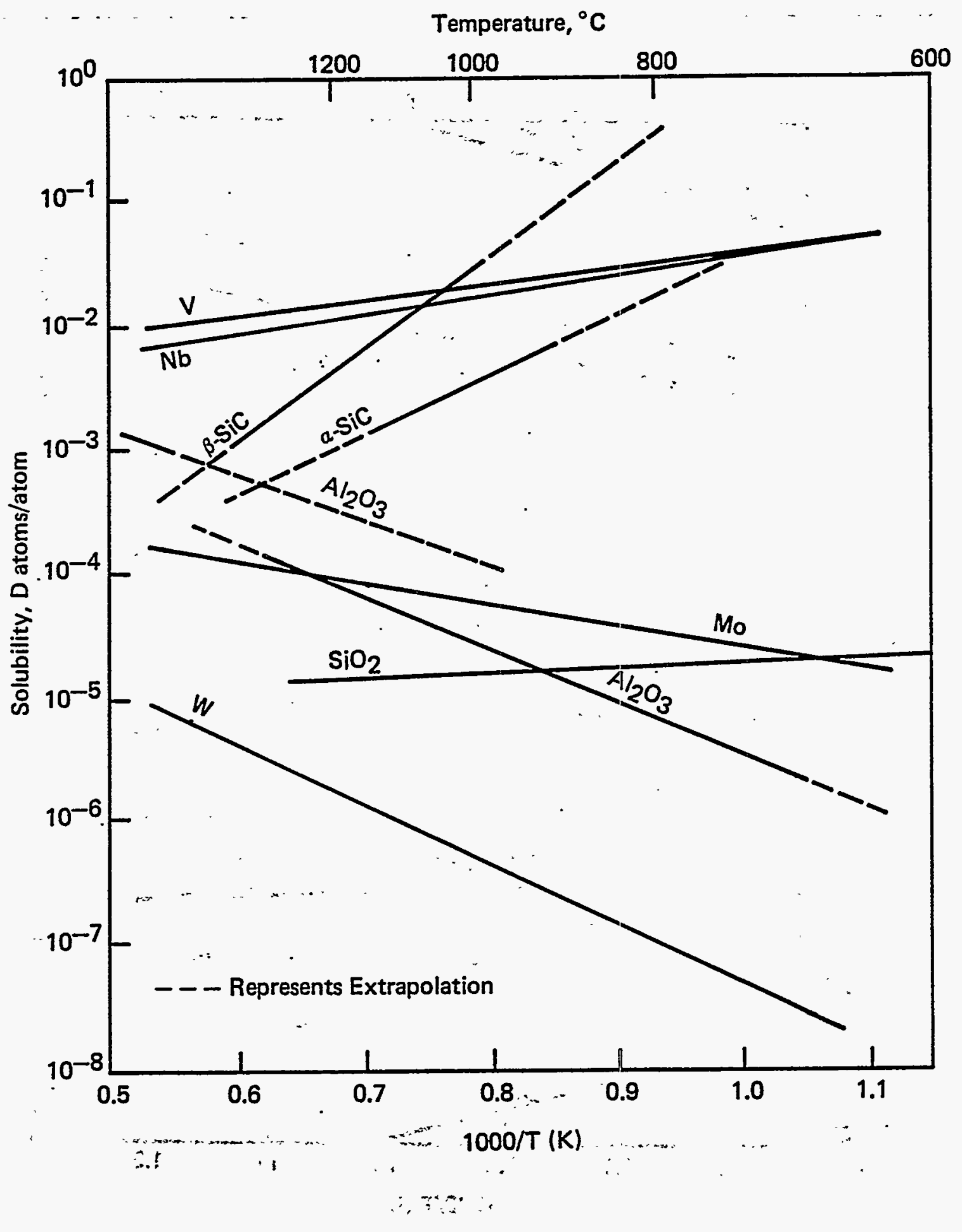

Figure 3.4 - Hydrogen solubility as a function of temperature for selected metals and refractories [3.39]. 


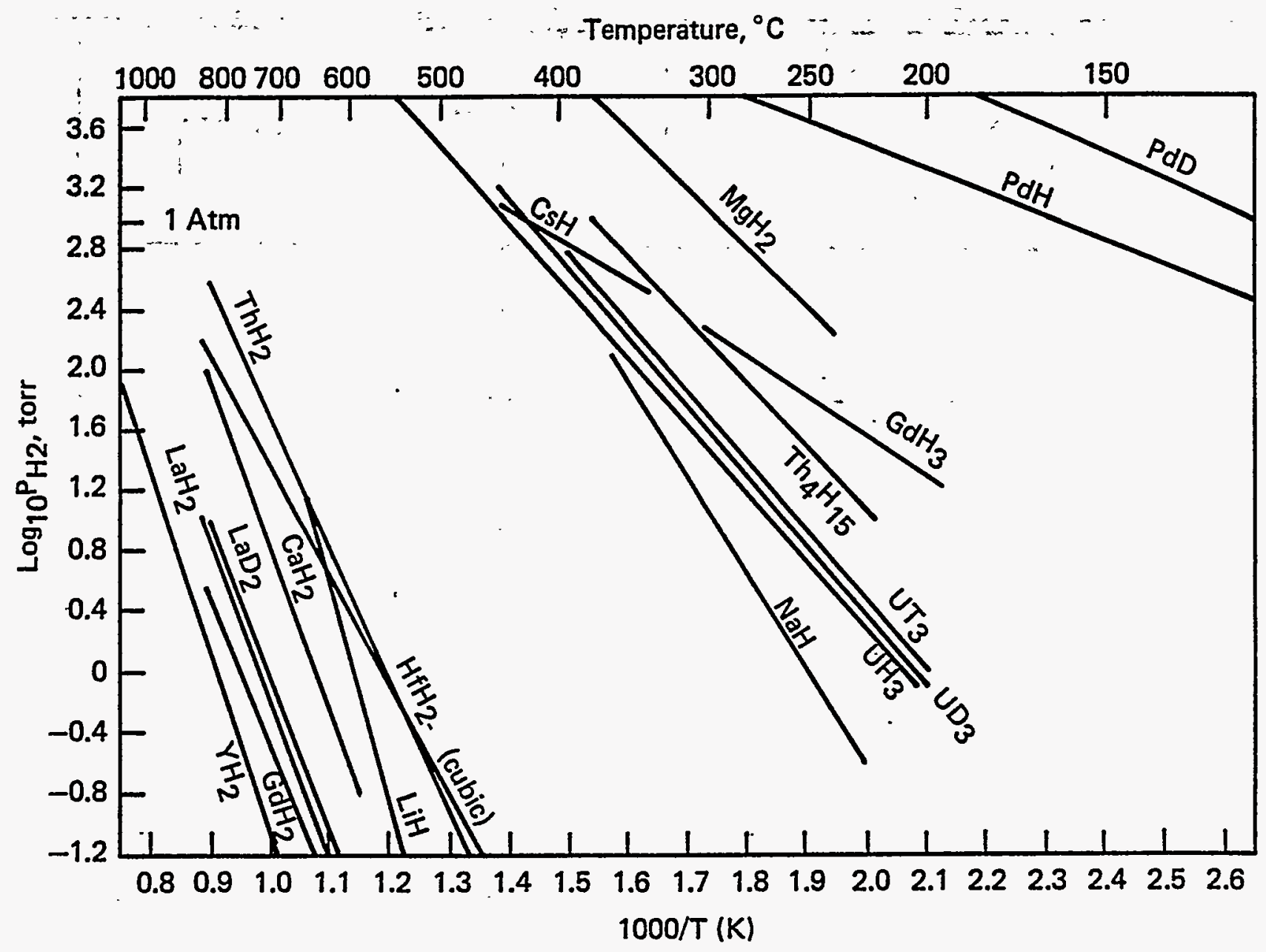

Figure 3.5 - Decomposition overpressure as a function of temperature for various metal hydride phases [3.40].

shown in Figure 3.8, where $\alpha$ is the intersite distance and $\Delta G^{\ddagger}$ is the free energy of activation for the jump. Since the jump requires activation energy, the frequency of jumping is a function of temperature: the higher the temperature, the faster the 'diffusion [3.37]. Since loading the sites with solute species decreases the jumps available to a particular species, most diffusion determinations are run at low concentrations [3.41]. 


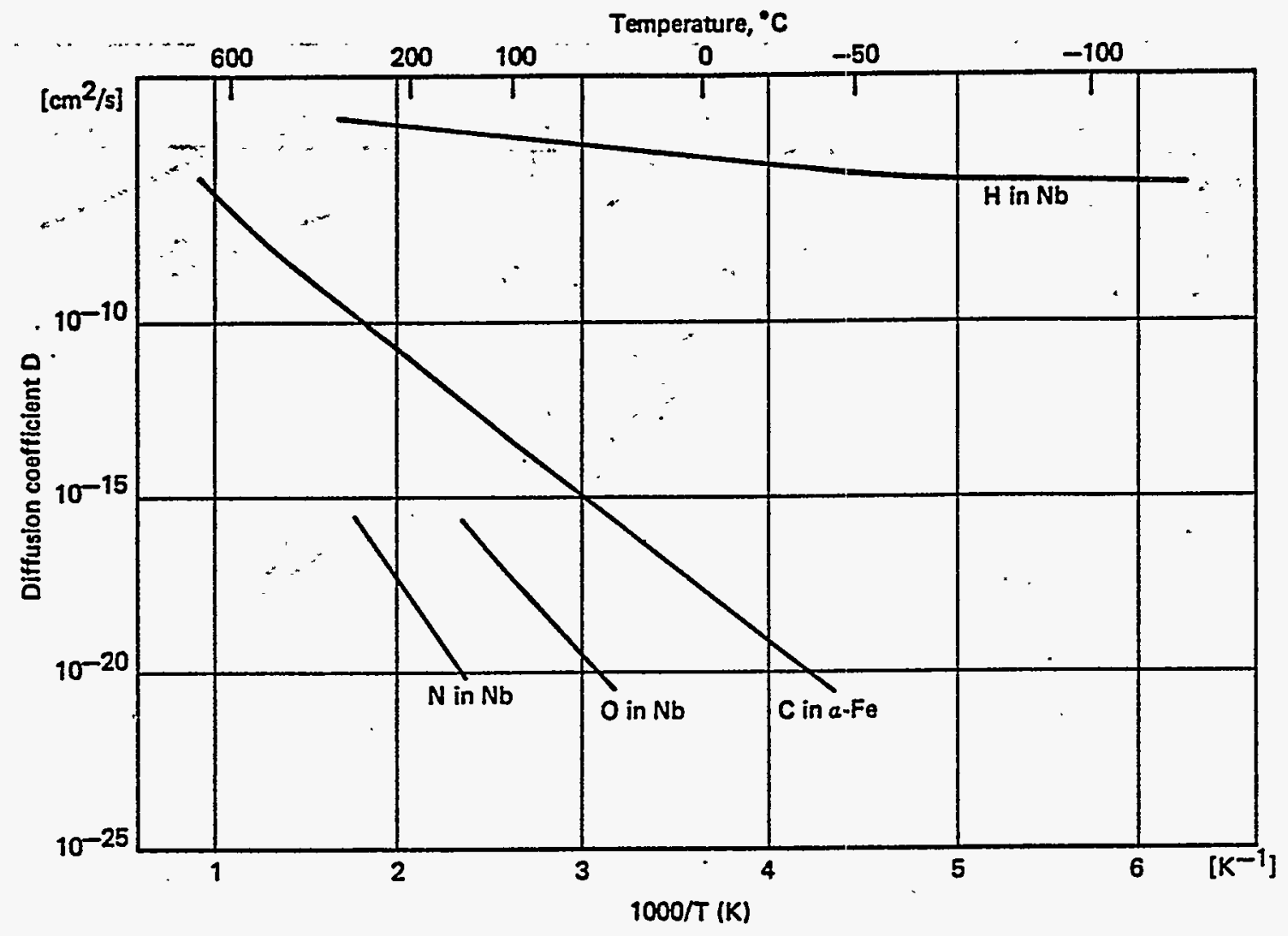

Figure 3.6 - Diffusivity of several light elements in metals as a function of temperature [3.41].

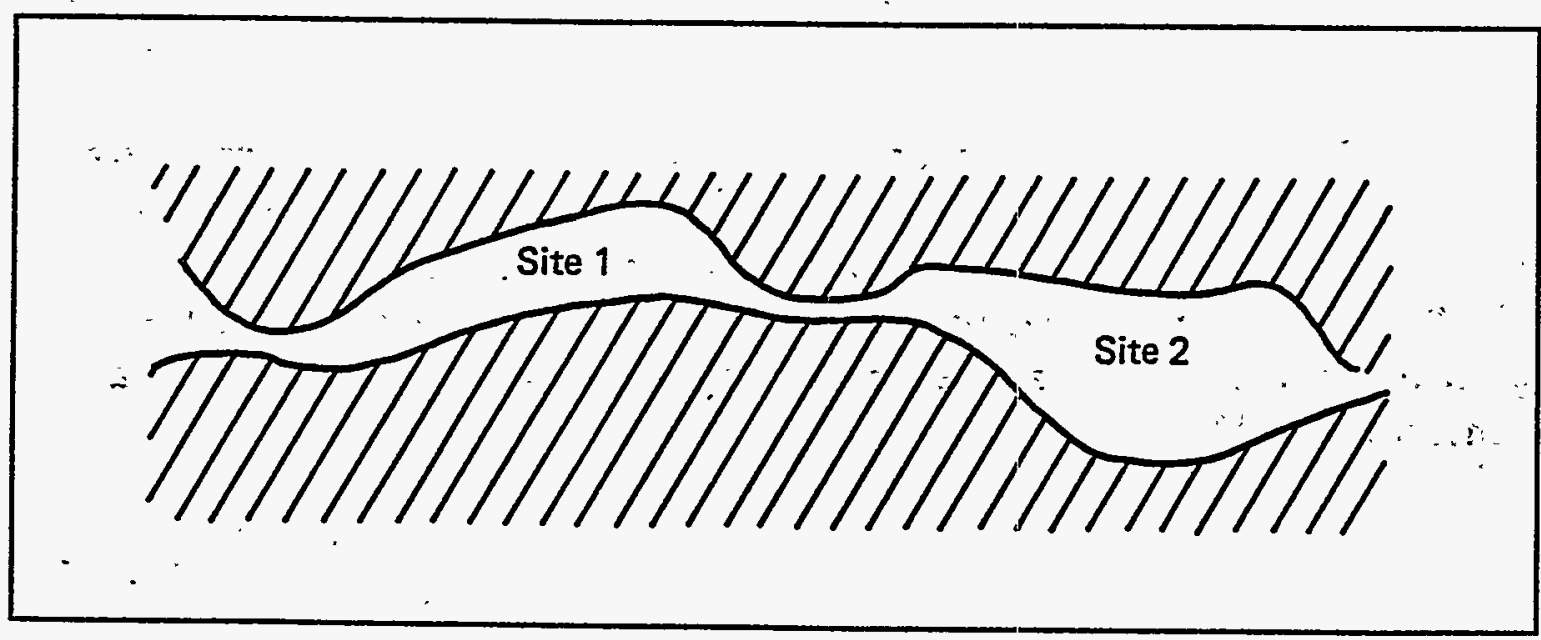

Figure 3.7 - Simplified depiction of two hydrogen solution sites in an amorphous material, with a nurrowing (high energy) pathway between sites. 


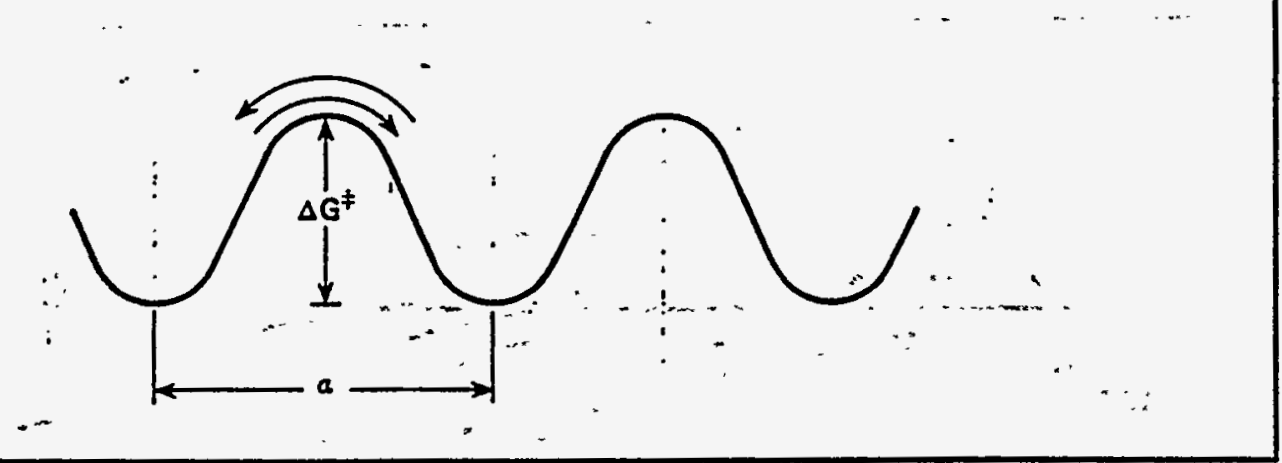

Figure 3.8 - Simple potential energy contour for the solution sites and connecting paths shown in Figure 3.7. $\alpha$ represents the intersite distance and $\Delta G \ddagger$ is the activation energy.

According to P. S. Shewmon [3.37], Fick's first law states that the flux (J) of a diffusing species away from its source is a direct function of concentration gradient

$$
\left(\frac{d c}{d x}\right): . \quad J=-D \frac{d c}{d x} .
$$

where $D$ is the diffusion constant (see Figure 3.9).

Plots of the diffusion constant as a function of inverse temperature for various materials are shown in Figures 3.10-3.12. The relationship noted between activation energy and melting point (a rough measure of internal bonding energy) of a material is shown in Figure 3.13.

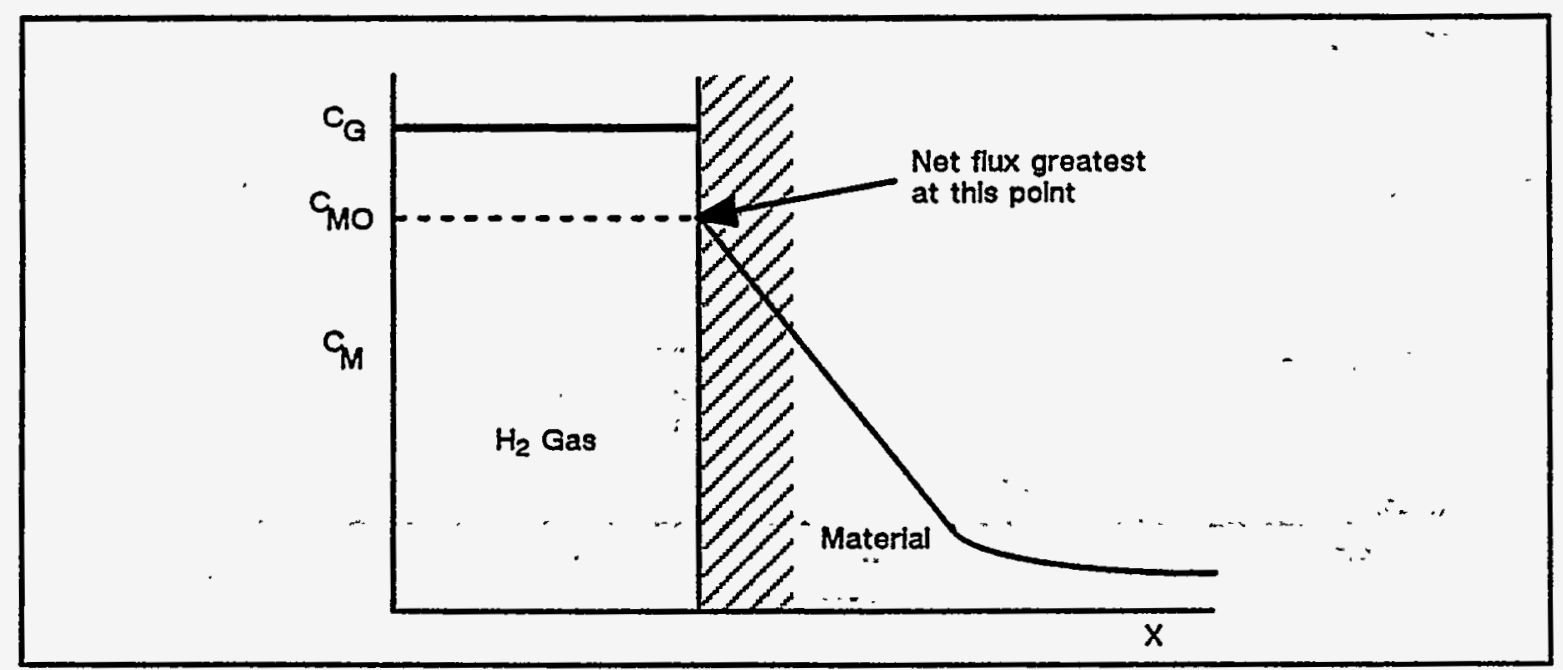

Figure 3.9-Hydrogen gas concentration, $C_{M}$, as a function of distance into an arbitrary material at some time prior to the onset of equilibrium permeation (or solution). The ratio $C_{M O} / C_{G}$ is a measure of the solubility of hydrogen in the material [3.37]. ( $\left(C_{M O}\right.$ is concentration in material at its surface; $C_{G}$ is concentration in gas.) 


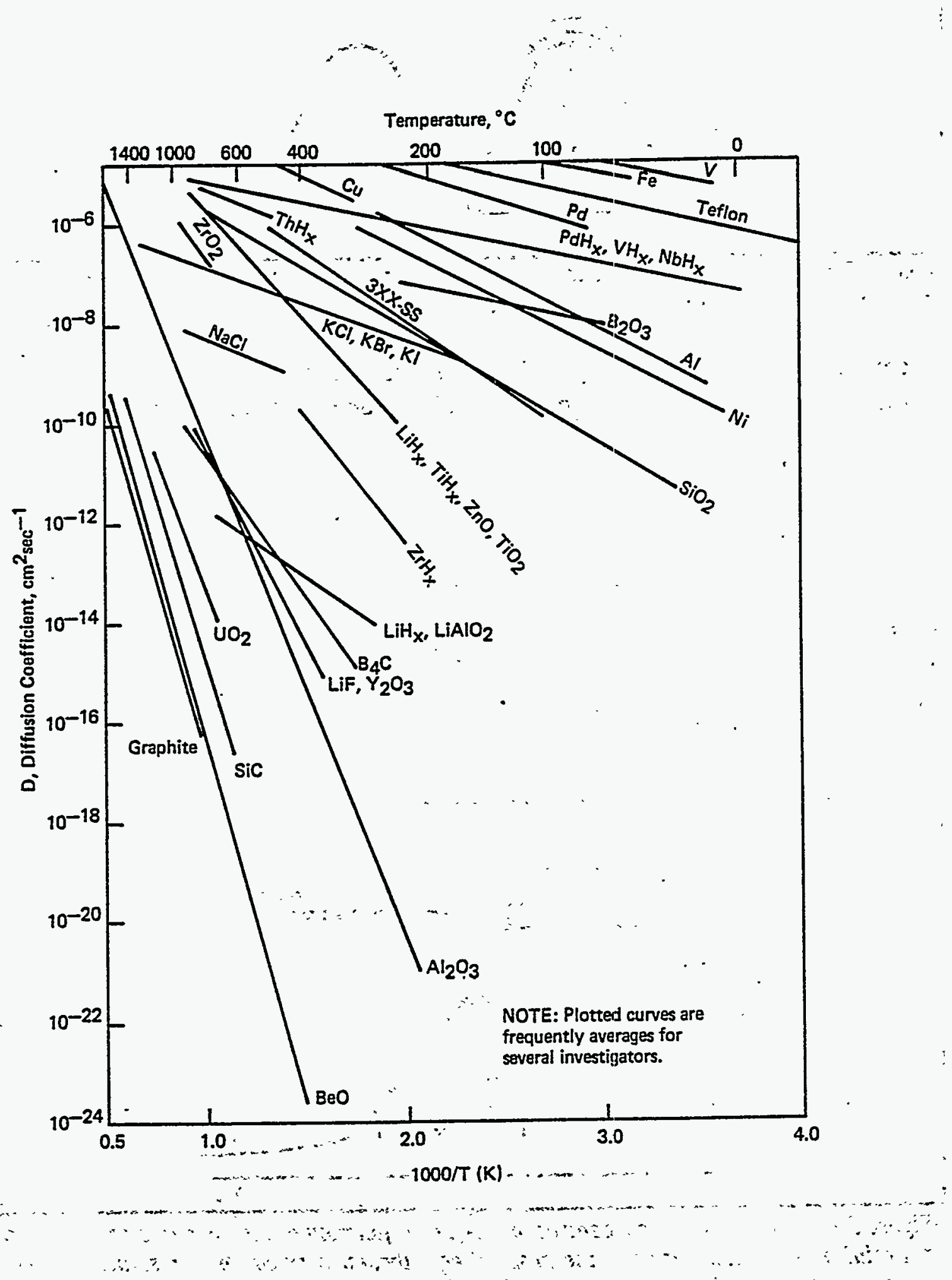

Figure 3.10 - Hydrogen diffision coefficients in various metallic and nonmetallic solids as a function of temperature [3.24]. 


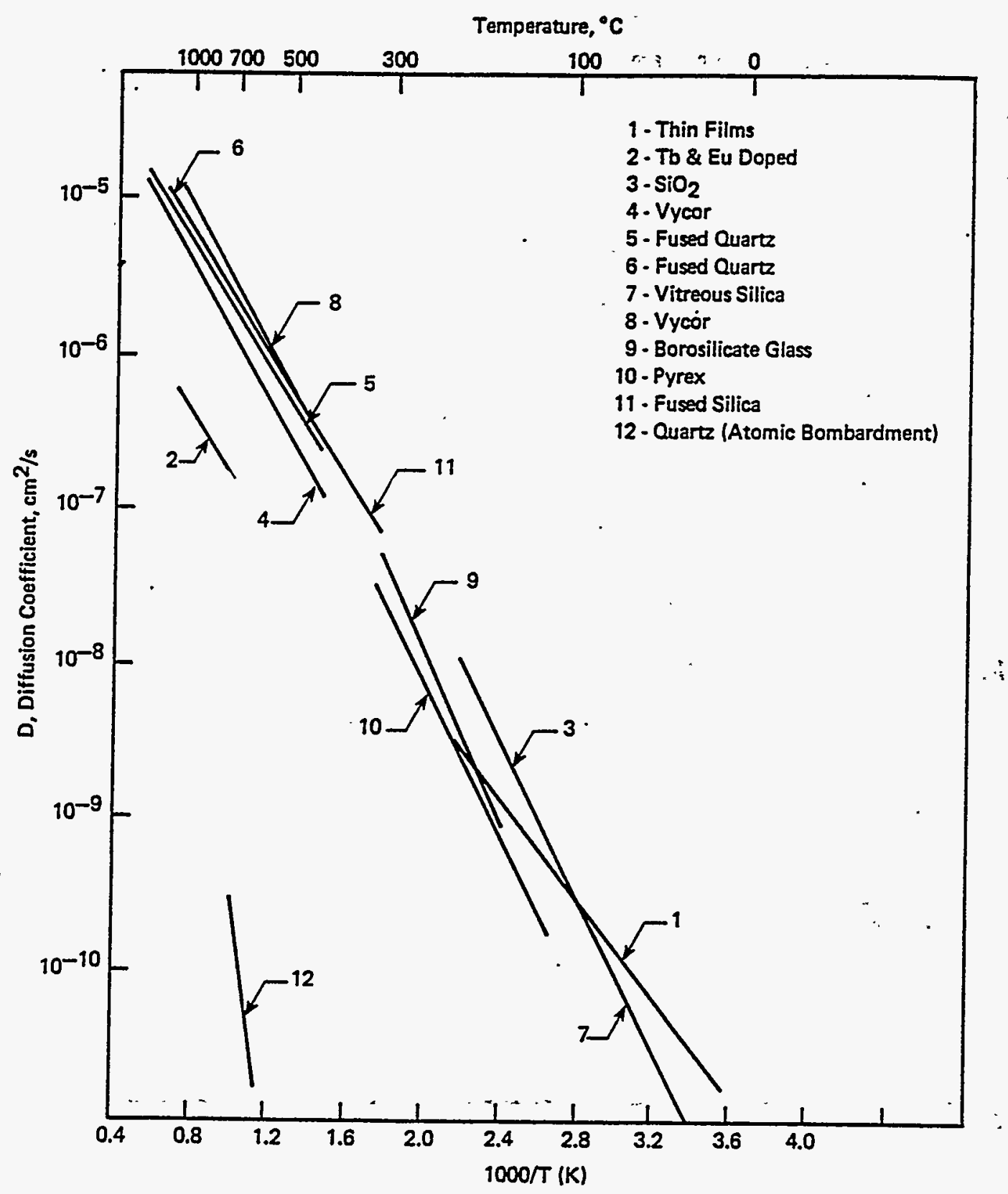

Figure 3.11 - Diffusion coefficients for hydrogen in silicas [3.24]. 


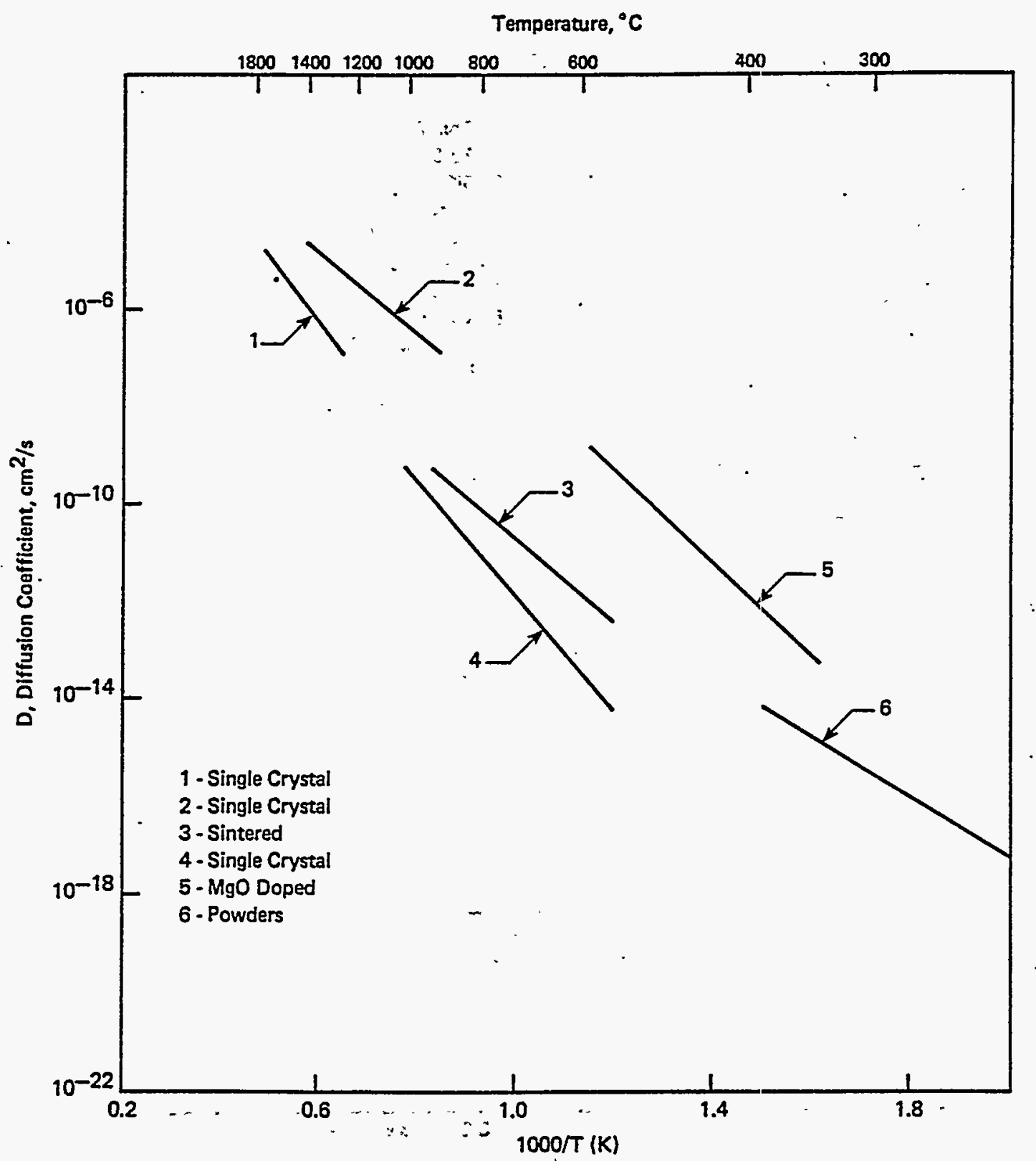

Figure 3.12 - Diffusion coefficients for hydrogen in aluminas [3.24].

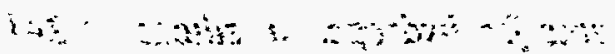




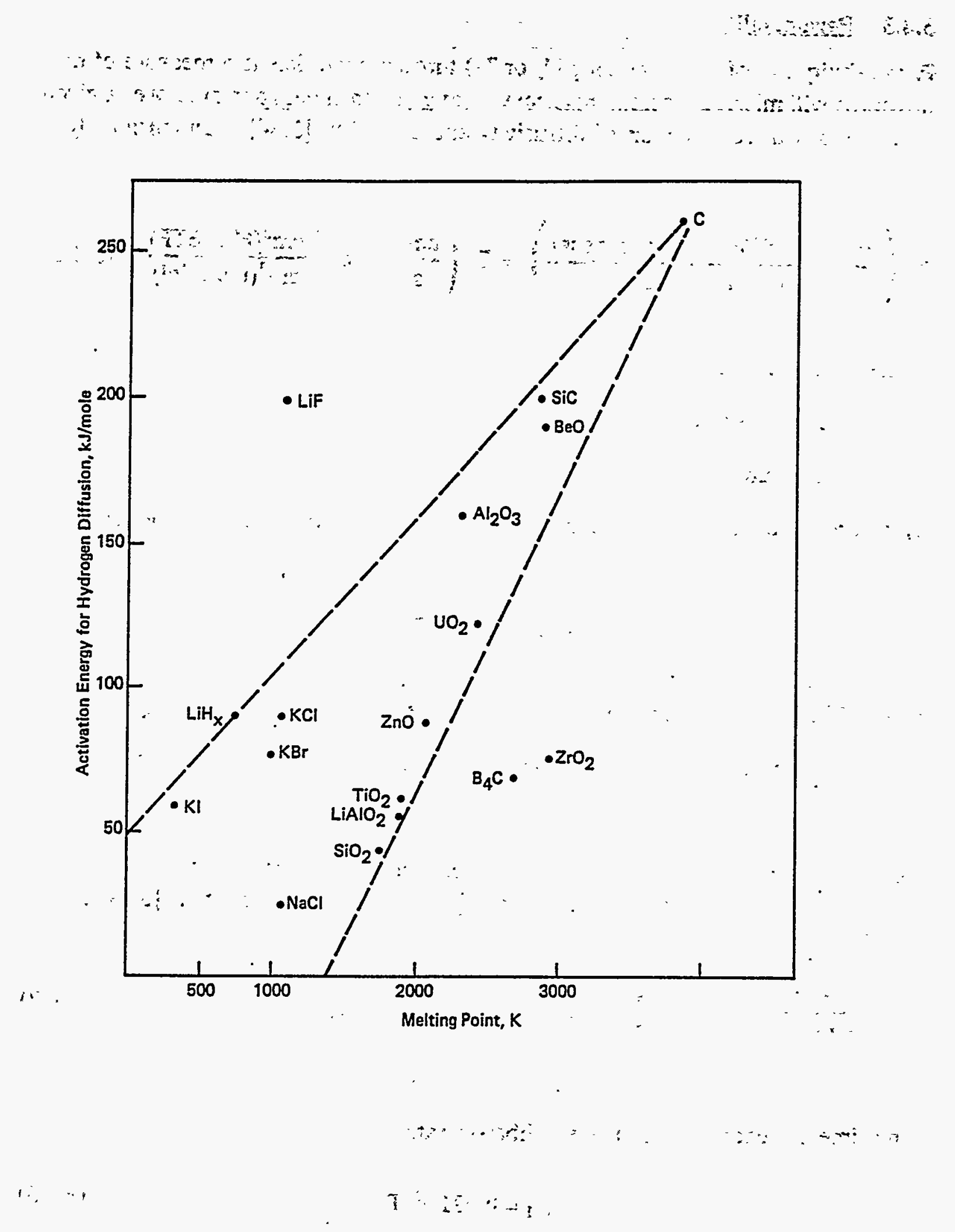

Figure 3.13 - Correlation of melting point with hydrogen diffusion activation energy [3.24]. 


\subsubsection{Permeability}

Permeability ( $\Phi$ ) of gas (including $\mathrm{H}_{2}$ or $\mathrm{T}_{2}$ ) through materials is a measure of how much gas will migrate across a material wall of given thickness and area over a given time. It is a direct function of diffusivity and solubility [3.34]. Dimensionally,

$$
\Phi\left(\frac{\mathrm{cm}^{3}\left(\mathrm{H}_{2}, \mathrm{STP}\right) \cdot \mathrm{cm}(\text { thickness })}{\mathrm{cm}^{2}(\text { area }) ! \mathrm{s}}\right)=\mathrm{D}\left(\frac{\mathrm{cm}^{2}}{\mathrm{~s}}\right) \cdot \mathrm{S}\left(\frac{\mathrm{cm}^{3}\left(\mathrm{H}_{2}, \mathrm{STP}\right)}{\mathrm{cm}^{3}(\text { material })}\right)
$$

where $\Phi$ is permeability,

$\mathrm{D}$ is diffusivity, and

$S$ is solubility.

To determine the equilibrium permeation rate through a substance, use the following formula:

$$
\mathrm{P}=\boldsymbol{\Phi} \cdot \mathrm{A} / \mathrm{l}=\mathrm{DSA} / \mathrm{l}
$$

where $\mathrm{P}$ is the equilibrium permeation rate (generally measured in $\mathrm{cm}^{3}\left(\mathrm{H}_{2}, \mathrm{STP}\right) / \mathrm{s}$ ),

$A$ is the area of the substance over which permeation occurs, and

$l$ is the thickness of the substance.

Permeation through a substance does not reach equilibrium immediately, but approaches its steady state value according to the following equation [3.29, 3.42]:

$$
\frac{\mathrm{P}(\mathrm{t})}{\mathrm{P}(\mathrm{t}=\infty)}=1+2 \sum_{\mathrm{n}=1}^{\infty}(-1)^{\mathrm{n}}\left[\exp \left(-\mathrm{Dn}^{2} \pi^{2} \mathrm{t} / l^{2}\right)\right]
$$

The time to reach $10 \%$ of the equilibrium rate is

$$
t_{0.1}=0.081 l^{2} / D
$$


The time to reach $90 \%$ of the equilibrium is

$$
\mathrm{t}_{0.9}=0.312 l^{2} / \mathrm{D}
$$

The following materials are listed in order of increasing permeability: ceramics and graphite, silicas, nonhydriding metals, hydriding metals, and polymers. Plots of hydrogen permeability as a function of inverse temperature for these materials are shown in Figures 3.14 and 3.15 : The permeability of many other hydrogen-bearing molecules through polymers has been studied [3.26, 3.29]. For such molecules, permeability can be well in excess of that for hydrogen through a polymer (see Tables 3.4 and 3.5). This must be considered when handling tritiated water or organic solvents.

Two factors readily influence the permeability of a metal: surface oxide and surface area. Because the permeability of hydrogen through a metal oxide at a given temperature is usually orders of magnitude lower than it is through the metal, a thin surface oxide can markedly reduce the permeability of hydrogen through the material $[3.43,3.44]$. For example, if LiD.salt is placed in contact with the surface of a stainless steel specimen, the oxide is reduced, allowing increased permeation (Figure 3.16). If a metal undergoes surface oxidation in the presence of steam, permeability decreases as oxidation proceeds (Figure 3.17).

The surface area of a specimen with a surface film can also affect permeability [3.42]. If the total microscopic area of a surface oxide is increased by abrasion without otherwise altering the specimen, observed permeability will often increase, approaching the intrinsic permeability of the base metal (with salt, see Figure 3.16).

Cold working stainless steels generally does not greatly affect the solubility, diffusivity, or permeability of hydrogen [3.46]. An exception is 304L stainless steel, where induced martensitic transformation allows pathways of enhanced diffusivity [3.42]. (30.4L is nevertheless a common construction material for tritium handling.) In addition, gamma irradiation of a stainless steel sample does not affect permeability over several hours at the hundreds of rad dose level [3.38]. However, tritium beta irradiation at the surface of a metal may introduce defects into the surface oxide barrier layer over several months, thereby increasing overall permeability. 


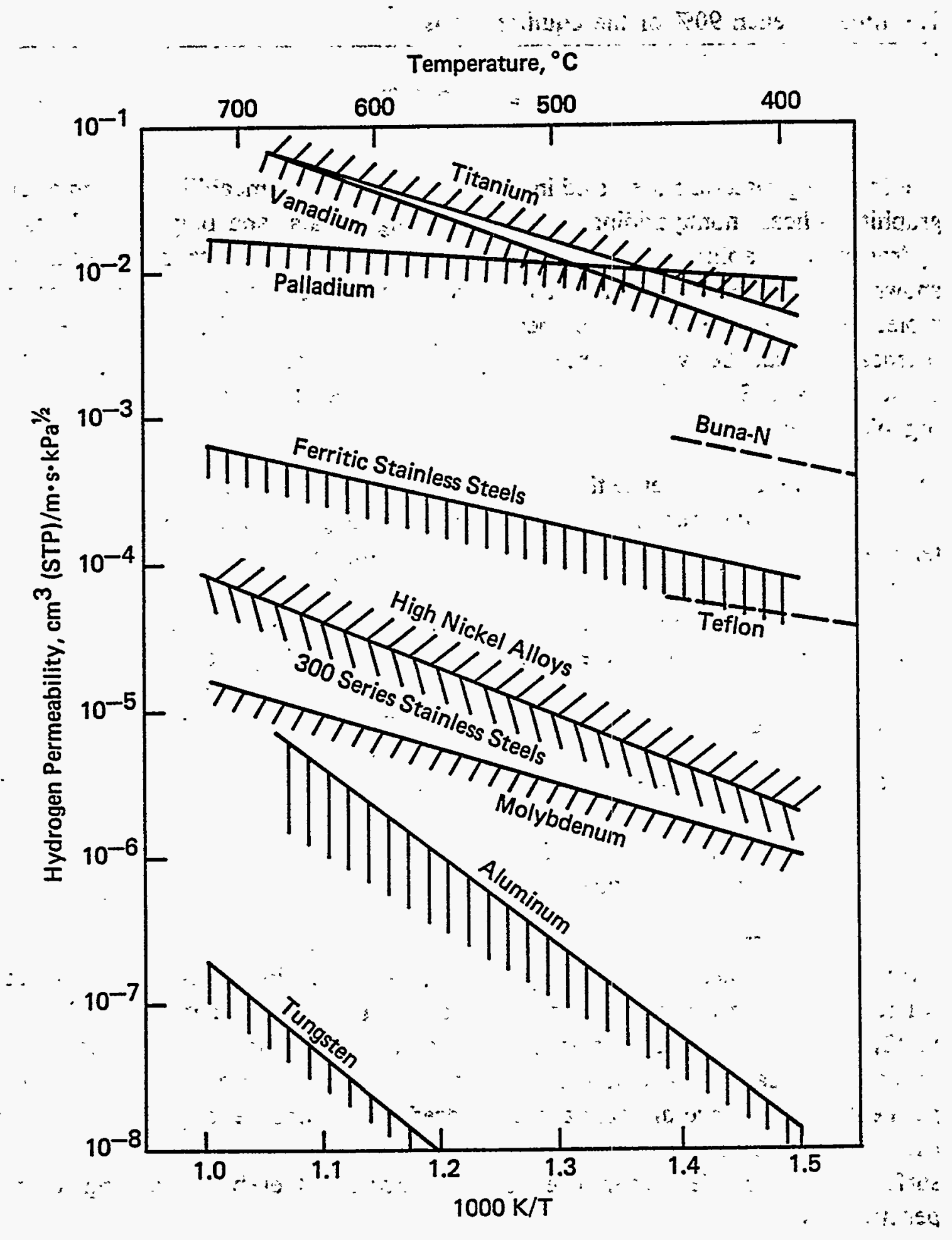

Figure 3.14-Hydrogen permeability as a function of temperature for selected metals and alloys [3.38]. 


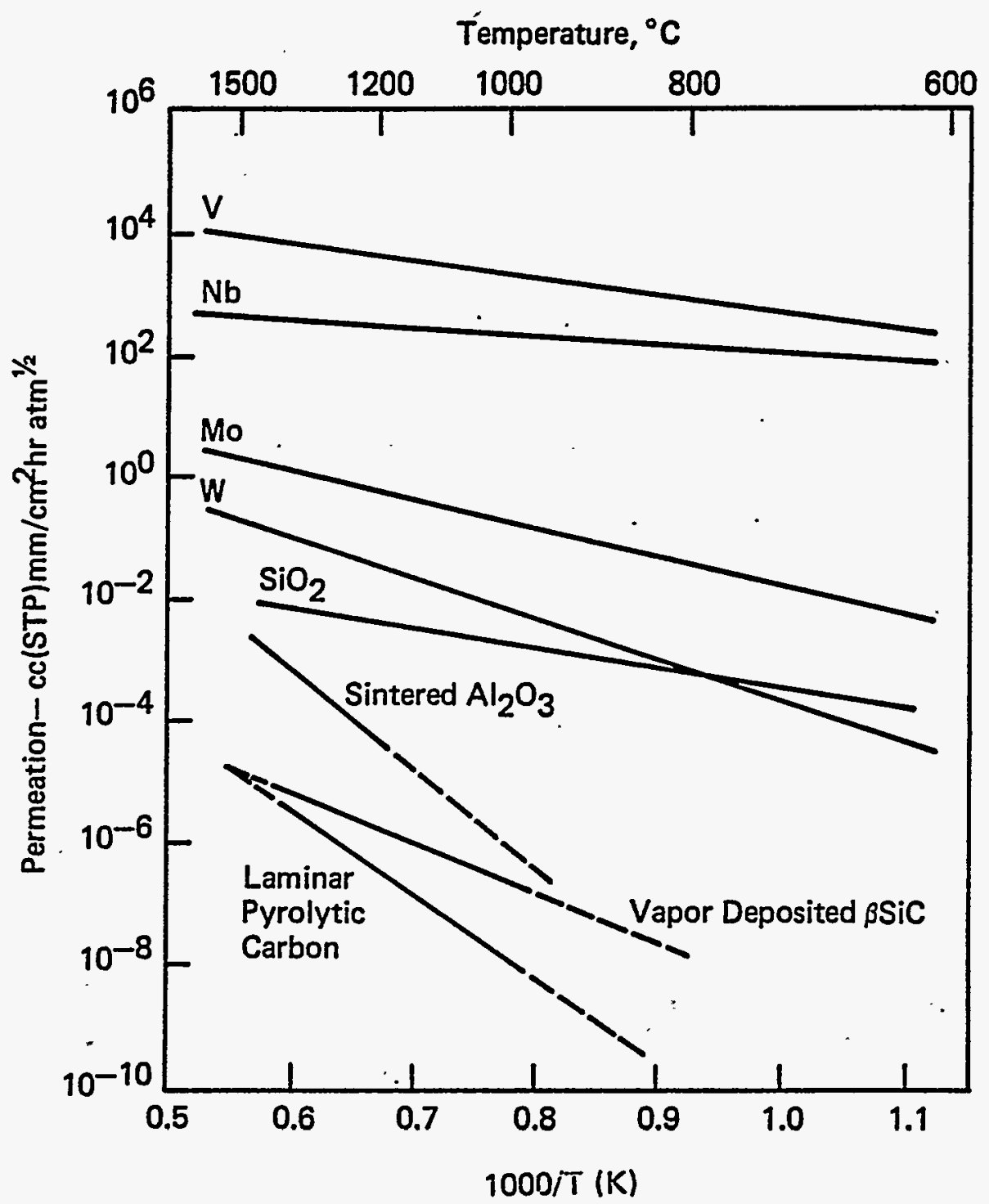

Figure 3.15 - Comparison of hydrogen permeation coefficients in refractory metals to those in $\mathrm{Al}_{2} \mathrm{O}_{3}, \mathrm{SiC}$, and PyC at 1 atmosphere :[3.39]. 
Table 3.4 - Permeability of Poly (Butadiene-Acrylonitrile (35\%))

Rubber to Penetrants at 25 to $30^{\circ} \mathrm{C}$

\section{Penetrant}

Nitrogen

Oxygen

Methane

Diisobutylene

Helium

Hydrogen

Carbon dioxide

Water

Methanol

Carbon tetrachloride.

Ethyl acetate

Benzene

Methyl ethyl ketone

$$
P=\frac{\left(\mathrm{cm}^{3} \text { at STP }\right)\left(\mathrm{mmx} 10^{7}\right)}{\left(\mathrm{cm}^{2} \mathrm{~s}\right)(\mathrm{cmHg})}
$$

0.0042

0.016

0.032

0.045

0.084

0.095

0.13

17.5

246

465

3280

6050

6100

Table 3.5 - Permeability of Pölymer Films to Water Vapor $\left(25^{\circ} \mathrm{C}\right)$

Film

Poly(vinylidene chloride) (Saran)

Polytetrafluoroethylene (Teflon)

Butyl rubber

Polyethylene (density 0.960 )

Polyethylene (density 0.938)

Polyethylene (density 0.922 )

Polypropylene (density 0.907 )

Poly(vinyl chloride)

Poly(vinyl chloride-vinyl acetate

Poly(ethylene terephthalate) (Mylar)

Polystyrene

Polyacrylonitrile

Polybutadiene

Poly(styrene-butadiene)

Poly(butadiene-acrylonitrile (62\%))

Polyisoprene (natural rubber)

Polyamide (nylon 66) (95\% relative humidity)

Cellulose acetate

Cellulose acetate (15\% dibutyl phthalate)

Ethyl cellulose, plasticized

Poly(vinyl alcohol), $\rho=2.3 \mathrm{~cm} \mathrm{Hg}$

$$
\mathbf{P}=\frac{\left(\mathrm{cm}^{3} \text { at STP }\right)\left(\mathrm{mmx} 10^{8}\right)}{\left(\mathrm{cm}^{2} \mathrm{~s}\right)(\mathrm{cmHg})}
$$

$0.3-1.0^{\mathrm{a}}$

0.3

1.3

1.2

2.5

9.0

5.1

6.1

7.0

13

12

13

47

\section{9}

aDependent on grade.

'Dependent on relative humidity. 


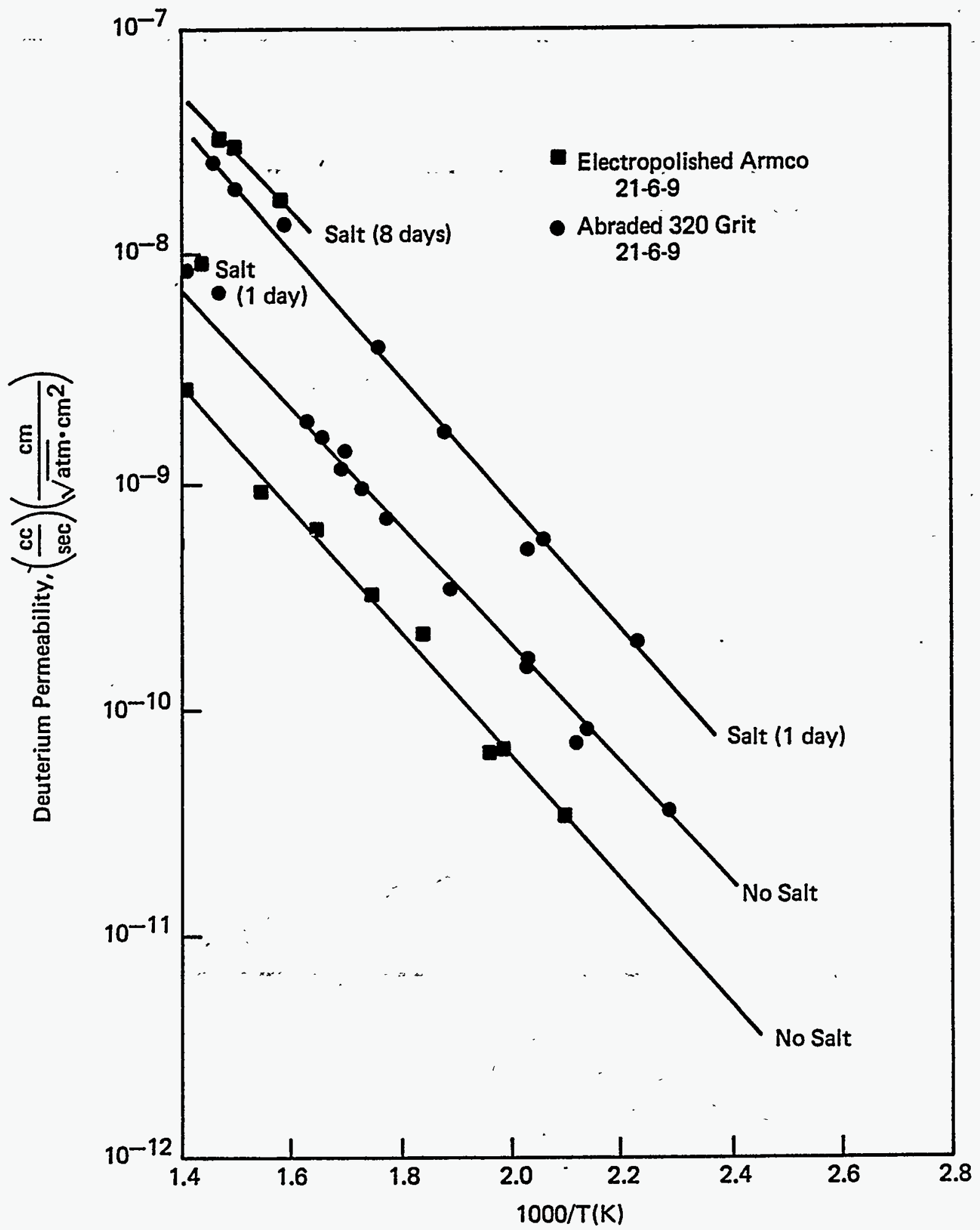

Figure 3.16-Permeability of deuterium through 21-6-9 steel as a finction of temperature and surface conditions. LiD "salt" was placed against oxide barrier layer [3.42]. 


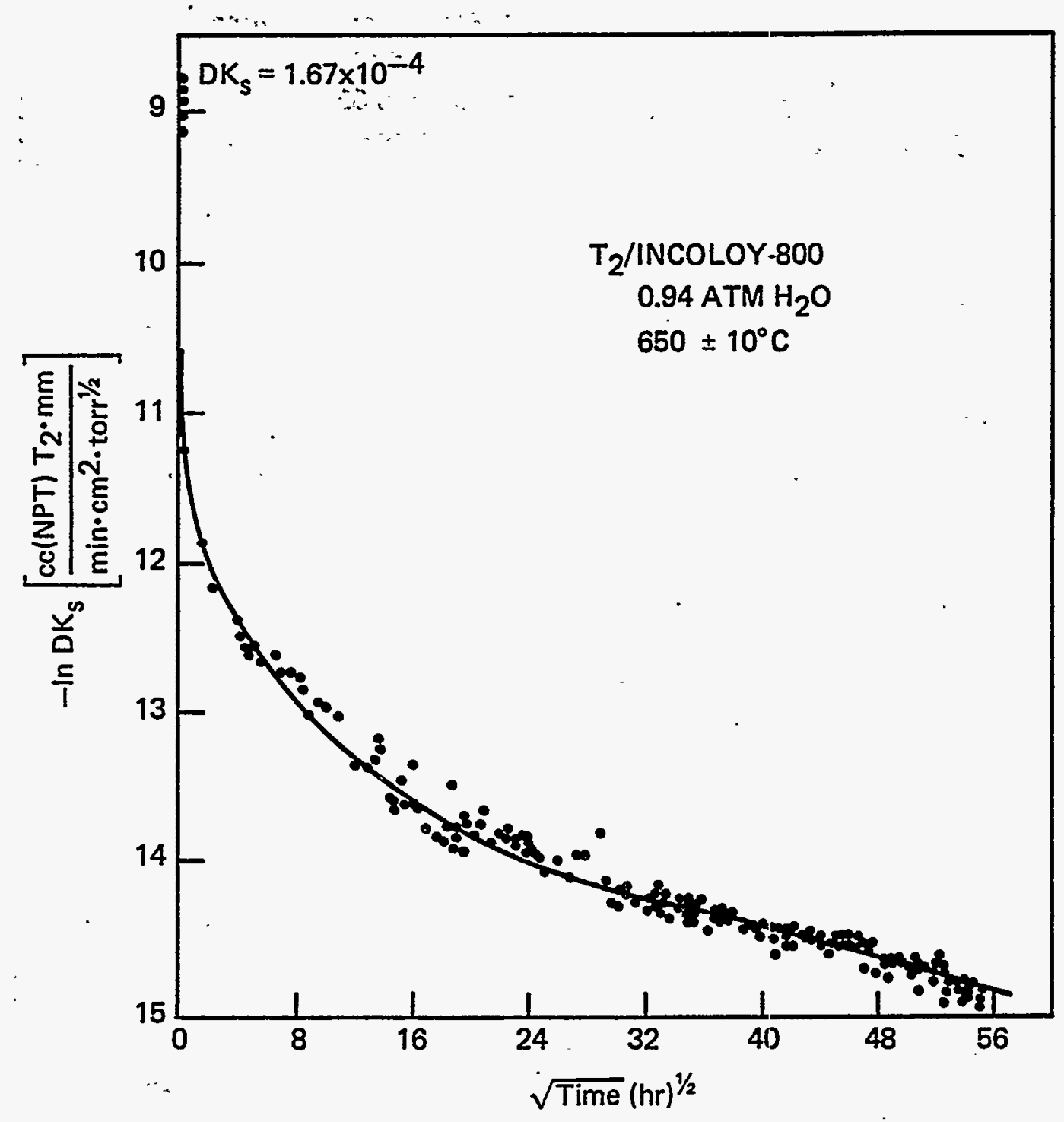

Figure 3.17-Permeation rate as a function of time for tritium through Incoloy $\because$ at $650^{\circ} \mathrm{C}$ in the presence of steam [3.45]. 


\subsection{Biological Properties of Tritium}

\subsubsection{General}

Tritium is usually encountered in the workplace as tritium gas (HT, DT, or $\mathrm{T}_{2}$ ) or as tritium oxide (HTO, DTO, or $\mathrm{T}_{2} \mathrm{O}$ ). Other forms of tritium also exist, such as metal tritides, tritiated pump oil, and tritiated gases (methane, ammonia, etc.). Deuterated and tritiated compounds generally have the same chemical properties as the hydrogenated compounds, while some minor isotopic differences in reaction rates have been noted [3.47; see also section 3.2.2]. These various tritiated compounds have a wide range of uptake and retention in humans under similar exposure conditions. For example, tritium gas, upon inhalation, is only slightly incorporated into the body, and it is rapidly eliminated (i.e., exhaled); whereas tritiated water vapor is readily taken up and retained by the body.

\subsubsection{Metabolism of Gaseous Tritium}

Following a brief exposure to tritium gas (HT), small amounts of the gas are dissolved in the bloodstream. According to the laws of partial pressures, the dissolved gas is circulated in the bloodstream with a resident half-time of about two minutes, and most of the gas is exhaled along with the gaseous waste products, carbon dioxide and normal water vapor. If the exposure persists, the gas is found in the extra- and intercellular body fluids. A small percentage of the gaseous tritium is converted to the oxide form (HTO), most likely in the gastrointestinal tract [3.48, 3.49]. Early experiments involving human exposure to a concentration of $9 \mu \mathrm{Ci} / \mathrm{mL}$ resulted in an increase in the HTO concentration in urine of $7.7 \times 10^{-3} \mu \mathrm{Ci} / \mathrm{mL}$ per hour of exposure. Although obviously independent of the breathing rate, this conversion can be conveniently expressed as the ratio of the HTO buildup to the tritium inhaled as $\mathrm{HT}$ at a nominal breathing rate $(20 \mathrm{~L} / \mathrm{min})$. In this context, the conversion is $0.003 \%$ of the total gaseous tritium inhaled [3.51]. More recent experiments [3.52] with six volunteers resulted in a conversion of $0.005 \%$. For gaseous tritium exposures, there are 2 doses: (1) a lung dose from the tritium in the air in the lung, and (2) a whole body dose from the tritium gas that has been converted to water. This tritiated water converted in vivo acts as an exposure to tritiated water.

Skin absorption of gaseous tritium has been found to be negligible [3.51, 3.52] compared to inhalation. Small amounts of tritium can enter skin through contact with contaminated metal surfaces, which results in elevated organically bound tritium in tissues and in urine (see sections 3.5.4 and 3.5.5).

\subsubsection{Metabolism of Tritiated Water}

The biological incorporation (uptake) of airborne HTO can be extremely efficient: up to $99 \%$ of inhaled HTO is taken into the body within seconds [3.50]. Ingested liquid 
HTO is almost complett ly absorbed by the gastrointestinal tract and quickly appears in the venous blood [3.51]. Within minutes, it can be found in varying concentrations in the organs, fluids, and tissues of the body $[3.50,3.53]$. Skin absorption is also important, especially during hot weather, because of the normal movement of water through the skin. For skin temperatures in the range of 30 to $40 \mathrm{C}$, the percutaneous absorption of HTO is about 50\% that for HTO by inhalation [3.54]. It can be expected that, independent of the absorption mechanism, absorbed HTO will be uniformly distributed in all biological fluids within one to two hours [3.51]. Therefore, shortly after an exposure to HTO, the tritium will be uniformly distributed throughout the tissue of the body in body water and in the exchangeable (labile) hydrogen sites in organic molecules. This tritium has a retention that is characteristic of water. A small fraction of the tritium becomes incorporated into more strongly bound hydrogen sites in organic molecules. This gives rise to a long-term retention that is characteristic of the turnover of cellular components, which can be adequately modeled as the sum of two or more exponentials. Hence, retention of tritiated water can be described as the sum of three exponentials: one characteristic of body water, and two longer term components that represent tritium incorporated into nonlabile cellular hydrogen sites.

\subsubsection{Metabolism of Other Tritiated Species}

Most tritium handled in laboratories is in the form of tritiated gas or tritium oxide. However, tritium handling operations may result in the formation of other compounds, such as tritiated hydrocarbons and metal tritides, and the contamination of surfaces and liquids, such as pump oil. These materials often present special safe handling problems.

\subsubsection{Tritiated Surfaces}

Studies have shown that when there is contact between skin and glass or a metal surface that has been exposed to high concentrations of tritium gas, tritium is transferred to the body in an organic form $[3.55,3.60]$. This organically bound tritium gives rise to elevated tritium concentrations in skin at the point of contact $[3.56,3.59$, $3.60]$. and in other tissues $[3.58,3.59]$, as well as a large amount of organically bound tritium in urine. The full metabolic pathway of this organically bownd tritium is unknown, but models that have been developed suggest that the dose to skin at the point of contact may be the limiting factor in exposures of this type [3.52, 3.61].

\subsubsection{Metallic Tritides}

Although numerous metals are commonly.used for storing, pumping, and packaging of tritium, little information on their metabolic properties is available. However, some compounds such as uranium tritide and lithium tritide are unstable in air. For these, exposure to air produces totally different results: uraniurn tritide, being pyrophoric, 
releases large quantities of tritiated water; lithium tritide, a hydroxyl scavenger, releases mostly tritium gas.

Tritides of metals - such as titanium, niobium, and zirconium - are stable in air. For particles of these tritides, the primary organ of concern is the lungs, and lung deposition models such as the one presented in ICRP Publication 30 [3.62] are used. However, there are difficulties with using such models. Depending on the particle size distribution of the metallic tritide inhaled, lung retention estimates can be in error by up to $80 \%$. Also, cross-correlations of lung retention estimates are based on the tritium leaching abilities of biological fluids, which depend on the chemical and physical form of the material in question. "These particles may also produce organically bound tritium from contact with lung tissue, which would further compound the metabolic uncertainties:

\subsubsection{3: Other Tritiated Solids}

Depending on the composition of a material, tritiation occurs through exchange reactions and/or through mechanisms such as solubility, permeation; and diffusivity. The specific activity of such materials varies with the following:

- The relative concentration of the exposing gas

- The relative humidity of the exposing gas

- The total reaction time

Radiation damage may also be expected, particularly in cases where possible exposure mechanisms lead to embrittlement.

Little is known about the metabolic behavior of many tritiated solids. Some materials, such as those that give up their tritium easily (outgas), can be considered as possible inhalation hazards, skin absorption hazards, or both.

\subsubsection{Tritiated Liquids}

Next to HTO, the most commonly encountered tritiated liquid is tritiated vacuum pump oil. Comparisons between facilities have shown that the specific activities of pump oils can easily range from a few $\mathrm{mCi} / \mathrm{L}$ to a few tens of $\mathrm{Ci} / \mathrm{L}$. The wide range in specific activities may result from variations in the tritium concentration and total throughput of tritium:

Next to pump oils; the most commonly encountered group is tritiated solvents. . Since all solvents, by their nature, can be absorbed through the skin, and since most solvents are relatively volatile, the pathways for tritiated solvents can, as a first approximation, be expected to be șimilar to the pathways for HTO. However, many solvents affect 
specific organs. The combined toxicity is largely due to the chemical nature of the solvent. Hence, exposure to tritiated solvents may result in a significant difference between the establishment of body water equilibria compared to that observed for tritiated water.

\subsubsection{Other Tritiated Gases}

In a nitrogen or air-filled glovebox, a tritium release may result in the formation of other tritiated gases, such as ammonia and perhaps methane. The toxicity of these gases is not believed to be greater than that of tritium oxide.

\subsubsection{Single Compartment Modeling of HTO Retention}

Studies of biological elimination rates in humans for heavier-than-normal water species go back to 1934 when the body water turnover rate of a single subject was measured using $\mathrm{HDO}$ [3.63]. Since that time, several additional studies have been conducted on a number of subjects with HDO and HTO, with the HTO studies being more prevalent. A summary is presented in Table 3.6.

Table 3.6. Heavier-Than-Normal Water Biological Half-Life

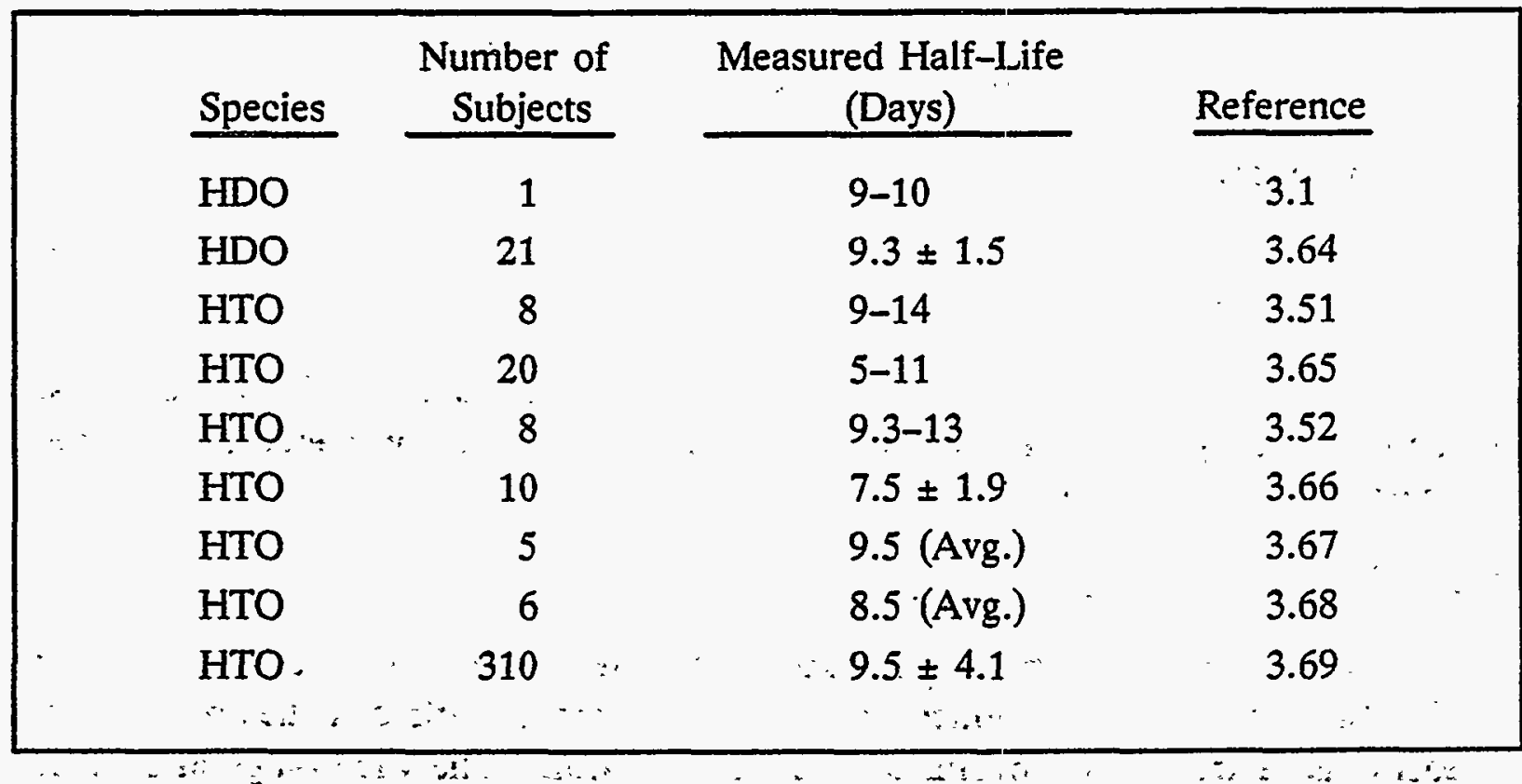

A simple average of the data summarized in Table 3.6 suggests a value of 9.4 days for the measured biological half-life. Also, the data deviate from this simple average by as much as $\pm 50 \%$ : As discussed later, there are 'good reasons for such large *: deviations: $: \cdot$.

As a first approach to modeling the observed biological half-life, one can estimate the half-life based on the throughput of water, using the equation: 


$$
\frac{\mathrm{dA}}{\mathrm{dt}}=\lambda A_{o}=\frac{\ln 2}{T_{b}} A_{0}
$$

where $\mathrm{dA} / \mathrm{dt}=$ the daily throughput of water $(3 \mathrm{~kg})$,

$$
A_{0}=\text { the total body water mass }(42 \mathrm{~kg}) \text { [3.70], }
$$

In $2=$ the natural $\log$ of 2 , and

$\mathrm{T}_{\mathrm{b}}=$ the resultant biological half-life [3.53].

Thus, the elimination rate is $3 / 42=0.0714$ day $^{-1}$ and the theoretical biological half-life for HTO is

$$
\mathrm{T}_{b}=\ln 2 / 0.0714=9.7 \text { days }
$$

which compares favorably with the 9.4 day average value determined from Table 3.6.

The above modeling and values are also based on the assumption that the biological half-life of tritium is a function of the average daily throughput of water. This part of the hypothesis, therefore, must also be in agreement with experimental and theoretical cross-checks.

It has been observed experimentally that when water intake is $2.7 \mathrm{~L} /$ day, the half-life for HTO is 10 days; when water intake is increased to $12.8 \mathrm{~L} /$ day, the half-life drops to 2.4 days [3.51]. Agreement of experimental observations with the simple model is good, and, for the high intake value, the lack of better agreement should not be a serious concern considering model simplicity. Other factors that affect the biological half-life of HTO in the human body are discussed below.

Biological half-lives as a function of mean outdoor temperatures at the time of tritium uptake have also been studied. The data suggest that biological half-lives are shorter when assimilations occur in warmer months [3.69]. For example, the $7.5 \pm 1.9$ day half-life shown in Table 3.6 begins to fall into line when it is noted that the data were taken in southern Nigeria where the mean outdoor temperature averages $80^{\circ} \mathrm{F}$ [3.66]. In contrast, the $9.5 \pm 4.1$ day half-life was determined over several years in North America, where the mean outdoor temperature averaged $63^{\circ} \mathrm{F}[3.66,3.69]$. Such findings are consistent with metabolic pathways involving sensible and insensible perspiration. As such, the skin absorption/desorption pathways can become an important part of body metabolic throughput of normal water.

Lifestyles may also significantly influence the variation in biological half-lives. In one case, the biological half-life in an adult male was followed for approximately four months following an acute exposure. During this time, the half-life appeared to 
fluctuate between 4 and 10 days at regular intervals. Closer scrutiny revealed that the subject was a weekend jogger. As a result, the appearance of two very different biological half-lives was totally valid.

Variations in biological half-lives have also been shown to be inversely correlated with age [3.69]. In these cases, however, the data suggest that age correlations introduce variations in the biological half-life of no more than $\pm 20 \%$. When compared to reduction factors of 50 to $250 \%$ produced by total fluid throughput and/or skin temperature correlations, age correlations are a secondary correction.

\subsubsection{Multi-Compartment Modeling}

For single compartment modeling, the half-life of interest is that for HTO in the body water. Although the half-life can vary by more than a factor of two for the same person, the HTO component of the biological half-life can be expected to be about 10 days. As was noted in section 3.5.3, however, prolonged exposures can be expected to show signs of two additional components that range from 21 to 30 days and 250 to 550 days, respectively. The former reflects the existence of a labile organic pool; the latter suggests the existence of a more tightly bound organic pool [3.71].

To calculate doses, the overall contribution from organically bound tritium has been found to be relatively small: i.e., less than about 5\% for acute exposures [3.72] and about $10 \%$ for chronic exposures [3.61]. The ICRP methods for computing the annual limits on intake in air and water use the body water component only, including the assumption of a 10-day biological half-life [3.73].

\subsection{References}

3.1. P. S. Rohwer, and E. L. Etnier, "Estimation of Dose to Man from Environmental Tritium," in Tritium Technology in Fission, Fusion, and Isotopic Applications, American Nuclear Society National Topical Meeting, Dayton, Ohio, 1980, CONF-800427, p. 1.

3.2. J. A. Miskel, Tritium, A. A. Moghissi and M. W. Carter, eds., Messenger Graphics, Phoenix (1973), p. 79.

3.3. H. T. Peterson, and D. A. Baker, Fusion Technol., 8 (1985), p. 2544.

3.4. T. B. Rhinehammer and L. J. Wittenberg, An Evaluation of Fuel Resources and Requirements for the Magnetic Fusion Energy Program, MLM-2419, Monsanto Research Corp. (1978).

3.5. Handbook of Chemistry and Physics, D. R. Lide (ed.), 72th Ed., Chemical Rubber Company (1991), p. 11-29. 
3.6. ' E. A.'Evans, Tritium änd Its Compounds, van Nostrand Company, New Yórk (1966).

3.7. J. W. Pyper, and C. K. Briggs, Kinetics of the Radiation-Induced Exchange Reactions of H2, D2, and T2, UCRL-52380, Lawrence Livermore National Laboratory, Livermore, California (1978):

3.8. G. T. McConville, D. A. Menke, and R. E. Ellefson, Fusion Technol., 8, (1985), p. 2245.

3.9. I. Kaplan, Nuclear Physics, Addison-Wesley, Reading, Massachusetts (1963), p, 253 and 346-388.

3.10. C. R.: Rudy, and K. C. Jordan; Tritium Half-Life, MLM-2458, Monsanto : Research Corporation, Miamisburg, Ohio (1978).

3.11. DOE Order 5633.5,. Nuclear Materials Reporting and Date Submission Procedures. 1987.

3.12. M. P. Unterweger, B. M. Coursey, F. J. Schima, and W. B. Mann, Int. J. Appl. Radiat. Isot., $3 I$ (1980), pp. 611-614.

3.13. W. B. Mann, M. P. Unterweger, and B. M. Coursey, Int. J. Appl. Radiat. Isot., 33 (1982), pp. 383-386.

3.14. B. M. Oliver et al., Int. J. Radiat. ${ }^{i}$ Appl. Instrum., Part A, Appl. Radiat. Isot., 38. (1987), p. 959.

3.15. B. M. Oliver et al., Int. J. Radiat. Appl. Instrum., Part A, Appl. Radiat. Isot., 40, (1989), p. 199.

3.16. S. C. Curran, J. Angus, and A. L. Cockroft, Phil. Mag., 40 (1949), p. 53.

3.17. E. R. Graves and D. I. Meyer, Phys. Rev., 76, (1949), p. 183.

3.18. G. H. Jenks, F. H. Sweeton, and J. A. Ghormley, Phys. Rev., 80 (1950), p. 990.

3.19. M. H. van de Voorde, Effects of Radiation on Materials and Components, CERN-70-5, European Organization for Nuclear Research (1970).

3.20. M. M. Mueller, A Calculation of the Beta Energy Absorbed by Tritiated Gases in Spherical Vessels, LAMS-2580, Los Alamos National Laboratory, Los Alamos. New Mexico (1961):

3.21. P. M. S. Jones, P. Ellis, and C. G. Hutcheson, Exchange of Hydrogen Isotopes Between Methane and Erbium Tritide, AWRE-0-93/66, Atomic Weapons : Research Establishment, United Kingdom. (1966): : 
3.22. S. Dushman, Scientific Foundations of Vacuum Technique, 2nd. ed., John Wiley \& Sons, New York (1962), Chapter 8.

3.23. J. E. Shelby, J. Appl, Phys., 48 (1977), p. 3387.

3.24. T. S. Elleman, et al., Hydrogen Diffusion, Dissolution, and Permeation of Nonmetallic Solids, ORO-4721-T1, North Carolina State University (1979).

3.25. G. J. van Amerongen, J. Appl. Phys., 17 (1946), p. 972.

3.26. C. E. Rogers, in Polymer Permeability, J. Comyn (ed.), Elsevier, New York (1985), pp. 11-74.

3.27. R. Speiser, "Thermodynamics of Metal-Hydrogen Systems," Metal Hydrides, W. M. Mueller, ed., Academic Press, New York (1968), pp.-51-89.

3.28. R. H. Doremus, Glass Science, John Wiley \& Sons, New York (1973), Chapter 8.

3.29. Diffusion in Polymers, Chapters 2, 3, 8, J. Crank and G. S. Park (eds.), Academic Press, New York, (1968).

3.30. 'J: E. Shelby, J. Appl. Phys., 45 (1974), p. 2146.

3.31. R. W. Lee, J. Chem. Phys., 38 (1963), p.: 448.

3.32. R. A. Causey et al., J. Amer. Ceram. Soc., 61 (1978), p. 221.

3.33. K. Verghese, J. Nucl. Water., 85 \& 86 (1979), p. 1161.

3.34. R. W. Webb, Permeation of Hydrogen Through Metals, NAA-SR-10462, North American Aviation (1965).

3.35. F. Waelbroeck et al., J. Nucl. Mater., 85 \& 86, (1979), p. 345.

3.36. C. A. Wert, in Hydrogen in Metals II, Chapter 8, G. Alefeld and J. Volkl (eds.), Springer-Verlag, New York (1978).

3.37. P. S. Shewmon, Diffusion in Solids, McGraw Hill, New York (1963), Chapter 2.

3.38. V. A. Maroni and E. H. van Deventer, J. Nucl. Mater., 85 \& 86 (1979), p. 257.

3.39. R. A. Causey et al., Tritium Diffision in Nonmetallic Solids of Interest to Fusion Reactors, ORO-4721-6, North Carolina State University (1977).

3.40. G. G. Libowitz, The Solid State Chemistry of Binary, Metal Hydrides, Benjamin, New York (1965), p. 52. 
3.41. J. Volkl and G. Alefeld, Hydrogen in Metals I, Chapter 12, Springer-Verlag, Berlin (1978).

3.42. M. R. Louthan and R. G. Derrick, Corros. Sci., 15 (1975), p. 565.

3.43. R. A. Strehlow and H. C. Savage, Nucl. Technol., 22 (1974), p. 127.

3.44. G. R. Caskey, Jr., in Radiation Effects on Solid Surfaces, M. Kaminsky (ed.), American Chemical Society, Washington, D. C. (1976).

3.45. J. T. Bell, Tritium Permeation Through Incoloy 800 Oxidized In Situ by Water Vapor, CONF-780508-12, Oak Ridge National Laboratory (1978).

3.46. G. W. Powell et al., Corrosion, 26 (1970), p. 223.

3.47. J. F. Thompson, Biological Effects of Deuterium, Macmillan, New York (1963).

3.48. M. Ichimasa, et al., Comparison of Oxidation Activity of Tritium Gas Among Various Animals and Man - Analysis of Intestinal Bacterial Flora for Oxidation, Third Japan-U.S. Workshop on Tritium Radiobiology and Health Physics, Kyoto, Japan, 8-10 November 1988.

3.49. Y. Ichimasa, et al., Can Oxidation of Tritium Gas in Intestine Be Suppressed by a Drug in Rats?, Third Japan-U.S. Workshop on Tritium Radiobiology and Health Physics, Kyoto, Japan, 8-10 November 1988.

3.50. E. A. Pinson, The Body Absorption, Distribution, and Excretion of Tritium in Man and Animals, LA-1218, Los Alamos Scientific Laboratory, Los Alamos, New Mexico, 1951.

3.51. E. A. Pinson and W. H. Langham, J. Appl. Physiol., 10 (1957), p. 108-126.

3.52. B. F. Peterman, J. R. Johnson, and R. G. C. McElroy, Fusion Technology, 8, (1985), p. 2557-2563.

3.53. R. C. Thompson, J. Biol. Chem., 197 (1952), P. 81.

3.54. R. V. Osborne, Health Phys., 12 (1966), p. 1527-1537.

3.55. J. D. Eakins and W. P. Hutchinson, The Radiological Hazard from Tritium Sorbed on Metal Surfaces, AERE-R-5988, UK Atomic Energy Authority, Harwell, England (1969).

3.56. J. R. Johnson, R. M. Brown, and D. K. Myers, Rad. Prot. Dosim., 16:1-2 (1986), p. 17-21.

3.57. J. D. Eakins, W. P. Hutchinson, and A. E. Lally, Health Phys., $28: 3$ (1975), pp. 213-224. 
3.58. B. F. Peterman, J. R. Johnson, D. W. Dunford, and R. G. C. McElroy, Internal Dosimetry of Tritiated Hydrogen Gas, CFFTP-G-84034, Canadian Fusion Fuels Technology Project, Mississauga; Ontario (1985).

3.59. J. R. Johnson, J. R., E. S. Lamothe, J. S. Jackson, and R. C. G. McElroy, Fusion Technology, 14 (1988), p. 1147-1152.

3.60. M. E. Hutchins and B. E. Vaughn, Health Phys., 11 (1965), p. 1047-1053.

3.61. J. R. Johnson and D. W. Dunford, Health Phys., 48:1 (1985), p. 110-113.

3.62. International Commission on Radiological Protection, Publication 30: Part 1, Limits for Intakes of Radionuclides by Workers, Pergamon Press, New York, 1979.

3.63. G. Von Hevesy and E. Hofer, Klin. Wschr., 13 (1934), p. 1524.

3.64. P. R. Schloerb et al., J. Clin. Invest., 29 (1950), p. 1296.

3.65. P. Fallot, A. Aaberhardt, and J. Mason, Int. J. Appl. Rad. Isotopes, 1 (1957), p. 237.

3.66. J. M. Foy and H. Schnieden, J. Physiol., 154 (1960), p. 169.

3.67. C. R. Richmond, W. H. Langham, and T. T. Trujillo, J. Cell Comp. Physiol., 59 (1962) p. 45.

3.68. K. F. Wylie, W. A. Bigler, and G. R. Grove, Health Phys., 9 (1963), p. $911-$ 914. See also, Health Phys. 11, (1965) p. 62.

3.69. H. L. Butler and J. H. Leroy, Health Phys., $I 1$ (1965) 283-285.

3.70. International Commission on Radiological Protection, Report of the Group on Reference Man, Publication 23, Pergamon Press, New York, 1975.

3.71. National Committee on Radiation Protection and Measurements, Tritium in the Environment, NCRP Report No. 62, Washington, D.C., (1979).

3.72. R. G. Patzer, Radiation Dose from Non-Exchangeable Tritium in Rats After Tritium Oxide Ingestion, Doctoral Thesis, University of Michigan, Ann Arbor, Michigan, 1968.

3.73. International Commission on Radiological Protection, Health Phys., 17 (1969) p. $389 .:$. 


\section{Chapter 4 \\ Operational Health Physics}

\subsection{Purpose and Scope}

Tritium health physics programs at DOE sites are often unique because of the mission-oriented objectives of each facility. Each facility has independently developed standards, including its own management philosophy, design criteria, and in-house controls. Because of these factors, there may be several ways to establish procedures that comply with federal, state, and local regulations. This chapter reviews the basic criteria that must be considered for establishing a sound radiation protection program for tritium work; it specifically addresses the unusual properties and behavior of tritium. Information has been gathered from numerous published works in the areas of fundamental and applied tritium research. Where appropriate, the published information has been supplemented with unpublished observations of day-to-day tritium-handling experience at DOE sites over a considerable number of years.

Although this chapter focuses on the tritium aspects of a health physics program, general elements and resource references of broader health physics programs are also provided.

\subsection{Administration}

Policies and procedures must be established to implement the radiation protection program within the facility. Organizational responsibilities for radiation protection must be clearly defined and staffing and resources must be sufficient to accomplish the assigned tasks. Health physics staff must clearly understand their authority, responsibilities, accountabilities, and interfaces with other support groups.

A variety of administrative controls can be used to enhance an effective tritium health physics program. Some examples include requiring radiation work permits for work done in tritium areas and holding planning meetings with workers before beginning work in areas that may be highly contaminated. These controls help ensure that all workers understand their responsibilities and the role of the health physicist(s) on the job. Workers in jobs with a high potential for tritium exposure should have constant health physics coverage to ensure that tritium exposures are minimized.

An internal audit program must be established to provide periodic assessments of performance. The audit program should evaluate all the major elements of the health physics program on a regular frequency, not to exceed every three years. Audit findings must be reported to management who is responsible for ensuring that prompt corrective actions are taken when necessary. 
Radiation protection requirements for the control and use of radioactive materials, as outlined in DOE Order 5480.11 [4.1] and implemented by radiation protection staff must

- Provide safe operations and clearly identify areas of potential hazard,

- Establish a sound technical base for limits, methods, and personnel protection standards,

- Plan for all work involving radioactive materials, and

- Include adequate provisions for recording radiological conditions. determining protective clothing requirements, setting work limitations, and supplying special instructions.

Technical criteria should be established for defining radiation areas, airborne radioactivity areas, and potentially contaminated areas. Dose rates, contamination levels, and radiation work permits should be clearly posted at the entrance to such areas. "Notice to Employees" forms, as required by DOE, must also be posted in appropriate locations in each facility.

Effective exposure control methods, which include accurate and timely survey data, should be used to maintain exposures as-low-as-reasonably achievable (ALARA). A personnel dosimetry program should ensure that appropriate individuals are included in the program and that personnel radiation exposures are accurately determined and recorded. Dosimeters must be designed to measure the types of radiation and energies, and range of exposures encountered in the workplace. However, bioassay programs, rather than dosimeters, are used to monitor exposures to tritium.

A formally structured program should be established to ensure that exposures are maintained ALARA. Realistic, measurable ALARA goals for reducing radiation exposures should be established. Any sources of man-made, nonproductive, low-level radiation should be eliminated [4.2].

Radiation exposure records must be maintained to permit easy retrieval, facilitate trend analysis, and help in the control of radiation exposure. Records of past experiences are necessary for managing future radiation exposures. Radiation protection records shall be generated and maintained in compliance with ANSI N13.6 [4.3].

\subsection{Bioassay and Internal Dosimetry}

Exposure to tritium oxide (written HTO in this Chapter) is by far the most important type of tritium exposure because it results in the distribution of HTO throughout the soft tissue of the body. The HTO enters the body by inhalation or skin absorption. When immersed in airborne HTO, the body takes in approximately twice as much 
tritium through the lungs as through the skin [4.4]. The average biological half-life of tritium is 10 days, but it can vary naturally by $50 \%$ or more depending on the body-water turnover rate. This has been verified by calculation and by actual measurements of tritium concentrations in body water following exposure. Following an exposure to elemental tritium (written HT in this Chapter), the body takes gas into the lungs and, according to the laws of partial pressures, some of it dissolves in the blood stream, which distributes it to the body water $[4.5,4.6]$.

According to International Commission on Radiological Protection (ICRP) Publication 30 [4.7], the derived air concentration (DAC) for elemental tritium (HT) is $2 \times 10^{10}$ $\mathrm{Bq} / \mathrm{m}^{3}$ (or $540,000 \mu \mathrm{Ci} / \mathrm{m}^{3}$ ) and for HTO is $8 \times 10^{5} \mathrm{~Bq} / \mathrm{m}^{3}$ (or $21.6 \mu \mathrm{Ci} / \mathrm{m}^{3}$ ). The ratio of these DACs and, therefore, the relative hazard of exposure to the lungs is 25,000 . However, when a person is exposed to HT in the air, two kinds of exposures

actually result: one to the lung and one to the whole body. During exposure to HT, a small fraction of the tritium exchanges in the lung and is transferred by the blood to the gastrointestinal (GI) tract where it is oxidized by enzymes in the gut [4.6]. This results in a buildup of HTO, which remains in the body (with its usual half-life); whereas, the HT is rapidly eliminated by exhalation following the end of the exposure. The resultant dose from the exposure to this HTO is roughly comparable to the effective dose from the lung exposure to HT. Thus, the total effective dose from HT exposure is about 10,000 times less than would result from an equal exposure to HTO (for workers doing light work). For both HTO and HT exposures, a bioassay program that samples body water for HTO is an essential element of a good personnel monitoring program $[4.8,4.9]$.

\subsubsection{Sampling_Schedule and Technique}

Following an exposure to HTO, it is quickly distributed throughout the blood system and, within 1 to 2 hours, throughout the extra- and intracellular volumes and the remaining body water. Once equilibrium is thus established, the tritium concentration is found to be the same in samples of blood, sputum, and urine [4.5, 4.10]. For bioassay purposes, urine is normally used for determining tritium concentrations in body water.

Workers who may be or who have been exposed to tritium are normally required to submit urine samples for bioassay on a periodic basis. The sampling period is usually daily to biweekly, or may be longer, depending on the potential for significant exposure.

Following an incident or a work assignment with a higher potential for exposure, a special urine sample is usually required for each individual involved. The preferred method is to wait about 1 to 2 hours for the equilibrium to be established. The bladder is then voided. A sample submitted soon thereafter should be reasonably 
representative of the body water concentration [4.11]. A sample collected before equilibrium is established will not be representative because of dilution in the bladder or because the initial concentration in the blood will be higher than an equilibrium value. However, any early sample may still be useful as an indication of the potential seriousness of the exposure.

At the bioassay laboratory, $1 \mathrm{~mL}$ of the urine is typically mixed with 10 to $15 \mathrm{~mL}$ of a suitable scintillation cocktail and counted in a liquid scintillation spectrometer. At many laboratories, the urine is initially counted as received and if the concentration is above a certain value (e.g., $0.1 \mu \mathrm{Ci} / \mathrm{L}$ ), the urine is distilled or spiked with a standard and recounted. The counting efficiency may be affected by quenching although this can be corrected electronically.

The dose equivalent rate in the body water can be calculated directly from the concentration of HTO in body water $(42 \mathrm{~L})$, which until secently was considered to be the critical (or reference) organ. ICRP 30 states that the average dose to the soft tissue $(63 \mathrm{~kg})$ can be assumed to be equal to the effective dose equivalent $[4.7,4.12]$. This change in the critical (or reference) organ effectively dilutes the tritium, and thereby lowers the calculated dose rate accordingly. Thus, the dose equivalent rate, $R\left(t_{0}\right)$, to the soft tissue, can be calculated from a urine concentration of $C_{0}(\mu C i / L)$ as follows:

$$
\begin{aligned}
R\left(t_{0}\right)= & C_{0}\left(\frac{\mu C i}{L}\right) \times 3.7 \times 10^{4} \frac{\mathrm{dps}}{\mu C i} \times 5.7 \times 10^{3} \frac{\mathrm{eV}}{\mathrm{dis}} \times 3600 \times 24 \frac{\mathrm{sec}}{\mathrm{day}} \times \frac{42 \mathrm{~L}}{6.3 \times 10^{4} \mathrm{grams}} \\
& \times 1.6 \times 10^{-12} \frac{\mathrm{erg}}{\mathrm{eV}} \times 10^{-2} \frac{\mathrm{rad}-\mathrm{gram}}{\mathrm{erg}} \times 1.0 \frac{\mathrm{rem}}{\mathrm{rad}}=1.94 \times 10^{-4} \mathrm{C}_{0} \frac{\mathrm{Rem}}{\mathrm{day}}
\end{aligned}
$$

From the dose rate $R(t)$, the committed dose $\left(D_{\infty}\right)$ can be calculated from

$$
D_{\infty}=\int_{0}^{\infty} R(t) d t
$$

Following a bioassay measurement, the quantity $R(t)$ can be estimated from an assumed biological half-life. A previously measured value (for that individual) or the average value (for reference man) of 10 days may be used [4.12]. In that case,

$$
\mathrm{D}_{\infty}=R\left(t_{0}\right) \int_{0}^{\infty} e^{-\lambda} d t=R\left(t_{0}\right) \int_{0}^{\infty} e^{-0.6933 / t_{b d t}}=\frac{R\left(t_{0}\right) 10}{0.693}
$$

where $\quad D_{\infty}=$ the committed dose equivalent

$$
R\left(t_{0}\right)=\text { the daily dose rate at } t=t_{0}
$$

$\lambda=$ the elimination constant

$\mathrm{Tb}=$ the biological half-life in days. 
However, if a more precise calculation of the individual's dose is required, the actual biological half-life should be determined from the values of subsequent bioassay data.

For very low exposures $(<1$ to $10 \mu \mathrm{Ci} / \mathrm{L}$ ), no great error is incurred by assuming a constant half-life between weekly sampling points. For higher exposures, samples should be taken more often to determine the dose more accurately.

As mentioned earlier, a pure HT exposure can be thought of as a combination of a lung exposure from the HT and a whole body exposure from the HTO converted from the HT dissolved in the blood. The whole body dose can be determined as outlined above by analysis for HTO in the urine. Since the effective dose equivalents from the lung and whole body exposures are approximately equal, the total effective dose can be conservatively obtained by multiplying the HTO whole body dose by 2 .

In general, this is too conservative since a release of pure tritium gas with $<0.01 \%$ HTO is highly unlikely. With only a slight fraction $(-0.1 \%)$ of HTO in the air, the effective dose is essentially the HTO whole body dose as determined by bioassay.

In any exposure to HTO, a certain small fraction of the tritium exchanges with nonlabile organic hydrogen in the body where it remains until metabolism or exchange eliminates the tritium. Following a high acute or any chronic exposure, two- and three-component elimination curves have been observed (ranging from 30 to 230 days) [4.13]. Although most of the dose results from the HTO in all of these observed cases, personnel receiving such exposures should be monitored until urine concentrations are down to the range of $<0.1$ to $1 \mu \mathrm{Ci} / \mathrm{L}$ in order to calculate the dose more precisely.

It has also been observed that skin contact with metal surfaces contaminated with tritium produces tritium-labeled molecules in the skin (possibly catalyzed by the metal), which in turn results in longer elimination times for the labeled or metabolized constituents [4.14]. Lung exposure to airborne metal tritides may also cause unusual patterns of tritium concentrations in body water due, supposedly, to retention of these particulates in the lung with subsequent leaching and possible conversion to organically bound tritium. For these and other reasons, it is good practice to follow the elimination data carefully and to look for organically bound tritium in the urine.

\subsubsection{Dose_Reduction}

The committed dose following an HTO exposure is directly proportional to the biological half-life, which in turn is inversely proportional to the bodywater turnover rate. This rate varies from individual to individual. Such things as temperature, humidity, work, and drinking habits may cause rate variations. Although the average biological half-life is 10 days, it can be decreased by simply increasing fluid intake, especially of liquids that are diuretic in nature, e.g., coffee, tea, and beer [4.6]. The 
half-life may then be reduced to 4 to 5 days; however, a physician should be consulted before any individual is placed on a regimen that might affect his/her health. It is essential that medical supervision be involved if diuretics are taken because the resultant loss of potassium and other electrolytes can be very serious if they are not replaced. Such drastic measures may result in a decrease in half-life to 1 to 2 days [4.11]. Even more drastic is the use of peritoneal dialysis or a kidney dialysis machine. These may reduce the half-life to 13 and 4 hours, respectively [4.15]. Such extreme techniques should be used only in life-threatening situations involving potential committed dose equivalents that would exceed about 100 rem without such treatment.

Individuals whose urine concentrations exceed established limits should be relieved from work involving possible further exposure to radiation, whether from tritium or other sources. Limits are generally suggested or imposed by the health physics organization to make certain that the annual worker dose limits are not exceeded. The operating group may impose even stricter limits on their staff than those imposed by the health physics group. The actual values, which may range from 5 to $100 \mathrm{Ci} / \mathrm{L}$, are often dependent on the availability of replacement personnel and the importance of the work that needs to be accomplished.

Results of bioassay sampling should be given to workers who submit samples as soon as they are available. The results may be posted, or the workers may be personally notified. Moreover, the results are required to be kept in the workers' personal radiation exposure records or medical files. Like any other radiation exposure, any dose in excess of limits specified by DOE Order 5480.11 must be reported to DOE authorities $[4.1,4.16]$.

\subsection{Measurement Techniques}

Because an extensive review of tritium measurement techniques is beyond the scope of this guide, it will be presumed that the reader is already acquainted with the fundamentals of radiation detection instruments. However, for those not familiar with them, an extensive review of "Tritium Measurement Techniques" can be found in NCRP 47 [4.11]. Moreover, a review of site-specific measurement techniques can also be found in WASH-1269, "Tritium Control Technology" [4.17]. Some of the following has been adapted from both sources. However, since both documents were published in the 1970s, it can be expected that some of the information will be dated although . techniques have not changed very much since that time.

This section discusses instruments or techniques to monitor tritium for health and safety purposes. However, since instruments to monitor processes often involve the same or similar detectors, they are also included in the discussion. 


\subsubsection{Air Monitoring}

Fixed ionization chamber instruments are the most widely used instruments for measuring tritium in gaseous forms in laboratory, environmental, and process monitoring applications. Portable ionization chamber instruments are also used to control contamination and to supplement fixed instrument measurements. Such simple devices require only an electrically polarized ionization chamber, suitable electronics, and, in most cases, a method for moving the gas sample through the chamber-usually a pump. Chamber volumes typically range from a tenth to a few tens of liters, depending on the required sensitivity. The output is generally given in units of concentration (multiples of $\mu \mathrm{Ci} / \mathrm{m} 3$ or $\mathrm{Bq} / \mathrm{m} 3$ ) or, if a commercial electrometer or picoammeter is used, in current units which must then be converted to concentration. The following rule-of-thumb can be used to convert current to concentration: concentration $(\mu \mathrm{Ci} / \mathrm{m} 3)=1015 \times$ current (amps)/chamber volume (liters). For real-time tritium monitoring, the practical lower limits of sensitivity range from 0.1 to $10 \mu \mathrm{Ci} / \mathrm{m} 3$.

For measurements of low concentrations, sensitive electrometers are needed. For higher concentrations, e.g., $>1 \mathrm{mCi} / \mathrm{m} 3$, the requirements on the electronics can be relaxed, and smaller ion chambers may be used [4.11]. Smaller chambers also need less applied voltage, but because of a greater surface area to volume ratio, there is a greater likelihood for residual contamination. in the chamber, which elevates the background. Response times for higher level measurements can be made correspondingly shorter. However, small chambers and chambers operated at low pressures may have significant wall effects so that the above rule-of-thumb may not apply. Such instruments would have to be calibrated to determine their response.

Although most ionization chambers are of the flow-through type that require a pump to provide the flow, there are presently a number of facilities that use so-called "open window" or "perforated wall" chambers. These chambers, which may employ a dust cover to protect the chamber from dust and other particulates, allow the air or gas to penetrate through the wall to the inside chamber. Such instruments are currently being used as single point monitors at several facilities to monitor rooms, hoods, gloveboxes, and ducts.

\subsubsection{Differential Monitoring}

Because of the greater toxicity of HTO compared to HT (the DAC is 25,000 times greater according to ICRP 30) [4.7], it is often desirable to know the relative amounts of each species following a release into a room or release to the environment. In the case of stack monitoring, this is best accomplished by taking discrete samples of the stack effluent using bubblers or desiccants in conjunction with a catalyst for oxidizing the HT (see Section 4.4.3). For differential monitoring, the simplest technique is to 
use a desiccant cartridge in the sampling line of an air monitor. The result is a measurement of the HT concentration. Without the cartridge, the total tritium concentration is measured. Subtraction of HT from the total produces the HTO concentration. The technique may be used manually with one instrument or automatically by switching a desiccant cartridge in and out of the sampling line.

Another technique involves using a semipermeable membrane tube bundle in the sampling line to remove the HTO (preferentially over the HT), which is then directed to an HTO monitor $[4.18,4.19]$. After removing the remaining HTO with another membrane dryer, the sampled air is directed to the HT monitor. Although this technique is slower than the one requiring a desiccant cartridge (response and equilibrium times being 1 to 2 minutes and 10 to 20 minutes, respectively), it does not require a periodic cartridge replacement. Furthermore, it can be adapted to measure tritium in both species in the presence of noble gases or other radioactive gases by adding a catalyst after the HTO dryers, followed by additional membrane dryers for the HTO converted from the HT by the catalyst.

\subsubsection{Discrete Sampling}

Discrete sampling differs from real-time monitoring in that the sampled gas (usually air) must be analyzed for tritium content by liquid scintillation counting. The usual technique is to flow the sampled air through either a solid desiccant (molecular sieve, silica gel, or drierite) or water or glycol bubblers. For low-flow rates (approximately 0.1 to $1 \mathrm{~L} / \mathrm{min}$ ), bubblers may be used. Bubblers are more convenient for sampling, but are less sensitive than the solid desiccant technique. Glycol or water may be used but glycol is generally preferred for long-term sampling. In any case, the collected water is then analyzed for HTO. For differential monitoring of HTO and HT, a heated catalyst (usually a palladium sponge) is used between the HTO desiccant cartridge or bubblers and the HT cartridge or bubblers. In a different arrangement, palladium is coated on the molecular sieve in the HT cartridge to oxidize and absorb the resulting HTO. However, this technique is usually only employed for environmental monitoring $[4.11,4.13,4.17,4.20]$.

Another technique for sampling HTO in air is to use a "cold finger" to freeze HTO out of the air; an alcohol and dry ice mixture in a stainless steel beaker works well. To determine the concentration, the relative humidity must be known. A soft plastic bottle squeezed several times to introduce the air (containing the HTO) into the bottle is another method. A measured quantity of water is then introduced and the bottle is capped and shaken. In a minute or less, essentially all the HTO is taken up by the water which is then analyzed [4.21].

Other techniques involve placing a number of vials or other small specially designed containers of water, cocktail, or other liquid in selected locations in the area being 
monitored. After a period of time (usually a number of days) the liquid in the containers is analyzed. The result is qualitative (for open containers) to semiquantitative (for specially designed containers) [4.22].

\subsubsection{Process Monitoring}

Ionization chambers are typically used for monitoring stacks, rooms, hoods, glove boxes, and processes. The outputs can be used to sound alarms, activate ventilation valves, turn on detritiation systems, and for other functions. In general, it can be expected that stack, room, and hood monitors will require little nonelectronic maintenance (i.e., chamber replacement because of contamination) because under routine circumstances, the chambers are constantly flushed with clean air and are not exposed to high tritium concentrations. Glove box monitors, however, can be expected to eventually become contaminated, especially if exposed to high concentrations of HTO. Process control monitor backgrounds can also be expected to present problems if a wide range of concentrations (e.g., 4 to 5 orders of magnitude) are to be measured.

Mass spectrometers, gas chromatographs, and calorimeters are generally used as workhorse instruments for process monitoring. Because of their relative insensitivities, however, these instruments cannot be used to detect tritium much below a few parts per million $(\mathrm{Ci} / \mathrm{m} 3)$. For this reason, care must be taken in interpretating analytical results and the related health physics concerns. It is not uncommon, for example, to find that samples that show no trace of tritium when analyzed on a mass spectrometer actually contain several curies of tritium.

\subsubsection{Surface Monitoring}

In general, it is not possible to measure the total tritium contamination on a surface except by destructive techniques. When tritium penetrates a surface even slightly it becomes undetectable because of the weak energy of its beta particles. With open-window probes operated in the Geiger Muller (GM) or proportional regions, it is possible to measure many of the particles emitted from the surface. However, quantifying that measurement in terms of the total tritium present is difficult since the history of every exposure is different, and, consequently, the relative amounts of measurable to unmeasurable tritium are different. Such monitoring probes are : routinely used to measure the accessible part of the contaminating tritium. Care must be taken to protect the probe from contamination. When monitoring a slightly contaminated surface after monitoring a highly contaminated one, contamination of the probe can be an immediate problem. Placing a disposable mask over the front face of the probe can reduce, but never eliminate, this contamination, particularly when the tritium is rapidly outgassing from the surface being monitored. 
For highly contaminated surfaces $(>1 \mathrm{mCi} / 100 \mathrm{~cm} 2)$, it is possible to use a thin sodium iodide crystal or a thin-window GM tube to measure the characteristic and continuous $x$-rays (bremsstrahlung) emitted from the surface as a result of the interaction of the beta particle with the surface material. In terms of total surface tritium, such measurements are semiquantitative at best.

\subsubsection{Liquid Monitoring}

Liquid is almost universally monitored by liquid scintillation counting. For liquids other than water, care must be taken to ensure that the liquid is compatible with the cocktail. Certain chemicals can degrade the cocktail. Other are not miscible and may retain much of the tritium; still others result in a high degree of quenching. In addition, samples that contain peroxide or that are alkaline may result in chemiluminescence, which can interfere with measuring. Such samples should first be neutralized before counting. Chemiluminescence and phosphorescence both decay with time. Phosphorescence, activated by sunlight or fluorescent lighting, decays in the dark in a few minutes (fast component) to several days (slow component). Chemiluminescence, the result of chemical interaction of sample components, may take days to decay at room temperatures, but takes only hours to decay at the cold temperatures of a refrigerated liquid scintillation spectrometer. Distillations may be necessary for some samples; use of quenching curves or a special cocktail may be necessary for others.

For rather "hot" samples, as may be the case for vacuum pump oils, bremsstrahlung counting may be useful $[4.23,4.24,4.25]$. This technique may also be useful for active monitoring of "hot" liquids. Liquids may also be actively monitored with scintillation flow cells, which are often made of plastic scintillator material or of glass tubing filled with anthracene crystals. However, both types are prone to memory effects due to tritium contamination. In addition, flow cells are also prone to contamination by algae or other foreign material which can quickly degrade their counting efficiency.

\subsection{Instrument Types and Calibration}

Several types of instruments are used for monitoring tritium in air and on surfaces and for counting tritium samples. Such instruments are calibrated with several different methods and sources. All instruments used for monitoring tritium for health and safety reasons should be calibrated regularly. The calibration frequency is typically 6 months for portable or other instruments receiving extensive use, 12 months for fixed instruments, and 12 months or longer for simple instruments such as stack samplers.

\subsubsection{Air Monitors}

Ionization chambers used for monitoring air are described in Section 4.4.1. The techniques used to calibrate ion chamber instruments can vary, but traditionally they 
are calibrated with tritium gas if it is practical to do so. If an instrument (or an : instrument system) is calibrated with tritium gas once, then it is generally not necessary to repeat this type of calibration. Thereafter, an electronic calibration from the front end of the electrometer preamplifier (if accessible) made with a calibrated current source (or calibrated resistor and calibrated voltage source) can be used. This is followed by a determination that there is adequate voltage on the chamber and that the chamber is connected. The latter is verified by using an external gamma source. Finally, if the chamber is of the flow-through type, proper flow must be verified.

Gas-flow proportional counters are not commonly used for monitoring air in the United States although there has been some renewed interest in them in recent years for monitoring stacks. This type of instrument is common in West Germany where regulations require monitoring at very low levels. Their advantages are enhanced sensitivity (approximately $0.01 \mu \mathrm{Ci} / \mathrm{m}^{3}$ ) and the ability to discriminate against background radiation. Disadvantages include

- Increased cost and complexity

- Need of a carrier-counting gas

- Low flow rates resulting in slower instrument response

- Limited range (up to approximately $1 \mathrm{mCi} / \mathrm{m}^{3}$ )

Gas-flow proportional counters are particularly attractive as stack monitors where increased sensitivity is desirable and a slower response time is not a problem [4.11].

Liquid and solid scintillation detectors have been developed in Canada and elsewhere to monitor air for HTO, but apparently are not widely used for this purpose because of their complexity. Moreover, the liquid scintillation technique is expensive because it requires a continuous supply of scintillation cocktail [4.26].

For instruments such as gas-flow proportional counters or scintillation counters, use of tritium gas for routine calibration purposes is justified because of the nature of the detectors.

\subsubsection{Surface Monitors}

Count rate instruments equipped with windowless gas-flow proportional probes, thin sodium iodide crystals, or thin-window GM tubes and used to monitor surfaces were described in Section 4.4.5. Tritiated polystyrene sources can be used to calibrate survey instruments for monitoring surfaces. Sources are constructed of thin plastic disks for which the tritium beta emission rate from the surface can be determined and:? certified [4.27]. The theoretical tritium counting efficiency of gas-flow proportional counters is $50 \%$. However, normal field conditions (i.e., rough, dirty, or porous 
surfaces) can reduce the counting efficiency to $10 \%$ or less. More stable sources of ${ }^{63} \mathrm{Ni}$ can also be used to verify the operation of surface monitoring instruments. However, the tritium counting efficiency cannot be determined with ${ }^{63} \mathrm{Ni}$.

\subsubsection{Tritium Sample Counters}

There are primarily two types of instruments for analyzing tritium samples for radiation protection purposes: gas-flow proportional counters and liquid scintillation spectrometers.

Gas-flow proportional counters are commercially available with or without a window over the counting chamber and with or without a sample changer mechanism.

Windowless counters must be be used for tritium samples because of the low energy of the tritium betas. When a large number of samples can be counted overnight, a proportional counter with an automatic sample changer is recommended. When a number of samples need to be counted quickly, several proportional counters with single-sample capacity may be used simultaneously to obtain prompt results. Gas-flow proportional counters have drawbacks when compared to liquid scintillation counters:

- A tendency to become contaminated

- Loss of tritium from the sample prior to counting

- Low and inconsistent counting efficiency.

The theoretical tritium counting efficiency for $2 \pi$ proportional counters is $50 \%$ under ideal conditions. However, when dirty smear papers or thick porous samples are counted, the counting efficiency may be reduced to $10 \%$ or less. Tritiated polystyrene sources can be used to calibrate proportional counters [4.27]. More stable ${ }^{63} \mathrm{Ni}$ sources can also be used to verify the operation of proportional counters.

Liquid scintillation counting has become established as the most convenient, reliable, and practical way of measuring tritium in the liquid phase and is also much preferred over gas-flow proportional counting of tritium smears. The technique consists of dissolving or dispersing the tritiated compound in a liquid scintillator cocktail, and counting the light pulses emitted from the interaction between the tritium betas and the cocktail. The light pulses are counted by a pair of photomultiplier tubes which, coupled with discriminator circuitry, can effectively distinguish between tritium betas and those from other sources [4.11].

Liquid scintillation spectrometers should be calibrated regularly according to standards traceable to the National Institute of Standards and Technology (NIST). Quench . standards, available from the instrument manufacturer or: readily made in the laboratory, may be used to establish the counting efficiency for tritium as a function of 
changes in the light spectrum due to properties of the sample. In the newest counters, the quenching levels, and hence the counting efficiencies, for different samples can be determined automatically. The tritium counting efficiency for slightly quenched samples is usually between $35 \%$ and $50 \%$ [4.28].

\subsection{Contamination Control and Protective Measures}

Controlling contamination is an effective method of limiting uptake of tritium by workers. The primary methods of monitoring the effectiveness of contamination control are smear surveys and off-gassing measurements. For situations where tritium contamination cannot be prevented, a number of protective measures provide engineered controls over the spread of tritium contamination: respiratory protection, gloves, and protective clothing.

\subsubsection{Methods of Contamination Control}

Any material exposed to tritium or a tritiated compound has the potential of being contaminated. Although it is difficult to quantify tritium contamination levels, several methods are available to evaluate the existence and relative extent of contamination, including smear surveys and off-gassing measurements. Good housekeeping and work practices are essential in maintaining contamination at acceptable levels.

The total amount of surface contamination is not an indication of its health or safety implications. Rather, the loose, removable tritium is a more important indicator; this tritium can be transferred to the body by skin contact or may outgas and become airborne. Loose contamination is routinely monitored by smears (or swipes), which are wiped over a surface and then analyzed by liquid scintillation or proportional counting.

\subsubsection{Smear Surveys}

Smear counting is an important part of the surface monitoring program. It is used to control contamination, to minimize uptake by personnel, and to prevent or minimize its spread to less contaminated areas. Routine surface monitoring is required, and additional special monitoring should be provided when the conditions or situation warrant it.

An effective tritium health physics program must also specify the frequency of routine smear surveys. Each facility should develop a routine surveillance program that may include daily smear surveys in areas such as laboratories, process areas, step-off pads, change rooms, and lunchrooms. In many locations within a facility, weekly or monthly routine smear surveys may be sufficient: The frequency should be dictated by operational experience and the potential for contamination. In addition to the routine survey program, special surveys should be made on material being moved to a less 
controlled area. This will help prevent the spread of contamination from controlled areas.

Action levels should be established in accordance with Table 4.1 to meet the intent of DOE Order 5400.5 and $5480.11[4.29,4.1]$. The action levels should be based on reasonably achievable goals and health physics considerations for both workers and the public. The tritium surface contamination levels shown in Table 4.1 are derived from the recommendations in ICRP 25 [4.30].

The smears are typically small round filter papers used dry or wet (with water, glycol, or glycerol). Wet smears are more efficient in removing tritium and the results are more reproducible, although the papers are usually more fragile when wet. However, results are only semiquantitative, and reproducibility within a factor of 2 agreement (for wet or dry smears) is considered satisfactory. Ordinarily, an area of $100 \mathrm{~cm} 2$ of the surface is wiped with the smear paper and quickly placed in a liquid scintillation counting vial with about $10 \mathrm{~mL}$ of cocktail, or 1 or $2 \mathrm{~mL}$. of water with the cocktail added later. It is important to place the swipe paper in liquid quickly after wiping since losses by evaporation can be considerable, especially if the paper is dry. The counting efficiency is not much affected by the swipe being small.

Foam smears are also commercially available. These dissolve in most cocktails and do not significantly interfere with the normal counting efficiency. Alternatively, the smear paper may be counted by gas-flow proportional counting but because of the inherent counting delays, tritium losses prior to counting can be significant [4.11]. Moreover, counting efficiencies may be difficult to determine and can be expected to vary greatly from one sample to the next. Another drawback is potential contamination of the counting chamber when counting very "hot" smears. For all of these reasons, a liquid scintillation spectrometer is the preferred system.

\subsubsection{Off-Gassing Measurements}

Basic off-gassing measurements can be made using at least two different methods. The simplest method is to "sniff" the surface for airborne tritium using a portable or fixed tritium monitor. The most reliable methods, however, involve the use of a closed-loop system of known volume, and a flowthrough ionization chamber monitor. By placing the material inside the volume and by measuring the change in concentration over a period of time, accurate determinations of tritium off-gassing rates can be made on virtually any material. The initial off-gassing rate measured is the required value, since the equilibrium concentration may be quickly reached in a closed volume, especially if the volume is small.

The uptake of tritium from off-gassing materials is difficult to predict. Off-gassing tritium that is readily measured is an indication of contaminated equipment that should not be released for uncontrolled use. 


\section{Table 4.1 - Surface Contamination Levels Acceptable for the Release of Materials for Uncontrolled Use (adapted from DOE Orders 5400.5 and 5480.11$)[4.29,4.1]$.}

\begin{tabular}{|c|c|c|c|}
\hline Nuclides(a) & $\begin{array}{r}\text { Average }^{(b, c, f)} \\
\left(\mathrm{dpm} / 100 \mathrm{~cm}^{2}\right)\end{array}$ & $\begin{array}{c}\operatorname{Maximum}(b, d, f) \\
\left(d p m / 100 \mathrm{~cm}^{2}\right)\end{array}$ & $\begin{array}{c}\text { Removable }(b, e, f) \\
\left(\mathrm{dpm} / 100 \mathrm{~cm}^{2}\right)\end{array}$ \\
\hline $\begin{array}{l}\mathrm{U}-\mathrm{Nat},{ }^{235} \mathrm{U},{ }^{238} \mathrm{U} \text {, and } \\
\text { associated decay products }\end{array}$ & $\begin{array}{c}5,000(\mathrm{~g}) \\
(10,000)\end{array}$ & $\begin{array}{l}15,000 \\
(30,000)\end{array}$ & $\frac{1,000}{(2,000)}(\mathrm{g})$ \\
\hline $\begin{array}{l}\text { Transuranics, }{ }^{226} \mathrm{Ra},{ }^{228} \mathrm{Ra} \\
{ }^{230} \mathrm{Th},{ }^{228} \mathrm{Th},{ }^{231} \mathrm{~Pa},{ }^{227} \mathrm{Ac} \text {, } \\
{ }^{125} \mathrm{I},{ }^{129} \mathrm{I}\end{array}$ & 100 & 300 & 20 \\
\hline $\begin{array}{l}\text { Th-Nat, }{ }^{232} \mathrm{Th},{ }^{90} \mathrm{Sr},{ }^{223} \mathrm{Ra} \text {, } \\
{ }^{224} \mathrm{Ra},{ }^{232} \mathrm{U},{ }^{126} \mathrm{I},{ }^{131_{\mathrm{I}},{ }^{133} \mathrm{I}}\end{array}$ & 1,000 & 3,000 & 200 \\
\hline $\begin{array}{l}\text { Beta-Gamma emitters } \\
\text { (nuclides with decay modes } \\
\text { other than alpha-emissions or } \\
\text { spontaneous fission), except } \\
{ }^{0} \mathrm{Sr} \text {, noted above }\end{array}$ & 5,000 & 15,000 & 1,000 \\
\hline $\begin{array}{l}\text { Tritium (with no labeled } \\
\text { DNA precursors) }\end{array}$ & $\begin{array}{c}50,000 \\
(100,000)\end{array}$ & $\begin{array}{r}150,000 \\
(300,000)\end{array}$ & $\begin{array}{l}10,000(\mathrm{~g}) \\
(20,000)\end{array}$ \\
\hline
\end{tabular}

(a) Where surface contamination by both alpha- and beta-gamma emitting nuclides exists, the limits established for alpha- and beta-gamma-emitting nuclides should apply independently.

(b) As noted in this table, disintegrations per minute (dpm) means the rate of emissions by radioactive material as determined by correcting the counts per minute observed by an appropriate detector for background, efficiency, and geometric factors associated with the instrumentation.

(c) Measurements of average contaminants should not be averaged over more than one (1) square meter. For objects of less surface area, the average should be derived for each such object.

(d) The maximum contamination level applies to an area of not more than $100 \mathrm{~cm} 2$.

(e) The amount of radioactive material per $100 \mathrm{~cm} 2$ of surface area should be determined by wiping that area with dry filter or soft absorbent paper, applying moderate pressure, and assessing the amount of radioactive material on the wipe area with an appropriate instrument of known efficiency. When removable contamination on objects of less surface area is determined, the pertinent levels should be reduced proportionally and the entire surface should be wiped.

(f) The average and maximum radiation levels associated with surface contamination resulting from beta-gamma emitters should not exceed $0.2 \mathrm{mrad} / \mathrm{hr}$ at $1 \mathrm{~cm}$ and $1.0 \mathrm{mrad} / \mathrm{hr}$ at $1 \mathrm{~cm}$, respectively, measured through not more than seven (7) milligrams per square centimeter of total absorber.

(g) Typical levels allowed for controlled usage "onsite." 


\subsubsection{Protection Against Airborne Contaminants}

Several important engineering controls are available for tritium protection. The most commonly used methods to protect personnel against potential inhalation include differential pressure zoning, dilution ventilation, room-air detritiation systems, and local exhaust ventilation techniques. Depending on the relative hazard, additional personnel protective measures should be considered, including, but not limited to, air-supplied respirators (self-contained breathing apparatus), air-supplied suits, and temporary enclosures.

\subsubsection{Differential Room Pressure Zones}

Differential room pressure zones are used in virtually all tritium facilities. In general, this technique establishes a natural flow path that leads from less to more hazardous areas. Used in conjunction with dilution ventilation and local exhaust ventilation techniques (Sections 4.6.2.2 and 4.6.2.4), differential zoning is an important line of defense against the migration of tritium into areas where it is not wanted.

Typical pressure zoning controls should be arranged as follows:

- Using outside air pressure as the reference, office areas and other uncontrolled areas will generally be held between zero $(0.00)$ differential and -0.01 inches of water column.

- Main access corridors outside of the radioactive materials area (RMA) will generally be held between -0.01 in. and -0.025 in.; main access corridors inside the RMA will generally be held between -0.01 in. and -0.05 in.

- Individual rooms within the RMA will generally be held between -0.1 and -0.15 in.

- Differential glovebox pressures will typically range from -0.25 in. to -1.0 in. In special cases the pressures may differ from those in the above example.

\subsubsection{Dilution Ventilation}

Dilution ventilation is the once-through flow technique of exchanging outside air for inside air for comfort and basic contamination control. For comfort control, this technique typically cools outside air in the summer and warms the air in the winter. Dilution ventilation techniques are inherently inefficient although heat exchangers can help conserve energy. However, this technique obviously results in environmental releases, which may be minimized by using a room-air detritiation system. For. information on room-air detritiation systems, see Section 4.6.2.3.

Room air exchange rates in most working environments are typically set to about four air changes per hour. At many tritium facilities, however, exchange rates are routinely 
set to 10 air changes per hour in radioactive materials areas and 4 to 6 air changes . per hour in offices and other noncontrolled areas. Thus, depending on the size of the facility, it can be expected that the total air throughput for any given tritium facility will be approximately $10^{6}$ to $10^{8} \mathrm{~m}^{3} /$ day, or higher. Because of increased energy costs in recent years, a number of sites have examined the feasibility of retrofitting air handling systems with computerized flow control systems. They would permit a lower flow rate whenever conditions allow, such as worker comfort, minimal air concentrations of tritium, etc. Following a tritium release, a higher exhaust rate could be initiated. Facilities that are equipped with room detritiation systems may also favor lower ventilation rates in order to contain the tritium more easily following a sudden. release into a room [4.31].

It is important for planning purposes for health physicists to know room air exchange rates to determine waiting times before re-entering a room after a tritium release. To determine the tritium activity in a room, this formula may be used:

$$
\text { Final Value }=\text { Initial Value } \mathrm{x} \exp (-\mathrm{xt})
$$

where $\mathrm{x}$ is the number of volume changes per hour and $t$ is the total time in hours after the release. The initial value of tritium air activity is assumed to have reached equilibrium. In a real release situation, room monitors are relied upon, rather than the results of calculations that assume perfect mixing. Portable tritium monitors should also be used upon entering a room following a tritium release.

\subsubsection{Room-Air Detritiation Systems}

There may be some special situations where it is desirable to provide a Room-Air Detritiation System, not for personnel protection, but to minimize a potential release to the environment. Such a system uses tritium monitors located in the room exhaust duct to activate (close) fast acting dampers. The dampers then route the exhaust through a special oxidation/drying system and return the air to the room. This recycle loop continues until most of the tritium released has been converted to water and trapped on the dryers. Although such a system can dramatically reduce the number of curies released to the stack, it actually increases the potential for exposure to anyone remaining in the room since the recycled air has elevated levels of tritium oxide.

\subsubsection{Local Exhaust Ventilation}

The primary advantage of local exhaust ventilation techniques is the removal of airborne tritium, regardless of its evolution rate or chemical or physical form. In addition, these techniques use relatively low flow rates compared to normal ventilation requirements. 


\subsection{Fumehoods}

Fumehoods often serve as the exhaust points of once-through ventilation systems. In theory, linear flow established at or near hood openings (face velocities) draw the contaminants through the hoods and into the exhaust ductwork. The capture of gases and vapors in the hood generally require lower-face velocities than those needed for the capture of particulates. Large and intermediate-sized particles, for example, sometimes are difficult to capture because of their inherent mass and the forces of gravity. On the other hand, smaller particles, (below a few microns in size), can be expected to behave in a manner similar to that for gases and vapors.

For tritium work in a fumehood, face velocities in the range of 100 to $150^{\circ}$ linear feet per minute (lfpm) are used. Higher velocities, e.g., 150 to $200 \mathrm{lfpm}$, can produce turbulent flow resulting in eddy currents that can sweep tritium back to the operator. The problem can be further compounded by the location of equipment within the hood, the design of the hood itself, and personnel traffic in front of the hood. Therefore, operations involving the use of fumehoods should be periodically reviewed to ensure that adequate face velocities are being maintained.

\subsection{Canopy Hoods}

Canopy hoods are used in place of fumehoods for housing large equipment. Designed for specific applications, canopy hoods are used at many tritium facilities for the following:

- To enclose glovebox pass-through port operations,

- To house experiments that are too large to fit into a fumehood, and

- To house tritium gas pumping systems.

Although used with either natural or forced air exhaust, canopy hoods are most effective for hot- and warm-air processes where rising thermal currents help pull air into the hood. For tritium work, canopy hoods are usually designed such that heat-producing equipment (e.g., pumps) can be placed at floor level. Hood door openings, which usually slide to the right and to the left, must be designed so that they can function without interfering with the worker or the operation. However, because the protection afforded by canopy hoods can quickly be lost when cross drafts are introduced, hood openings must be kept to a practical minimum whenever the hood is in use.

Portable local ventilation can be provided where needed by a flexible duct ("elephant trunk") with air flow maintained by a separate blower or by the building exhaust system. For suggested applications of flexible ducts, see Section 4.8. 


\subsubsection{Air-Supplied Respirators}

In general, only air-supplied respirators are effective in preventing inhalation of airborne tritium. Air-supplied respirators are of two types: self-contained breathing apparatus (SCBA) and full-faced supplied air masks, for which air is supplied from a breathing air compressor of pressurized bottles.

A self-contained breathing apparatus, consisting of a full-face mask fed by a bottle of compressed air carried on the worker's back, provides excellent protection against HTO inhalation. Because the mask provides no protection against absorption by most of the skin, the SCBA is normally reserved for emergency use only.

SCBAs can be used as an added precaution during certain maintenance or operations that experience has shown should not result in the release of significant amounts of HTO. The potential for exposure is nevertheless real and the SCBA gives the worker time to leave the area if necessary before a skin exposure occurs.

\subsubsection{Air-Supplied Suits}

Because of the inherent disadvantages normally associated with respirators and other breathing apparatus, air-supplied plastic suits that completely enclose the body are widely used by facilities that handle large quantities of tritium. Prior to air-supplied suits being used at DOE facilities, however, suits must be tested and approved by a DOE Respirator Advisory Committee (RAC). Details of the approval procedures are discussed elsewhere [4.32].

The main objectives of air-supplied suits are to (1) provide a layer of circulating air between the worker and the suit, (2) provide an adequate supply of breathing air for the worker, and (3) maintain an adequate flow of air from the interior of the suit to the exterior to help keep the body cool. The incoming air must meet the criteria of Type 1, Grade D breathing air, as specified in the Compressed Gas Association Standard [4.33]. The air-supply system should be designed to ensure a high degree of reliability.

Capacity requirements for air-supply systems are dependent on flow requirements for specific suit designs. A wide range of flow rates are used in RAC-approved suits (from 6 to $20 \mathrm{cfm}$ per suit), and it is not uncommon to have several workers on a manifold system at the same time. Therefore, system capacities should be designed to provide adequate flow to each suit user. Capacities in excess of several hundred cubic feet per minute may be needed per system.

For tritium work, air-supplied suits must be constructed of materials that have acceptable permeation protection against HTO. They must also provide appreciable tear and abrasion resistance. Because they are intended for use in many different : 
environments, suits must be designed to provide adequate vision, to minimize interference with normal work movements, and to be put on and taken off easily. Noise levels, resulting from the flow of air coming into suits, must be maintained at levels less than OSHA workplace standards, and they must comply with RAC criteria. Because of the closed environment, and because of the additional background noise caused by the flow of air into the suits, communication methods between personnel may require special equipment.

\subsubsection{Temporary Enclosures}

A more effective way to contain tritium may be to construct a tent (temporary canopy hood or a temporary glovebox). The primary difference between the two is that hoods generally exhaust to the stack, while gloveboxes generally exhaust to cleanup systems. For tritium, tents can be thought of as being the nominal equivalent of a reactor-type contamination control point when large pieces of equipment or entire areas must be worked on.

Structural members for tents can literally be anything. Smaller glove-bag operations, for example, recommend the use of Tinker-Toys for support. For larger operations, PVC pipe, scaffolding supports, and standard off-the-shelf fittings can be used, along with anything else that is available. Tent walls are usually made of 3-, 6-, or 12-mil fire-retardant PVC plastic sheeting, depending on strength requirements that may develop because of the facility's differential pressures [4.34].

Tenting operations are usually designed to allow personnel to work inside. In most cases, personnel working inside wear air-supplied plastic suits. For these reasons, communication links between personnel inside and outsicle become vital. Moreover, because many tenting operations involve the use of welding, brazing, grinding, and/or other hot processes, additional emphasis must be placed on possible fire hazards.

\subsubsection{Protection Against Surface Contamination}

Protective equipment worn by workers is one of the most important aspects of an effective health physics program. Since tritium can be easily absorbed through the skin or by inhalation, personnel protective equipment must protect against both exposure routes. The following describes protective measures and equipment.

\subsubsection{Glovebox Housekeeping}

The primary method for minimizing exposures during glovebox work is good housekeeping. Workers should strive to minimize the tritium concentration inside the glovebox by being constantly alert to proper valve adjustments, temperatures, and other environmental indicators of the integrity of the primary containment system. If significant quantities of tritium escape containment, the glovebox atmosphere should be 
purged to the glovebox detritiation system. Workers should also minimize the number of instruments, tools, and other materials inside the glovebox.

\subsubsection{Gloves}

In most operations, the hands and forearms of workers are vulnerable to contact with tritium surface contamination. Thus, the proper selection of gloves and glove materials is essential.

Many factors should be considered in selecting the proper type of glove, including chemical compatibility, permeation resistance, abrasion resistance, solvent resistance, glove thickness, glove toughness, glove color, shelf life, and unit cost. Gloves are commercially available in materials such as butyl rubber, natural rubber, neoprene rubber, neoprene and natural rubber blends, nitrile (Buna- $N$ ) and polyvinyl chloride (PVC) plastics, polyvinyl alcohol (PVA) coated fabrics, and viton.

Table 4.2 shows the chemical compatibility of eight of the available glove materials along with recommended and nonrecommended uses. The data clearly indicate that certain types of materials are not recommended for use with certain types of chemicals. Different types of gloves should be readily available for use in routine handling of chemicals.

TABLE 4.2 - Chemical Compatibility of Available Liquid-Proof Glove Materials

\begin{tabular}{|c|c|c|}
\hline Material & Recommended For & Not Recommended For \\
\hline Butyl & $\begin{array}{l}\text { Dilute acids and alkalies, ketonic } \\
\text { solvents, gas and vapor permea- } \\
\text { tion protection }\end{array}$ & $\begin{array}{l}\text { Petroleum oils, distillates, and } \\
\text { solvents }\end{array}$ \\
\hline $\begin{array}{l}\text { Natural Rubber } \\
\text {.... }\end{array}$ & $\begin{array}{l}\text { Ketonic solvents, alcohols, photo- } \\
\text { graphic solutions }\end{array}$ & $\begin{array}{l}\text { Petroleum oils, distillates, and } \\
\text { solvents }\end{array}$ \\
\hline Neoprene & $\begin{array}{l}\text { Concentrated nonoxidizing acids } \\
\text { and concentrated alkalies }\end{array}$ & Halogenated or ketonic solvents \\
\hline $\begin{array}{l}\text { Neoprene/Natural } \\
\text { Blends }\end{array}$ & $\begin{array}{l}\text { Dilute acids and alkalies, deter- } \\
\text { gents, and photographic solutions }\end{array}$ & $\begin{array}{l}\text { Halogenated or rubber ketonic } \\
\text { solvents }\end{array}$ \\
\hline Nitrile & $\begin{array}{l}\text { Petroleum-based solvents, distil- } \\
\text { lates, and oils }\end{array}$ & Halogenated or ketonic solvents \\
\hline $\begin{array}{l}\text { PVC } \\
. \quad\end{array}$ & $\begin{array}{l}\text { General purpose, low-risk hand } \\
\text { protection }\end{array}$ & Halogenated or ketonic solvents \\
\hline PVA & $\begin{array}{l}\text { Halogenated solvents, paint shop } \\
\text { applications }\end{array}$ & Water or water-based solutions \\
\hline Viton & $\begin{array}{l}\text { Halogenated solvents, concen- } \\
\text { trated oxidizing acids }\end{array}$ & Aldehydes, ketonic solvents \\
\hline
\end{tabular}


Table 4.3 lists some of the physical properties of commercially available gloves that can be found in common use at most facilities. Listed in order of their cost, gloves range from well under $\$ 1$ per pair for the thinnest (0.005 in. thickness) disposable PVC gloves to more than $\$ 30$ per pair for viton ( 0.012 in. thickness). Also included in Table 4.3 are additional considerations for glove length, as well as comparisons of shelf-life, glove toughness, and HTO permeation characteristics.

The rating system for the data in Table 4.3 is as follows: Under Shelf Life, "Excellent" refers to an indefinite time span with no obvious loss of properties; "Poor" refers to a time span of between 6 and 12 months, the loss of basic properties being obvious; "Fair" and "Good" refer to arbitrary time spans of 2 and 4 years, respectively, with some loss of properties becoming evident over time.

The use of two or more glove layers should be considered in these situations:

- For complex chemical operations, such as waste treatment and handling

- For maintenance operations with potential exposure to a wide variety of chemical compounds, such as replacing plumbing on large-scale vacuum effluent capture systems that have been in tritium service for several years.

Although basic protection schemes can be determined for most combinations of chemical species, the best gloves are combinations of three layers of liquid-proof gloves and an underlying layer of absorbent glove material, i.e., a cotton glove liner. Different-colored layers for indicating which layers fail to meet protection requirements should also be considered. This further means of protection would prove beneficial for most workers except for the small percentage who are color-blind.

\subsection{Selection of Box Gloves for Varying Box Environments}

Gloves most commonly used for glovebox work include single compound gloves made from neoprene, hypalon, and butyl, and multi-compound gloves made from laminates of neoprene on hypalon, ethylene propylene (EPDM) on butyl, and neoprene on butyl. Primary selection criteria are normally based on chemical compatibility and permeation characteristics. The former is a function of outbound HT/HTO permeation and inbound air and water vapor permeation. Secondary selection criteria should include considerations of durability, toughness, and cost.

For inert box applications, atmospheres are normally maintained with helium, argon, or nitrogen. Because of the critical nature of "dry box" criteria, moisture levels are routinely maintained at levels that range from a few, to a few tens of parts-per-million (ppm), depending on the overall size of the system and net in-leakage of outside moisture. For maintenance boxes, or any other boxes that are regularly opened to room-air, atmospheres can be maintained with air as long as the potential for flammable or explosive mixtures is avoided. 
TABLE 4.3 - Physical Properties of Commercially Available Gloves

\begin{tabular}{|lcclll|}
\hline Glove Material & $\begin{array}{c}\text { Length } \\
\text { (in.) }\end{array}$ & $\begin{array}{c}\text { Thickness } \\
\text { (in.) }\end{array}$ & $\begin{array}{l}\text { Shelf } \\
\text { Life }\end{array}$ & $\begin{array}{l}\text { Relative } \\
\text { Toughness }\end{array}$ & $\begin{array}{l}\text { HTO Permeation } \\
\text { Protection }\end{array}$ \\
\hline PVC & 11 & 0.005 & Fair & Fair & Poor \\
PVC & 11 & 0.010 & Good & Good & Fair \\
PVC & 11 & 0.020 & Excellent & Excellent & Good \\
Neoprene/Natural & 14 & 0.020 & Good & Good $\cdots$ & Good \\
Rubber Blend & & & & & \\
Neoprene & 11 & 0.015 & Excellent & Good & Good \\
Neoprene & 18 & 0.022 & Excellent & Good & Good \\
Natural Rubber & 11 & 0.015 & Poor & Fair & Good \\
Nitrile & 13 & 0.015 & Excellent & Excellent & Good \\
Nitrile & 18 & 0.022 & Excellent & Excellent & Good \\
Butyl & 11 & 0.012 & Excellent & Poor & Excellent \\
PVA & 12 & 0.022 & Good & Excellent & Poor \\
Viton & 11 & 0.012 & Excellent & Excellent & Excellent \\
\hline
\end{tabular}

(a) As a coated, flock-lined fabric, the thickness of PVA gloves can vary by as much as $\pm 20 \%$. Because the PVA coating is water soluble, other properties of PVA gloves can also be expected to vary, depending on their long-term exposure to moisture.

For single component gloves, the data in Tables 4.2 and 4.3 suggest that butyl gloves will provide the best protection against permeation. However, when the work involves using petroleum-based oils, distillates, or solvents, (as do many situations that involve the use of machine tools inside glove boxes), butyl gloves can be expected to deteriorate rapidly because of their limited resistance to these chemicals. For this type of work, hypalon or neoprene gloves are recommended over butyl. Hypalon and/or neoprene cannot be recommended for systems where moisture or oxygen levels are allowed to remain relatively high, particularly when box environments remain fairly static over long periods of time. These conditions tend to favor the formation of HTO, and breakthrough can be expected in time spans as short as 4 to 6 weeks.

\subsection{Protective Measures for Glovebox Work}

Work in a glovebox can sometimes produce relatively high intakes compared to work performed in a hood. Typically, the increases can range between two and three orders of magnitude. More importantly, the increased levels are related to the time spent 
working in the gloves and to the glovebox concentrations, which are usually much higher than those found in fumehoods.

Ideally; these protective barriers are applied before box work is performed:

- A shoulder-length fabric barrier for perspiration absorption and HTO dilution.

- A shoulder-length glove (e.g., polyethlene veterinarian glove) to minimize direct contact between the skin and the box glove surface.

- A wrist-length, disposable latex or PVC glove to help guard against localized high concentration exposures [4.35].

Regardless of the glove combination used, the following precautions are important for minimizing the total dose:

- Work time in the glovebox should be controlled to limit exposure,

- All protective equipment (gloves, glove liners, and possibly lab coats) should be . disposed of after each work session,

- The hands and forearms should be washed in cool water after each work session to remove the surface HTO and reduce the possibility of absorption during washing.

\subsubsection{Lab Coats and Coveralls}

Lab coats and coveralls (fabric barriers) are worn at various times in almost all tritium facilities. Lab coats are normally worn as part of the daily routine for the general protection of street clothes. For added protection, coveralls are sometimes worn instead of a lab coat when the work is unusually dusty, dirty, or greasy. However, the protection afforded by lab coats and coveralls is minimal (except for short exposures) where tritium is airborne, but they are quite effective in preventing skin contact with contaminated surfaces.

Unless they are treated with water-resistant or water-proofing agents, open-weave fabrics, such as those normally associated with lab coats and coveralls, provide minimal barriers against the airborne diffusion of HTO. Moreover, the HTO protection that is afforded is the result of straightforward mechanical factors: some of the HTO is absorbed in the weave of the fabric, some is trapped in air pockets between layers of fabrics, and some is trapped in air pockets that separate the fabric layers from the skin. Perspiration levels near the skin surface, both sensible and insensible, add an additional short-term dilution factor. For the most part, however, unless lab coats and/or coveralls are changed often (every 10 minutes or so, which is impractical), equilibrium is reached and all barrier effects are nullified [4.35]. The 
fact that lab coats and coveralls do not cover all of the skin is probably of minor importance where tritium is airborne.

Water-proof and water-resistant lab coats and coveralls have been tested at various laboratories. In most cases, however, they are not recommended for everyday use because of the excessive discomfort inflicted on the worker. Many facilities prefer using open-weave fabrics for lab coats and coveralls and using an approved laundry for contaminated clothing. Other facilities have opted instead to use disposable paper lab coats and coveralls, exchanging the costs associated with a laundry for the costs associated with replacement and waste disposal.

\subsubsection{Shoe Covers}

Although shoe covers do provide protection against the spread of contamination and exposure, the routine use of shoe covers in a tritium facility must be thoroughly weighed against actual need. Like lab coats and coveralls, shoe covers offer little protection against spreadable particulates and/or gases and vapors. As a general rule, shoe covers are not recommended for controlling spreadable contamination except in highly contaminated areas, because good housekeeping (i.e., regular sweeping, mopping, and waxing of floors), provides better control. Using liquid-proof shoe covers should be considered to prevent the spread of local contamination such as from spills of tritium-contaminated liquids and solids.

\subsection{Decontamination}

Methods available for decontaminating materials are based on material composition and the extent of tritium contamination. Effective decontaminating agents include soap and water, detergents, bleach, and alcohol. Since decontamination is often difficult, especially where surfaces are exposed to high concentrations of tritium for extended periods, tools and specialized equipment routinely used in contaminated areas should be labeled and stored there for reuse.

Action levels should be established for the different tritium facility control zones to ensure that tritium contamination levels do not build up over time. For example, administrative limits for uncontrolled material release and clean areas may range from 1000 to $10,000 \mathrm{dpm} / 100 \mathrm{~cm}^{2}$ at different facilities. Smearable limits in controlled zones may be much higher, but an effective health physics program should have procedural limits on the amount of smearable contamination permitted. When these action levels are exceeded, timely decontamination efforts should be initiated.

In spite of all the precautions normally taken, there may be occasional tritium contamination of workers. Decontamination of the skin should be initiated as soon as possible after any potential skin exposure to minimize absorption into the body. Effective personal decontamination methods include rinsing the affected part of the 
body with cool water and soap. If the entire body is affected, a shower should be taken using soap and water as cool as can be tolerated. The water should be cool to keep the pores of the skin closed and to reduce transfer of HTO across the skin.

\subsection{Maintenance}

Maintenance activities and operations sometimes require work to be done on equipment outside of a hood or glovebox environment. Several techniques are available for this type of operation, such as the containment huts or tents discussed in Section 4.6.2.7. Flexible ventilation ducts (typically 8 or $10 \mathrm{in}$. in diameter), sometimes referred to as "snorkels" or "elephant trunks" can be placed directly over or adjacent to the work to be performed as discussed in Section 4.6.2.4. Flexible ducts can also be used to provide adequate ventilation during maintenance in a glovebox with a panel removed. In this application, a flexible duct can be connected to a gloveport before the panel is removed, and then the work can proceed with safety. If the flexible duct is connected to a building exhaust system, the flow rate may not be adequate for some jobs. In this case, it may be necessary to add a supplemental blower in the flexible duct line.

\subsection{References}

4.1. DOE Order 5480.11, Radiation Protection for Occupational Workers, 1988.

4.2. $\quad$ R. L. Kathren, A Guide to Reducing Radiation Exposure to As Low As Reasonably Achievable (ALARA), DOE/EV/1830-T5, Battelle Pacific Northwest Laboratory, Richland, Washington (April 1980), pp. 233.

4.3. American National Standards Institute, American National Standard Practice for Occupational Radiation Exposure Records Systems, ANSI N13.6-1972.

4.4. R. V. Osborne, "Absorption of Tritiated Water Vapour by People," Health Physics, 12 (1966), pp. 1527-1537.

4.5. E. A. Pinson, The Body Absorption, Distribution, and Excretion of Tritium in Man and Animals, LA-1218, Los Alamos Scientific Laboratory, Los Alamos, New Mexico (1951).

4.6. E. A. Pinson and W. H. Langham, "The Physiology and Toxicology of Tritium in Man," J. Appl. Physiol., 10 (1957), pp. 108-126.

4.7. International Commission on Radiological Protection, Publication 30: Limits for Intakes of Radionuclides by Workers, Part 1 and Supplements, Pergamon Press, New York, 1979.

4.8. American National Standards Institute, American National Standard for Dosimetry - Internal Dosimetry Programs for Tritium Exposure - Minimum Requirements, ANSI N13.14-1983. 
4.9. Environmental Health Directorate, Bioassay Guideline 2, Guidelines for Tritium Bioassay, Report of the Working Group on Bioassay and In Vivo Monitoring Criteria to the Federal-Provincial Advisory Committee on Environmental and Occupational Health, 83-EHD-87, Ottawa K1A OK9, Canada, (1987).

4.10. R. C. Thompson, "Studies of Metabolic Turnover with Tritium as a Tracer: II. Gross Studies on the Mouse," J. Biol. Chem., 197, (1952), pp. 81.

4.11. National Committee on Radiation Protection and Measurements, Tritium Measurement Techniques, NCRP Report No. 47, Washington, D.C. (1976).

4.12. International Commission on Radiological Protection, Publication 23: Report of Task Group on Reference Man, Pergamon Press, New York, 1974.

4.13. National Committee on Radiation Protection and Measurements, Tritium in the Environment, NCRP Report No. 62, Washington, D.C. (1979).

4.14. J. D. Eakins, W. P. Hutchinson, and A. E. Lally, "The Radiobiological Hazard from Tritium Sorbed on Metal Surfaces," Health Physics, 28 (1975), pp. 213-224.

4.15. P. Henry, "Contamination par le Tritium et Epiration Extravinale," Radioprotection, 9:1 (1974), pp. 41-81.

4.16. DOE Order 5484.1, Environmental Protection Safety, and Health Protection Information Reporting Requirements, 1981.

4.17. T. B. Rhinehammer, and P. H. Lamberger, editors, Tritium Control Technology, Monsanto Research Corporation Report WASH-1269, Miamisburg, Ohio (1973).

4.18. R. V. Osborne, and R. G. C. McElroy, "Applications of Membranes to Monitoring for Tritiated Water Vapor," In Proceedings of an International Symposium on Management of Gaseous Waste from Nuclear Facilities, Vienna, Austria, February 18-22, 1980.

4.19. R. A. Jalbert, "A New Tritium Monitor for the Tokamak Fusion Test Reactor," Fusion Technology, 8 (1985), pp. 2077-2081.

4.20. H. G. Ostlund, and A. S. Mason, "Atmospheric HT and HTO:I Experimental Procedures and Tropospheric Data 1968-1972," Tellus, XXVI (1974), pp. 91-101.

4.21. A. N. Auf der Maur and T. Lauffenburger, "A Simple Method for Collection of HTO from Air," Proceedings of the Fifth International Congress of the

$$
4-27
$$


International Radiation Protection Association, Jerusalem, Israel, March 9-14, 1980, Volume III, pp. 57-60.

4.22. K. G. Harrison, M. Marshall, D. J. Ryden, J. Myatt, R. L. Otlet, D. B. Punter, A. J. Walker, J. Forde-Johnston, and H. J. Reid, "Recent Developments in Monitoring for Tritium in Air," Proceedings of the Fourth International Symposium on Radiation Protection - Theory and Practice, Malvern, England, June 4-9, 1989.

4.23. T. Westermark, L. Devell, and N. A. Ghanem, "On the Use of Bremsstrahlung for the Determination of Tritium in Aqueous and Organic Systems," Nuclear Instruments and Methods, 9 (1960), pp. 141-144.

4.24. J. C. Rosen, G. R. Laurer, and M. Eisenbud, "Carbon-14 and Tritium Measurement by Means of Bremsstrahlung Emissions," Science, 157 (1967), pp. 77-78.

4.25. M. L. Curtis, "Detection and Measurement of Tritium by Bremsstrahlung Counting," Health Physics, 23 (1972), pp. 17-23.

4.26. R. A. Jalbert, "Monitoring Tritium in Air Containing Other Radioactive Gases," LA-9514-MS, Los Alamos National Laboratory .(1982).

4.27. G. T. Falk and R. C. King, "Radioautographic Efficiency for Tritium as a Function of Section Thickness," Radiation Research, 20 (1963), pp. 466-470.

4.28. Y. Kobayashi and D. V. Maudsley, Biological Applications of Liquid Scintillation Counting, Academic Press, Inc., New York (1974).

4.29. DOE Order 5400.5, Radiation Protection of the Public and the Environment, 1990.

4.30. International Commission on Radiological Protection, Publication 25: The Handling, Storage, Use, and Disposal of Unsealed Radionuclides in Hospitals and Medical Research Establishments, Pergamon Press, New York, 1976.

4.31. R. A. Jalbert, "Tritium Control at the Tritium System Test Assembly," Proceedings of the 5th International Congress of the International Radiation Protection Association, Jerusalem, Israel, March 9-14, 1980, 2, pp. 229-232.

4.32. O. D. Bradley, Acceptance-Testing Procedures for Air-Line Supplied-Air Suits, LA-10156-MS, Los Alamos National Laboratory, 1984.

4.33. Compressed Gas Association, Compressed Air for Human Respiration, CGA-G7.1, New York (1968).

4.34. National Fire Protection Association, Facilities Handling Radioactive Materials, NFPA 801, Quincy, MA (1980). 
4.35. W. R. Bush, Assessing and Controlling the Hazard From Tritiated Water, AECL-4150, Atomic Energy of Canada Limited, Chalk River, Ontario, Canada (1972).

4.36. R. D. Evans, The Atomic Nucleus, 10th edition, McGraw-Hill, New York (1965).

4.37. J. D. Eakins and W. P. Hutchinson, The Radiological Hazard from Tritium Sorbed on Metal Surfaces, AERE-R-5988, UK Atomic Energy Authority, Harwell, England (1969).

4.38. M. E. Hutchins and B. E. Vaughn, "Skin Contact Transfer of Tritium from Brass," Health Physics, 11 (1965), pp. 1047-1053.

4.39. J. R. Johnson, E. S. Lamothe, J. S. Jackson, and R. G. C. McElroy, "Metabolism and Dosimetry of Tritium from Tritium Gas Contaminated Surfaces," Fusion Technology, 14 (1988), pp. 1147-1152. 


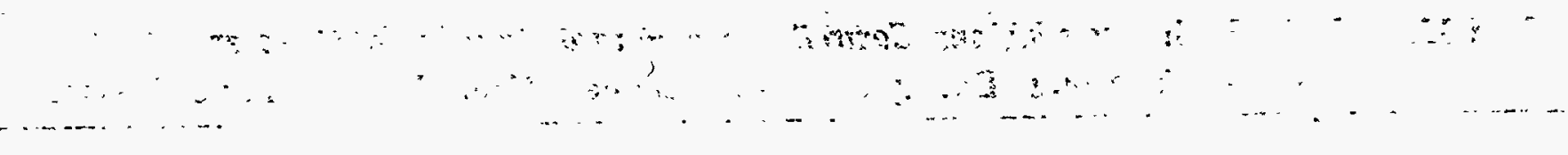

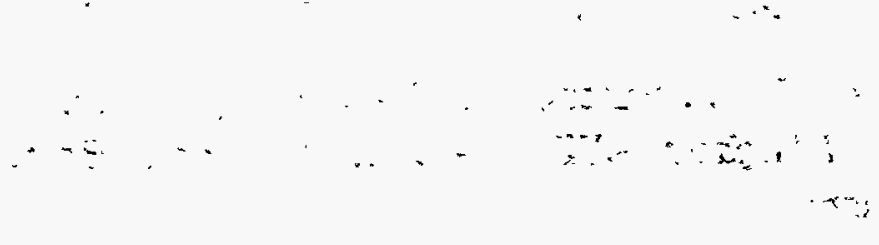




\section{Chapter 5 \\ Facility Design}

\subsection{Design Objectives}

Several specific objectives must be considered when designing a tritium facility:

- To protect people and the environment,

- To produce a quality product,

- To allow for disposing of waste materials,

- To ensure the quality of the facility,

- To consider the decontamination and decommissioning (D\&D) of the facility, and

- To enable accounting for tritium in the facility.

These objectives can be met through safe, timely, and cost-effective design.

Certainly one of the most important objectives of tritium facility design is to protect people and the environment. The people to be protected include operating personnel, plant personnel, and the public. Protecting the environment includes limiting both liquid and gaseous releases. Obviously, the best way to protect people and the environment from tritium is to keep the tritium in the process where it belongs and to contain any material that escapes.

Another consideration of primary importance in the design of a tritium facility is fabricating a quality product. This could be a product in the traditional sense, or a product as abstract as quality research. A facility designed to manufacture a tritiated component might not be appropriate for the research and development of that same component.

The design of a tritium facility must also take into account the processing of wastes. The types of wastes produced, their treatment, and their ultimate disposition should be considered. As by-products of the facility, wastes must meet specifications, be carefully controlled, and be disposed of through well-regulated processes.

Ensuring quality is another objective of facility design. This is achieved through documentation and peer reviews of calculations, drawings, test data, and inspection reports produced during the design process. This information is invaluable to the safe operation of the facility and must be kept up-to-date.

The eventual $D \& D$ of the facility should also be considered while the facility is being designed. The equipment size, the surface finish of equipment and rooms, and many other design factors can make facility D\&D easier or more difficult. Planning for D\&D during the 
design stage can save a considerable amount of money over the useful life of a facility and can reduce the cost of the eventual $D \& D$.

Another design consideration is accounting for tritium in the facility. All facilities, especially those with large tritium inventories, must be designed so that the amount of tritium contained within them can be determined in accordance with DOE Order 5633.3. The amount of material in the process must be measurable. Many design decisions can affect the ability to make these measurements accurately and safely.

Finally, the design of a tritium facility should be timely and cost-effective. This does not necessarily mean the lowest capital cost, but more closely approximates the minimum life cycle cost. A rigorous life-cycle cost analysis often cannot be accomplished because the "cost" of occupational and public exposure to tritium is not well defined. A system that is expensive to operate, degrades the environment, and is difficult to decommission could have a low capital cost. Sometimes, in the name of cost or schedule, shortcuts are taken in the facility design. More often than not, these shortcuts result in larger capital and operating costs. It is not uncommon for the design of a tritium facility to be 20 to $25 \%$ of the total capital cost.

\subsection{Building Criteria}

\subsubsection{Structure}

To determine the structural integrity to be designed into a tritium facility, the acceptable risk of damage as a result of natural phenomena must be decided. The ultimate responsibility for determining an acceptable risk of damage rests with the facility operating management and the DOE. The degree of risk that is acceptable should be based on characteristics of the facility such as vuinerability of occupants, programmatic impact, characteristics of tritium in the facility (inventory, physical state, toxicity, etc.), factors affecting offsite release, and replacement costs. Natural phenomena include earthquakes, winds, tornados, and floods. This subject is covered in depth in the "Design and Evaluation Guidelines for Department of Energy Facilities Subjected to Natural Phenomena Hazards" [5.1].

When evaluated using these guidelines, most tritium facilities will fall into the moderate risk class or category. Facilities in this category have performance goals of occupant safety, continued function, and confinement of hazardous materials. One performance goal is based on a risk of less than 10-4 annual probability of the onset of loss-of-confinement. Since this criterion is site-specific, no other comments will be made here other than to refer to the "Safety Analysis and Review System," DOE Order 5481.1B [5.2], and the "General Design Criteria Manual," DOE Order 6430.1 [5.3], for other minimum structural requirements.

The internal structural design should incorporate a floor loading capability sufficient to support the expected live load and equipment. This loading capability should be at least 200 
$\mathrm{lb} / \mathrm{ft}^{2}$ to allow for future additions and changes. Maintaining differential pressure zones within the facility is important, and these should be included in the initial design. Uncontrolled air leakage into a room (low pressure) and/or building should be minimized to reduce the load on the air handling unit. Air leaks typically occur at interfaces of walls, floors, and ceilings, at duct penetrations to rooms, at electrical conduit and pipe penetrations, through conduits, at door seals, and at supports for lights and other equipment. If seals are installed when the facility is constructed, a successful room leak test will be much easier. Total air leakage into rooms that handle significant quantities of tritium has been successfully limited to less than $1 \%$ of the volume of the room per minute at 0.05 inches of water pressure differential. The specific facility design and the addition of a room detritiation system could change this criterion.

The interior finish of walls and ceilings should be smooth, tough, easy to clean, and free of pin holes. Concrete block with fillers and epoxy paint has been successfully used to accomplish these goals. Continuous vinyl flooring is preferable in areas where contaminated liquids (water or oils) may be handled. Vinyl floor tile has been used successfully in some facilities. Routing and protection of the multitude of wires and cables needed in most new tritium facilities should be considered. Perimeter cable trays and electrical ducts within the operating or laboratory rooms provide one method of routing and protecting wires and cables.

\subsubsection{Location and Layout}

The location of a tritium facility should take into account the expected external natural forces, such as floods, surface water flow, water table, winds, falling objects, and earthquakes. Potential occupational and public exposure, resulting from an accidental release of contaminated material into the surrounding area, should also be examined. It is advisable to locate the facility as close as possible to existing radioactive support functions, such as a waste handling building. The location of a central analytical system and common house vacuum systems should be carefully considered. Any transfer lines that handle gaseous tritium should be as short as possible, must be secondarily contained, and should be located in areas protected from large equipment that could accidentally damage the lines.

The layout of a tritium facility is another important consideration. The floor plan can either add to or detract from the efficiency, safety, and functioning of the total facility. The objective of the layout should be to optimize the movements of personnel, material, and equipment to safely accomplish the desired functions under both routine and accident conditions. A tritium facility normally comprises two main areas: the radiation control area, which includes the process area, and the uncontrolled area. The process area consists of rooms containing gloveboxes, fumehoods, and systems that perform the main functions of the facility. The remainder of the radiation control area consists of support functions.

The facility should contain a central, tritium, monitor readout system and a counting monitor room that can be reached from both the radiation control area, normal mode, and 
the uncontrolled area, emergency mode. Many tritium facilities use a secondary cleanup system to handle contaminated gaseous waste streams from vacuum pumps, glovebox purge systems, and other support equipment. The layout should allow the secondary cleanup system's piping lines to be exposed for easy inspection. The secondary cleanup system should be as close to the tritium handling area as possible.

In addition, space should be provided to allow the efficient handling and movement of support materials. This space should include areas for the following:

- Decontaminating equipment and material,

- Maintenance and repair,

- Drumming liquid waste,

- Drumming and compacting solid wastes,

- Staging waste drums. and trash boxes, and

- Storing health physics and decontamination supplies.

One of the most frequently overlooked space requirements is the need for radiation control area offices. Halls and corridors should be arranged to allow the optimum routine movement of people and materials, as well as the infrequent movement of equipment to loading docks. Change rooms and rest rooms should be located at the interface between the radiation control area and the uncontrolled area to facilitate the movement of people and allow the handling of both clean and dirty clothing.

The uncontrolled area should house all the air-handling supply systems and the exhaust fans downstream of the filter banks. The filter banks themselves, if required, should be within the controlled area. The main supply of all other utilities, such as steam, gases, water, fire protection risers, and electrical transformers, should be located in the uncontrolled area. The number of parts within the radiation control area should be minimized. It is always advisable to locate sump pumps, if required, on the uncontrolled side with raised tops to minimize the chance of getting contaminated water into the sump. It is a good practice to avoid using any underground liquic waste lines.

The layout should also include space for locker rooms, rest rooms, offices, uncontrolled area laboratories, halls and corridors, staging areas, emergency spare parts, and loading docks that can serve both the radiation control and the uncontrolled areas. An uncontrolled area, such as a receiving dock, should be provided where crates, packing, boxes, and other shipping wastes can be discarded before unpacked materials are moved to the radiation control side. This dock helps reduce the amount of contaminated wastes generated.

Maintenance is an important part of any tritium facility. Therefore, the layout should provide for shops for mechanical and electrical work in both the radiation control and 
uncontrolled areas. A desirable feature for glovebox operations (if costs and the process allow it) is to arrange gloveboxes in two rows with a maintenance access corridor common to the backs of the boxes. This allows maintenance tents to be set up and torn down without interfering with the operational side of the gloveboxes. Gloveboxes for repairing contaminated equipment can be an important feature if expensive contaminated equipment can be repaired and salvaged. All layouts must include separation firewalls for the facility to comply with existing fire codes. In addition, corridors and exits required by the National Fire Protection Association (NFPA) Life Safety Code must be incorporated into the facility design [5.4].

Some useful rules of thumb that must be carefully applied while considering the uniqueness of a facility include the following:

- A standard glovebox line ( $3 \mathrm{ft}$ deep) requires approximately 7 feet of space on each side, or a minimum room width of 17 feet.

- Two parallel rows of standard gloveboxes with a maintenance access corridor 6 feet wide between them can be installed in a room with a minimum width of 26 feet.

- To install a single glovebox and associated equipment, $17 \mathrm{ft}^{2}$ of floor space per linear foot of glovebox front is necessary; $13 \mathrm{ft}$ is required to install parallel rows of gloveboxes and associated equipment.

- The total radiation control area, including adjacent corridors and support areas, requires $11 / 2$ to 2 times the room space estimated above.

- The uncontrolled area in a tritium facility requires approximately the same amount of floor space as the controlled area.

- Design of the facility and equipment typically represents 20 to $25 \%$ of the total capital cost.

\subsubsection{Services and Utility Systems}

\subsubsection{Ventilation}

The air ventilation system plays a key role in controlling the spread of contamination, in addition to providing the necessary humidity and temperature control for a building. Differential pressure zones should be established within a building to ensure that the air flows from areas with less hazardous to areas with more hazardous contamination potential. A typical arrangement is to have the gloveboxes operating at approximately -0.5 inches of water pressure with a maintenance access corridor operating at -0.15 inches, the operational side of the glovebox operating at -0.1 inches, normal access corridors operating at -0.05 inches, and the uncontrolled side of the building operating at zero differential or atmospheric pressure (see Figure 5.1). 


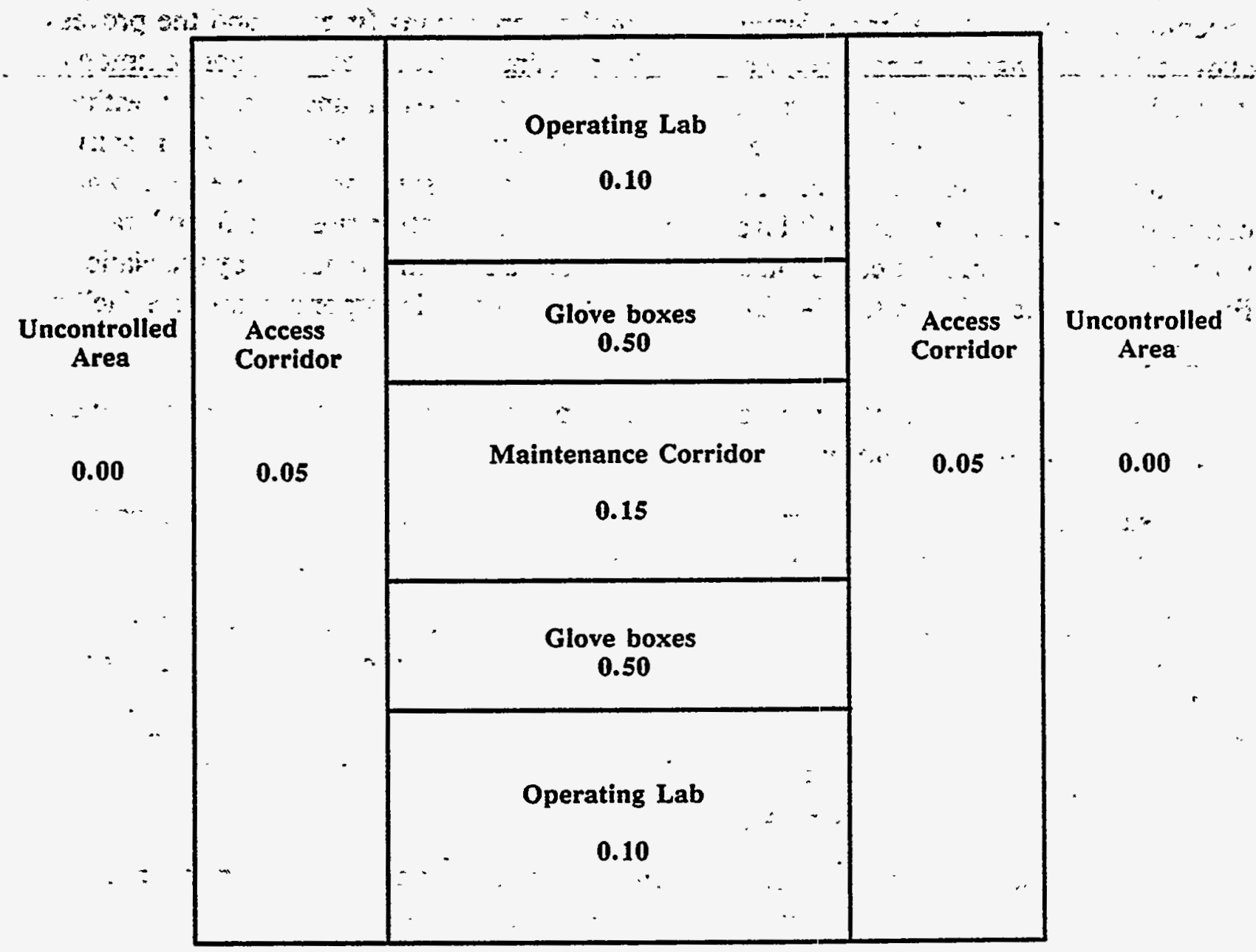

NOTE: All pressures refer to atmospheric pressure and are expressed in inches of water column negative pressure.

Figure 5.1 - Pressure differentials for a tritium facility.

Some facilities are designed for series air flow between the uncontrolled side and the next lower pressure zone. All air should be filtered and single pass; potentially contaminated air should not be recycled. The radiation control area should have a minimum of 10 air changes per hour, although the number of air changes may be reduced if the heat load and other factors permit. Humidity is generally controlled to less than $50 \%$ relative humidity, and the temperature is determined by the specific process equipment. The thermal stability required, which is related to manufacturing needs, is usually in the range of $\pm 2^{\circ} \mathrm{F}$. The amount of air flow exhausted through a fumehood has been a point of contention for years. Most sites require a linear velocity of 100 to $200 \mathrm{ft} / \mathrm{min}$ for a typical hood opening. Velocity should be determined by the specific requirements of a facility. 
The tritium concentration within a room is usually measured by one or more room monitors. Monitors are recommended on the main exhaust duct and on all branches. Monitors are necessary on the exhaust air stream to account for all tritium released to the environment.

Fire dampers are normally required on all supply ducts because they penetrate fire walls. (For more information, see NFPA Publication 90A [5.5].) However, exhaust ducts have been installed without fire dampers to guarantee that any smoke generated by a fire could be removed from the rooms and that room pressure differentials could be maintained. Some facilities have sprinklers inside the exhaust ducts at the fire wall to cool the air flow during a fire. Mist eliminators may be required to preclude filter plugging if there is a filter bank. In addition, room exhaust must continue during a loss of primary power. Therefore, exhaust fans are sometimes connected to an emergency power source that will take over if the primary source fails. In special situations, emergency power may also be needed for supply fans.

\subsubsection{Electrical System}

A reliable electrical supply is important to ensure critical systems run uninterrupted under both normal and emergency conditions. Normal power needs should be met by two independent primary feeders. The preferred primary feeder provides basic service to the building, whereas an alternate primary feeder provides backup to the preferred primary feeder.

If normal power fails, emergency power should be provided to the facility from a reliable local source. The source should be a turbine or diesel generator with automatic starting and switchover equipment. Even with an emergency generator, a continuous supply of electrical power should not be assumed. All electrical equipment should be designed to go into a safe mode if the power fails (fail-safe). An uninterruptible power supply may be required for computers, tritium monitors, and other critical systems in the facility.

The lighting for the facility should meet DOE Order 6430.1 guidelines [5.3]. Switches should be installed on the lights in the glovebox rooms to permit dimming of the lights outside the gloveboxes. This will improve viewing for personnel working inside the gloveboxes with the glovebox lights activated.

\subsubsection{Fire Protection}

In most facilities, automatic sprinkler systems should be of wet-pipe, ordinary hazard design and installed in accordance with NFPA Publication 13 [5.6]. Special provisions should be made to collect released sprinkler water in holding tanks until the water can be evaluated for possible tritium contamination. A location should be selected within the radiation control area for a sump collection pit, and a pump equipped with above-ground piping should be used to move the potentially contaminated water into the holding tanks. Operating areas should be sealed at the perimeter walls and should be designed with raised thresholds at doors to contain the water and drain it into the sump pits. The amount of water 
requiring storage will depend on the individual site and individual facility design. If buildings have properly sized compartments, a quick fire response group, and a low level of combustible material, that can be serviced with a 10,000-gallon storage capacity.

\subsubsection{Cooling Water}

Cooling within the glovebox systems and equipment is normally required for pumps and other heat-generating systems. A water recirculating system is necessary for this, and several factors should be considered when implementing such a system. The water must be isolated from the general plant cooling system. If plant cooling such as brine is used, the brine should be sent through an isolation heat exchanger, to prevent cross-contamination of the brine with the water loop that goes to the gloveboxes. Any leakage from either the brine or the water loop should be to the outside of the heat exchanger and not into the other stream. The water loop that goes to the gloveboxes and equipment should have a limited volume. Water sensors can be provided on glovebox floors to detect any leaks and to shut off the flow to the box when leaking occurs. However, no automatic water makeup system should be provided for the glovebox loop. This loop should be designed with the assumption that it will, in all probability, become slightly contaminated over the life of the facility. The glovebox loop and heat exchanger should reside within the radiation control area, and the cooling water should be monitored periodically for tritium.

\subsubsection{Breathing_Air}

All major tritium facilities require breathing air systems for bubble suits. These suits are used during maintenance and emergency situations. Gas bottles, tube trailers, or reliable oil-free pumps should provide the breathing air, which must meet accepted breathing air requirements $[5.7,5.9]$. No contaminants, such as carbon monoxide, organics, or dirt, are allowed, and the air should be dried to help keep personnel cool.

Supply stations for bubble suits should be strategically located throughout the radiation controlled side of the facility in corridors adjacent to the glovebox areas. These supply stations should contain pressure regulators, flow meters, valves, pressure gauges, filters, a water removal trap, and quick-connects that are for bubble suits only. (An alternate method is to have flow meters on the air supply hoses themselves.) A provision should be made to provide air supply hoses with quick-connect fittings in both the corridor and the operating areas. Routing hoses through partly open doors should be avoided. Stations should be located so hose lengths do not exceed 100 feet; the best length is 50 feet or less. .

\subsubsection{Process Gases}

Most tritium facilities require numerous process support gases including compressed air, nitrogen, argon, helium, and counting gases. The manifolds for these gases should be taid out to allow their use throughout the building. Care must be exercised when installing these gas lines to gloveboxes to ensure no backflow occurs and to prevent cross-connections that 
could cause either radioactive or nonradioactive gas contamination. Flow-limiting devices or orifices are recommended for any gases going into gloveboxes.

Hazardous gases, such as hydrogen, oxygen, and combustible organics, should be handled with special care, should be used only where necessary, and ordinarily should not be part of a general gas manifold system. Instead, supplies of the hazardous gases should be kept adjacent to areas where they are used. These gases should be kept in ventilated storage coffins, and jacketed lines are preferred when the gases are outside the fumehoods or gloveboxes.

Overpressure protection should always be provided for all gas lines in accordance with ANSI-B31.1 [5.10]. All pressure relief devices, especially those that might be contaminated, should be vented to a safe location. Valve operators, and other gas-operated equipment inside gloveboxes, should be activated with the same gas that provides the glovebox atmosphere and should be vented with the same care. This minimizes the contamination of the glovebox atmosphere.

\subsection{Special Systems}

\subsubsection{Primary Tritium Handline Systems}

\subsubsection{Design Principle}

One underlying principle of general design seems appropriate to the design of tritium facilities: a simple, straightforward design will greatly enhance the probability of having a successful operation. For example, using a glovebox to contain valves, pumps and other components is preferable to using separate containers to adequately double contain individual components because of the added complexity of the design. Simpler designs result in a more leak-tight system, less maintenance, and, ultimately, lower equipment costs. Although safety considerations sometimes prohibit using simple systems, they are preferable when there is a choice.

\subsubsection{Piping Systems}

The process piping system is the primary containment system for tritium. Therefore, it demands careful attention to design and installation. The ideal system is all metal that is compatible with hydrogen and contains nothing that is susceptible to hydrogen embrittlement or radiation damage. The recommended construction material for most systems is austenitic stainless steel, typically 304 or 316 , with a low carbon content. However, copper and aluminum have also been used successfully for low pressure systems.

Preconstruction cleaning or treating of piping system components is important to maintaining product purity. Tubing used in the system should be cleaned or treated by a method that will achieve a surface reduction (reduced roughness) inside the tubing of at least $90 \%$. The piping and tubing should be welded together to eliminate any virtual leak at 
the joint. For valves, pumps, and other major equipment items that require disassembly of joints, engineered couplings with demountable metal gasket seals are recommended. Pipe-threaded joints should be avoided. The best valves to use are packless (metal diaphragm or bellows) with metal stems and valve seats for manually operated valves. Torque limiting handles should be used on manual valves whenever possible to avoid damaging valve seats. Some sites prefer to use double valves on all major components. Experience has shown that for reliability, valves and fittings should be disassembled when possible, cleaned, reassembled, function-tested, and leak-tested at operating pressures before being installed in the system. Vendors typically do not test valves for helium leaks at operating pressures, nor do they cycle valves before testing.

\subsubsection{Pressure Protection}

Systems that handle tritium, and those in which integrity must be ensured, should be conservatively designed and tested for helium leaks. Tanks are typically fabricated according to ASME Boiler and Pressure Vessel Code, Section VIII, Divisions 1 and 2. The helium leak tests should be performed at a pressure that corresponds to the maximum allowable operating pressure (MAOP) of the system. This term should not be confused with maximum allowable working pressure (MAWP), the design pressure for individual components. The need to create a new pressure level, the MAOP, for low pressure tritium systems arises because typical components are capable of safely handling pressures far in excess of those that will be routinely encountered. This safety margin does not result from ultraconservative engineering design, but rather from the availability of commercial components, the ease of fabrication, and the use of components that have been recommended for tritium handling.

A typical example of these practical considerations is a tank with an MAWP of $400 \mathrm{psi}$, but which will be routinely operated at a normal operating pressure (NOP) of only $75 \mathrm{psi}$. It is not advisable to expose personnel to the unwarranted risk of leak testing at the MAWP when systems will not be operated near these levels. Components, such as vessels, should be hydrostatically tested at $150 \%$ of the MAWP.

Other considerations should be the need to test the system for helium leaks with rupture disks in place and also the need to leak test various components within the system that have different pressure ratings. Tritium systems should be designed with rupture disk protection. These disks are constructed to be leak-tight under normal operating conditions; whereas, relief valves have been found unacceptable because tritium leaks occur through the valve seat seals. Experience has shown that, if normal operating conditions routinely approach the limits of the rupture disc, "flexing" will cause unacceptable leakage or failure. Table 5.1 illustrates the various pressures for a typical tank used in a tritium facility with an NOP of 75 psi.

For higher pressures and larger tanks, the systems would not be so conservatively designed, but the same principles should be used. Rupture disks should be vented to a secondary, 
evacuated, catch tank that is also protected with rupture-disks and is designed to accept the maximum potential volume release. This will allow the recovery of lost tritium from the catch tank. The disk of this catch tank should vent to the normal tritium capture system. A relief valve installed downstream of the catch tank rupture disk will prevent a major loss of tritium if the pressure only slightly exceeds the rupture disk relief value.

Table 5.1 - Pressures for a Typical Tank

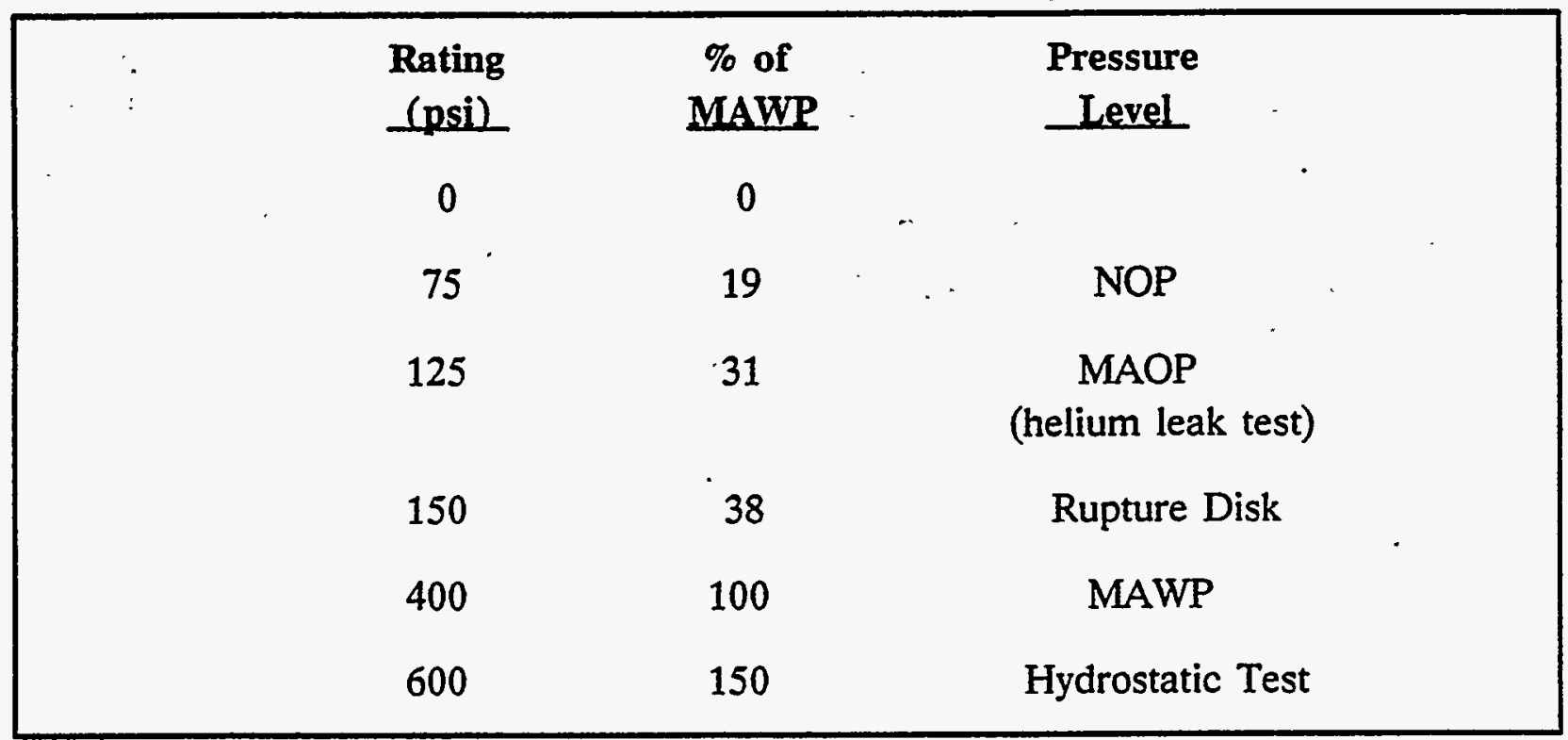

\subsubsection{Gas Movers}

Many different means of pumping tritium are used. Metal hydride beds can be used both as pumps and as storage units. Tritium pumps ideally should have no moving seals and no liquid or organic lubricants or seals, but should have positive displacement, reliability, convenience, and the ability to pump from the low millitorr range to over $30 \mathrm{kpsi}$. However, no available pump has all these characteristics. Commonly used pumps include rotary vane pumps with magnetic drive and low vapor polyphenylether oil, metal diaphragm pumps, metal bellows pumps, scroll pumps, mercury displacement pumps, cryogenic compression pumps, magnetically suspended turbomolecular pumps and molecular drag pumps. The latest development work on pumps should be researched before selecting a tritium pump for low-pressure work. High pressure applications typically utilize oil-driven diaphram compressors, with triple diaphram containment. Hydride based "pumps" can also be used to generate pressures as high as 1000 atmospheres.

For applications where avoiding oil contamination is critical, "dry" rotary pumps (multistage roots or claw pumps) are recommended. - Direct-drive or belt-drive, 'rotary, vane vacuum pumps are often recommended for general purpose, rough vacuum support for tritium systems in the small volume range (less than $20 \mathrm{ft} 3 /$ min displacement). The vacuum pump should exhaust to the tritium capture system. A system can be designed to feed fresh oil from outside the glovebox to the vacuum pumps for periodic oil changes. -The 
used oil then goes to a receiver tank and finally into a piping system that holds spent oil. Directly transferring oil from the spent oil tank inside the glovebox to a waste drum outside the glovebox has proved to be an efficient and safe way to dispose of waste oil. For systems in which the vacuum pump can pump directly on a tritium tank, a pressure switch and automatic valve that will close if a set pressure is exceeded should be used on the pump inlet. An alarm and a manual override for handling any expected higher pressures are usually included.

\subsubsection{Gas Storage}

Two methods are commonly used for storing elemental tritium: as a gas in tanks and as a solid as a tritide. Tritium can also be stored as a liquid or solid, but this requires significant refrigeration and has inherent safety disadvantages. It can also be stored as tritium in water or other suitable compounds or chemical forms. Although possible, these methods are not commonly used because of the greatly increased radiological hazards introduced by these chemical forms of tritium.

Bulk storage tanks are the most common and easiest to design storage units. Working pressures near atmospheric pressure are the most common although some high-pressure applications exist. Any secondary containment system should be designed to withstand a total failure of the primary containment system.

Hydride storage of elemental tritium gas is also common. Several hydrides are available for this use, with uranium hydride as the most common. In a 2-L volume at room temperature with an overpressure (dissociation pressure) of less than 1 torr, $1000 \mathrm{~L}$ (STP) of hydrogen can be stored as uranium trihydride powder. The hydrogen can be released easily by heating the uranium hydride to $400^{\circ} \mathrm{C}$ for 1-atm dissociation pressure. Higher temperatures are required if higher pressures are needed. Temperatures above $700^{\circ} \mathrm{C}$ should be avoided because of iron/uranium interactions that can result in catastrophic failure of the primary container.

Many other metals and alloys form hydrides with different storage characteristics. Hydrogen-to-metal ratios and dissociation pressure-to-temperature relationships are of special design interest. Some other metals of interest for storing tritium include palladium, titanium, and alloys of lanthanum-nickel.

\subsubsection{Maintenance}

The inspection and maintenance of the primary tritium-containing system must be considered during the design phase. If the primary system is to be secondarily contained, provisions should be made in the design to allow it to be inspected and maintained without breaching the secondary containment system. The most common way is to build the primary system so that it can be disassembled through the gloves of the secondary system. The resulting pieces should then be small enough to fit through the passbox or another exit. 
The parts of the primary system most susceptible to failure should be easily replaceable without breaching the secondary containment.

It is important to determine what tools will be used in the glovebox, especially for items needing frequent maintenance. A set of these tools should remain in the glovebox. The number of tools should be minimized by using as many common parts as possible. For those parts of the primary containment system that are too large to dismantle and remove without breaching the secondary system, an alternative method must be developed. This often involves temporarily enlarging the secondary boundary. If the secondary containment system is a glovebox, it can be enlarged by building a plastic "tent" around the glovebox. This tent must be ventilated to an appropriate tritium capture system and held at a pressure negative to the room. With this tent in place, sections of the secondary system can be removed, allowing access to the primary systems. Before the primary or secondary tritium containment system is breached, all tritium should be pumped to another system and isolated from the area to be breached. After removal of the tritium, the system to be breached should be placed under vacuum or purged to a capture system.

\subsubsection{Instrumentation}

The instrumentation necessary for tritium systems requires state-of-the-art technology if high accuracy, high resolution, and stability of the final displayed readings are required. Sensors and transducers located inside the glovebox should be of high quality construction and, typically, made of 316 or $316 \mathrm{~L}$ stainless steel to avoid material problems. Resistance temperature devices (RTDs) are most often used for high-accuracy temperature measurements with a four-wire hookup. Pressure measurements may require highly accurate strain gauge transducers with the 8- or 10-wire hookup technique. Temperature and pressure probes are available with metal gasket fittings to ensure the integrity of the primary containment system. The fittings are inert-gas welded to the sensors and tested for helium leaks to ensure there are no leaks greater than $10-9 \mathrm{STP}-\mathrm{cm} 3 / \mathrm{s}$ with a differential pressure of the MAOP.

All temperature controllers, especially those used for hydride bed heaters, should have a secondary controller that functions as a high-limit, on-off device. When the set point on the high-limit controller is exceeded, all power should be eliminated from the heater circuit. In addition, many hydride beds have fusible links as part of the heater circuit in the heated zone. This link is designed to fail and cut off power to the heater before the primary container fails.

Where practical, temperature and pressure sensors should be calibrated in place, thereby eliminating the need for removal from the glovebox. Stainless steel blocks welded into the glovebox wall with sensor wells inside and outside the glovebox have worked well for temperature :calibration. Pressure sensors can also be calibrated in place by providing the 
correct piping to a central calibration station inside or outside the glovebox. Extreme care should be taken when potentially contaminated lines are run outside the glovebox.

If in-place calibration is not possible, then sensors and transducers must be removed from the glovebox and calibrated in a facility capable of handling contaminated equipment. Hermetically sealed bulkhead connectors should be used for all power and signal cabling entering or exiting the glovebox. Using multiplexing techniques to reduce the amount of cabling may be beneficial for some applications.

To gather and control the data that these instruments generate, typically computers are used. Data acquisition and control (DA\&C) can be accomplished in a number of ways. Factors to be considered when selecting the primary data acquisition system include the following:

- The system should be designed with the user in mind and with regard to the available support. The user should be able to work with the system easily and efficiently, and adequate support should be available for both hardware maintenance and questions or problems regarding the software.

- Reliable hardware that adequately performs the required tasks should be selected. Factors such as computing or data acquisition speed, accuracy, memory, and mass storage requirements should be considered.

- The software required for a job varies according to the type of hardware and the nature of the application. A good rule of thumb is, whenever possible, to use software that is commercially available from the computer manufacturer or a third-party vendor. Developing software is usually not recommended because it is expensive, time-consuming, and requires considerable expertise.

- The software should be selected with the user in mind. For example, a system to be used by a chemical operator with limited prograrnming skills, should be a menu-driven software package that is user-friendly. A user with more advanced computer skills may want command-driven software or the option of programming in a higher level language such as BASIC, FORTRAN, or PASCAL.

- For larger tritium systems in which data from several different operations must be gathered and correlated, a distributed network is recommended. In such a network, the primary DA\&C system for each operation is a dedicated microprocessor capable of stand-alone operation. Each processor may be linked to other microprocessors and a host computer (minicomputer, super minicomputer, or mainframe) that provides supervisory functions. In this arrangement, the operation of individual processes depends only on its dedicated

: DA\&C system and is unaffected by failure of the host computer or other DA\&C

$\therefore \quad$ systems. The dedicated DA\&C systems should be selected according to the 
criteria discussed above, with the added stipulation that the communications hardware and software be available for networking.

- For ease of maintenance, as much of the instrumentation as possible should be located in an area that is unlikely to become contaminated.

\subsubsection{Glovebox Layout}

Gloveboxes provide excellent secondary containment, but the primary system must also perform its intended function. Therefore, it is important to lay out the equipment inside the glovebox carefully so it can be reached and seen when necessary. Typical maximum reach arcs are in the 20 to 22 in. range. Allowance must be made for reaching into pass-throughs and passboxes. A clear area should be left toward the front of the box to allow tools and material to pass down the boxline.

If a large quantity of material or equipment is to be routinely moved through the glovebox, a conveyor system should be considered. One of the better conveyors is a unit that has a moving belt riding directly on the work surface of the glovebox, which is about 36 inches high. The drive assembly is below the work surface in the glovebox well. With this design, items cannot fall off, but can still be transferred.

The maintenance reach, as well as routine operations, must be considered. For example, it may be necessary to reach an item with two hands to get wrenches on fittings and equipment. A good way to guarantee maintainability is to install the maintenance fittings through gloveports and then simulate arm reaches during construction. Another convenient approach is to make a plywood mock-up of gloveboxes and equipment to establish the layout.

Attention must be given to anchoring pieces of equipment and piping to meet the seismic criteria for the location. Rigorous analysis is usually not necessary, but some care is required. The same can be said for the equipment mounted on the outside of the gloveboxes. In most cases, anchoring items to the floor of the room or to the glovebox will be sufficient to meet the requirements, but large or heavy items may need special attention. Measurement equipment, such as electronic scales, may require grouting, marble tables, or heavy decks. For gloveboxes connected by primary and secondary piping, some flexibility must be provided.

\subsubsection{Secondary Protection}

\subsubsection{Strategy}

True secondary containment systems are able to completely contain all tritium that escapes from the primary containment system. The two most common methods are to enclose the primary system in a fumehood or to enclose it in a glovebox. Either can be designed to 
protect the operating personnel. The difference between the two methods lies in their ability to prevent tritium from reaching the environment. In general, gloveboxes are efficient at protecting both the operating personnel and the environment [5.11]. In a typical fumehood, any tritium released from the primary system is released to the environment. If the amount of tritium being handled is small enough that its release to the environment is acceptable, fumehood containment may be appropriate. Each site must decide what constitutes an acceptable tritium release based on its individual features.

During the design of the secondary containment system, it is important to avoid the possibility that both the primary and secondary containment systems will fail simultaneously. The most common error is constructing a secondary system that cannot withstand the pressure generated by a primary containment failure. A common example is a glove box that has insufficient passive relief capacity to deal with a large leak from the primary system.

The form of the tritium (elemental or oxide) must also be considered. The oxide (HTO) is more than 10,000 times more hazardous than the elemental form; therefore, the design of secondary containment should reflect this. In addition, HTO permeates gloves 10 to 100 times faster than elemental tritium. To counteract these properties of the oxide, it may be necessary to dry the glovebox atmosphere to reduce the HTO concentration. It may also be necessary to minimize the operator's time in gloves, use double-ventilated gloves, or use ventilated gloveport covers. When some or all of these precautions are taken, high concentrations of tritiated water can be handled safely in the gloveboxes.

\subsubsection{Gloveboxes}

The primary focus of the secondary confinement approach is the glovebox. The necessary integrity must be designed into the glovebox if it is to function as intended over the life of the facility. Most gloveboxes for handling tritium are fabricated out of stainless steel ( 304 is the most common) with enough rigidity (7- to 11-gauge thickness) to provide good surfaces for sealing gaskets. The metal surface should be smooth (2B mill finish) with no pockets that could trap material and hinder decontamination. Gloveboxes fabricated from weldable aluminum alloys have also be used successfully and may have advantages over stainless steel in some applications.

Some facilities use welding wherever possible in glovebox fabrication, then $x$-ray the welds to ensure their quality. Other sites use a weld sample standard to establish weld quality and technique. The most common window material is laminated safety plate glass, usually $3 / 8$ to $1 / 2$ inches thick, sealed to the box with rubber channel gaskets. These gaskets are often made of silicone rubber. Lexan has also been used successfully as window material and may be preferable in some applications where glass may crack. Electrical and electronic feed-throughs are hermetically sealed and gasket-mounted. Smooth, sturdy gloveports that allow the user to change gloves are mounted on either the metal or the glass area of the glovebox. Enough gloveports must be provided to accommodate the maintenance and 
functional requirements of the layout. Seismic anchors should be provided to anchor the glovebox to the floor or a reinforced wall.

A flange or metal surface can be provided where a plastic tent can be taped to the box for performing maintenance inside the box. Tents are normally required when a large item is removed from the box or when maintenance cannot be performed through the gloves. If pumps or other heat-producing items are to be housed inside the box, a temperature-controlling heat exchanger may be needed. Gloves for the box should be selected for the specific application while keeping in mind ruggedness and resistance to permeability by hydrogen and water.

The ultimate requirement is for the box to be helium leak tight. Boxes have been constructed that were helium leak tight with probe detection levels less than $10-6 \mathrm{STP} \mathrm{cm} 3 / \mathrm{s}$. It is common practice to leak test the boxes at the fabricator's plant and again after all equipment has been installed inside the gloveboxes at the permanent location.

Routine entry/exit passboxes should be provided where frequent movement of material is required. If an inert atmosphere is used in the glovebox, then a flushable passbox with an evacuation/fill cycle should be used (see Figure 5.2). Doors to the passbox should be as tight as the glovebox. The doors should exit into a fumehood that can act as a contamination control device for items exiting the glovebox. In areas where no routine material movement is required, a trash/maintenance port is usually acceptable. Materials sealed in a plastic bag can be moved into or out of the glovebox through the port.

\subsubsection{Transfer Lines}

There will be occasions when the system design requires the flow of tritium from one glovebox to another that is not immediately adjacent. In that case, a transfer line between gloveboxes is required. The line should be secondarily contained and should have the same integrity as the glovebox. One way to accomplish this safely is to install an inside stainless steel line that is continuous through the glovebox wall with connections to the tritium systems inside the boxes on both ends. An outside stainless steel jacket line should be provided over the inside line and should terminate at the glovebox wall. All welds in both the primary line and the outside jacket should be helium leak tested. The annular space between the two lines can be seal-welded inside the gloveboxes, and an instrument to monitor either pressure or vacuum can be installed in one box. This works well for low-pressure transfers, but for higher pressures, a rupture disk may be required to vent a leak to a safe catch tank. For installations where independent motion of separated gloveboxes is possible during seismic events, a system using flexible piping and secondary conduit may be preferable. 


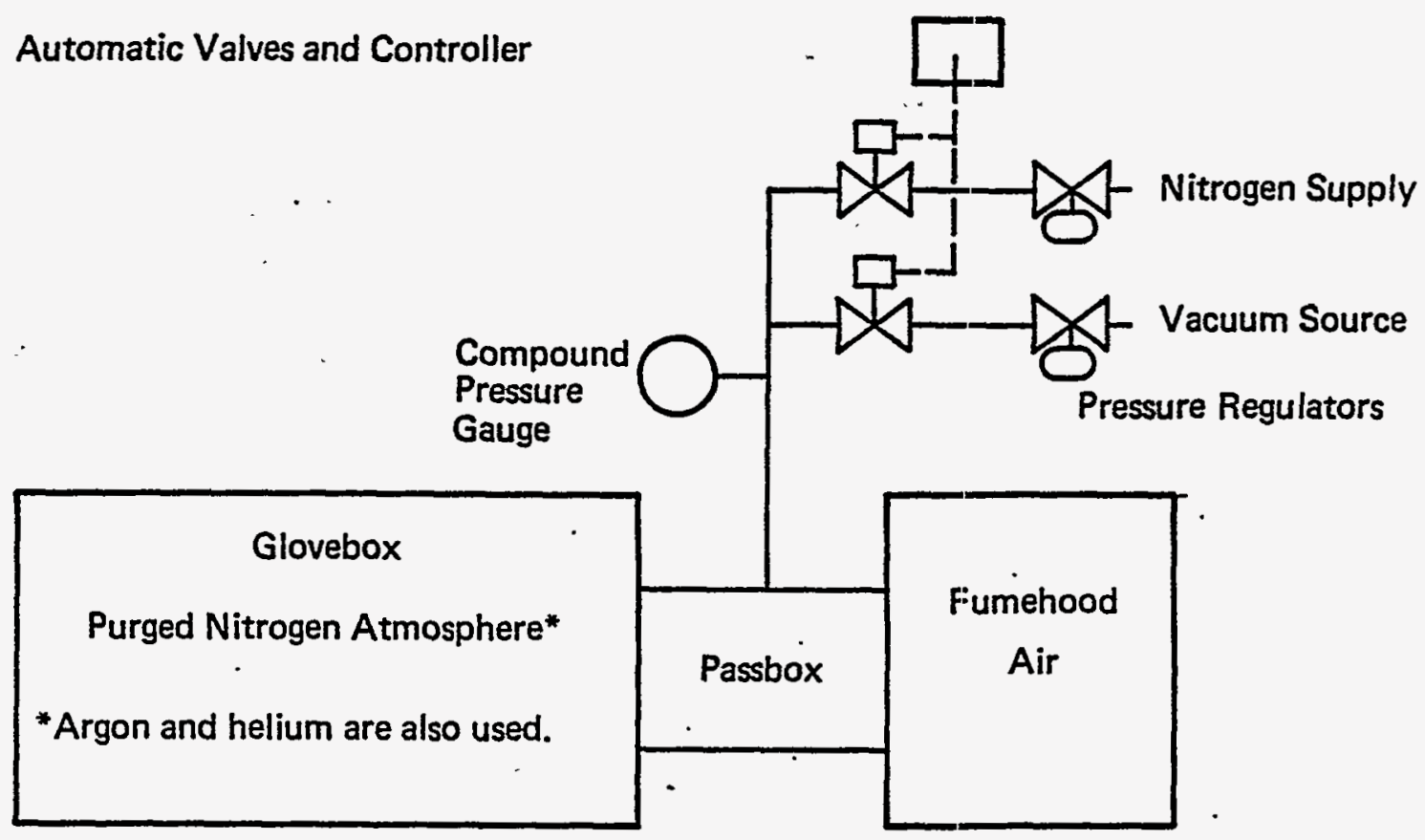

Figure 5.2 - Glovebox, passbox, and fumehood exit.

\subsubsection{Special Secondary Containment Systems}

Although gloveboxes are the most commonly used form of secondary tritium containment, other methods are available. The most important design goal of any secondary system should be the complete containment of any tritium that escapes the primary system. Other design goals include being able to monitor the quantity of tritium that escapes to the secondary containment system and being able to remove it (i.e., clean it up).

After the glovebox, the most commonly used secondary design, is the doubly contained tank. This is actually a tank inside of a tank that has been designed to properly contain any inlet or outlet lines. The secondary tank is designed to withstand the release of the maximum possible gas load in the primary tank. Normally, the annular space between the tanks is evacuated, monitored, and alarmed for a pressure rise. The secondary tank usually has a removable port to allow access to the primary tank, including pressure and temperature transducers.

A vacuum dewar can also be used as secondary containment for cryogenic processes. As with the doubly contained tank, the annular space is evacuated, monitored, and alarmed. The dewar is usually removable to allow access to the cryogenic process. However, care must be taken prior to removing the secondary tank port or dewar to ensure no tritium has collected between the primary and secondary containment systems. 


\subsubsection{Purge Systems}

An excellent way to maintain the atmosphere inside the secondary containment or the glovebox system is with a purge system that uses inert gas: nitrogen, argon, helium, etc. Typically, a $0.1-\mathrm{ft} 3 / \mathrm{min}$ flow of gas is swept through the secondary containment system, which is maintained at -0.5 inch of water pressure. The continuous purge of gas removes any tritium that may leak into the box and provides a sample for a tritium monitor to detect any leakage. The discharged gas is sent to a tritium capture system. In addition, the purge system's controls are designed so that gloveboxes cannot be overpressurized or underpressurized. If the monitor detects a high concentration of tritium, a higher purge rate (10 $\mathrm{ft} 3 / \mathrm{min}$ ) can be activated to reduce residence time by a factor of 100 .

It should be noted that nitrogen is not truly inert and reacts with tritium to form ammonia. This ammonia formation is most likely to occur as a result of nitrogen leaking into the process from the secondary containment system. The implications of ammonia formation in the process are discussed in Sections D.3 and E.4.4.

Figure 5.3 shows the typical equipment in a purge system. The system includes flowmeters for flow control, regulators for pressure control, and differential pressure switches for pressure measurements inside the gloveboxes. If the pressure does not fall within preset ranges, the pressure switches shut off either the source (pressure) or vacuum (exhaust), depending on which out-of-range condition exists.

The purge control system should be backed up by a bubbler system. A bubbler system is a passive, two-chambered device that will vent pressure or vacuum as a last resort to protect the glovebox from structural failure (Figure 5.4). One way to size bubblers is to establish a maximum flow rating of about $60 \mathrm{ft} 3 / \mathrm{min}$ per bubbler. A typical system has 2-inch copper lines from the glovebox through the bubbler to the stack exhaust duct. The total pressure drop from the box to the stack varies with the length of the line, level of vacuum pump oil in the bubbler, and stack exhaust pressure. This pressure drop should be approximately 5 inches of water with 3 inches of oil in the bubbler and a $60 \mathrm{ft} 3 / \mathrm{min}$. flow through a 2-inch diameter line. The oil level in the bubbler can be adjusted to reduce the pressure in the glovebox to the desired level. Valves in the bubbler line should be avoided. Although vacuum pump oil is generally used in bubblers, other fluids such as glycol are acceptable.

As mentioned in Section 5.2.3.6, flow-limiting devices are recommended for any gas or vacuum source entering the glovebox. Any sum of these sources, gases or vacuum, should not exceed the flow capability, positive or negative, of the passive relief for a particular glovebox. A tritium capture system for the bubbler exhaust lines should be considered if there is enough tritium in the glovebox to exceed the overpressure capability of the glovebox. Care must be exercised in designing this capture system to ensure the bubblers still function properly. 


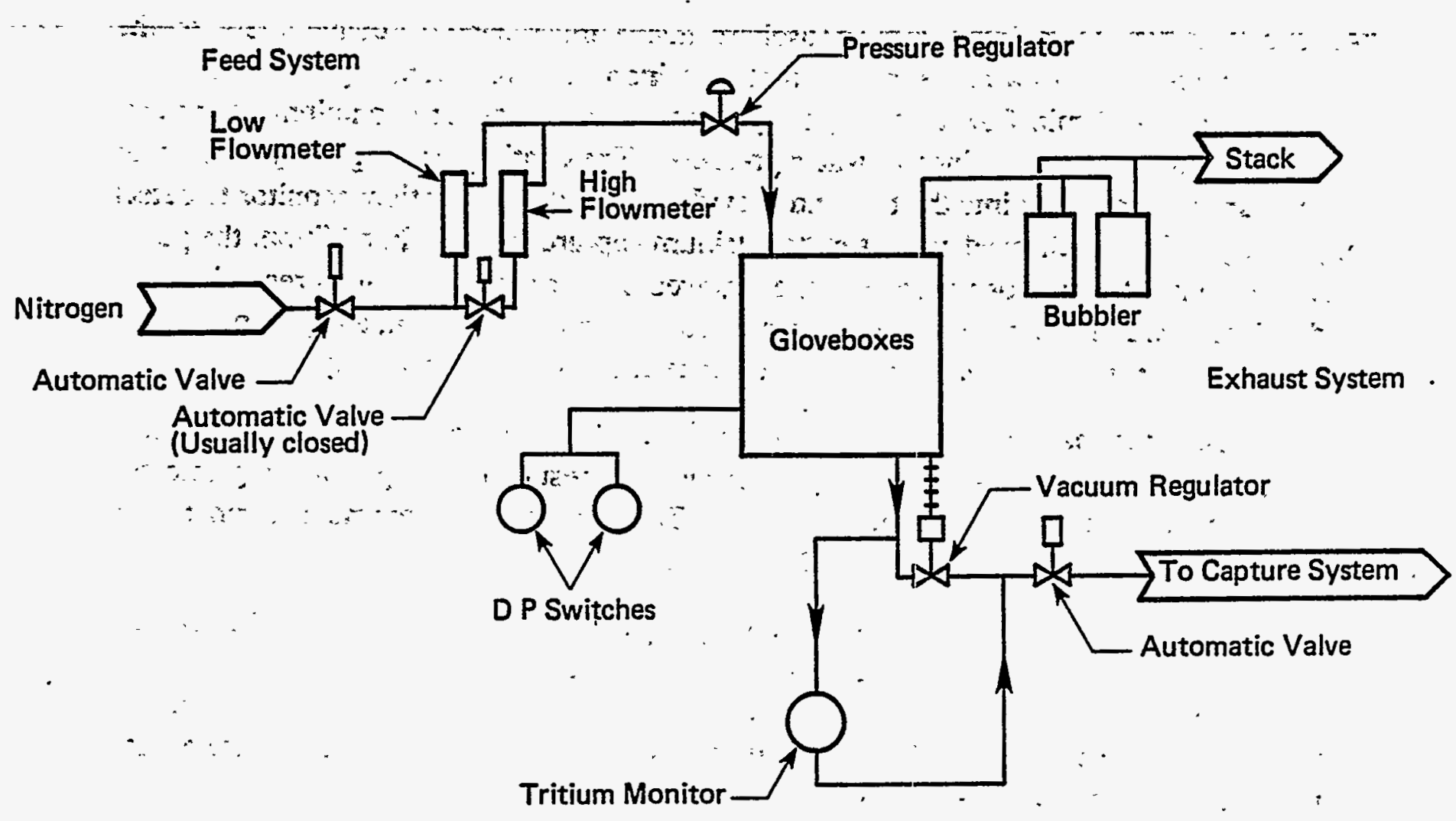

Figure 5.3 - Purge system for a secondary containment system.:

\subsubsection{Secondary Cleanup Systems}

No matter how good the primary containment system is, there will be leaks or releases to the secondary containment system. Therefore, at times it will be necessary to remove tritium from the space between the primary and the secondary systems. Tritium can be removed by moving gas (e.g., Nitrogen, Argon, Helium, or air) through the secondary space to a tritium removal system. This can be done with a once-through purge, a closed recirculation loop, or some coimbination of the two. In all three cases, the most commonly used process, first oxidizes any hydrogen in the gas, including tritium, to water, and then dries the gas. The tritiated water is then collected for further processing or disposal. For a once-through purge, the detritiated dry gas is released into the atmosphere. If a closed recirculation loop is used, the detritiated dry gas is recirculated into the secondary system. The third option is to purge the secondary containment directly to the stack when the tritium concentration is low, or directly to the tritium removal system when the concentration is high. This method, which is the least desirable, must be carefully designed. It requires a fast, reliable tritium monitor and a primary process that releases tritium slowly; i.e., it cannot be a high-pressure process. 


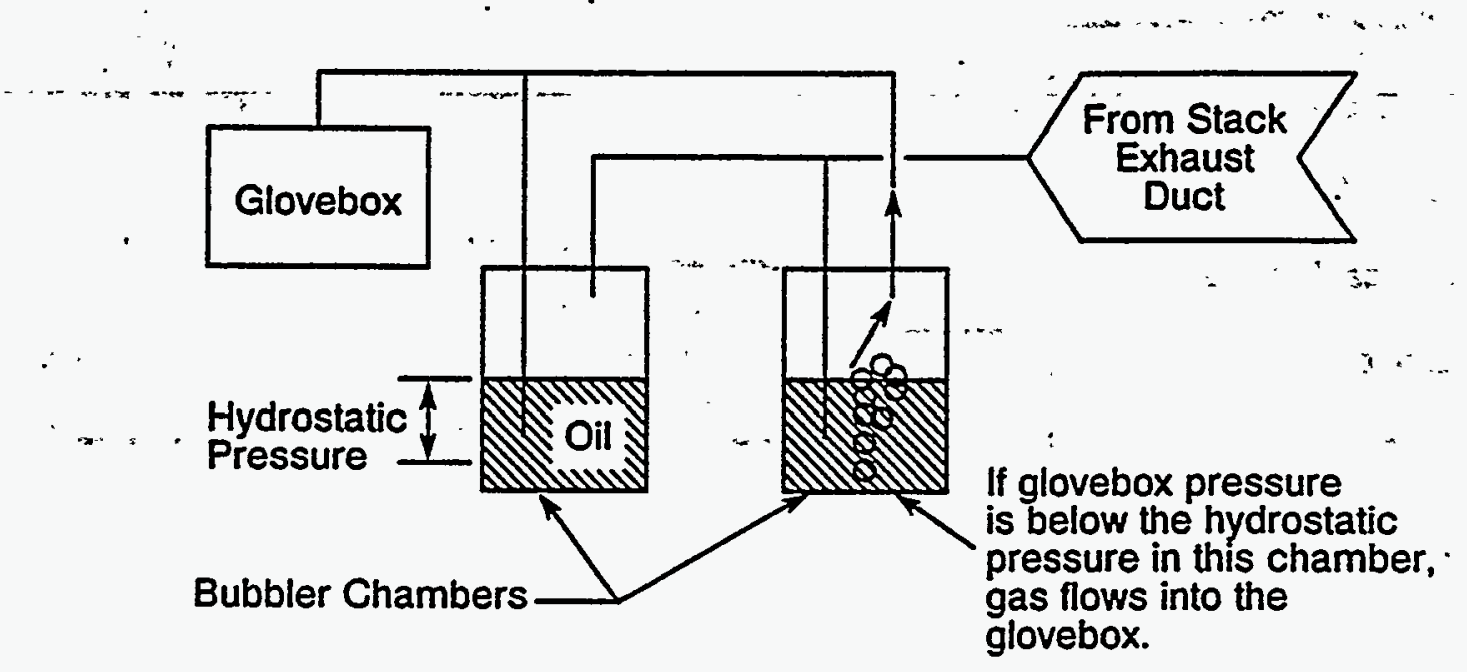

Bubbler Operation with Glovebox Pressure High

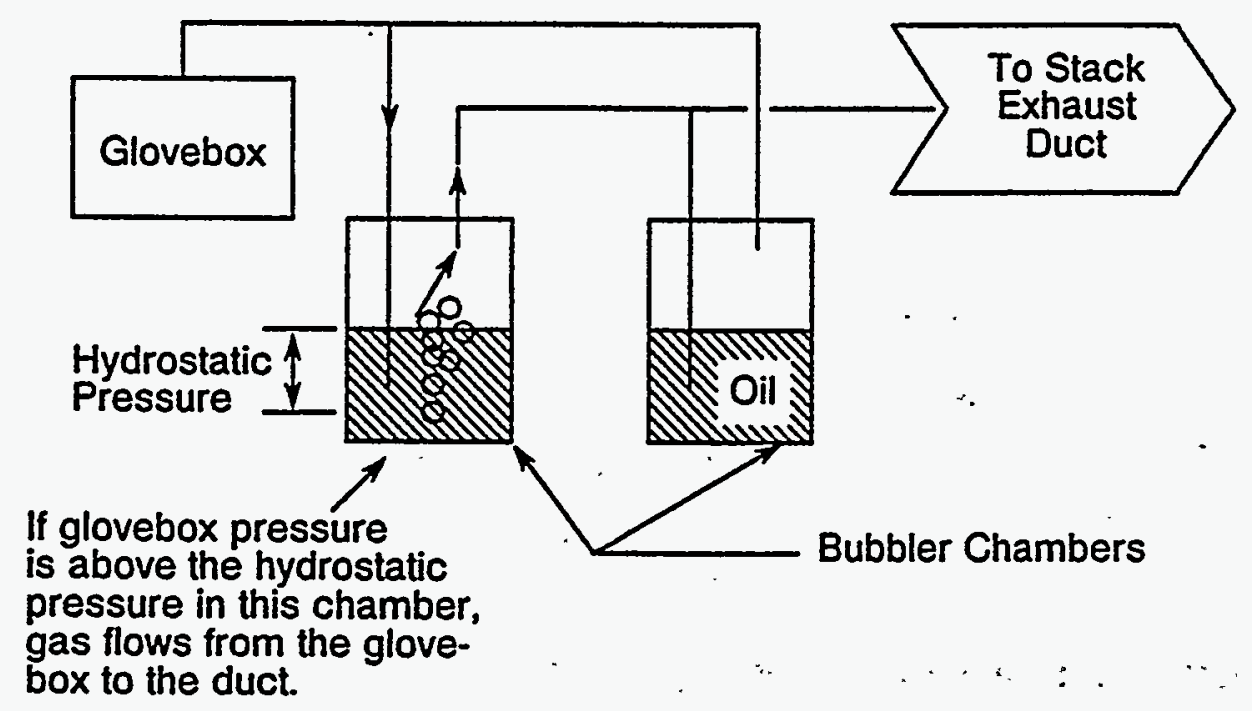

Figure 5.4 - Boxline passive relief system (bubbler).

The tritium removal system can be either dedicated to a single secondary system or common to several secondary systems. A dedicated system can be designed with oxygen and/or water removal to provide an inert boxline atmosphere when desired. The advantage of a common system is that flexibility, redundancy; and spare capacity can be built in more easily (see Figure 5.5). 


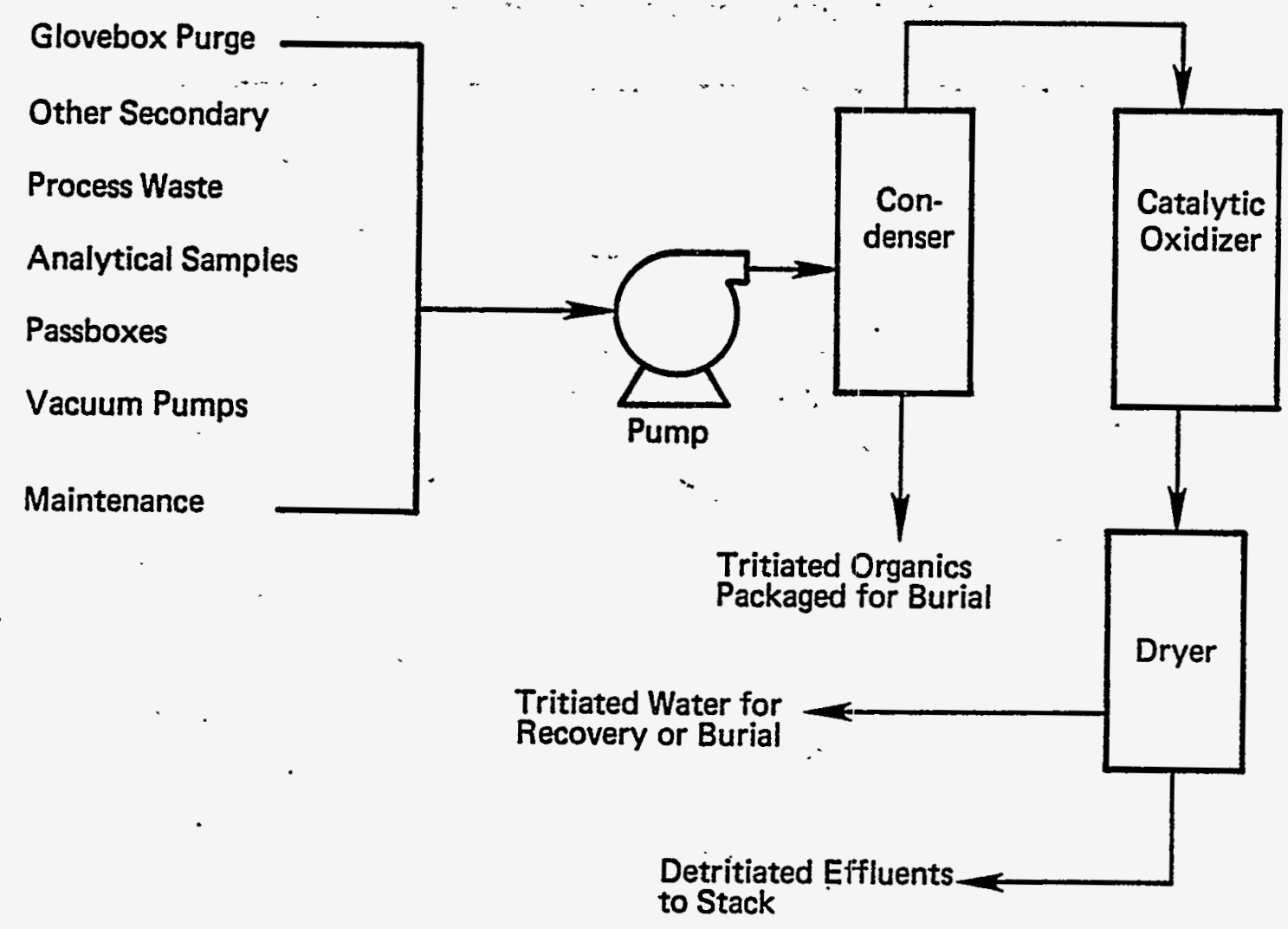

Figure 5.5 - Secondary cleanup system.

\subsubsection{Room Containment}

It is possible to contain tritium within one room. To accomplish this, the room must be relatively leak tight and must be ventilated to a tritium cleanup system. This cleanup system can be "on" continuously or activated only during a tritium release. The efficiency of this method depends on the leak tightness of the room and the size of the room cleanup system. Room containment can be either secondary or tertiary containment.

\subsection{Quality Control}

Quality control is one of the most important aspects of a successful tritium facility. It must begin at the design stage and continue through construction and completion. It is important to have experienced and qualified engineers reviewing the design as well as creating it. It is also important to seek input from personnel with appropriate operating experience during all stages of facility design and checkout. This ensures the system will function as designed, and mistakes in concepts are caught in the early stages of the project.

Care should be exercised in generating the specifications for the facility. These must be clearly written, must be easy to follow, and must permit inspection for compliance. The 
designer should ensure all important points are thoroughly covered, and necessary specifications can be met. It is much easier and less expensive to correct problems at the writing stage than in the field.

The potential for a quality facility begins at the design phase and extends throughout construction. Providing a clean work area for craftsmen and issuing white gloves and white sheets on work area benches are just two of many ways to emphasize that a tritium system should be cleanly assembled. Where practical, the craftsmen should have the same equipment to check their work as the inspector will use following the operation to catch mistakes.

Quality should be built into the facility from the start. A major factor in ensuring quality is hiring competent, conscientious employees. Inspectors should be qualified and knowledgeable in the areas they are inspecting. For critical tritium-handling systems, a successful method has been to permit the design engineer to perform the field inspections. In all cases, the decision should be made before inspections are begun as to whose approval is needed to make an exception to the specifications in each area. For example, an engineer may approve one kind of exception, while the general manager of the facility might have to approve another kind.

\subsection{Quality Assurance}

A quality assurance plan should be established to ensure tritium facilities meet the objectives and requirements outlined in DOE Order 5700.6B [5.12]. Provisions of this plan should apply to the quality control activities required in site selection, design, construction, procurement, and installation of equipment and facilities. Documentation and peer review of these activities are required to ensure the quality of the project. Timely audits should be conducted to check and verify this documentation.

Quality assurance and quality control are two areas where there is no optimum stopping place. Because resources are limited, there must be a willingness to stop at some point where the returns appear to be diminishing.

\subsection{Emergency Signals}

If a critical system or service is functioning outside its normal operating range, the appropriate individuals must be notified so corrective actions can be taken. This requires that alarms, such as flashing lights, bells, and buzzers, function in the work area during normal operations. In addition, a plan should be established to notify the appropriate persons promptly if an accident occurs during off-hours or weekends. What to include, who to call, and required actions are specific to each site. However, tritium monitors for rooms, stacks, gloveboxés, and cooling water systems are often alarmed. Special gases, effluent removal systems, electric power, ventilation air flows, critical temperatures and pressures, and jacket pressures for the tritium transfer lines are often monitored. The processes to be 
monitored should be those that could negatively affect personnel, the environment, the process, and/or the product, if normal operating ranges are exceeded.

\subsection{Decontamination}

The design of a tritium facility should provide for a controlled area where items can be decontaminated. The type and extent of equipment needed varies with the process. Two items normally included in a tritium facility are fumehoods, with water and/or steam for cleaning, and a water collection and control system. The water system minimizes the amount of water used and ensures it is collected and controlled in a manner that will allow further processing or disposal.

\subsection{Security}

The security of a facility must be considered in its design. Not only must the processes be secure, but also materials, products, and any computer that handles classified data and information. Security requirements can have a major impact on equipment and total costs.

\subsection{Accountability}

Material accountability must also be considered when designing a tritium facility. Equipment that allows inventory of the tritium at regular intervals is essential. Furthermore, the ability to calibrate tank volumes and pressure- and temperature-measuring devices, as well as the ability to measure tritium concentrations, must be built into the process. For more information on measurement and accountability, see Appendix D.

\subsection{References}

5.1. Department of Energy Natural Phenomena Hazards Panel, Design and Evaluation Guidelines for Department of Energy Facilities Subjected to Natural Phenomena Hazards, prepared by Lawrence Livermore National Laboratory, October 1985.

5.2. DOE Order 5481.1B, Safety Analysis and Review System, September 23, 1986.

5.3. DOE Order 6430.1A, General Design Criteria, April 6, 1989.

5.4. National Fire Protection Association, Life Safety Code, NFPA 101, Quincy, Massachusetts (1991).

5.5. National Fire Protection Association, Installation of Air Conditioning and Ventilating Systems, NFPA 90A, (1989).

5.6. National Fire Protection Association, Standards for the Installation of Sprinkler Systems, NFPA 13, (1991). 
5.7. Occupational Safety and Health Act of 1970, "Breathing Air Requirements," OSHA 29 CFR 1910.134.

5.8. American National Standards Institute, Commodities Specification for Air, CGA-G7.1, ANSI Z86.1-1973.

5.9. American Society of Mechanical Engineers, Power Piping - American National Standard Code for Pressure Piping, ANSI-B31.1-1989.

5.10. L. J. Wittenberg, Nucl. Technol., 38 (1978), pp. 434-440.

5.11. DOE Order 5700.6B, Quality Assurance, September 23, 1986. 



\section{Chapter 6 \\ Tritium Waste Management}

\subsection{Gaseous Effluents}

\subsubsection{Description of Waste Streams}

Gaseous effluents containing tritium can result from several operations. Most often, effluents containing relatively small quantities of tritium result from single-pass ventilation of laboratories where small quantities of tritium are handled in fumehoods or other enclosures. This air flow is monitored, diverted to a stack, and released to the environment. Concentrations of tritium in these effluents are typically small fractions of a microcurie per cubic meter.

Effluents containing higher concentrations of tritium can result from other processes. The decision on how to handle these waste streams depends largely on the concentration of tritium in the effluents and the form of the tritium.

\subsubsection{Applicable Regulations}

The Environmental Protection Agency (EPA) has specified a maximum permissible concentration of $1.5 \times 10^{-9} \mathrm{Ci} / \mathrm{m}^{3}$ for tritium in air under the National Emissions Standards for Hazardous Air Pollutants (NESHAPs) [6.1]. The NESHAPs concentration limit is based on limiting the effective dose equivalent to the public to $10 \mathrm{mrem} / \mathrm{yr}$, and it is applicable outside the facility boundaries of DOE sites [6.1].

DOE Order 5400.5 specifies Derived Concentration Guides (DCGs) for tritium to limit the committed effective dose equivalent to $100 \mathrm{mrem} / \mathrm{yr}$ for the public (onsite and offsite) [6.2]. The maximum allowable concentration of tritium in air in unrestricted areas is $2 \times 10^{-7} \mathrm{Ci} / \mathrm{m}^{3}$, and this concentration may be averaged over a period not greater than one year. DOE Order 5400.5 further requires that effluent concentrations be as low as reasonably achievable (ALARA) based on the best available technology (BAT) for treatment, and on technical and economic considerations.

The Nuclear Regulatory Commission (NRC) has also established concentration limits for tritium in air in unrestricted areas. The current NRC concentration limit is $1 \mathrm{x}$ $10^{-7} \mathrm{Ci} / \mathrm{m}^{3}[6.3]$, and the proposed revision to $10 \mathrm{CFR}$ Part 20 specifies a limit of $7 \mathrm{x}$ $10^{-8} \mathrm{Ci} / \mathrm{m}^{3}$ [6.4]. These limits, however, apply only to NRC-licensed facilities and are not applicable to DOE sites.

The concentration limits apply at the boundary of the restricted area; therefore, the concentration of radioactive materials discharged through a stack or similar conduit can be measured at the point where the material leaves the conduit. If the conduit 
discharges within the restricted area, the concentration at the boundary may be determined by applying appropriate factors for dilution or dispersion between the point of discharge and the boundary. These concentration guidelines are important when the option to dilute and release gaseous effluents is selected. (Some states may have more stringent regulations.)

If concentrations of tritium in the effluents are relatively large and effluent volumes are small enough (intermittent operations) that capture and disposal of the tritium becomes an option, the Department of Transportation (DOT) regulations covering transport for burial are applicable [6.5]. Gaseous tritium wastes may be shipped commercially, provided the package is a DOT specification shipping container. If the quantity of gaseous tritium in a cylinder exceeds $200 \mathrm{Ci}$, that cylinder must meet the DOT Specification 7A Type A test requirements, with two exceptions. For the drop test, the cylinder must be dropped from a height of 30 feet rather than 4 feet. The penetration test must be done from a height of 5.5 feet rather than 3.3 feet. Specific and general packaging requirements are given in 49 CFR 173.411 and 173.412 [6.5].

Quantities of tritium gas greater than $1,000 \mathrm{Ci}$ must be packaged in a Type B package. Quantities less than $200 \mathrm{Ci}$ per package must meet the general requirements for packaging radioactive materials. Quantities less than $20 \mathrm{Ci}$ per package are exempt from all marking and labeling requirements and may be transported as limited quantity.

DOE and commercial burial grounds may have restrictions that are more limiting than the DOT regulations regarding concentrations and total quantities of tritium contained within pressure vessels. Burial ground criteria should be investigated before deciding to capture, transport, and bury gaseous effluents.

\subsubsection{Treatment}

If concentrations of tritium in the gaseous effluent are sufficiently low, and if local environmental concerns and state regulations allow, a cost-effective method to dispose of gaseous effluents is to dilute and release. Many small commercial operations and some federal facilities handling tritium take advantage of this option.

Tritium effluents are released to the atmosphere through stacks in which dilution takes place before any release reaches unrestricted areas. An effective monitoring and surveillance program must be maintained to ensure that average concentrations fall within the guidelines. Any peaks as a result of accidental releases or production fluctuations within the facility must be detected and taken into account.

If the concentrations in the gaseous effluents are sufficiently high, and volumes generated are sufficiently low, the gaseous effluent can be captured, placed in gas cylinders, and discarded. This option applies only in limited situations, but it can be an effective means of treatment and disposal. 
Other methods of treatment for gaseous effluents involve converting the gaseous tritium to another physical form that can be further treated and rendered acceptable for disposal. For example, this process might involve converting the gas to an oxide in a reaction chamber, removing that oxide in a drying bed, and converting the collected liquid into a stable waste form by solidification with concrete or other solidification agents [6.6]. This process can be adapted to handle large quantities of air with significant concentrations of tritium. A typical flow diagram for such a system is shown in Figure 6.1.

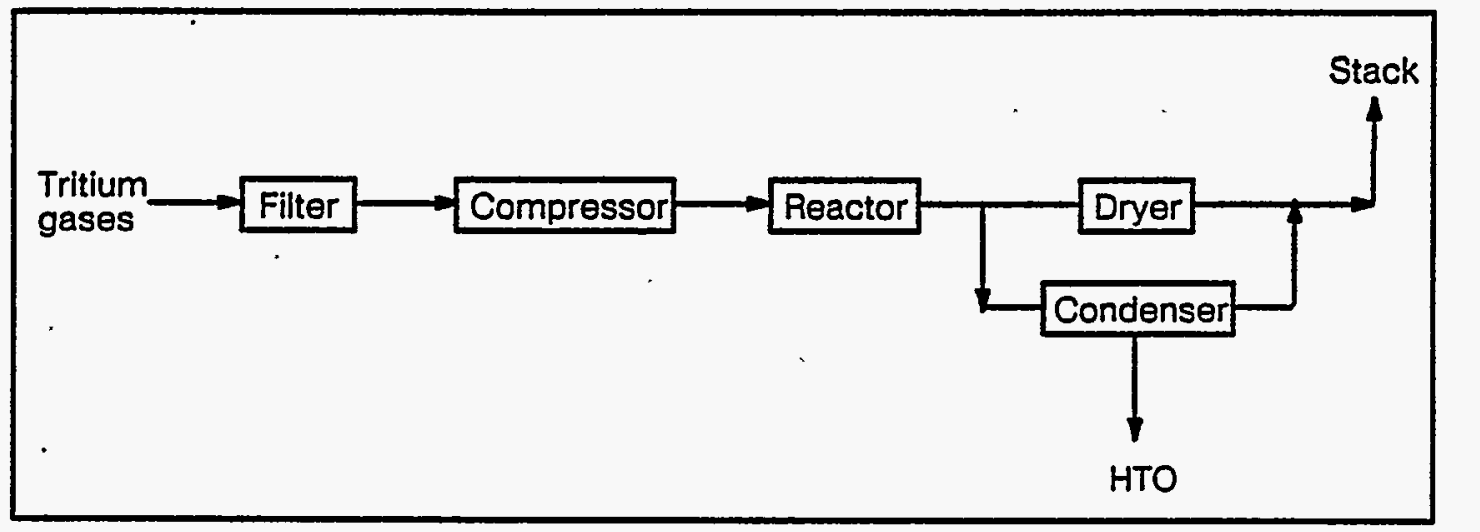

Figure 6-1 - Typical detritiation system.

Another option involves adsorbing tritium gas onto a reactive bed such as charcoal, followed by the regeneration or disposal of that bed at room or cryogenic temperature. Hydriding an active metal surface with tritium and subsequently regenerating or disposing of the resulting solid waste provides yet another conversion option.

Of course, the preferred option for treatment of gaseous tritium and, in fact, for all other forms of tritium, is capture and recovery. Gaseous tritium can be converted to a liquid, captured, then processed for recovery. The recovery process is discussed further in Section 6.2.3.

\subsubsection{Packaging and Transportation}

Packaging and transporting gaseous effluents pertain only to effluents that have been captured and placed in a gas cylinder and must be transported for offsite disposal. Applicable DOT regulations were discussed in Section 6.1.2.

Leak-tight containers that meet the requirements of 49 CFR 173.411 and 173.412 must be used [6.5]. They should be marked and labeled in accordance with Part 172, subparts D, Marking Requirements, and E, Labeling Requirements. Gaseous effluents must be sufficiently characterized with respect to form, concentration, and 
total quantity to provide the required information on the manifest documents that accompany the shipment. Gaseous effluents packaged in compliance with the above requirements may be transported commercially by ground or by air to the final disposal site.

\subsubsection{Disposal}

Commercial burial grounds in the United States, including U.S. Ecology sites in Richland, Washington, and Beatty, Nevada, and the ChemNuclear site in Barnwell, South Carolina, accept cylinders containing gaseous tritium under specific conditions. Current DOE policy, however, requires disposing of DOE facility wastes at a DOE disposal site rather than a commercial site. Waste acceptance criteria for the Nevada Test Site (NTS) [6.7] require radioactive gases to be stabilized or absorbed so that pressure in the waste package does not exceed 115 atmospheres at $20^{\circ} \mathrm{C}$. Compressed gases as defined by 49 CFR 173.300 are not accepted for disposal. Other DOE sites impose similar restrictions.

\subsection{Liquid Wastes}

\subsubsection{Description of Waste Streams}

Liquid effluents contaminated with tritium can originate from a wide range of activities and can contain concentrations from fractions of microcuries per liter to more than $1,000 \mathrm{Ci}$ per liter. Two types of liquid wastes are categorized by the chemical makeup of the waste stream: aqueous and organic. Separate treatments and regulations apply to each of these categories.

\subsubsection{Applicable Regulations}

DOE Order 5400.5 specifies a DCG of $2 \times 10^{-3} \mathrm{Ci} / \mathrm{m}^{3}$ for tritium in liquid effluents. This concentration limit was derived to limit the maximum effective dose equivalent of an individual to $100 \mathrm{mrem} / \mathrm{yr}$. Although not directly applicable to DOE facilities, the NRC provides guidelines for maximum permissible concentrations of tritium in liquid effluents from NRC-licensed facilities in $10 \mathrm{CFR} 20.106$ [6.3]. The current NRC limit for the release of tritium to unrestricted areas is $2 \times 10^{-3} \mathrm{Ci} / \mathrm{m}^{3}$. Proposed revisions to 10 CFR 20 specify a tritium concentration limit of $1 \times 10^{-3} \mathrm{Ci} / \mathrm{m}^{3}$ [6.4].

The same allowances given in Section 6.1.2 for diluting discharges into the air between the point of release and the site boundary apply to concentrations of tritium in liquid effluents. As stated previously, each contractor must check for more restrictive state regulations.

In addition, the NRC allows the disposal of limited quantities of tritium in sanitary sewage systems, as described in 10 CFR 20.303 [6.3]. The limit can be arrived at two ways: 
- The total quantity of tritium released in any one day cannot exceed $10 \mathrm{mCi}$.

- The average daily quantity of sewage cannot have a concentration of more than $0.1 \mathrm{Ci} / \mathrm{m}^{3}$.

The activity released in one month, when divided by the average monthly quantity of sludge, cannot exceed $0.1 \mathrm{Ci} / \mathrm{m}^{3}$. The total activity of tritium released in one year cannot exceed $\mathbf{5} \mathbf{C i}$.

Other NRC regulations that apply to the disposal of tritium-contaminated liquid effluents deal specifically with the disposal of liquid scintillation cocktails. These cocktails, which usually contain tritium concentrations of less than $0.05 \mu \mathrm{Ci} / \mathrm{g}$, may be considered exempt from the NRC regulations and can be treated as nonradioactive waste. If a scintillation cocktail contains a waste listed in the EPA Resource Conservation and Recovery Act (RCRA). or exhibits flammability as specified in EPA RCRA regulations, it must be treated as hazardous waste and disposed of in accordance with RCRA regulations [6.8]. Scintillation cocktails that can be classified as nonhazardous by RCRA definition have been developed commercially and should be evaluated for use wherever feasible.

EPA regulations regarding tritium-contaminated liquid effluents fall into two main categories. First, the RCRA specifies ways in which the hazardous chemical wastes must be treated, packaged, and discarded. As mentioned, scintillation cocktails containing tritium may fall into this category. If the concentration of tritium exceeds the $0.05 \mu \mathrm{Ci} / \mathrm{g}$ de minimis value, these wastes must be considered as mixed wastes; that is. they exhibit both radiologic and toxic characteristics.

In addition to these regulations, the EPA also specifies an upper limit for the permissible concentration of tritium in drinking water and has proposed a revised limit of $90 \mathrm{pCi} / \mathrm{mL}$ [6.9]. For tritium released to the environment as a liquid effluent going into a stream or river, or for tritium that may migrate from a burial ground into an aquifer, pathways must be evaluated and reasonable assurance must be given that the acceptable tritium level will not be exceeded when a drinking water source is involved. This concentration standard can be the limiting factor in dealing with the release of liquid tritium effluents to the environment.

The DOT allows the shipment of tritium in liquid form as long as specific packaging requirements are met. However, since no burial grounds will accept liquid tritiated waste for disposal, a reference to these DOT requirements as they might pertain to shipments of waste is irrelevant.

\subsubsection{Treatment}

As with gaseous effluents, dilution and release to the environment can be used for treatment and disposal of liquid effluents. EPA regulations, NRC regulations for 
licensees, DOE requirements for DOE contractor facilities, and other requirements that may be placed on facilities by states must be met.

Another technique for treating liquid effluents that may be more desirable from an environmental perspective is absorption or solidification of the liquid effluents in appropriate media for subsequent burial. In the absorption process, materials such as vermiculite or diatomaceous earth can be used to absorb carefully measured quantities of tritiated liquid. Even though these materials have been and continue to be used, some burial grounds are moving away from absorbent materials, and requiring a nonleaching, free-standing solid for disposal.

The following are some of the problems experienced with these materials:

- Uneven distribution of the liquid on the absorbent material,

- Subsequent desorption and absorption down through the package that causes a pool of liquid to collect at the bottom, and

- Desorption and evaporation, followed by condensation at the surface of the package.

Additional problems may result from penetration of the waste container and subsequent leakage of the liquid tritium and/or absorbent material into the surrounding medium. However, for small, laboratory-scale quantities of tritiumcontaminated aqueous solutions and relatively low tritium concentrations, absorption onto such media is an appropriate treatment prior to disposal.

Solidification of tritiated water with cement or other materials that form a monolith provides a waste package of high integrity that is more acceptable for disposal at commercial and DOE burial sites. Numerous commercially available solidification agents have been developed in an attempt to increase the load capacity for liquid radwaste. Load capacities ranging from 25 to 40 gallons of water per 55-gallon drum are typical [6.10]. Agents that allow larger loading capacities are usually more expensive, resulting in little economic advantage, and they provide no better retention of the tritium. Regardless of the treatment and containment provided prior to disposal, tritium is capable of migrating out of the waste package and into the surrounding medium to some degree. Barriers can significantly affect this migration. They are discussed in Section 6.2.4.

As mentioned in Section 6.1.3, in some cases gaseous effluents may be converted in reaction chambers (e.g., palladium beds) to tritium oxide, which can then be captured on drying beds (i.e., molecular sieves) and treated as liquid effluent by solidification. Organic components in the gaseous effluent, such as pump oil vapors and laboratory solvents, can be selectively removed using special oil filters, cooling steps followed by driers loaded to remove organics, and other techniques. However, a clean separation is somewhat difficult. 
A third treatment for aqueous tritiated waste is recovery. One recovery process involves a step in which impurities in the waste water are removed. This is followed by a combined electrolysis and catalytic exchange (CECE) process [6.6]: Catalytic exchange uses a hydrophobic precious metal catalyst to enhance the HT to HTO exchange reaction. This step is then coupled with electrolysis to remove all tritium from the feed stream. The remaining aqueous phase can be discarded to the environment.

Organic tritiated wastes may be solidified and shipped for burial as low-level radioactive waste if they are not hazardous wastes by EPA RCRA definitions. For example, waste oils are not currently regulated under RCRA, but may be considered for inclusion in the near future. State regulations pertaining to tritiated waste oils may vary.

Other organics that are nonflammable and are not listed as hazardous wastes by the EPA also qualify for this disposal method. A scintillation cocktail containing a hazardous organic solvent and less than $0.05 \mu \mathrm{Ci}$ of tritium per gram can be disposed of as hazardous waste and shipped offsite to commercial waste disposal contractors who incinerate it. Similarly, scintillation cocktails using nonhazardous solvents that meet the de minimus concentration for tritium may be handled as nonhazardous wastes. Incineration of all organic tritiated wastes is an attractive option that is being pursued by the DOE for many of its organic mixed waste streams. However, until jurisdiction over regulating these waste streams is established and permitting processes are defined, little progress can be made.

\subsubsection{Packaging_and Transportation}

Currently, no disposal sites accept tritiated liquid wastes that have not been solidified or absorbed in appropriate media. Therefore, packaging and transportation requirements for shipping tritiated liquid are not pertinent. However, packaging and transporting liquid wastes that have been absorbed or solidified for disposal will be reviewed.

The package used most often for transportation and disposal of liquid wastes is a DOT Specification $17 \mathrm{H}$ or $17 \mathrm{C} 55$-gallon steel drum. Depending on the concentration and total quantity of tritium in the waste package, additional barriers inhibiting tritium migration should be utilized. Low specific activity (LSA) waste (containing less than $0.3 \mathrm{mCi}$ tritium per gram) can be packaged directly in the 55-gallon drums with no barriers other than thin-wall polyethylene bags to ensure safe handling during packaging.

As concentrations exceed the LSA category and the total quantity of tritium in the waste package approaches $20 \mathrm{Ci}$, additional containment such as a rigid liner, either metal or plastic, should be provided. Tritium quantities that exceed $20 \mathrm{Ci}$. per 
package require additional barriers, such as high-density polyethylene rigid liners. At quantities in the range of hundreds of curies per package, asphalt barriers and multiple packagings, such as 30 -gallon drums within 55-gallon drums, should be used to control tritium migration.

Packaging high-activity tritium waste (containing up to $30,000 \mathrm{Ci}$ ) involves solidifying the liquid in a plaster of paris mix inside a 40 -mil high-density polyethylene 28 -gallon liner. This liner is placed inside a 30 -gallon $17 \mathrm{H}$ steel drum coated with an asphalt-bearing paint on the inner wall. A nonhardening barrier of asphalt is then placed over the top of the 28-gallon drum before the lid is placed on the larger drum. The 30-gallon package is then overpacked in a 55-gallon steel drum with an asphalt barrier at its top and bottom. Absorbent material is placed in the remaining annular space. Nonhardening asphalt has been shown to be an excellent barrier to tritium migration and is recommended for situations in which high-activity tritium must be packaged for disposal [6.11].

A maximum of $1,000 \mathrm{Ci}$ of tritium per waste container may be shipped as a Type $\mathrm{A}$ quantity of radioactive material in a $17 \mathrm{H}$ or $17 \mathrm{C}$ steel drum or in other approved Type A packages, such as welded steel boxes [6.5]. Quantities of tritium exceeding the 1,000-Ci level must be overpacked or packaged in a Type B container, such as the N55 overpack for 55-gallon drums.

\subsubsection{Disposal}

Two disposal options, release to the sanitary sewer system and release through other plant effluents, have already been discussed. As mentioned, commercial waste disposal facilities and DOE burial grounds will not accept liquid tritiated wastes for disposal or burial. After the liquid streams have been solidified, wastes can be disposed of at commercial facilities and DOE burial sites. Commercial facilities may impose a surcharge to dispose of solidified tritiated waste, depending on the total curie content of the package. In addition, disposal criteria at DOE sites may require incorporating some of the barriers for prohibiting migration previously discussed.

The goals of all burial sites, both DOE and commercial, are to prevent tritium migration into the groundwater where it may reach a source of drinking water and to limit the gaseous tritium effluents. Barriers established to retard this migration will greatly enhance the performance of the waste package in the burial ground until decay can effectively reduce the hazard. Tests to demonstrate reduced migration rates are recommended.

Some burial sites, such as the Nevada Test Site, provide further containment for high-activity tritium (HAT) packages by placing them in welded steel bins prior to burial. Other burial sites are moving in the direction of engineered burial. At some sites, barriers are designed into the disposal facility to prevent the introduction of 
water into the waste package. Other engineered disposal methods in which the waste packages are placed in "greater confinement disposal," that is, at depths to 100 feet, are also being examined.

\subsection{Solid Wastes}

\subsubsection{Description of Waste Streams}

Tritiated solid waste streams can contain a wide variety of materials. These include combustible plastics and paper generated in general laboratory operations, as well as noncombustibles such as contaminated equipment, tools, "gloveboxes, and fumehoods.

\subsubsection{Applicable Regulations}

Solid tritiated waste streams are not characterized as a facility effluent, and, as a result, there are no corresponding DOE, NRC, or EPA effluent standards. There are, however, DOT regulations that apply to transporting solid tritiated wastes for disposal [6.5]. They call for packaging LSA materials that have an upper limit of $0.3 \mathrm{mCi} / \mathrm{g}$ in strong, tight packages. As the total quantity of tritium within the waste package increases, additional barriers should be provided.

At levels greater than $1,000 \mathrm{Ci}$ per package, a Type $\mathrm{B}$ container or overpack is required. A DOT Specification $7 \mathrm{~A}$ Type A package, such as a $17 \mathrm{C}$ or $17 \mathrm{H} 55$-gallon steel drum, can be used for quantities up to $1,000 \mathrm{Ci}$. Packages containing up to $20 \mathrm{Ci}$ per package are considered limited quantities and are exempt from many of the marking and labeling requirements [6.5].

Solids often involve surface contamination and are not a homogeneous mixture of radionuclide and host material, as is normally assumed when describing LSA materials. The waste can still be considered LSA material if the radioactive material is not readily dispersible and if the surface contamination, when averaged over an area of $1 \mathrm{~m}^{2}$, does not exceed $1.0 \mu \mathrm{Ci} / \mathrm{cm}^{2}$, or $2,200,000 \mathrm{dis} / \mathrm{min} / \mathrm{cm}^{2}$ [6.5]. These criteria allow large items with surface tritium contamination to be classified in the LSA category.

\subsubsection{Treatment}

If the solid wastes are compactible, they can usually be compacted prior to offsite shipping for burial to reduce the total volume of waste to be discarded. Commercial compactors are available, although they may have to be modified to allow adequate handling of offgassing that might take place during the operation.

Incineration is a viable technique to reduce the volume of combustible tritiated solid wastes. Most of the tritium in the offgas will escape into the environment. With a wet 
offgas handling system, some of the tritium may be captured, but it will appear in the liquid effluent.

Shredding or other volume reduction techniques can also be used to process solid waste contaminated with tritium. During the volume reduction process, it is sometimes useful to apply a surface coating to the material in an attempt to fix any tritium near the surface while volume is being reduced. Paints or other spray coatings are effective in retarding tritium release from surface contamination. Another technique that can be used to substantially reduce the quantity of tritium on solids is decontamination. This can be done by wiping with damp rags, or, in extreme cases, steam can be used as a decontamination medium for gloveboxes or other equipment.

\subsubsection{Packaging and Transportation}

Refer to Sections 6.1.2, 6.1.4, and 6.2.4.

\subsubsection{Disposal}

Commercial and DOE burial sites accept solid tritiated wastes for disposal. Neither type of burial site accepts liquid wastes or free liquids in solid wastes, nor do they accept mixed waste (tritium-contaminated wastes that also contain organics that might cause them to fall under RCRA regulations). These limitations apply to all low-level radioactive wastes, not just tritium. There are no restrictions at commercial or DOE facilities with regard to solid tritium waste that would not also apply to other types of low-level radioactive waste. In some cases, a burial surcharge may be imposed if the curie content per package is large.

\subsection{References}

6.1. U.S. Environmental Protection Agency, National Emission Standards for Hazardous Air Pollutants, Code of Federal Regulations, Title 40, Part 61, 54 FR 51654-51715, December 15, 1988.

6.2. DOE Order 5400.5, Radiation Protection of the Public and Environment, February 8, 1990.

6.3. U.S. Nuclear Regulatory Commission, Code of Federal Regulations, Title 10, Part 20.

6.4. U.S. Nuclear Regulatory Commission, Advance Notice of Proposed Rulemaking, Proposed Revision to Code of Federal Regulations, Title 10, Part 20, 51 FR 1091-1216, January 9, 1986.

6.5. U.S. Department of Transportation, Code of Federal Regulations, Title 49, Parts 172-177. 
6.6. American Nuclear Society, Proceedings of the National Topical Meeting on Tritium Technology in Fission, Fusion, and Isotopic Applications, Dayton, Ohio, 29 April - 1 May 1980.

6.7. U.S. DOE Nevada Operations Office and Reynolds Electrical \& Engineering Company, Nevada Test Site Defense Waste Acceptance Criteria, Certification and Transfer Requirements, NVO-325, October 1988.

6.8. U.S. Environmental Protection Agency, Resource Conservation and Recovery Act, Code of Federal Regulations, Title 40, Parts 261-268.

6.9. U.S. Environmental Protection Agency, Advance Notice of Proposed Rulemaking, Proposed Revision to Code of Federal Regulations, Title 40, Part 141, 51 FR 34859, September 30, 1986.

6.10. Mound Technical Manual MD-70180, Mound Radioactive Liquid Waste Disposal, Current Issue.

6.11. Mound Technical Manual MD-21358, Tritiated Liquid Waste Packaging Procedures for SW-149, Current Issue.

\subsection{Additional Reading}

DOE Order 5400.1, General Environmental Protection Program Requirements, November 9, 1988.

DOE Order 5480.11, Radiation Protection for Occupational Workers, December 21, 1988.

National Committee on Radiation Protection and Measurements, Tritium in the Environment, NCRP Report No. 62, Washington, D. C. (1979).

International Atomic Energy Agency, Proceedings of the Symposium on the Behavior of Tritium in the Environment, San Francisco, California, 16-20 October 1978 (1979).

U.S. Atomic Energy Commission, Sources of Tritium and Its Behavior Upon Release to the Environment, USAEC Critical Review Services, 1968. 


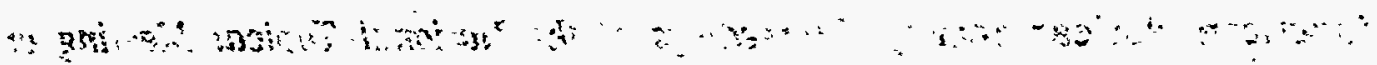
-

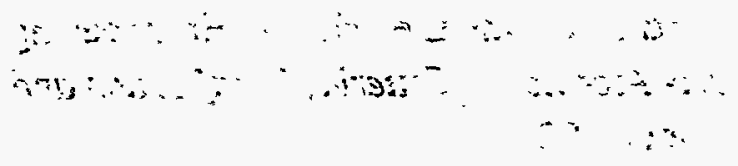

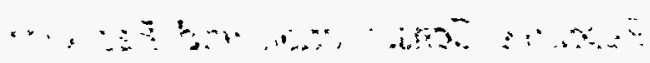

$$
\begin{aligned}
& -35 \cdots \infty
\end{aligned}
$$

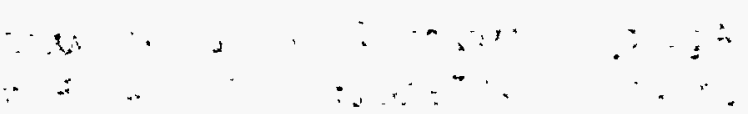

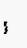

$$
\therefore \quad \ldots \ldots+4
$$

$\therefore:$

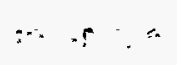

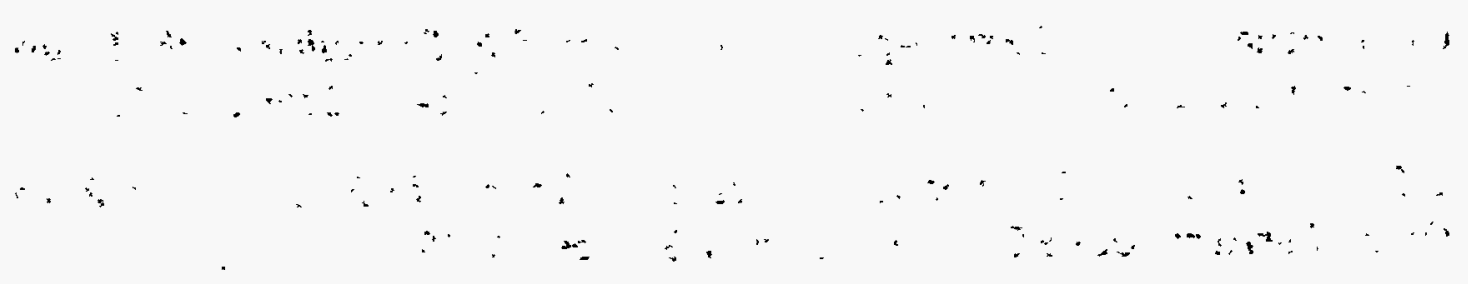

$$
i+\infty
$$




\section{Appendix $\mathbf{A}$ Material Compátibility}

The compatibility concerns raised for tritium/material interactions are manyfold:

- The mechanical integrity of the material,

- Escape rate of tritium into and through the material,

- Contamination of tritium by the material and vice versa, and

- Gettering capabilities of a substance for tritium.

Mechanical integrity is a function of how well the material dissipates the energy of colliding beta particles and of how well it excludes tritium from its bulk; i.e., solubility and diffusivity: Escape rates are largely a function of diffusivity, solubility, and, therefore, permeability. Cross-contamination occurs when materials contain hydrogen or carbon in their bulk or at their surface or when the materials absorb a significant amount of tritium. Gettering capabilities are largely a function of alloy overpressure.

\section{A.1 Nonhydriding Metals}

The mechanical integrity of nonhydriding metals in the presence of tritium is excellent because the electron bands carry away the energy of colliding beta particles without disrupting the metal structure or bonding [A.1]. These metals form the most common class of tritium containment structural materials. They generally include 304L, 316L, 321, 21-6-9, and Nitronic stainless steels, as well as copper and aluminum. Inconel, Ni-Cr alloys, and 400-series stainless steels are generally not chosen because of corrosion or hydrogen embrittlement sensitivity. At high pressures of tritium gas, however, classical hydrogen embrittlement, as well as helium-3 embrittlement, can occur in accepted materials. For example, for 304L stainless steel samples exposed to $9 \mathrm{kpsi}$ of tritium at $423 \mathrm{~K}$ for 6 months then aged 1.5 years, fracture toughness decreased by a factor of 6 . Of this, a factor of two could be attributed to helium-3 alone [A.2].

Substantially different fracture modes are observed between aged tritium-loaded and unloaded steel specimens, as shown in Figure A.1 [A.3]. Helium-3 is văstly less soluble in metals than is hydrogen (tritium); helium pockets (bubbles) form with high internal pressures:-Hydrogen embrittlement also contributes to this seffect.:

Permeative escape rates of tritum through nonhydriding metals are generally acceptable at temperatures below 100 to $300^{\circ} \mathrm{C}$ and for thickness of $0.1 \mathrm{~cm}$ or more. For 304 stainless steel $0.3 \mathrm{~cm}$ thick with a $1000-\mathrm{cm}_{2}^{2}$ surface area exposed on one side to tritium gas of $1 \mathrm{~atm}$ pressure at $300 \mathrm{~K}$, the permeability is $1.6 \times 10^{-4}$ 


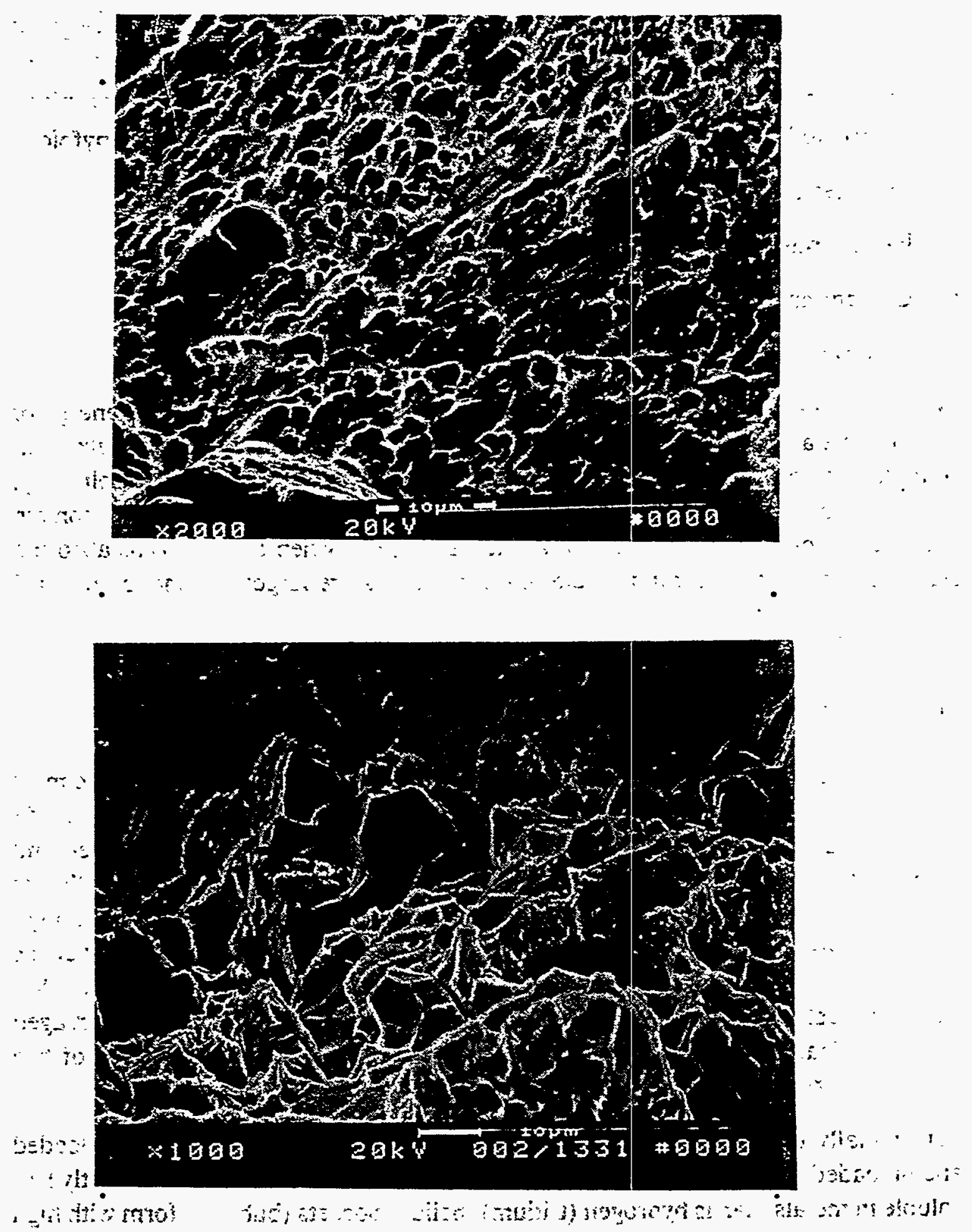

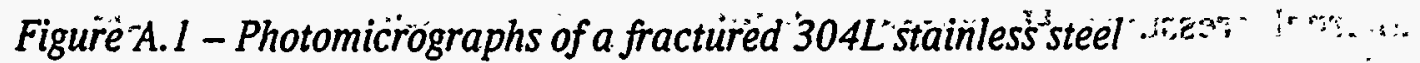
sample exposed to approximately $10 \mathrm{kpsi}$ of tritium.gas for about

?

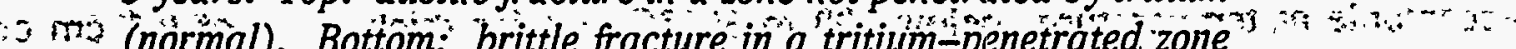

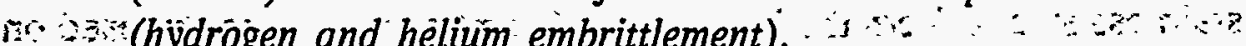

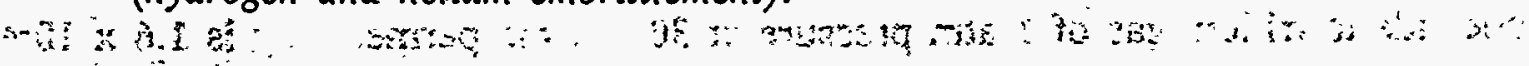


$\mathrm{Ci} /$ day $\left(\mathrm{t}_{0.9}=636\right.$ years). However, at $800 \mathrm{~K}$, the permeability is $540 \mathrm{Ci} /$ day $\left(t_{0.0}=7\right.$ hours). The temperature dependence of permeation is often astounding.

Cross-contamination between nonhydriding metals and tritium does occur often enough to be troublesome. Oxide layers on metals often contain hydrogen and are further covered with a thin adsorbed carbonaceous film when originally grown in room air. Upon exposure to such a surface, tritium gas may become contaminated over hours or days with hundreds to thousands of parts per million of protium (as $\mathrm{HT}$ ) and methane (as $\mathrm{CT}_{4}$ ) as the surface layers are radiolyzed, exchanged, and chemically reduced [A.4-A.7]. The tritium exchanged into the oxide layer represents contamination of the material. Since diffusion of tritium in the bulk material is usually slow at room temperature, the extent of surface oxide contamination may greatly surpass the bulk contamination of a component. Cross-contamination can be minimized by minimizing material surface areas, choosing an impermeable material with a thin or nonexistent oxide layer, and maintaining cleanliness.

Tritium present in an oxide layer can be removed by acid dissolution of the oxide or more gently by isotopic exchange with normal water [A.8-A.11] or activated hydrogen gas (i.e., plasma). Since diffusion of oxide- or bulk-dissolved tritium back to the surface of a material undergoing decontamination is often slow, exchange.at an elevated temperature may be advantageous.

\section{A.2. Hydriding Metals}

When exposed to tritium gas, hydriding metals absorb large volumes of tritium to form tritide phases, which are actually new chemical compounds, such as $\mathrm{UT}_{3}$ [A.12]. The mechanical integrity of the original metallic mass is often severely degraded as the inclusions of a brittle, salt-like hydride form within the mass [A.13]: Because of this property and their large permeability to hydrogen, hydriding metals are not to be used for constructing pipelines and vessels of containment for tritium gas. They have great utility, however, in the controlled solidification and storage of tritium gas, as well as in its pumping, transfer, and compression.

Uranium, palladium, and alloys of zirconium, lanthanum, vanadium, and titanium are presently used or are proposed for pumping and controlled delivery of tritium gas [A.14-A.16]. Several of these alloys are in use in the commercial sector for hydrogen pumping, storage, and release applications [A.17-A.19]. As was shown in Figure 3.5, gaseous overpressure above a hydride (tritide) phase varies markedly with temperature; control of temperature is thus the only requirement for swings between pumping and compressing the gas.

The plots in Figure 3.5 predicted overpressures in equilibrium with hydrides. In practice, pumping speeds or gaseous delivery rates (the kinetic approach to 
equilibrium) are functions of temperature (diffusion within the material), hydride particle size, and surface areas and conditions [A.20, A.21]. Poisoning of a uranium or zirconium surface occurs when oxygen or nitrogen is admitted and chemically combines to form surface barriers to hydrogen permeation. In practice, these impurities may be diffused into the metal bulk at elevated temperatures, thereby reopening active sites and recovering much of the lost kinetics [A.14, A.22]. Other metals and alloys (e.g., $\mathrm{LaNi}_{5}$ ) are less subject to poisoning, although alloy decomposition can occur [A.15].

Helium-3, generated as microscopic bubbles within the lattice of tritides, is not released except by fracture and deformation of metal grains. This usually occurs at high temperatures or after long times [A.16]. When a tritide is heated to release tritium, helium -3 is also released to some extent. The cooled metal, however, does not resorb the helium-3. The practice of regenerating a tritide storage bed to remove helium-3 immediately prior to use for pure tritium delivery is therefore common [A.12].

If helium-3 (or another inert impurity) accompanies tritium gas that is sorbed onto a tritide former, helium blanketing may occur [A.15]. The sorption rate slows as the concentration of helium in the metal crevices leading toward active sites becomes high. Normal gaseous diffusion is often not sufficient to overcome this effect. Forced diffusion by recirculating the gas supply can be used to overcome blanketing [A.12, A.14].

\section{A.3. Graphite}

Because they generally have high surface areas, graphite samples adsorb large amounts of hydrogen gas $\left(4 \times 10^{18}\right.$ molecules/g for a graphite pellet used in gas-cooled reactors) [A.23]. Methane, protium, and possibly water are generated from beta irradiation of the graphite surface [A.24]. The surface of the graphite will be contaminated with chemically bound tritium, and decontamination may be possible by baking at $500^{\circ} \mathrm{C}$ in the presence of a hydrogen exchange medium, such as $\mathrm{H}_{2}, \mathrm{H}_{2} \mathrm{O}$, or $\mathrm{NH}_{3}$. Except for possible surface erosion, graphite will probably not be degraded mechanically over a period of several years, as bulk diffusion and solubility are extremely low.

\section{A.4." Glasses}

Various data suggest that tritium gas in the presence of its chemically activating beta irradiation energy could reduce silica bonding to $-\mathrm{Si}-\mathrm{T}$ and $-\mathrm{Si}-\mathrm{OT}$ species. At temperatures above $300^{\circ} \mathrm{C}$, deuterium appears to reduce a silica network [A.25], and dissolved deuterium in a gamma irradiation field has the same effect [A.26]. The migration of tritium into glass structures could thus cause embrittlement and possibly fracture under stress over several months or years. Evidence also suggests that activated hydration of glassy silica structures under $T_{2} O$ exposure is possible. 
Embrittlement (unexpected fracture) of a Pyrex syringe stored for two to three years after being used to transfer $\mathrm{T}_{2} \mathrm{O}$ was experienced at Mound.

Permeability of silica glasses is one to two orders of magnitude greater than that for stainless steel over the temperature range 0 to $200^{\circ} \mathrm{C}$. Tritium handling systems constructed largely of glass have nevertheless been widely used, although this material is not in favor today except for tritium lamp containment. The exchange of tritium with naturally occurring hydroxyl groups in various glasses and on their surfaces is a source of protium contamination to tritium, perhaps $1 \% \mathrm{HT}$ into $1 \mathrm{~atm}$ tritium within a $1-\mathrm{L}$ glass container after 1 year [A:6]. Decontaminating a highly exposed glass of its bound tritium would require a significant number of water washes or ${ }^{\circ} 300^{\circ} \mathrm{C}$ hydrogen permeation flushes [A.27]. This effort is likely to be costly and is often not warranted by the value of the part undergoing decontamination.

\section{A.5. Ceramics}

Because tritium's solubility, diffusivity, and permeability are so much lower for ceramics than for glasses, ceramics undergo little or no bulk disruption from tritium. However, some mechanical degradation of regions near the surface is possible. The depth of the area affected is a function of diffusivity and time. Oxygen release from $\mathrm{Al}_{2} \mathrm{O}_{3}$ (sapphire) windows in the presence of liquid $\mathrm{T}_{2} \mathrm{O}$ has recently-been noted at Mound, although compatibility with tritium gas has been described as excellent [A.28]. The exchange of surface and near-surface protium is likely, although mutual contamination of tritium and the ceramic should be less than that for glasses. Tritium-contaminated ceramics can probably be decontaminated by warm water or steam flushes or by etching in an acidic solution.

\section{A.6. Plastics, Elastomers, änd Oils}

Organics are readily permeated by tritium (gas or water) and are therefore subject to disruption of their bulk chemistry. There are few or no mechanisms for rapidly delocalizing beta energy, and substantial mobility of organic chains occurs within polymer structures (particularly amorphous regions). Once formed, reactive organic intermediates can thus react with each other.

These effects are important when considering the design of tritium systems. Damage to components, such as gaskets, valve tips, and O-rings, must be carefully considered (see Figure A.2). Component failure during service can cause a major release of tritium. Because elastomer seals often become embrittled, maintenance on nearby sections of piping may cause seals to develop leaks as the result of mechanical movement in the seal area.

Figure A.3 shows several polymer chain modifications that take place following activation by beta radiation to ionic or excited species [A.29]. Cross-linking and 

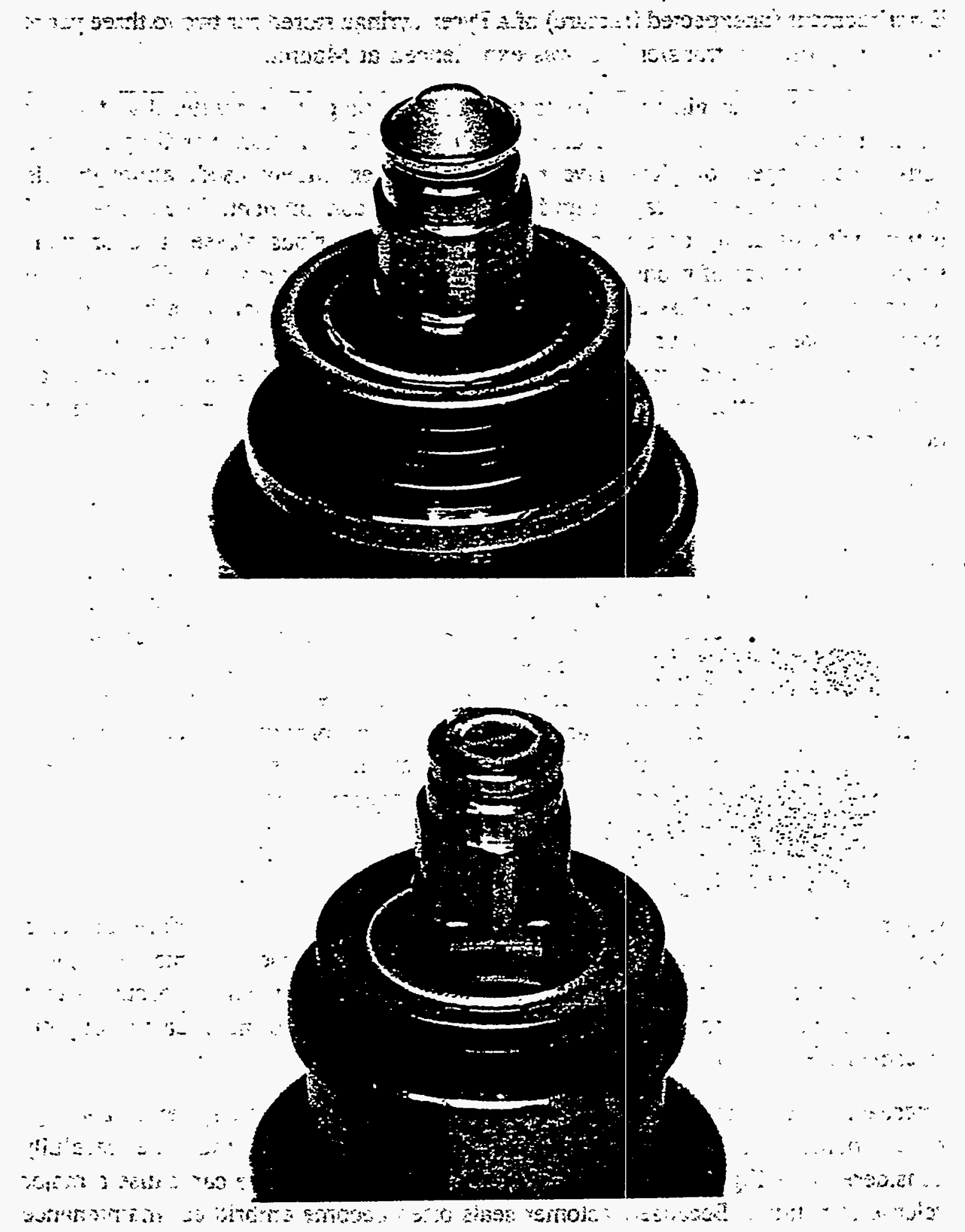

s, Figure A.2 - Kel-F stem tips on valves before (top) and after (bottom) exposure to 2 atm of high-purity $T_{2}$ for 2 years. The bottom figure. shows the results of radiation damage.
Fracture occurred at the stress point where the valve tip was closed against as stainless steel seat. 

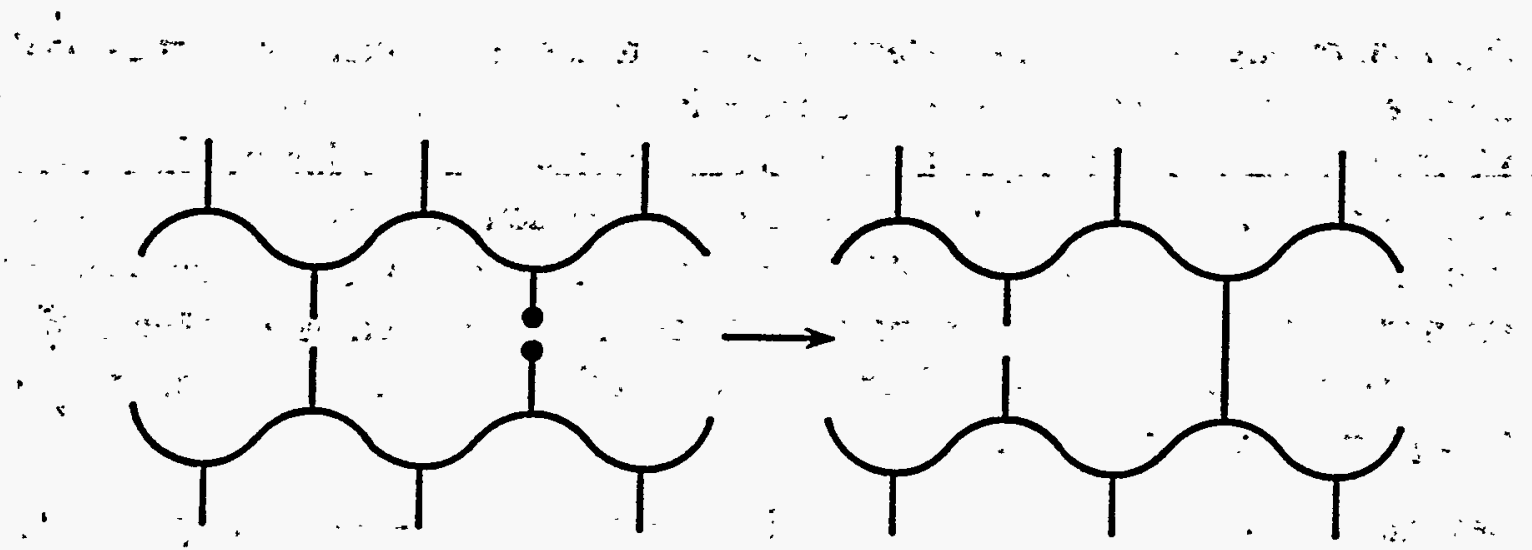

a) Cross-linking: the formation of chemical bonds between two polymeric chains.

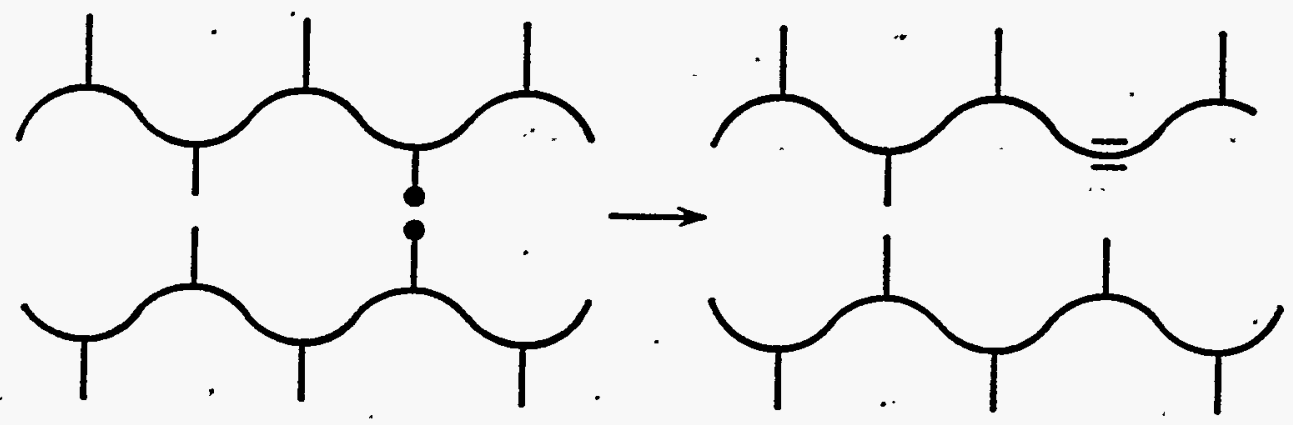

b) Unsaturation: the formation of double chemical bonds within the polymer chain.

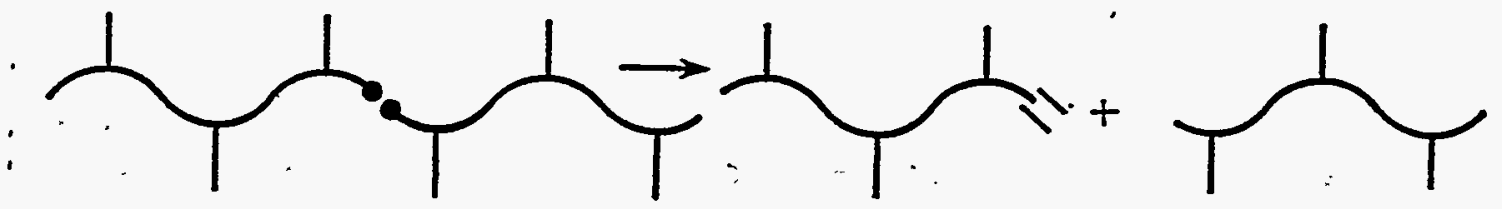

c) Degradation: the fracturing of polymer molecules.

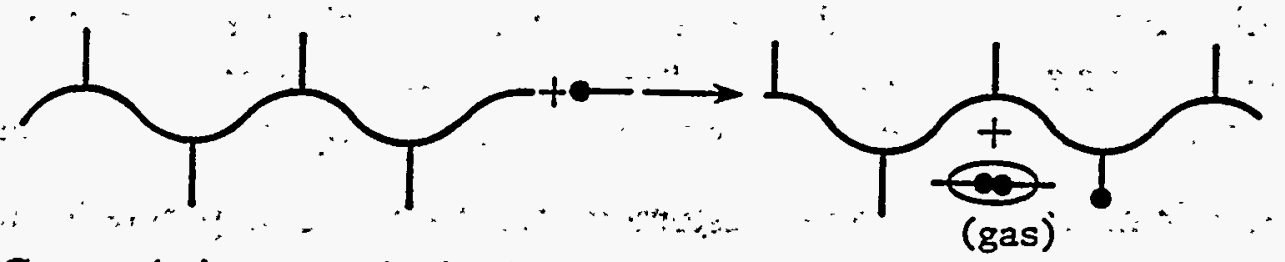

d) Gas evolution: results in the rupture of small molecules from the polymer.

Figure A.3 - Modifications to polymer chains that occur following activation by irradiation to excited 'states, ions, or radical species. 
degradation are the most important processes to the mechanical properties of the polymer. These both compete in a material, but those polymers that are most sterically hindered appear to preferentially degrade. Steric hindrance prevents neighboring chains from linking and also imparts structural strains that are relieved upon chain scissioning. Cross-linking is noted mechanically by an increase in tensile strength and a decrease in elongation, whereas degradation is evidenced by a decrease in tensile strength, an increase in elongation, and softening of the polymer to a gummy consistency [A.30].

Several factors affect polymer stability. First, energy-delocalizing aromatic structural groups increase polymer stability by distributing energies of excited states. In addition, halogen atoms within polymers generate free radicals and thus promote radiation damage. Substituents on aromatic groups that extend the delocalized bonding network are further stabilizers. Finally, saturated aliphatics are more radiation- resistant than those that are unsaturated; isolated double bonds are readily excited to ions or radicals [A.29].

Organic compounds, in order of decreasing radiation resistance, are aromatics, aliphatics, alcohols, amines, esters, ketones, and acids. Figures A.4 through A.7 show the relative radiation resistances of thermoplastic resins, thermosets, elastomers, and base oils to gamma radiation [A.29]. Extension to beta radiation is probably reasonable. In tritium gas, however, substantial differences in irradiation of polymer surface as compared to bulk can occur. This results from the greater density of tritium (and the much greater range of the beta in the tritium gas) outside the polymer compared to inside the polymer bulk.

Some direct experience of polymers with tritium has been obtained. Teflon, Viton, or Kel-F exposure in tritium produces the acid TF, noted as $\mathrm{SiF}_{4}$ gas in a glass system [A.31]. Because of this acid production, tritium + moisture + Teflon in a stainless steel system at pressures of approximately $1300 \mathrm{~atm}$ caused catastrophic stress corrosion cracking of $0.76-\mathrm{mm}$ thick stainless steel tube walls in 16 hours. Substituting deuterium for tritium or removing Teflon or moisture caused no failure [A.32]. Also, Figure A.4 shows that radiation damage to Teflon is more severe than to all other thermoplastics, a fact that has been confirmed in tritium handling. Teflon is therefore not recommended in the presence of concentrated tritium streams.

The increase in hardness of several elastomers after 87 days of exposure in 100 torr tritium was investigated [A.31]. Hardening increased in the following order: natural - butadiene/styrene - chlorosulfonates < butadiene/acrylonitrile " chloroprene < silicone(crumbled). This series follows quite well the relative stabilities as determined under gamma radiation. Another experiment noted the total compression set in several elastomers at 100 atm•days tritium exposure [A.33]. Damage increased in the series: $\mathrm{EPR}<\mathrm{SBR}<$ Viton $<$ nitrile $<$ urethane $<$ silicone. 


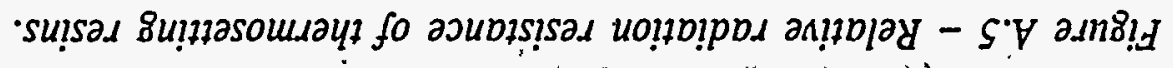

(כ) $L_{-} 6$ s6ja 'asog ajnsodx $\exists$ emureg

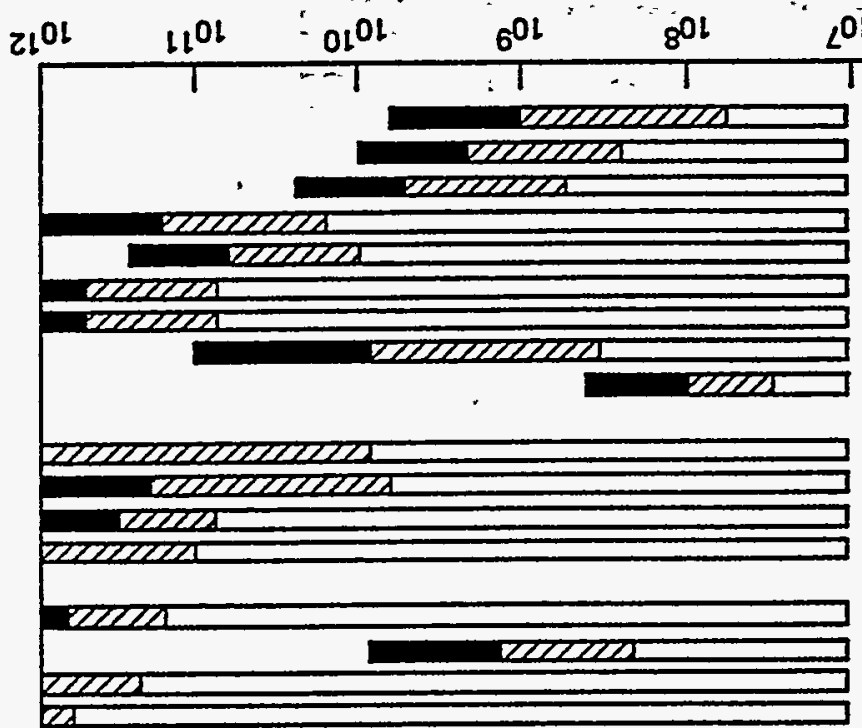

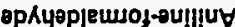

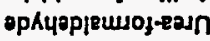

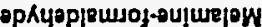
u!sod'ouesnpa|lyun 'ouoग!Is

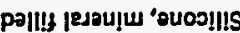

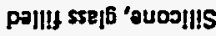
pollgun 'A27sokiod

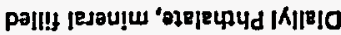
pall!! [esau! 'Jazsokjod pशIIII SSE 16 ' 20250 Ritod ourutasnkjod

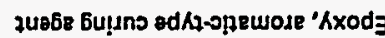

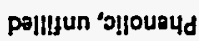

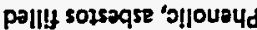

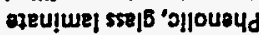

esก pอมฺแแ!

ANOJFejs!jes UaHO गqEsn skemןe KjJeכN

ग!ISEId to AI!!!?

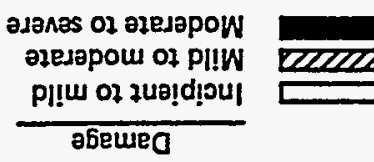
96euro

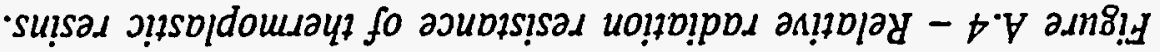

(0) ${ }_{7} 6$ s6.

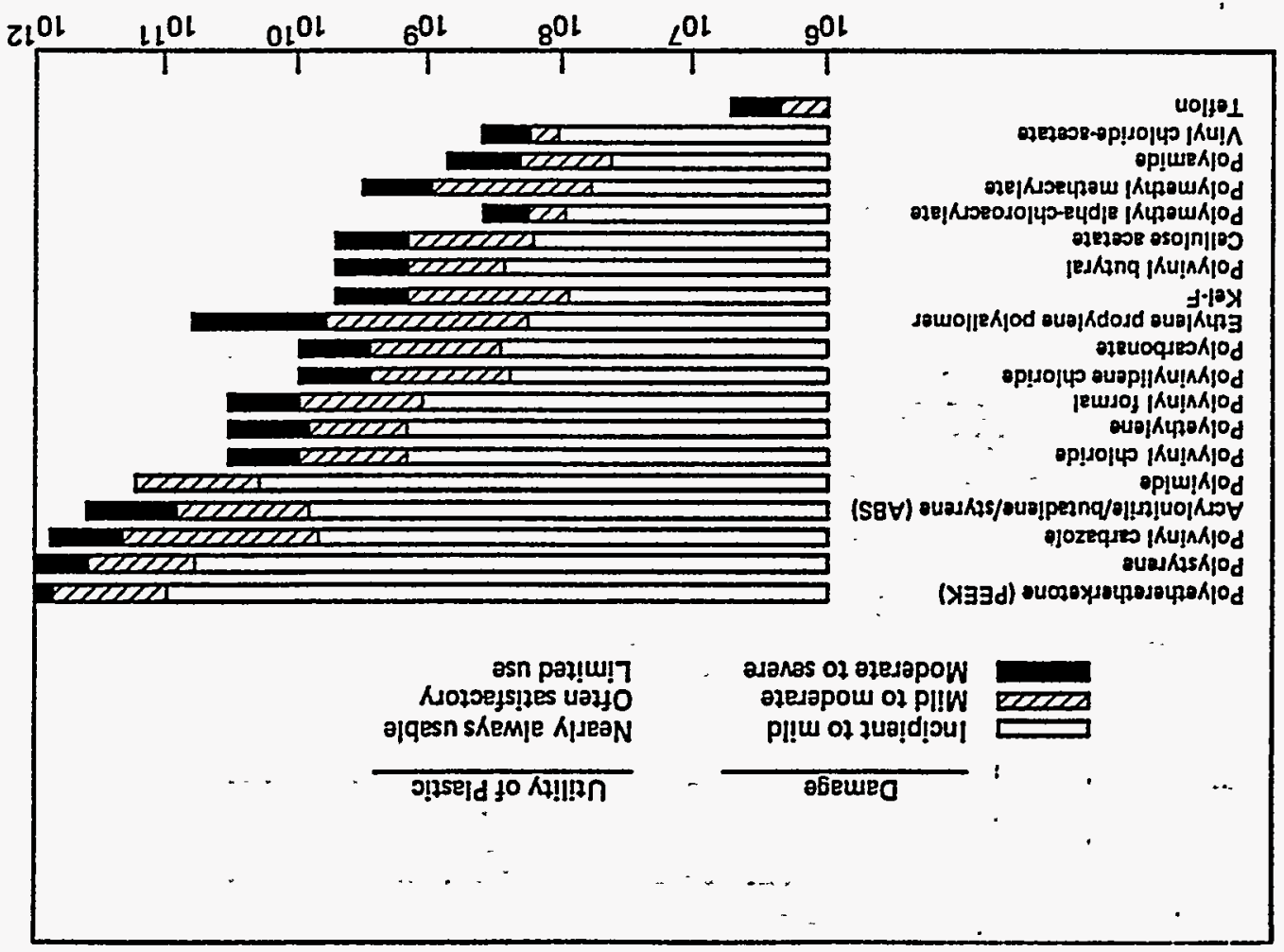




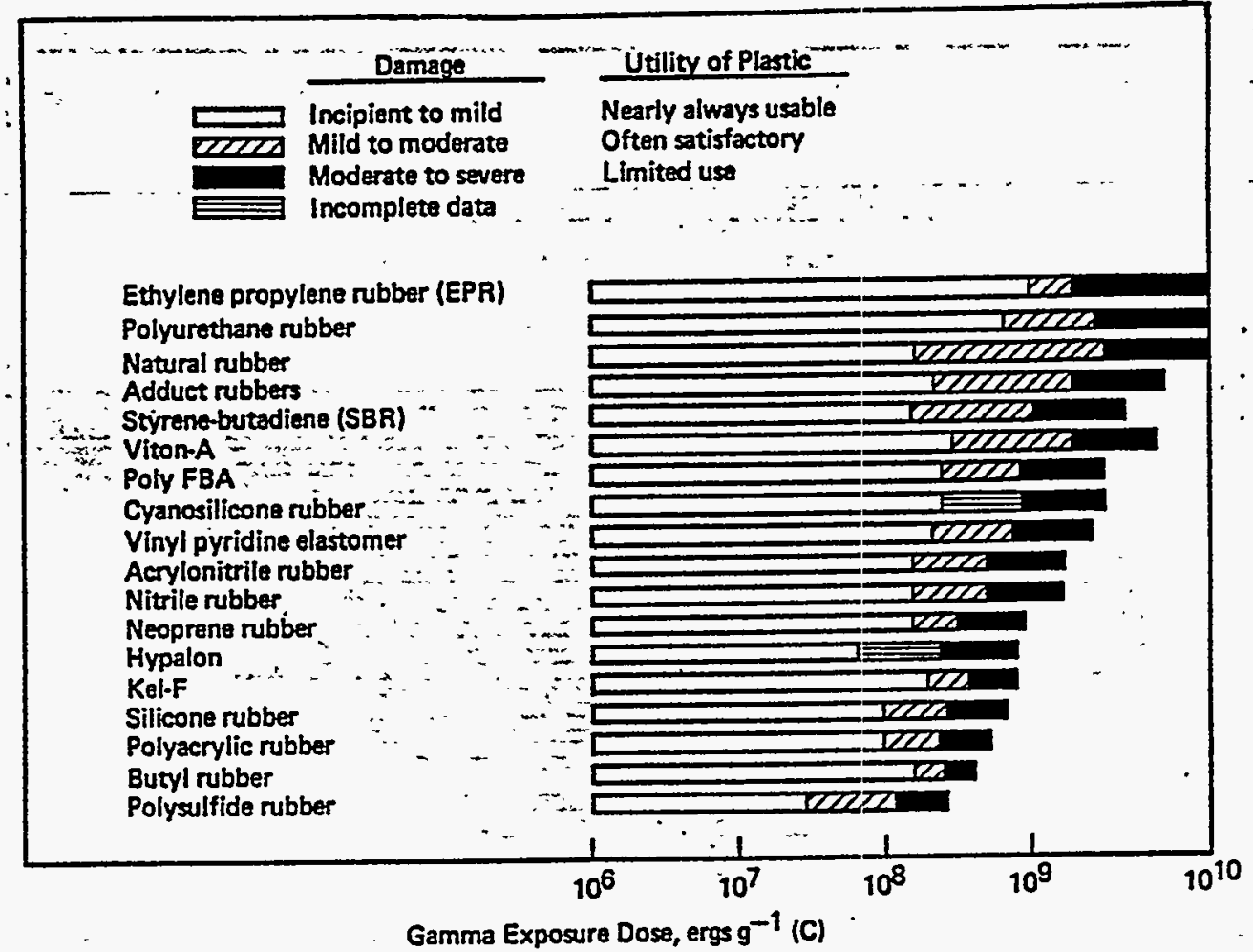

Figure A.6 - Relative radiation resistance of elastomers.

Gamma Radiation resistance of base oils

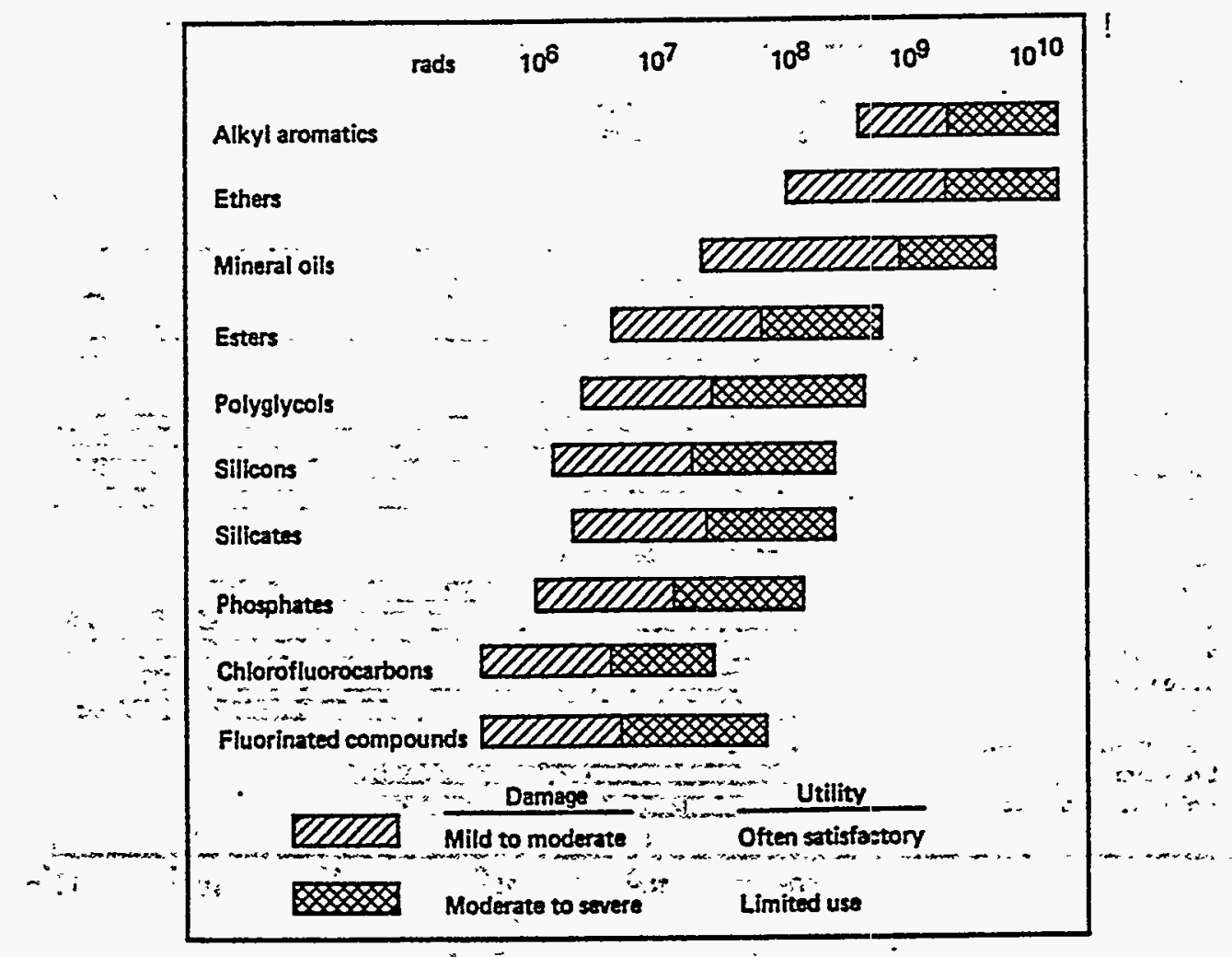

Figure A.7 - Relative radiation resistance of base oils. 
Surface and bulk effects have been noted in numerous polymer/tritium studies. In one study, hardening of neoprene occurred throughout the bulk, while hardening of natural rubber primarily occurred at the surface (crack propagation) [A.31]. Total incorporation of tritium into a polyethylene powder was found not to be a function of the amount of powder, but of the exposed surface area [A.34]. Radiation-induced fluorescence from the surface of high-density polyethylene exposed to tritium was shown to be orders of magnitude greater than that from the bulk [A.35].

Polyimides (good in the presence of gamma radiation) appear good in tritium handling and are recommended. Vespel stem tips for valves, when used with sufficient sealing force, continue to seal for several years in tritium ("STP). When used with less sealing force, however, leaks have been-noted across valve tips, possibly because of surface hardening. Polyimide gaskets under constant sealing load are probably adequate for years. In a documented study, after several polymers were exposed to tritium at approximately 1.5 atm for 130 days, tritium-induced polymer hardening increased in the series: Vespel (polyimide) "Kalrez (perfluoro) < Viton (perfluoro) [A.36].

Saturated hydrocarbon mineral oils (e.g., Duo-Seal) require frequent changes in tritium service because of vapor pressure increases (offgassing) and liquid viscosity increases. Silicone oils are rapidly polymerized or solidified. Polyphenyl ether oils last for years in similar service, but are expensive and may absorb significant amounts of tritium.

Fluorinated pump oils are not recommended for tritium service and certainly not for tritiated water vapor service. Tritium fluoride evolution and corrosion may result.

\section{A.7. References}

A.1. C. L. Bisson, and W. D. Wilson, "Atomistics of Tritium and Helium-3 in Metals," in Tritium Technology in Fission, Fusion, and Isotopic Applications, American Nuclear Society National Topical Meeting, Dayton, Ohio, 1980, CONF-800427, p. 78.

A.2. G. R. Caskey, Fusion Technol., 8 (1985), p. 2293.

A.3. A. J. West, and D. E. Rawl, "Hydrogen in Stainless Steels: Isotopic Effects on Mechanical Properties," in Tritium Technology in Fission, Fusion, and Isotopic Applications, American Nuclear Society National Topical Meeting, Dayton, Ohio, 1980, CONF-800427, p. 69.

A.4. G. A. Morris, Methane Growth in "Tritium Gas Exposed to Stainless Steel, UCRL-78162, Lawrence Livermore National Laborabory, Livermore, California (1976). : 
A.5. R. W. Bonham, and D. M. Holloway, J. Vac. Sci. Technol., 14 (1977), p. 747.

A.6. J. T. Gill, J. Vac. Sci. Technol., 17 (1980), p. 645.

A.7. J. T. Gill, W. E. Moddeman, and R. E. Ellefson, J. Vac. Sci. Technol., AI (1983), p. 869.

A.8. T. Hirabayashi, M. Saeki, and E. Tachikawa, J. Nucl. Mater., 120 (1984), p. 309.

A.9. T. Hirabayashi, M. Saeki, and E. Tachikawa, J. Nucl. Mater., 126 (1984), p. 38.

A.10. T. Hirabayashi, M. Saeki, and E. Tachikawa, J. Nucl. Mater., 127 (1985), p. 187.

A.11. T. Hirabayashi, M. Saeki, and E. Tachikawa, J. Nucl. Mater., 136 (1985), p. 179 and references therein.

A.12. R. S. Carlson, "The Uranium-Tritium System - The Storage of Tritium," in Radiation Effects and. Tritium Technology for Fusion Reactors, CONF-750989, Oak Ridge National Laboratory, 1976, p. IV-36.

A.13. E. Wicke, and K. Otto, Z. Phys. Chem., 31 (1962), p. 222.

A.14. J. T. Gill, B. E. Anderson, R. A. Watkins, and C. W. Pierce, J. Vac. Sci. Technol., Al (1983), p. 856.

A.15. M. S. Ortman, T. J. Warren, and D. J. Smith, Fusion Technol., 8 (1985), p. 2330.

A.16. R. C. Bowman, et al., Fusion Technol., 8 (1985), p. 2337.

A.17. H. Wenzl, Intl. Metals Reviews, 27 (1982), p. 140.

A.18. E. L. Huston, and G. D. Sandrock, J. Less-Common Met., 74 (1980), p. 435.

A.19. C. Boffito, et al., J. Vac. Sci. Technol., 18 (1981), p. 1117.

A.20. T. Hashino, and Y. Okajima, J. Phys. Chem., 77 (1976), p. 2236.

A.21. J. B. Condon, and E. A. Larson, J. Chem. Phys., 59 (1973), p. 855.

A.22. W. V. Lampert, et al., J. Vac. Sci. Technol., 18 (1981), p. 1121.

A.23. V Malka, et al., "Investigations on Sorption and Diffusion of Tritium in HTGR-Graphite," in Tritium -Technology in Fission, Fusion, and Isotopic Applications, American Nuclear Society National Topical Meeting, Dayton, Ohio, 1980, CONF-800427, p. 102. 
A.24. D. O. Coffin, and C. R. Walthers, Methane Generation from Graphite-Tritium Interaction, LA-7627-MS, Los Alamos National Laboratory, Los Alamos, New Mexico (1979).

A.25. J. E. Shelby, J. Appl. Phys., 45 (1974), p. 2146.

A.26. C. M. Hartwig, J. Chem. Phys., 66 (1977), p. 227.

A.27. M. Saeki, Radiochimica Acta, 38 (1985), p. 37.

A.28. D. O. Coffin, Tritium Compatibility of Alumina and Fosterite, LA-8021-MS, - Los Alamos National Laboratory, Los Alamos, New Mexico (1979).

A.29. M. H. van de Voorde, Effects of Radiation on Materials and Components, CERN 70-5, European Organization for Nuclear Research, 1970.

A.30. D. Sisman, et al., Radiation Effects on Organic Materials, Chapters 5, 6, 7, 9, R. O. Bolt and J. G. Carroll (eds.), Academic Press, New York, 1963.

A.31. L. M. Dorfman, The Interaction of Tritium with Polymeric Materials, KAPL-980 (Del.), Knolls Atomic Power Laboratory, Schenectady, New York (1953).

A.32: B. G. Monahan, et al., Materials Compatibility Study of 316 Stainless Steel at the LLL Tritium Facility, UCRL-81028, Lawrence Livermore National Laboratory, Livermore, California (1978).

A.33. P. E. Zapp, Effects of Tritium in Elastomers, DP-MS-82-54, Savannah River Plant, Aiken, South Carolina (1982).

A.34. P. M. S. Jones, and R. Gibson, The Interaction of Tritium Gas with Polythene, AWRE-0-16/63, Atomic Weapons Research Establishment, United Kingdom (1963).

A.35. J. T. Gill, Fusion Technol., 8 (1985), p. 2318.

A.36. B. D. McLaughlin, "Gasket Material Evaluation for Tokamak," Memorandum DPST-79-255, Savannah River Laboratory Technical Divison, Aiken, South Carolina, February 8, 1979.

\section{A.8. Additional Reading}

M. E. Malinowski, and P. R. Coronado, "Helium Release from Uranium Tritide," in Rudiation Effects and Tritium Technology for Fusion Reactors, CONF-750989, p. IV-53.

R. C. Bowman, and A. Attalla, "Studies of Helium Distribution in Metal Tritides," in Radiation Effects and Tritium Technology for Fusion Reactors, CONF-750989, p. IV-68. 


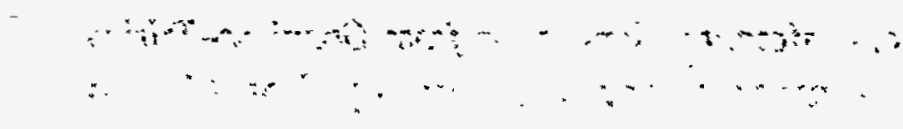

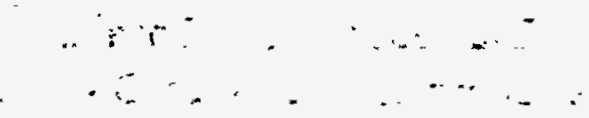

"3 "ary

(

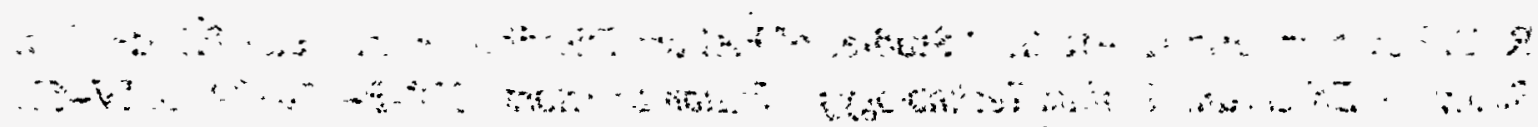




\section{Appendix B Procedures}

\section{B.1. Operating Procedures}

\section{B.1.1. General Operating Procedures -}

All tritium operations should be conducted under the guidance of, and in compliance with, a general operating procedure for tritium operations. The general operating procedure provides a guide for conducting operations by specifying proven operational techniques, incorporating facility design features into operations, incorporating support organizational functions into operations, and describing how to use these fundamental elements to conduct quality tritium operations safely and efficiently. The general operating procedure is intended to define the broader aspects of conducting tritium operations. Supplemental procedures are required where more detailed guidance is needed (Section B.1.2). Ordinarily, a general operating procedure encompasses the operations conducted in a building or large area, depending on the diversity of the tritium operations conducted within the facility. Since it is desirable to integrate tritium service functions within the same area as the tritium operations, general operating procedures are ordinarily quite voluminous.

Some fundamental elements to be considered in preparing a general operating procedure are discussed in the following paragraphs. Additional elements may be applicable to the procedure, depending on the operations. Once these elements are identified, the general operating procedure can be written so that guidance or criteria are incorporated in the procedure to meet intended objectives.

\section{B.1.1.1. Environment}

The preparers of the operational procedure, as well as the designers of the facility, should be fully aware of the regulations concerning the release of tritium to the environment in all possible forms and should develop procedures accordingly. In addition, management philosophy needs to be considered since administrative restrictions may be more limiting. This philosophy is often reflected in established effluent control goals that may become increasingly difficult to meet. Tritium handling systems should be designed, constructed, and operated to keep tritium effluents to the environment and occupational exposures as low as reasonably achievable (ALARA), the philosophy presented in Chapter 2.

\section{B.1.1.2. Quality and Efficiency}

The necessary level of quality and efficiency as a function of the end product should be defined. The manufacturing technique or process should be fully understood before a general operating procedure is generated. For this reason, the designers of 
the system should also provide operating procedures. The guidance contained within the procedures should minimize constraints on the operations while providing as much direction as possible so that quality results or products are produced.

\section{B.1.1.3. Technology}

The technology and operating techniques associated with successful tritium operations should be understood and, where possible, reflected within the guidance offered by the operating procedure. Some areas of high concern, where expertise needs to be incorporated into the procedures, are operation of metal hydride pumps (uranium and palladium beds), cryogenic pumping, pressurization, molecular sieve operation and maintenance, pressure relief mechanisms, calibration and maintenance of measurement systems for material control and accountability, transfer pump operation and maintenance, inert atmosphere control, passbox operation, vacuum and dry-train operation and maintenance, cold trapping techniques, and mass spectrometer sampling techniques. Many operations have the potential for failure. Therefore, procedures should be written assuming that the worst possible event could and probably will occur unless extreme caution is taken and proper handling techniques and procedures are followed.

\section{B.1.1.4. Hazards}

Explosive, high pressure, and radiological hazards should be identified in procedures for tritium operations. Even the best-designed tritium facility should be viewed as inherently hazardous. Procedures need to be explicit to prevent or mitigate accidents and to minimize the potential for release of material. The authors of procedures should be those who know the most about the systems and their operation. Notes of caution for critical steps are recommended to explain the logic of the operation sequence and the hazardous consequences of failure to follow the procedures.

\section{B.1.1.5. Unacceptable Actions}

Wherever possible, unacceptable actions should be cited in the general operating procedure. This particularly applies to actions that pose serious consequences or that could negatively impact operations.

\section{B.1.1.6. Responsibilities}

The general operating procedure should stress that safety, security, and compliance with procedures are the responsibility of the individual operator and operational management. All operating procedures should be reviewed and approved by at least the first level of management.

\section{B.1.1.7. Health Physics}

The approved health physics practices related to personnel, facilities, wastes, contamination control, protective equipment, maintenance operations, monitoring, 
bioassay, and emergency actions should be well-documented at tritium facilities. These practices must be integrated into the general operating procedure, and it must be stressed that the highest priority of any tritium operation is safety.

\section{B.1.1.8. Emergencies}

Emergency plans and procedures must be developed in accordance with the requirements of DOE Orders 5500.2A [B.1] and 5500.3 [B.2]. All foreseeable emergencies involved in operations should be addressed within the general operating procedure and the emergency plans. Actions for specific emergencies should be defined. A course of action that will allow operations to be placed in a safe holding condition with minimal time and effort should be identified. Several actions may need to be identified, depending on the operation in progress at the time of an emergency. Evacuation of a laboratory or building may be required; therefore, evacuation routes, assembly areas, and reporting requirements should be included in the written emergency procedures.

\section{B.1.1.9. Service Functions}

All functions that support primary operations should be described in the general operating procedure. Mass spectrometry, waste handling, calorimetry, and recovery are some of the functions normally involved in tritium operations. The same broad guidance that applies to the tritium operations should apply to these functions.

\section{B.1.2. Detailed Operating_Procedures}

Detailed operating procedures are required for tritium operations that are highly complex or involve a high risk. Detailed procedures are a guide for trained, knowledgeable personnel to follow to minimize or avoid actions that may release material to the environment, damage equipment, injure personnel, or compromise the quality of operations. The detailed operating procedures should be prepared in compliance with the general operating procedure. For complex or high-risk operations, a step-by-step guide, with each step requiring a sign-off by two operators, is recommended. An additional feature that should be included in a detailed operating procedure is a requirement that any deviation from the procedure be approved by a designated supervisor.

The same elements considered for the general operating procedure should be considered for a detailed operating procedure. The guidance, however, should be much more specific. The extent of the detailed guidance is an important consideration. A procedure that is too detailed might inhibit the efficiency of a function.

When preparing the procedure, the complexity of the operation, the condition of the facilities and equipment, and the risk to or worst possible effects on operations, site reputation, product, and personnel in the event of an accident must be taken into 
account. The procedure should include only the essential objectives. These should be determined by a detailed analysis of the consequences that could result from a particular unplanned action or accident

\section{B.2. Health Physics Procedures}

This section is intended as a guide for preparing health physics procedures for tritium operations. As technology and safety requirements related to tritium safety change, the health physics procedures' must be ur dated:" For new or unusual tritium operations, more-specific health physics procedures that address the operations may, be required to supplement general health physics procedures.

\section{B.2.1. General Information}

This section provides an introductory overview of the information contained in the health physics procedure.

\section{B.2.2. Purpose and Scope}

The intended scope and purpose of the procedure should be stated in this section.

\section{B.2.3. Responsibilities}

Management and employee responsibilities in complying with health physics procedures should be clearly stated in this section. In general, supervisors are responsible for the radiation safety of their employees and of visitors from outside organizations. As a condition of employment, tritium workers are responsible for performing assigned duties by following established health physics procedures. The responsibility of maintaining lines of communication between operations and health physics should be clearly defined. Finally, the responsibilities of the health physics organization, including surveying, monitoring, and bioassay reporting to operations management, should be stated.

\section{B.2.4." Building or Facility Description}

A description of the building and associated facilities should be provided. In this section, building floor plans and evacuation routes, areas where protective clothing is required, monitoring locations, and high-risk and low-risk areas should be discussed.

\section{B.2.5. Orientation and Training}

The requirements for health physics orientation and training of all tritium operations personinel should be stated. Some topics suggested for training include chemical and physical properties of tritium; protective clothing and equipment; monitoring and interpreting readings and level limits; biological effects of tritium exposures (urine sampling tand other personnel monitoring' methods and associated equipment); responses to alarms; caution and warning signs; radiation control areas; maintenance 


\section{B.2.5. Orientation and Training}

The requirements for health physics orientation and training of all tritium operations personnel should be stated. Some topics suggested for training include chemical and physical properties of tritium; protective clothing and equipment; monitoring and interpreting readings and level limits; biological effects of tritium exposures (urine sampling and other personnel monitoring methods and associated equipment); responses to alarms; caution and warning signs; radiation control areas; maintenance permits and operations; transfers of equipment and items within and outside of the laboratory, the building, and the plant site; decontamination of contaminated equipment and facilities; and environmental policies and effluent limits. For additional information on training, refer to Appendix $\mathrm{C}$.

\section{B.2.6. Monitoring}

Health physics organizations are required to maintain accurate, continuous room air monitors, provide monitoring services to personnel, and perform routine surveys of the contamination level of facilities. 'In this section of a health physics procedure, the maintenance, calibration, and routine examination of all radiation monitors used to indicate the level of radioactivity in the laboratories and in the effluents to the environment should be addressed.

\section{B.2.7. Protective Clothing and Equipment}

This section should give a complete description of all available protective clothing and equipment, including proper operation, handling, and use. Some of the topics addressed in this section should be respiratory protection (i.e., various types of masks and their proper use), shoe covers, rubber gloves (all types available), air-supplied plastic suits, and special clothing for high-risk tritium areas.

\section{B.2.8. Tritium Monitors}

This section should present a detailed account of the operation, use, and calibration of all available tritium monitors, along with information on analyzing readings. Methods of calculating tritium values should also be addressed. The various forms of tritium (HTO, oxide, or elemental gas) and how they affect measured results should be discussed. Detailed procedures are required, as personnel from departments other than health physics may be required to use tritium monitors and interpret the readings.

\section{B.2.9. Tritium Counters}

A description of the tritium counters used for measuring surface contamination should be presented. Included in this description should be the theory of 
Other essential topics related to breaching operations that should be covered in this section of the health physics procedure include testing for the presence of liquids (visual and nondestructive testing techniques), reducing contamination levels (use of increased air flow and solvents), using tent enclosures and protective clothing, performing post-breaching contamination surveys, and dealing with various types of tritiated contamination. The breaching operation should be documented from start to finish. Therefore, various forms, associated instructions, and approval or permit documentation should be included in the health physics procedure.

Special monitoring procedures are used during nonroutine operations such as breaching. Since such monitoring is often associated with operations having higher risks, the procedure should identify any unusual actions and requirements.

An accounting procedure and techniques for decontaminating tools and equipment should also be described in this section. The allowable level of contamination after decontamination should be specified.

The documentation, approvals, and allowable level of contamination for transferring equipment should be addressed. Similarly, the documentation, approval, packaging requirements, allowable quantities, and special handling requirements for transferring radioactive materials should be included.

The various types of wastes and the approved techniques for their packaging and disposal should be defined. The various approved markings for contaminated equipment, facilities, and other items should be presented. These markings convey an automatic warning or specific level of contamination. Specifications for designing and applying markings are available from the American National Standards Institute (ANSI).

Detailed guidance describing the decontamination techriques for personnel exposed to tritium should also be presented. In addition, the requirements for decontaminating wounds and limitations for access to radiation areas by personnel with wounds should be discussed.

\section{B.3. Maintenance Procedures}

The maintenance necessary to keep a tritium facility functioning properly presents special problems. Because of the health physics considerations necessary for all maintenance operations within a tritium facility, the expense and number of man-hours are much greater than for maintenance operations in a nonnuclear facility. A well-designed maintenance procedure offers the greatest possibility of ensuring that the maintenance operations for a tritium facility can be conducted in the safest and most efficient manner.

Maintenance of equipment in a tritium facility requires a prejob or planning conference, which should be described in the maintenance procedure. In addition, a 
Radiation Control Area Maintenance Permit is necessary for all such maintenance. Requirements and responsibilities for obtaining a permit, along with a description of documentation that may be required before a permit is issued, should also be discussed in the maintenance procedure.

\section{B.4. Emergency Procedures}

\section{B.4.1. General}

A tritium facility must have emergency procedures to ensure preparedness for a variety of emergencies. The procedures should be unequivocal and require minimal operations since emergencies occur suddenly and allow little time for interpreting procedural guidance. Not all emergency scenarios can be covered by a procedure, but certain fundamental emergency actions and monitoring techniques are applicable to almost all emergencies involving tritium. Some of the elements suggested for discussion in emergency procedures applicable to tritium facilities follow.

\section{B.4.2. Types of Emergencies}

All emergencies cannot be covered by any one procedure. Therefore, specific procedures are needed to address emergencies with the highest probability of occurrence and those with the most significant impact as determined by a study of the operations, equipment, and failure modes.

One of the most common emergencies is a tritium leak (catastrophic to a minimum level of detection) to the laboratory or outside environment. The emergency procedure for leaks should address techniques for locating and isolating the source of the leak, emergency air flow, maximum permissible exposure limits, protective equipment, evacuation routes and assembly areas, personnel and bioassay emergency monitoring, notification and reporting requirements, environmental monitoring, potential explosives, locations of barricades and emergency monitors, and decontamination operations. These elements are fundamental to all types of emergencies, regardless of seriousness.

\section{B.4.3. Personnel Contamination or Injury}

Procedures for emergency actions involving contaminated and/or injured personnel require specific instructions. Some elements to be considered are removing contaminated personnel from a radiation area to a nonradiation area for decontamination or other treatment, decontaminating personnel, determining exposures or ingestion (bioassay), and decontaminating and treating contaminated wounds.

\section{B.4.4. Special Emergency Teams}

Instructions are required to delineate the organization and direction of emergency teams. These should be included in the emergency procedures.s. 
B.4.5. Emergency Alarms

Alert, evacuation, and all-clear signals should be addressed by the emergency? procedures. They should be clearly defined and unmistakable to all personnel to ensure the proper response. Alarms, lights, and other signals that warn the operator of the status of critical points of an operation should be identified and addressed in specific operating procedures for equipment. The required response should be specified.

\section{B.5. Refèreñces}

B.1. DÖE Örder 5500.2A, Emergency Notification, Reporting, and Response Levels, April 13, 1988.

B.2. : DOE Order 5500.3, Reactor and Nonreactor Nuclear . Facility Emergency Planning, Preparedness, and Response Program for DOE Operations, August 13, 1981.
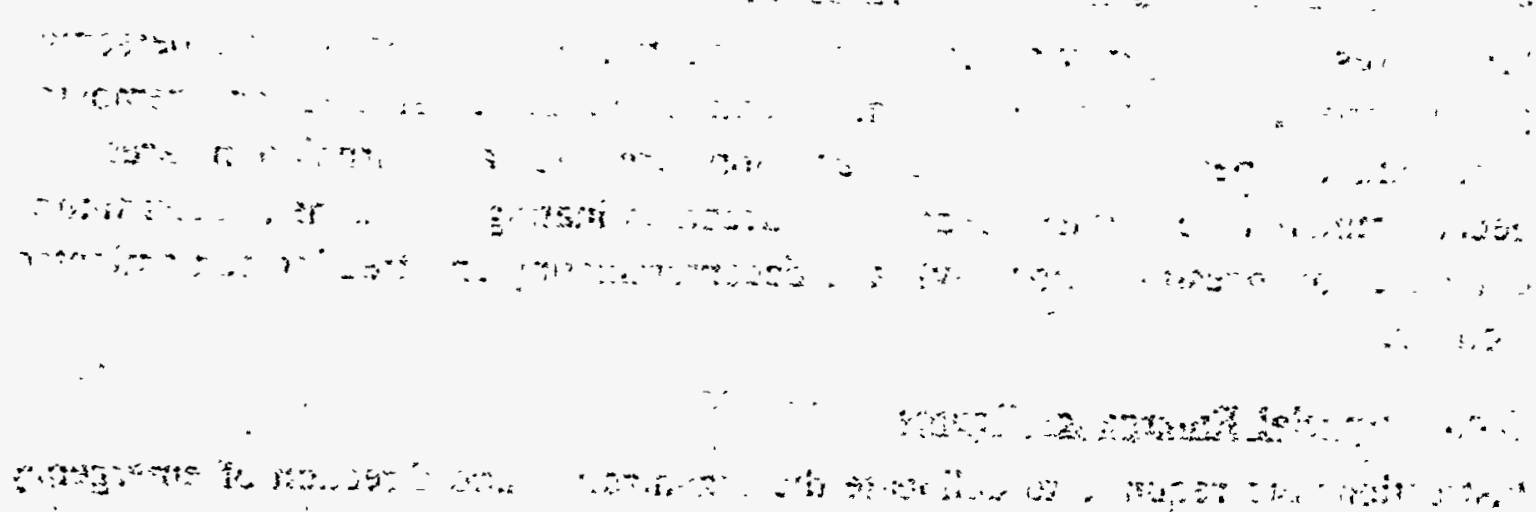

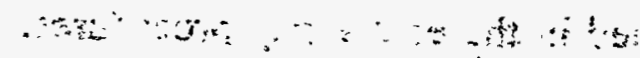




\section{Appendix C \\ Training}

\section{C.1. Introduction}

The tritium training program for DOE facilities, DOE contractors, and commercial users may vary according to specific objectives outlined by the DOE, the contractor, the commercial user, and stated or implied requirements, such as OSHA, ANSI, and the EPA. However, because of DOE Orders 5480.5, 5480.11, 5480.18, 5480.19, and 5480.20 , a tritium training program needs to be well planned, developed, and documented.

With limited technical and training support resources, it becomes prudent to develop activities and allocate assets in an efficient and productive manner. The following sections present recommendations and methods that may be used for training at a tritium facility.

\section{C.1.1. Development Methods}

Many changes have come about in recent years which necessitate developing formal training programs for non-nuclear related activities: Many of these guidelines stem from the Institute of Nuclear Power (INPO) training programs and several DOE Orders:

- DOE 5480.19, Accreditation of Performance-Based Training for Category Reactors and Nuclear Facilities

- DOE 5480.20, Personnel Selection, Qualification, Training, and Staffing Requirements at DOE Reactor and Non-Reactor Nuclear Facilities

These cornerstone orders present criteria for approaching, designing, developing, and implementing training. Overall, this approach is known as Performance-Based Training, or simply PBT. How the PBT approach is used is somewhat up to the affected personnel, but several major points stand out, which companies may use to their collective advantage in preparing training programs for the tritium staff.

\section{C.1.2. Needs Assessment :: :}

In some cases, the facility could benefit from a needs assessment prior to initiating a training program. The facility can conduct an assessment by using identified tritium experts at the facility, or by calling on personnel from outside the company who are 
recognized as experts. If management is involved, the training program can have a positive impact in accomplishing the overall mission of the tritium facility.

The facility can conduct the needs assessment in a variety of ways including interviews, observations, questionnaires, or round-table discussion. The resulting product answers the question of whether a formal training program should be developed. It may go so far as to identify initial areas to analyze further, such as Job and Task Analysis.

\section{C.1.3. Lob and Task Analysis}

For the hands-on operating groups, an ideal, though initially time-consuming, detail can be the Job and Task Analysis. The purpose of the analysis is to identify where general and specific training is needed. Such an analysis may become the cornerstone for developing qualifications for tritium operators. The job is analyzed by using interviews, one-on-one or small group observation, small group discussion with identified subject area experts, and reviews with management. The product of the review is the task listing.

From the list, a survey is developed and sent out to the tritium staff for their input. They rate the tasks on the list according to frequency, importance, and difficulty, by using some scoring criteria, such as the chart outlined in INPO Training Accreditation Program (TAP) Manual \#2. The survey results of general and specific types of tasks are reviewed by management to create a final training list. This list indicates the content of the tritium training program.

\section{C.1.3.1. General Training Programs}

For tasks that are common and general to all, it may be possible to create a General Training Program that tritium operators take as a prerequisite for their formal On-theJob Training. Such general classes might include

- A basic course on tritium,

- Some preparation for general radiation safety, such as the tritium beta and associated hazards,

- Safety requirements in operating specific or tandem systems,

- Some form/process for Hazard Communication (awareness and/or specifics as needed),

- An orientation to the importance of developing and using good procedures in the work area. $\cdots$ 


\section{C.1.3.2. Specific On-the-Job Training}

Specific On-the-Job Training (OJT), can be developed from the technical tasks that: personnel operating tritium systems need to be familiar with and competent in. These . tasks are developed by formally reviewing tasks from the analysis. Such a review produces the steps an operator takes to successfully complete the assigned job.

\section{C.1.4. Course Design and Development}

The courses need to be developed with consistency and purpose. Such courses include written lesson plans and some measurable level of achievement from the participant, whether it is a practical exercise, oral questions, or a written test. The focus should be on the technical and performance skills needed to do the job; in short, does the operator know what he is doing, why he is doing it, what can be done to prevent problems from occurring, and what to do if an undesirable event occurs?

\section{C.1.5. Instructors}

Training issues within a tritium facility are best handled by the experts in the field, the Subject Matter Experts, or SME's. 'The SME can be documented by the site management as such, and should be considered as the key resource in developing the training program.

Additionally, the personnel that deliver the training need to be proficient in presenting material. Such personnel may typically be the SME's. In any event, the instructional staff needs to be familiar with and trained in presenting instruction, either for OJT or in a classroom. The instructors co-develop the formal lessons, write out the questions, deliver the information, and evaluate participant performance.

\section{C.2. Operator Training}

An operator is a person who performs hands-on work: i.e., does something to transfer tritium, measure tritium, experiment with tritium, or otherwise directly handle systems involving accountable units of tritium. Because of the varied professional backgrounds of operators involved, management needs to consider such factors as professional training from accredited institutions, operating experience, or other areas of professional expertise. This could very well lead to several slightly different programs: one for operators, one for supervisors, and perhaps one for support personnel.: At any rate, the degree and effort associated with the training should be commensurate with the employees' stated job functions.

\section{C.2.1. Operator Example}

As an example, a general, introductory operator training program may contain the eleven elements listed below. Such a program is not intended to instantly qualify a 
person to become a tritium operator, but rather to give the participant a basic knowledge of tritium. It prepares the participant for more detailed training for the assigned work area, such as specific On-the-Job Training.

Personnel involved could be operators, supervisors, designers, and other laboratory personnel who work immediately in a tritium area. The purpose of the course is to provide employees with relevant information on situations that they may face while working with tritium in their specific job function. The following eleven possible areas of instruction are not intended to be exhaustive.

\section{Properties of Tritium}

A good place to start is a brief overview of atomic and molecular structure along with the concept of radioactive beta decay, introduction to biological effects, and pathways for tritium uptake. The personnel should be aware of "... where the isotope originates and how it can affect them ...."

\section{Tritium Use}

Discuss the uses of tritium, as applicable to the worksite or in general, to assist in giving the staff a sense of purpose. A wide range of topics could be discussed.

\section{Properties of Gases}

Review general chemistry, specifically the relationships between pressure, volume, and temperature, to assist in establishing a common ground for the participants. Using an enclosed piston system or balloons and liquid nitrogen are straight-forward ways of demonstrating the properties of gas.

\section{Design and Installation of Tritium Systems}

To demonstrate that a good plan/design may keep problems from arising, use a discussion format with exercises exhibiting good practices in engineering buildings, rooms, or glovebox facilities.

\section{Environment. Safety, and Health}

A lecture and practice exercises on the radiological concepts of tritium can assist in delivering the idea that protecting people begins with protecting each worker. Some topics to be discussed include

- The pathology of radiological injuries

- Techniques for tracking personal dose

- Case studies of past incidents 
To illustrate key properties and protective measures, give sample problems where the participant is asked what dose might be obtained under certain conditions of operation.

\section{Safety Reviews (Operational Surety)}

Since tritium work is team work, have a discussion to show potential roles of review committees in assisting and enhancing safe operating practices. Supplement this discussion by reviewing procedures or tracking unusual events. Additionally, discuss or simulate advantages of the review committee acting as an advisory panel in resolving or preventing problems.

\section{Tritium System Maintenance \& Laboratory Techniques}

Use hands-on laboratory exercises to illustrate how to operate tritium systems, how to monitor tritium in the laboratory, and how to plan and prepare for maintenance. Participants should practice these laboratory situations in a safe environment: i.e., using cold systems and inert gases as possible.

\section{Compatibility of Materials}

Using the materials from construction, discuss and demonstrate various transport and storage mechanisms and the interactions of tritium with polymers and organics. Some ideas for demonstrations include

- Using balloons filled with different gases to experiment with permeation/diffusion rates, and

- Penetration of wood strains into cross sections of small wood samples to illustrate penetration of tritium into solid containers.

Both of these examples can show how time is a factor to consider. The latter scenario simulates the effects of tritium on different types of material.

\section{Inventory Control and Accountability}

To remind personnel about the importance of knowing where the gas is, discuss and demonstrate measurement control and accounting techniques used with tritium. Discuss examples of unaccountable gains/losses of tritium to focus on the idea that the gas is often difficult to find.

\section{Qperation of Tritium Systems}

Give the participant some beginning practice in handling gas systems with a hands-on laboratory session involving the pump transfer of a gas. The gas used does not need to be tritium; quite the contrary, "safe" and relatively inexpensive 
samples of nitrogen, argon, or helium can be used. This session could include practicing protective measures, PVT calculations, and methods of accounting for

gas. All of this can carry extra emphasis if some sort of procedural plan has been developed and reviewed, perhaps through a tritium committee.

\section{Review}

Review the activities with a simulated occurrence or real activity surrounding a past event. The situation can be in the format of, "What would you do if . . .." The participants, given the conditions of the exercise, develop a scenario that might be used to respond to the incident. Development includes applying the techniques' established in items 1 through 10 above.

\section{C3. Evaluation}

Evaluation of operator performance can take the form of oral questions, practical examples, practice laboratory techniques, or written tests. It is most likely that facility management will use a combination of these methods. Such evaluations should be reviewed for technical validity and readability. Topical questions may be chosen from a collection of questions. Senior management should establish successful completion criteria. An $80 \%$ correct response is required for successful completion according to INPO or industry standards. In any event, further time should be spent on review/ practice as needed, so that the trainee has the correct information and understands why the information is important.

\section{C.4. Support Staff Training}

Often involved in supporting tritium operations are the Health Physics or Health Protective Forces group along with the Engineering or Maintenance group. Though not actively involved in the day-to-day tritium handling operations, these personnel should have their own programs geared toward the tasks they perform. However, one common link among all groups may be some general training on radiological protection.

\section{C.5. Documentation}

\section{C.5.1. Location of Documentation on Training}

Documentation of general and specific training should be maintained as part of a record system. Each facility may do this may dilfferently. One possibility is to have primary records stored in a central repository while duplicate records are kept near the tritium groups. This would enable tritium groups to have access to lessons, plans, and tests, yet permit the line user to have quick access for personnel reviews and audits. 


\section{C.5.2. Documentation for Historical Purposes}

Documentation of the requirements for the general and specific training program permits the user to trace the training progress of the staff. Such records can show the history of the training as well as when training is needed in the future.

\section{C.6. References}

C.1. DOE Order 5480.5, Safety of Nuclear Facilities.

C.2. DOE Order 5480.18, Accreditation of Performance-Based Training for Category A Reactors and Nuclear Facilities.

C.3. DOE Order 5480.19, Conduct of Operations Requirements for DOE Facilities.

C.4. DOE Order 5480.20, Personnel Selection, Qualification, Training, and Staffing Requirements at DOE Reactor and Non-Reactor Nuclear Facilities.

C.5. Training Accreditation Program Planning Manuals, (TAP 1, 2, 3). 



\section{Appendix D Inventory Control}

\section{D.1. Measurements}

Knowledge of the amount of tritium on hand or involved in a particular operation is essential for most tritium work. There are several ways to determine the amount of tritium present in a container or system. The method chosen will depend on the amount of tritium, its chemical and physical form, and the analytical methods available. For the purposes of this guide, it will be assumed that the physical conditions are those normally encountered in tritium process operations: temperatures around $300 \mathrm{~K}$ and pressures between 1 and 5,000 torr. Under these conditions, tritium can be in the elemental form as a gas, or it can be in some solid, liquid, or gaseous compound. In light of the above restrictions on pressure and temperature, uncombined elemental tritium in either the solid or liquid state will not be discussed.

Solid compounds can be assayed by calorimetry of the entire item of interest or of a representative sample of the whole. A sample can also be subjected to a destructive force that liberates the tritium. The tritium can then be captured and assayed by one of several techniques, including mass spectrometry, ionization counting, or calorimetry.

Liquid compounds can be assayed by calorimetry or by liquid scintillation counting. An alternate method is to decompose an aliquot of the material and assay the resultant gas by one of the methods discussed in Appendix E.

Gaseous materials can be assayed by calorimetry, ionization or gas proportional counting, or mass spectrometry. In most cases the latter two methods require that a representative sample be obtained and introduced into the assay instrument.

Two prime criteria to use in choosing an assay method are the safety of the personnel involved and the potential for a release to the environment. In some cases it may be difficult to obtain a representative sample safely. Withdrawing the sample may expose the operator to an unnecessary hazard, particularly if the compound is toxic, as is tritiated water, or if the compound easily and rapidly permeates protective clothing, as do some tritiated solvents. If a sample or the entire unit is to be moved to another location for assay, it must be in a container that preserves the integrity of the material and also totally contains the tritium. A secondary, or transport, container may be required to afford the necessary containment in the event of an accident during transport. Using metal capillary tubing to transport gas samples from a tank or process line to a mass spectrometer is a proven technique that preserves the 
integrity of the sample and totally contains the tritiated gas (see Appendix E). For more information on tritium containment, see Section 2.3.

After assay is completed, calculations are needed to determine a value for the amount of tritium. These may involve nothing more than a consideration of the size ratio between the assayed sample and the unknown. In the case of a quantity of gas that has been assayed by mass spectrometry or a tritiurn activity meter (TAM), the quantity of the gas must be known. In many situations, this quantity is calculated from the pressure and temperature of the gas in a container of known volume. By combining this information with a knowledge of the gas equation of state, a pressure/volume/temperature (PVT) calculation can be performed to calculate the number of standard liters of gas present. This volume is then multiplied by the assay value to determine the amount of tritium. For more information on this subject, see Section E.3.1.

\section{D.2. Measurement Control}

A measurement control system is recommended and, in most cases involving government-owned tritium, is required, with whatever measurement method is used. Measurement control, simply defined, is a method of determining whether a measurement system is functioning properly. Measurement control can determine the validity of tritium measurements. It will also aid in solving problems related to tritium inventories by pinpointing when the measurement system went out of control and possibly indicating the nature of the problem. In addition, a good measurement control system indicates when the situation is back in control. It can also aid in maintaining the precision of analytical instruments.

The following four elements are suggested in a measurement control plan: well-defined responsibilities for the quality of measurement results, control assessment, and removing a measuring device from and returning it to service; periodic control measurements using standards, comparisons with other techniques, repetition of the measurements over time, interlaboratory exchange programs, and diagnostic indicators; periodic assessment of the degree of control through the use of control charts, statistical tests, and searches for significant deviations; and documentation of the plan, the measurement procedures, the actual laboratory data, and the results of the control assessment.

When establishing and implementing a measurement control plan, the need to protect the health and safety of the employees, the public, and the environment must be kept in mind. The specific measurement control method should be chosen after careful consideration of all other sections in this guicle. 


\section{D.3. Holdup In Systems}

"Holdup" is a term used to describe a situation in which tritium is retained in a process system and not removed by the normal pumping or purging method. Holdup is undesirable from both the process and inventory points of view. The cause of holdup can be the strong sorption of tritium or some tritiated compound, coupled with an inappropriate choice of desorption technique, including inadequate time, temperature, or vacuum. Holdup is usually the result of a contaminant in the system or an equipment design problem, rather than an operator error. Contamination can result from a leak in the process piping that allows air or nitrogen from the containment atmosphere to enter the piping. The tritiated water and ammonia that may form are potential causes of process holdup. Other troublesome contaminants can be impurities in the gas that were deliberately introduced or are known to be present.

The important aspect of holdup from an inventory control perspective is that the retained tritium cannot be measured and is therefore not included in the inventory obtained by the usual techniques. Thus, holdup represents an apparent loss, or inventory difference (ID), of tritium from the inventory. To arrive at an accurate inventory, this loss must be quantified and included in the physical inventory, or the methods used to collect the tritiated gas must be modified so that complete, or quantitative, collection is ensured. Either approach is valid and both have been used effectively.

Holdup losses (IDs) can be quantified by using predictors, which are discussed in the next section. Effectively modifying the process techniques used to remove tritium and tritiated compounds from all components and surfaces of a system requires knowledge of the nature and cause of the holdup. As mentioned previously, contaminants can be one cause of holdup. Nitrogen and oxygen have been found to be especially troublesome, yielding ammonia and water, respectively. Both of these compounds strongly sorb on stainless steel surfaces, zeolite, and charcoal.

Holdup can also result from the incomplete removal of tritium from process components, such as zeolite (molecular sieve) beds and metal hydrides that are used as pumps, storage, or purification units. Complete regeneration of zeolites is difficult and requires close attention to the temperature, elapsed time, and purge gas flow. Complete removal of tritium from a metal hydride unit implies total decomposition of the hydride. This requires adequate temperature, adequate time, and a low base pressure.

\section{D.4. Predictors}

A predictor is an estimate, based on experiments, that quantifies a loss or a process holdup. Predictors can be helpful in accounting for process holdup and operating 
losses. Predictors must be periodically reverified to justify their continued use. Typical tritium process systems have both sampling losses and the potential for holdup.

Sampling losses are intentional, authorized removals from a process inventory. Sometimes they are individually too small to constitute an accountable unit $(0.01 \mathrm{~g}$ of tritium for DOE contractors), but the aggregate over an inventory period can exceed an accountable unit and in some instances represents a considerable sum.

In some situations, quantitatively determining the amount of tritium in a sample may be difficult. An example of this is a process that incorporates gas sampling by capillary. If the sample is delivered to a mass spectrometer, directly determining the amount of tritium contained in the sample would be difficult. In this situation, a predictor can be used to accurately estimate the total amount of tritium transferred to the analytical instrument over a given period of time. This total is related to the number of samples, the amount of gas in each sample, and the concentration of tritium in each sample. The amount of gas in each sample can be determined from the capillary length and internal diameter, the driving pressure, and the rate of the sample flow. From accurate records of this information, the total amount of tritium transferred from a process to an analytical system can be calculated. This calculated amount, or predictor, can be compared to the amount lost from the process and to the amount appearing in an effluent capture device downstream of the analytical instrument.

Agreement tends to justify continued use of the predictor. However, verification of the predictor must involve measuring the actual quantity of gas transferred under a given set of conditions. If the process volume is large, the pressure drop resulting from the removal of a single sample will be small and may be close to the readability of the pressure measuring device. This small change can introduce a large uncertainty in the measurement. In this situation, repeated withdrawals can be made to obtain a significant pressure drop, thereby allowing a more accurate reading.

Predictors can also be derived for the amount of tritium retained, or held up, in metal hydride beds and molecular sieve traps. (Holdup was discussed in Section D.3.) Since complete regeneration and quantitative removal of the inventory is difficult and time-consuming, a predictor may be useful. A hydrogen dilution procedure can be used to determine the volume of hydrogen retained in a metal hydride unit. This can be accomplished following the normal emptying of the unit by introducing a small amount of deuterium to the unit while it is still hot. After cooling, the unit should be reheated using the normal regeneration procedure, and the released gas can be collected, measured, and analyzed. From these data and the tritium concentration of the last gas driven off the unit by heating, holdup can be calculated. If this procedure is performed several times with consistent results over an extended period (1 year), a 
value will emerge that represents the amount of tritium held up in the metal hydride unit. This value can then be used as a predictor, or estimate, of the amount of tritium remaining in the unit following the normal inventory procedure. The value of the predictor can then simply be added to the normal inventory value to obtain a more accurate representation of the true inventory.

One method for establishing a predictor for zeolite (sometimes called molecular sieve) beds involves circulating a known quantity of protium or deuterium through the heated zeolite until the gas reaches a constant composition. The gas is pumped away, measured, and analyzed. Fresh gas is then introduced, and the circulation process is repeated. From a series of three exchanges, two independent sets of data can be obtained. From these data, the amount of tritium retained in a particular zeolite bed following a given regeneration process can be predicted. The predictor must be verified periodically.

\section{D.5. Accounting Practices}

\section{D.5.1. Materials Accounting}

The accounting system is a records and reporting system that provides a data base for tracking tritium inventories, for documenting transfers of tritium, and for detecting, verifying, and evaluating IDs at a facility. The accountability and reporting criteria for government-owned tritium are defined in DOE Order 5633.2 [D.1].

The materials accounting function should be administered by a group that is independent of any programmatic responsibilities. A material control and accountability program should include material accounting systems, material control procedures and systems, measurement systems, measurement control, and evaluation programs.

\section{D.5.2. Accountability Practices}

Tritium accountability is based on closure of material balances for each reporting area in a plant. A material balance area is an identifiable location, process, or organizational entity for which records are maintained showing the quantity of tritium moved into or out of the area. The method for computing balances is to add beginning inventory to receipts, then subtract shipments, measured discards, decay, and ending inventory from the total. This sum is the $\mathrm{DD}$. The uncertainty of the measurements will contribute to the $\mathrm{DD}$.

All entries in the accountability records should be based on measured values. Estimated system holdup is not acceptable unless a predictor has been quantitatively established. 
Significant IDs should be investigated, and the cause should be determined. Control charts are a useful tool for statistical evaluation of these data. It is important to be certain that diversion or theft is not occurring. Although tritium is not safeguarded with the same controls placed on special nuclear materials such as plutonium, it is a valuable material that must be protected.

Accountable quantities of tritium must not be allowed to enter or leave the facility without documentation. Shipping personnel should be required to report shipments and receipts to the accountability office, and an independent assay value should be obtained promptly.

High-activity tritium waste (quantities greater than $100 \mathrm{Ci}$ ) should be measured before being discarded. Waste streams, such as tritiated oil from pumps and tritiated water from collection tanks, should be sampled and measured by calorimetric assay or beta scintillation counting. Failure to measure such waste streams can lead to unexplained IDs.

A physical inventory of tritium should be completed at least annually. During the inventory period, all processing and transfer of tritium must be stopped, and bulk materials should be collected in containers of known volume for sampling and measurement. Cleanup activities may be required to remove material from process equipment. Following measurement and assay, IDs can be determined for each material balance area. Significant IDs should be investigated before processing is allowed to resume. A second inventory may be required if differences cannot be reconciled satisfactorily. Waste streams must also be measured during inventory shutdown for plantwide reconciliation.

The first physical inventory of a new process should be done soon after the process has gone into operation. Process holdup and loss mechanisms can be evaluated before the $\mathrm{ID}$ is considered to be out of control. Thus, loss mechanisms can be determined, and corrective action can be taken.

Control of tritium in each material balance area should be the responsibility of one person, generally called a custodian. Transfers into and out of the area should be measured and documented on a material transfer form signed by the custodian. Special forms that require custodians to enter specific pressure, volume, temperature, and mass spectrometry (PVT-MS) data can be used for transferring bulk tritium gas. If only the sender measures the gas and the measurement is biased, an ID will occur. Thus, it is a good accountability practice when transferring bulk tritium gas to require both the sender and receiver to obtain independent measurements and compare results after converting PVT-MS data to a common basis, such as grams or moles. Significant sender-receiver differences between two 
material balance areas should be investigated by the accountability office. Unresolved IDs can occur if transferred materials are not accurately measured.

Initiating a measurement control program will ensure tritium is accurately measured. Measurement laboratories run standards and maintain control charts to prove the data are within certain error limits. Processing areas can measure the same batch of material using two different measurement methods to provide accuracy cross-checks. Processing areas should document PVT and sampling methods to ensure these methods are acceptable. The accountability office should manage the overall measurement control program.

\section{D.5.3. Tritium_Decay}

Taking account of tritium decay is an essential element of good accounting practices and is required by DOE Order 5633.2 [D.1]. All tritium values should be decayed to a predetermined common date, preferably the first day of the processing month. The decay factors (Table D.1) should be furnished to all processing areas and measurement stations. Table D.1 contains the DOE-approved factors.

The facility decay adjustments should be maintained by the accountability group. The recommended method is by computer. Failure to apply proper decay routines could lead to unexplained IDs.

\section{D.6. References}

D.1. DOE Order 5633.2, Control and Accountability of Nuclear Materials: Responsibilities and Authorities, January 29, 1988.

D.2. DOE Order 5630.9, Reporting of Nuclear Materials, February 1988.

\section{D.7. Additional Reading}

R. E. Ellefson, and J. T. Gill, "Tritium Inventory Differences," presented at the 27th Annual Meeting of the Institute of Nuclear Materials Management, New Orleans, Louisiana, 22-25 June 1986, and published in J. Inst. Nuc. Mater. Manage., XV, 89-101. 
Table D.1 - Tritium Decay and Conversion Factors

\begin{tabular}{|c|c|c|c|}
\hline \multicolumn{4}{|c|}{ Atomic Weight $\ldots \ldots \ldots \ldots 3.01605$} \\
\hline \multicolumn{2}{|c|}{ Molecular Weight..$\ldots \ldots \ldots$} & \multicolumn{2}{|c|}{6.03210} \\
\hline \multicolumn{2}{|c|}{ Half-Life (DOE 5630.9) [D.2] } & \multicolumn{2}{|c|}{$12.3232 \mathrm{yr} \pm 0.0043 \mathrm{yr}(4500.95$ days $)$} \\
\hline \multirow{2}{*}{\multicolumn{2}{|c|}{ Calorimetry Factors . }} & \multirow{2}{*}{\multicolumn{2}{|c|}{$\begin{array}{l}3.087 \mathrm{~g} / \mathrm{W}(3.08657 \mathrm{~g} / \mathrm{W}) \pm 0.009 \\
0.3240 \mathrm{~W} / \mathrm{g} \pm 0.0009\end{array}$}} \\
\hline & & & \\
\hline \multicolumn{2}{|c|}{ Conversion Factors } & \multicolumn{2}{|c|}{$0.2691 \mathrm{~g} / \mathrm{L}(0.269126 \mathrm{~g} / \mathrm{L})$ at STP } \\
\hline & & \multicolumn{2}{|c|}{$3.72 \mathrm{~L} / \mathrm{g}(3.71572 \mathrm{~L} / \mathrm{g})$} \\
\hline \multicolumn{2}{|l|}{ Decay Factor } & $984602 / \mathrm{c}$ & $y-1$ \\
\hline Month & Factor & Days & Factor \\
\hline 1 & 0.99532 & 1 & 0.99985 \\
\hline 2 & 0.99067 & 2 & 0.99969 \\
\hline 3 & 0.98604 & 3 & 0.99954 \\
\hline 4 & 0.98143 & 4 & 0.99938 \\
\hline 5 & 0.97684 & 5 & 0.99923 \\
\hline 6 & 0.97227 & 6 & 0.99908 \\
\hline 7 & 0.96772 & 7 & 0.99892 \\
\hline 8 & 0.96320 & 8 & 0.99877 \\
\hline 9 & 0.95869 & 9 & 0.99861 \\
\hline 10 & 0.95421 & 10 & 0.99846 \\
\hline 11 & 0.94975 & 11 & 0.99831 \\
\hline 12 & 0.94531 & 12 & 0.99815 \\
\hline 13 & 0.94088 & 13 & 0.99800 \\
\hline 14 & 0.93648 & 14 & 0.99785 \\
\hline 15 & 0.93211 & 15 & 0.99769 \\
\hline 16 & 0.92775 & 16 & 0.99754 \\
\hline 17 & 0.92341 & 17 & 0.99739 \\
\hline 18 & 0.91909 & 18 & 0.99723 \\
\hline 19 & 0.91479 & 19 & 0.99708 \\
\hline 20 & 0.91051 & 20 & 0.99692 \\
\hline 21 & 0.90626 & 21 & 0.99677 \\
\hline 22 & 0.90202 & 22 & 0.99662 \\
\hline 23 & 0.89780 & 23 & 0.99646 \\
\hline 24 & 0.89360 & 24 & 0.99631 \\
\hline 25 & 0.88942 & 25 & 0.99616 \\
\hline 26 & 0.88526 & 26 & 0.99600 \\
\hline 27 & 0.88112 & 27 & 0.99585 \\
\hline 28 & 0.87700 & 28 & 0.99570 \\
\hline 29 & 0.87290 & 29 & 0.99554 \\
\hline 30 & 0.86882 & 30 & 0.99539 \\
\hline 31 & 0.86476 & $30.44^{\mathrm{a}}$ & 0.99532 \\
\hline 32 & 0.86071 & & 0.99524 \\
\hline 33 & 0.85669 & & \\
\hline 34 & 0.85268 & & \\
\hline 35 & 0.84870 & & \\
\hline 36 & 0.84473 & ${ }^{a}$ Avera & days/month. \\
\hline
\end{tabular}




\section{Appendix E \\ Measurement Techniques}

\section{E.1. Introduction}

Tritium quantity is measured by directly measuring a physical attribute of the tritium, such as its beta decay radiation, nuclear spin, or nuclear reaction cross sections, or by classical total mole measurements and compositional analysis. Low concentrations of tritium can be successfully measured with direct detection of the beta radiation (see Sections 4.7, E.5, and E.6). For higher concentrations or larger quantities of tritium (more than 0.03 mole \% or $3 \mathrm{Ci}$ ), two measurement methods have emerged as complementary techniques for accurately determining tritium quantity: mole measurement/compositional analysis and calorimetry.

Beta particles from tritium lose their energy in collisions with atoms or molecules in the medium containing the tritium (gas, liquid, or solid) or in collisions with the walls of the container. Ultimately, the energy deposited by the beta particles becomes thermal energy that can be measured as heat flow out of the sample using a calorimeter. A calorimeter design and an operating method that accurately measure tritium quantities are described in Section E.2.

For gaseous mixtures of hydrogen isotopes, helium, and permanent gas impurities, the method of mole determination by pressure, volume, and temperature measurement, coupled with compositional analysis of the gas mixture, provides an accurate determination of tritium in the 0.03 to 100 mole \% concentration range. Pressure, gas composition, and flow rate measurements are also important factors in making processing decisions. Measurement techniques for tritium in the gaseous form are presented in Sections E.3 and E.4.

\section{E.2. Calorimetry}

\section{E.2.1. Calorimeter Operation}

A radiometric calorimeter is an instrument used to measure heat output from items placed in its sample chamber. A resistance bridge calorimeter is the most commonly used calorimeter for measuring heat output from tritium samples. A resistance bridge calorimeter consists of two thermal elements (thermels), each separated from the inner wall of a submarine jacket by an annular space (see Figure E.1). The space, which can be filled with air, epoxy, or other insulating material, serves as a thermal resistance to heat produced in the sample area. Two resistance thermometers are wound over the entire length of each thermel, connected as a Wheatstone bridge, and supplied with a constant current (see Figure E.2). The bridge potential is directly related to the temperature difference between the two sides of the calorimeter. The calorimeter is placed in an isothermal environmental bath normally controlled to $\pm 0.001^{\circ} \mathrm{C}$. 


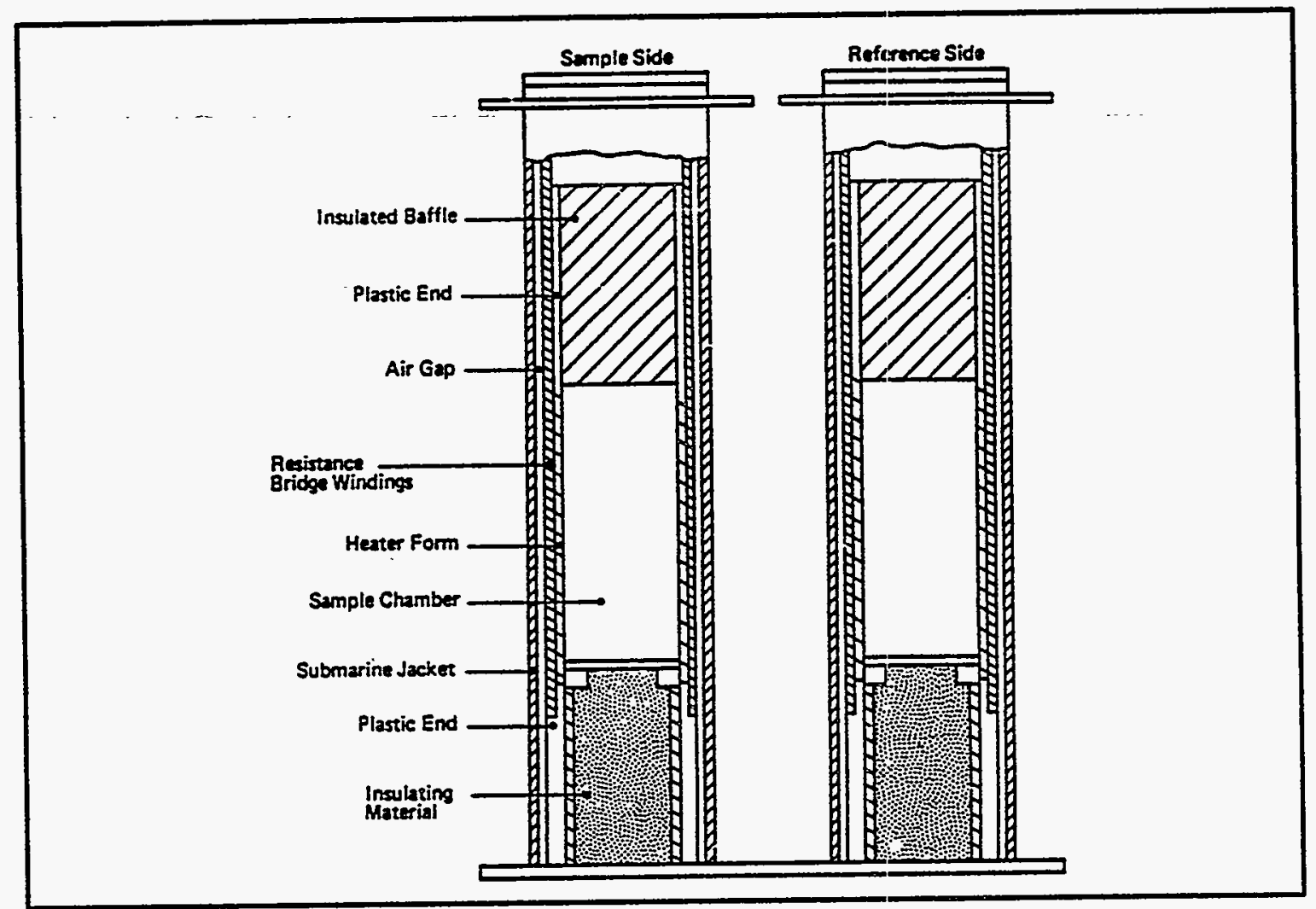

Figure E.I - Cross section of a twin bridge calorimeter.

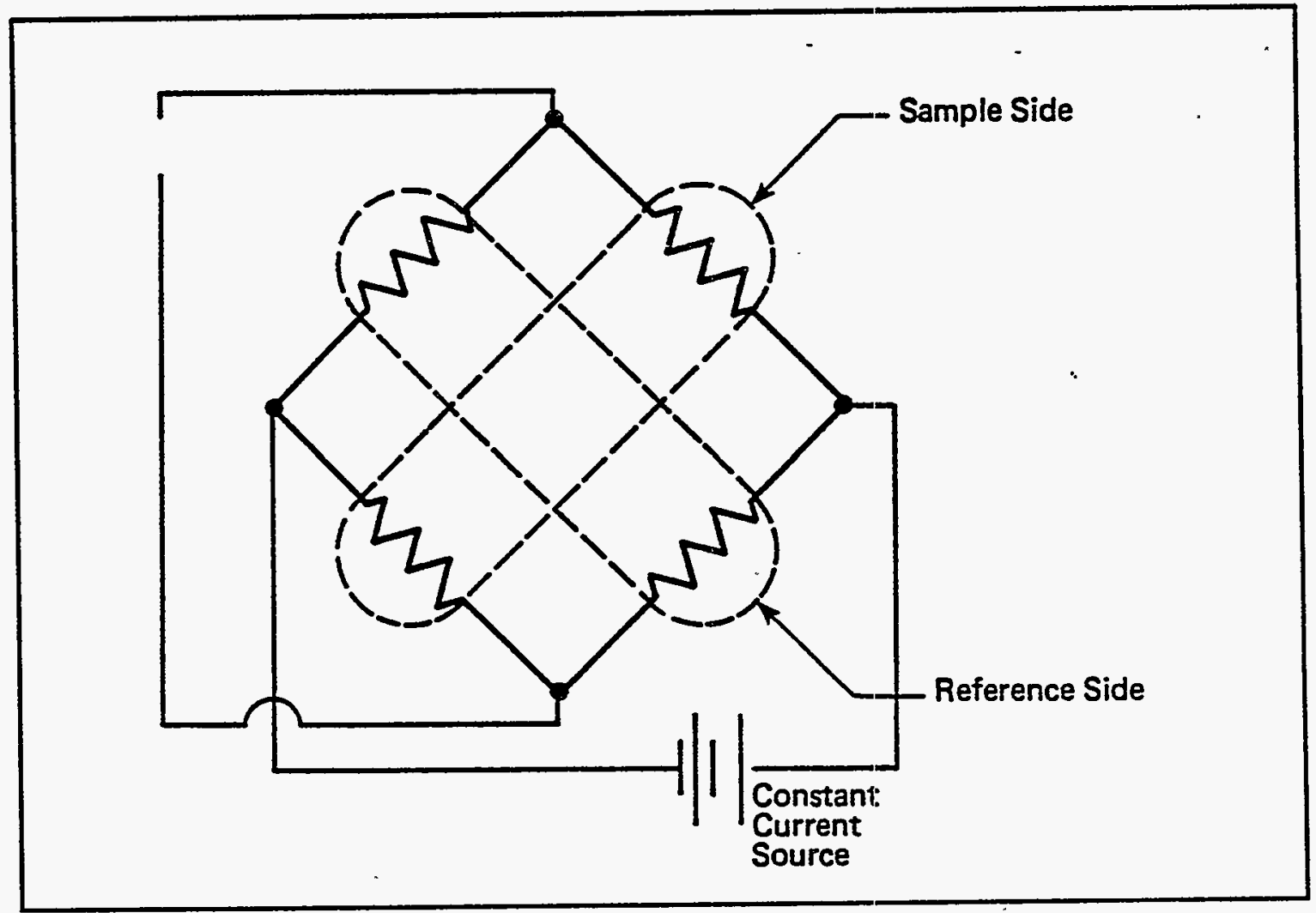

Figure E.2 - Bridge circuit. 
There are three types of resistance bridge calorimeters: full twin, over/under twin, and gradient bridge. The full twin calorimeter, which consists of two identical thermels placed side by side, provides the most precise measurements and is the least susceptible to environmental fluctuations. The main difference between the full twin and the over/under twin is that the reference thermel is located beneath the sample chamber in the over/under twin and may be shorter than that of the full twin. This calorimeter is slightly less precise and much taller than the full twin, but occupies only about half the amount of floor space. The reference and sample thermels of the gradient bridge calorimeter are concentric, with the reference on the outside: This design, although not as precise as the twin bridge design, is attractive for glovebox operations because it takes up less space than any other resistance bridge calorimeter. Any of these calorimeter designs can be used to obtain measurements with biases less than $0.1 \%$.

Two methods are commonly used to measure heat output from tritium samples. These are heater replacement and servo-control. These methods can be used for all resistance bridge calorimeter designs.

\section{E.2.1.1. Heater Replacement Method}

The heater replacement method consists of a three-step procedure to determine the power generated by a sample. First; an equilibration baseline, which is the bridge potential with the calorimeter empty with no heat being input to the calorimeter, is determined. Next, after the sample is placed in the calorimeter and permitted to equilibrate, a second bridge potential value is determined. The sample is then removed. Finally, an electrical heater inputs roughly the same amount of heat to the calorimeter as was contained in the sample, the calorimeter equilibrates, and a third bridge potential value is determined. Sample power can then be calculated using the formula:

$$
\mathrm{W}_{\mathrm{S}}=\mathrm{W}_{\mathrm{H}}+\left(\mathrm{BP}_{\mathrm{S}}-\mathrm{BP}_{\mathrm{H}}\right) /\left[\left(\mathrm{BP}_{\mathrm{H}}-\mathrm{BP}_{\mathrm{O}}\right) / \mathrm{W}_{\mathrm{H}}\right]
$$

where $\mathrm{W}_{\mathrm{S}}$ is the sample power, $\mathrm{W}$,

$\mathrm{W}_{\mathrm{H}}$ is the heater power, $\mathrm{W}$,

$\mathrm{BP}_{\mathrm{S}}$ is the bridge potential of the sample, $\mathrm{V}$,

$\therefore \mathrm{BP}_{\mathrm{H}}$ is the bridge potential of the heater, $\mathrm{V}$, and

BPo is the bridge potential of the empty calorimeter, $\mathrm{V}[\mathrm{E} .1]$

A predictive technique may be applied with this method to reduce the time required for measurement. The prediction routine monitors the bridge potential as a function 
of time, fits these data to an equation, and predicts the equilibrated bridge potential value. Using the predictive technique results in a time savings of about $40 \%$, with only a slight loss in precision and no significant increase in bias.

\section{E.2.1.2. Servo-Control Method}

Servo-control is the second measurement method. In this method, an electrical heater supplies continuous heat to the calorimeter. An equilibration value for the wattage supplied by the heater to the sample side is determined. The sample is then loaded, and the heat supplied by the heater is reduced so that the total power (electrical plus sample) supplied to the calorimeter remains constant. The power of the sample can then be determined from the following equation:

$$
\mathrm{W}_{\mathrm{S}}=\mathrm{W}_{\mathrm{HB}}-\mathrm{W}_{\mathrm{HS}}
$$

where $\mathrm{W}_{\mathbf{S}}$ is the sample power, $\mathrm{W}$,

$\mathrm{W}_{\mathrm{HB}}$ is the equilibrium heater power with no sample, $\mathrm{W}$, and

$\mathrm{W}_{\mathrm{HS}}$ is the equilibrium heater power with the sample loaded, $\mathrm{W}$ [E.2].

The primary advantage of this method is a decrease in the time required to estimate sample power without a significant loss in precision. Since a con- stant amount of heat is always supplied to the calorimeter, equilibrium is reached quickly when a sample is placed in, or removed from, the sample chamber. Time is also saved because no heater measurement is required.

\section{E.2.2. Calibration}

Standard radioactive heat sources should be used for calibration. Plutonium-238 heat sources for which the heat output as a function of time is certified to $\pm 0.02 \%$ are commercially available. These standards are measured in the calorimeter using the methods described in Section D.1, and the results are recorded. Random error and bias can then be determined by calculating the difference between measured and accepted values for the standard heat sources measured. Bias as a function of sample power should be characterized and tested for statistical significance. Bias corrections should be performed if statistically significant differences between measured and accepted values exist at the $95 \%$ confidence level.

The standards should also be measured at three positions within the calorimeter measurement chamber: top, middle, and bottom. Random error and bias must be determined for each of these positions. "If positional differences exist, sample measurements must also be corrected for heat distribution error. In most operations, however, the samples and standards can be placed in the center of the measurement 
chamber to minimize the effects of heat distribution error. Correction for heat distribution error is necessary only when the error is statistically significant and the item to be measured is shaped so that it cannot be centered in the sample chamber:

\section{E.2.3. Watts-Per-Gram Value for Tritium}

The beta particle $\left(\mathrm{e}^{-}\right)$released in the beta decay of tritium ultimately loses all of its energy as thermal energy from interaction with the gas or containment walls. The result is the generation of thermal power (measured in watts) for each gram of tritium $\left(\mathrm{T}_{2}\right)$ that is characteristic of the tritium beta decay process. Currently, the best available watts-per-gram value for tritium is $0.3240 \pm 0.0009 \mathrm{~W} / \mathrm{g}(95 \%$ confidence). Thus, from the thermal power levels of an item measured by calorimetry, a gram quantity of tritium can be determined using this watts-per-gram value.

\section{E.2.4. Sample Preparation}

Endothermic and exothermic processes, such as chemical reactions, can interfere with power measurements. To accurately measure tritium samples by calorimetry, steps should be taken to ensure that any reactions have been completed and that impurities which generate a relatively constant amount of heat, such as other radioactive materials, are well-characterized quantitatively or are eliminated.

\section{E.2.5. Measurement Control Methods and Expected Performance}

Measurement results from plutonium-238 heat standards should be analyzed to statistically determine the condition of the calorimeter from the standpoint of measurement control. The latest standard measured should be checked to verify that it is within three standard deviations of the expected value. The latest two standards measured should be checked to verify that both values are within two standard deviations of the expected values.

Control for some period, such as during the measurement of a batch of material, can be assessed by using an F-test to verify that the variance of the difference between measured and accepted values for standards measured during that period is not significantly different from historic variance. An early warning of control loss can be obtained by comparing the variance of recent baseline values (measurements with the sample chamber empty) with the variance of historic baseline values. In addition, environmental conditions, including the temperature of the environmental bath, room temperature, and humidity, should be monitored. If these conditions show any major changes, they should be brought back to normal, and the measurements should be repeated.

Response variation for a calorimeter must be characterized by measuring standards. A rough estimate of the measurement precision for any given calorimeter is 
$1 \mu \mathrm{W} / \mathrm{cm}^{2}$ of sample chamber surface area. If observed measurement precision for a calorimeter is more than a factor of two greater than this value, hardware, software, and operating procedures should be evaluated. In general, the smaller the calorimeter used for a given application, the better the precision. For example, a calorimeter with a sample chamber height of $8 \mathrm{~cm}$ and al diameter of $3 \mathrm{~cm}$ would be expected to have an accuracy of roughly $0.0001 \mathrm{~W}$ ( $3 \mathrm{Ci}$ of tritium), whereas a calorimeter with a sample chamber height of $24 \mathrm{~cm}$ and a diameter of $9 \mathrm{~cm}$ would be expected to have an accuracy of roughly $0.0007 \mathrm{~W}$ ( $21 \mathrm{Ci}$ of tritium).

Overall uncertainty in the gram value for tritium measurements can be found using a combination of measurement uncertainty, and uncertainty in the watts-per-gram value as follows:

$$
S(T)=\frac{S(R)^{2}}{n}+S(S)^{2}+\frac{(S(C) * W)^{2 \frac{1}{2}}}{P} / P
$$

where $S(T)$ is the total uncertainty, $W$,

$S(R)$ is the random error, $W$,

$S(S)$ is the calibration uncertainty, $W$,

$S(C)$ is the uncertainty in the watts-per-gram value, $\mathrm{W} / \mathrm{g}$,

$\mathrm{n}$ is the number of sample measurements,

$\mathrm{W}$ is the sample power, $\mathrm{W}$, and

$P$ is the watts-per-gram value, $0.3240 \mathrm{~W} / \mathrm{g}$.

\section{E.3. Mole Measurement and Compositional Analysis}

\section{E.3.1. Mole Determination by Pressure, Volume, and Temperature Measurement}

The moles of gas in a volume can be determined by accurately measuring the pressure, temperature, and volume occupied by the gas, and putting the values into the following equation of state:

$$
\mathrm{n}(\text { moles })=\mathrm{P} \times \mathrm{V} /(\mathrm{Z} \times \mathrm{R} \times \mathrm{T})
$$

where $P$ is the pressure,

$V$ is the-volume,

$\mathrm{Z}$ contains the deviation from an ideal gas,

$R$ is the gas constant with appropriate units, and

$\mathrm{T}$ is temperature, $\mathrm{K}$ (absolute temperature)... 
For gas pressures less than $50 \mathrm{psia}$, the value of $\mathrm{Z}$ is taken as unity. This introduces an error of less than $0.17 \%$. Normal PVT measurements using certified pressure transducers, temperature gauges, and volume valves can produce $0.8 \%$ accuracy routinely and accuracy as high as $0.5 \%$ on occasion. A systems calibration of a PVT system using weighed gas transfers produces mole measurements with $0.5 \%$ accuracy ( 3 sigma) routinely and $0.2 \%$ at best.

Pressure transducers for accurately measuring the pressure of tritium-containing gas require all-metal, welded construction and an accuracy-linearity-hysteresis value of $0.2 \%$ of full-scale or better. Strain gauge transducers with all parts that will be exposed to tritium made of 316 stainless steel and with a metal gasket fitting for attachment to the volume have been found to meet all the criteria for a pressure gauge for tritium service. One transducer model that has performed well has $0.1 \%$ full-scale accuracy, and most units show excellent long-term stability.

Readout electronics that allow readings from multiple strain gauges to be displayed are available. Others that interface with computers are also available. The main requirement for selection is accuracy of $0.2 \%$ or better. A useful feature for checking the integrity of the electronics is the reference calibration, RCal, mode of test. Each strain gauge transducer contains a tap that gives an offset to the panel reading that is approximately $75 \%$ of full scale. The actual offset number is unique to each transducer and can be used to check span and general performance of the electronics.

High-quality capacitance manometers $(\mathrm{CMs})$ with $0.08 \%$ reading accuracy are available. For tritium service, the $\mathrm{CM}$ must have the capacitance electrodes on the reference side, and the tritium must be exposed to a welded chamber and diaphragm. Quartz Bourdon tube gauges offer $0.002 \%$ of full-scale accuracy. These gauges are excellent for checking calibration of lesser transducers, but their expense, the risk of quartz breakage, and the possibility of helium-3 leakage make them less practical for general tritium use. Calibration checks of the transducers should be performed by a standards laboratory to ensure the transducers meet specifications. The transducer may be returned for repair only while it is not contaminated and is under warranty. Recalibration should be performed by the in-house standards laboratory after the first 90 days and at 6 -month intervals thereafter.

The location of the pressure transducer with respect to the volume on a PVT system requires some planning. If the transducer is to be calibrated in place, it should be placed on the line connected to the tank with an isolation valve between the tank and transducer. This allows a tank to be isolated while the process lines are used for calibrating the pressure transducer, which avoids having to fill the tank during calibration. This same isolation valve provides a means to isolate a tank for 
long-term storage, but prevents the pressure from being read until the valve is reopened.

An alternate method of attachment for the pressure transducer is to install it directly on the volume with an isolation valve between the transducer and volume. This allows direct reading at random times by opening the valve, yet still provides protection from leakage if the transducer diaphragm leaks. Pressure transducer calibration then requires an empty volume for in-situ calibration or removal of the transducer after the appropriate evacuation of the process line between the transducer and the isolation valve.

For measuring the temperature of the gas, there are many possible instruments. Two that are accurate, tritium-compatible, and commonly used are thermocouples and platinum resistance thermometers. Type $E$ thermocouples are well-suited for measuring at or near room temperature with an accuracy of $\pm 1^{\circ} \mathrm{C}$. This gives $0.3 \%$ uncertainty in the PVT measurement. However, temperature gradients of the same order of magnitude can also exist from self-heating and convection in gases with high tritium concentrations, which raises the overall uncertainty to $0.6 \%$. Platinum resistance thermometers have $0.5^{\circ} \mathrm{C}$ accuracy or better, but they are considerably more expensive than thermocouples.

Budget permitting, it is best to have two temperature probes in the tank: one on the cylindrical axis of the volume near an end and one on the axis near the center of the tank. If only one probe is used, it should be located on the axis near the center of the tank. Both types of temperature probes should have a stainless steel sheath and be long enough to be inserted into a thermal well that penetrates the required depth into the volume. A reasonably tight fit is necessary for good heat transfer.

The advantage to using a thermal well is that the thermocouple can be removed for calibration without venting the volume; therefore, the probe will not become contaminated. The disadvantage is some time lag in thermal response and a possible false reading as a result of heat conduction along the thermal well to the tank wall. The alternative is to weld a fitting onto the thermocouple sheath and introduce the probe directly into the gas. This enhances response time, but requires emptying the volume and handling a contaminated probe whenever a probe is calibrated. Thermal wells should never be used if PVT accuracies of $\pm 0.5 \%$ ( 3 sigma) or better are required.

A standards laboratory checks the calibration of the temperature probe by putting the reference probe and test probe in either an aluminum, stainless steel, or copper block and comparing the two over a temperature range of interest. One way to calibrate a temperature probe located inside a glovebox is shown in Figure E.3. It involves installing a stainless steel thermal block on the glovebox surface. The probe inside 


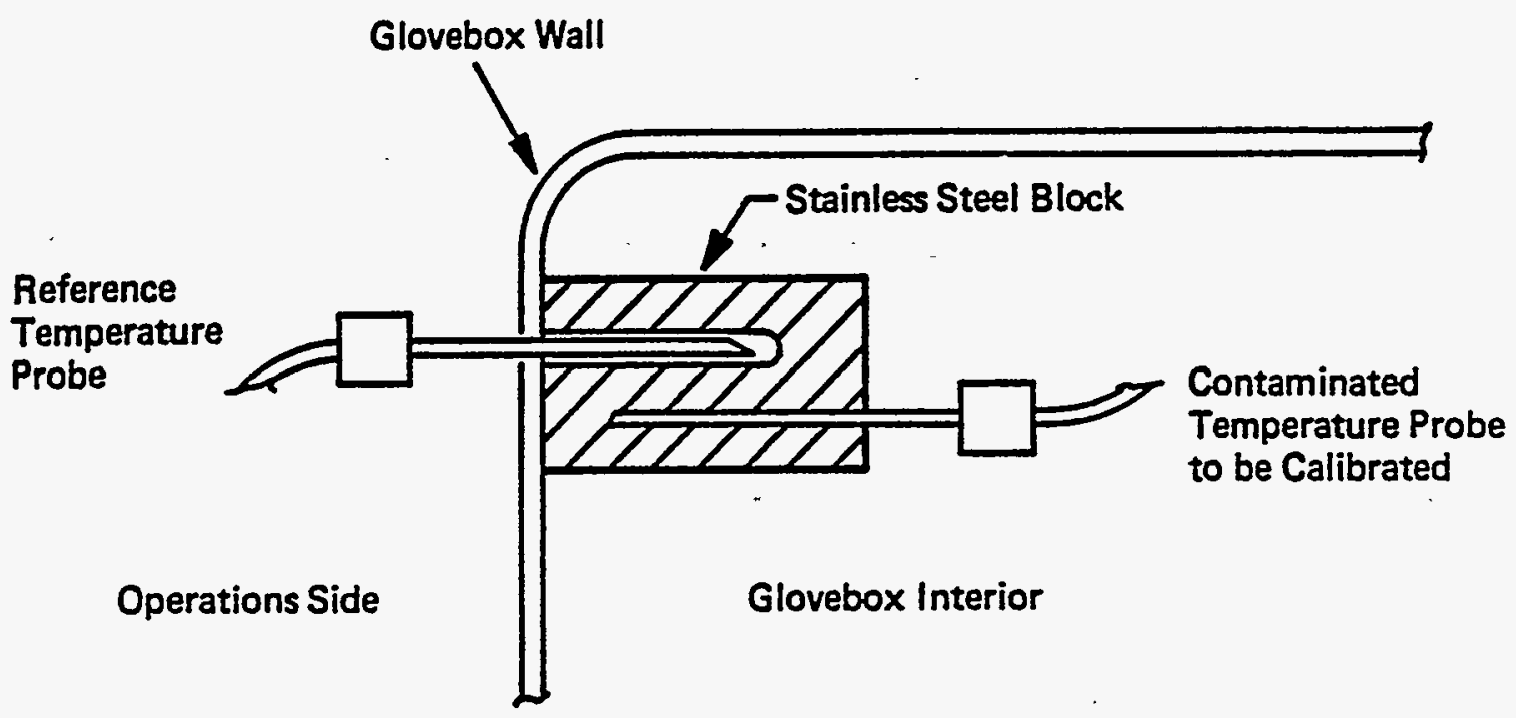

Figure E.3 - Calibration of temperature probe. A stainless steel block is welded to the wall of the glovebox with temperature probe wells on both sides of the wall. This provides contumination isolation and a common (ambient) temperature for checking the calibration of process temperature probe.

should be placed in the well of the block, while the uncontaminated reference probe remains on the outside of the glovebox in the thermal block. This reference probe should be in thermal contact with the block for calibration testing. This single-point calibration validates a previous full calibration. The temperature probe should be validated or recalibrated every six months.

The volume of the PVT system is a third factor that must be calibrated. The preferred way to determine the volume is to perform a series of weighed gas transfers into the PVT system; then calculate the volume using the equation of state and the known number of moles from weighing. In transferring the gas from the weighing vessel to the PVT system, the real volume of the system, including the feed lines and the exhaust side of the transfer pump, is defined. This method is a systems measurement approach to the task of calibrating the system to determine moles.

Another method for calibrating a volume is forward-reverse PVT. In this method, gas is loaded to a predetermined pressure into a known volume. The connecting valve to the volume to be calibrated is opened, and the new equilibrated pressure is recorded. The connecting valve is closed, and the known volume is evacuated. The flow is reversed, and the final equilibrated pressure is recorded. From these data, the unknown volume can be determined. Techniques that use water or oil to fill the volume should be avoided because air entrained in these fluids causes errors in measurement. A greater problem is the residual water or oil that contaminates process gas when the volume is put into use. 
A measurement control technique that is useful for validating the calibration of a PVT system is to compare the readings of the first system to those of another PVT system after a gas transfer. Control charts that plot mole differences of such transfers as a function of time can identify shifts in performance of the PVT systems over time. An additional check can be made if a known tritium quantity is transferred into the PVT system. The moles are determined, and, from the gas analysis data, a quantity of tritium can be calculated for comparison with the calorimetry value.

\section{E.3.2. Gas Composition Measurements}

\section{E.3.2.1. Expected Composition of Tritium Process Gas}

In tritium-handling facilities, the common form of the gas is molecular hydrogen. Associated with the tritium is the helium- 3 decay product that accumulates in the gas. To determine the chemical and isotopic purity of the gas, it is necessary to measure all six possible molecular species, as well as the helium components and common impurities. Impurities come from leakage of air or glovebox atmospheres (nitrogen, argon, helium), from degradation of hydrocarbons into methane (e.g., $\mathrm{CHDT}_{2}$ ), and from beta-induced consumption of oxygen to form water followed by nitrogen consumption to form ammonia. Table E.1 shows the molecular species of hydrogen, isotopes of helium and fragment ions formed by electron impact ionization, and mass analysis commonly used to measure the composition of gas mixtures. A mass spectrometer separates ion species according to their mass-to-charge ratio, M/Q. The "Resolving Power" column shows the mass resolution required by the mass spectrometer to separate the corresponding ion species into two measurable peaks. The resolving power is $\mathrm{M} / \Delta \mathrm{m}$, where $\Delta \mathrm{m}$ is the peak width (in atomic mass units) near the base (5\% of maximum height). This is most easily measured using mixtures with known component pairs: $\mathrm{He}-4$ and $\mathrm{D}_{2}$ requiring a resolving power of 160 and $\mathrm{He}-3$ and $\mathrm{HD}$ requiring a resolving power of 520.

Table E.1 - Mass Separation of Hydrogen-Helium Isotopic Components

\begin{tabular}{clc} 
M/Q & \multicolumn{1}{c}{ Ion Species } & $\begin{array}{c}\text { Resolving Power } \\
\text { (M/ } / \Delta \text { m) Required }\end{array}$ \\
2 & $\mathrm{D}^{+}, \mathrm{H}_{2}{ }^{+}$ & 1300 \\
3 & $\mathrm{HHe}^{+}+\mathrm{T}^{+}, \mathrm{HD}^{+}$ & 520 \\
4 & $4 \mathrm{He}^{+}, \mathrm{D}_{2}^{+} ; \mathrm{HT}^{+}, \mathrm{D}_{2}^{+}$ & $160 ; 980$ \\
5 & $\mathrm{DT}^{+}, \mathrm{D}_{2} \mathrm{H}^{+}$ & 865 \\
6 & $\mathrm{~T}_{2}{ }^{+}, \mathrm{D}_{3}{ }^{+}$ & 610
\end{tabular}




\section{E.3.2.2. Composition Measuring_Instruments}

Various types of mass spectrometers have been used for analyzing tritium-containing gases. Quadrupole mass spectrometers have unit mass resolution for practical applications in which the various ions at each nominal mass from 2 to 6 are not resolved. However, for in-process monitoring or other selected applications, the analytical data are useful. Resolution of the ion species at each mass can be accomplished to varying degrees by magnetic deflection mass spectrometers. Since the $1960^{\prime}$ 's, cycloidal and $180^{\circ}$ deflection mass spectrometers have been used with resolving powers of about 150 to 450 and 800 , respectively. Through a joint DOE laboratory collaboration in the late 1970's, specifications for a more modern instrument that would enable all species in Table E.1 to be independently measured were defined [E.3]. Today, magnetic sector mass spectrometers with the necessary resolution and computer control are in use.

For either quadrupole or magnetic deflection mass spectrometers, the sample quantity required for an analysis is about $1 \mathrm{~cm}^{3}$ (STP). Typically, additional gas will be consumed in obtaining a representative sample. The gas sample is introduced into the mass spectrometer through an inlet system that has a $1-$ to $3-\mathrm{L}$ volume (at 0.1 to 3.0 torr), then through a molecular leak, which further reduces the sample pressure to less than $1 \times 10^{-5}$ torr in the ionization region of the mass spectrometer. A typical analysis time is 20 to 30 minutes.

The molecular species of hydrogen and total helium can be determined by gas chromatography that uses a liquid nitrogen-cooled alumina column to separate the species. A thermal conductivity detector detects all species. A low-volume ion chamber added in series is used to detect HT, DT, and $\mathrm{T}_{2}$ only. Neon is the carrier gas. A room temperature Poropak $\mathrm{Q}$ column and a thermal conductivity detector find impurity species such as nitrogen, argon, and methane. Typically, $1 \mathrm{~cm}^{3}$ (STP) of gas is introduced into a sampling loop and injected into the chromatograph. Additional gas is involved in sample preparation. The quantity depends on the method of presentation of the sample. The molecular species of hydrogen can also be measured by laser Raman spectroscopy, but not all impurities of interest (e.g., helium-3, helium-4, argon) can be measured.

Beta scintillation detection provides a different analytical technique for determining the mole percent of tritium in gas samples. Commercial beta scintillation detectors using $\mathrm{CaF}_{2}(\mathrm{Eu})$ crystals and a photodiode/electrometer can be mounted on a volume (e.g., the mass spectrometer inlet volume) and calibrated to measure the partial pressure of tritium present. This partial pressure of tritium divided by the total sample pressure gives the mole fraction of tritium present (in any chemical form). Such a device can be included on the mass spectrometer inlet as an independent 
measure of total tritium concentration or set up as a separate and inexpensive measurement device.

\section{E.3.2.3. Sampling Techniques}

Portable sample bottles can be used to transport samples of gases from experiments or processes that are some distance from the analytical facilities. To obtain the best analytical results, care must be taken in fabricating and using the sample bottles. The recommended material for a sample container is 304 or 316 stainless steel with the inside surface polished (mechanically or electropolished) to minimize surface area. The surface should be degreased to minimize hydrocarbons. Under these conditions, the hydrogen ingrowth (as HD or HT) in tritium samples is low; i.e., less than 0.05 mole \% hydrogen ingrowth in one month [E.4]. If no efforts to clean and minimize the surface area are made, hydrogen ingrowth of 5 to 10 mole \% in the first month of exposure can be expected. Continued conditioning of tritium gas will reduce hydrogen ingrowth to approximately 0.2 mole \% per month. Storing sampled gases in unclean bottles alters their composition through hydrogen ingrowth and methane formation and may mask the process information desired from the sample.

Before sampling, the bottles must be evacuated. Residual pressure in the sample bottle becomes the partial pressure of contaminants in the sample taken. Sample pressure should be less than atmospheric pressure as a health physics precaution, but it should be near atmospheric pressure to obtain the highest dilution of residual gases from evacuation of the sample bottle. The outside of the sample bottle must be decontaminated to the level required by health physics procedures before it can be transported to the analytical laboratory.

Tritium processing facilities can be designed with the analytical facilities located central to the operations to allow remote sampling from the process areas [E.5]. Samples from these process areas can be transported to the analytical area by pressure gradient through stainless steel capillary lines. The inner diameter of the capillaries ranges from 0.03 to $0.05 \mathrm{~cm}$, while the outer diameter is $0.32 \mathrm{~cm}$ for a relatively thick, strong wall. Capillary lengths can range from 10 to $70 \mathrm{~m}$. To accommodate all the process points, a manifold with a valve for each capillary can selectively sample from many process points with no cross-contamination of the sample. A diagram of such a sampling and analysis network is shown in Figure E.4.

Capillary sampling allows the capillary to be directly inserted into the volume to be sampled or into a connection to an appendage valve on the tank for reliable isolation of stored gas from any leak or unplanned opening of the capillary valve on the manifold. The advantages of this type of sampling are the health physics and safety features of the method and the smaller amount of contamination in a capillary sample compared to a portable sample. The quantity of gas removed from the process by sampling is 5 to $40 \mathrm{~cm}^{3}$ (STP), depending on the length and inside 


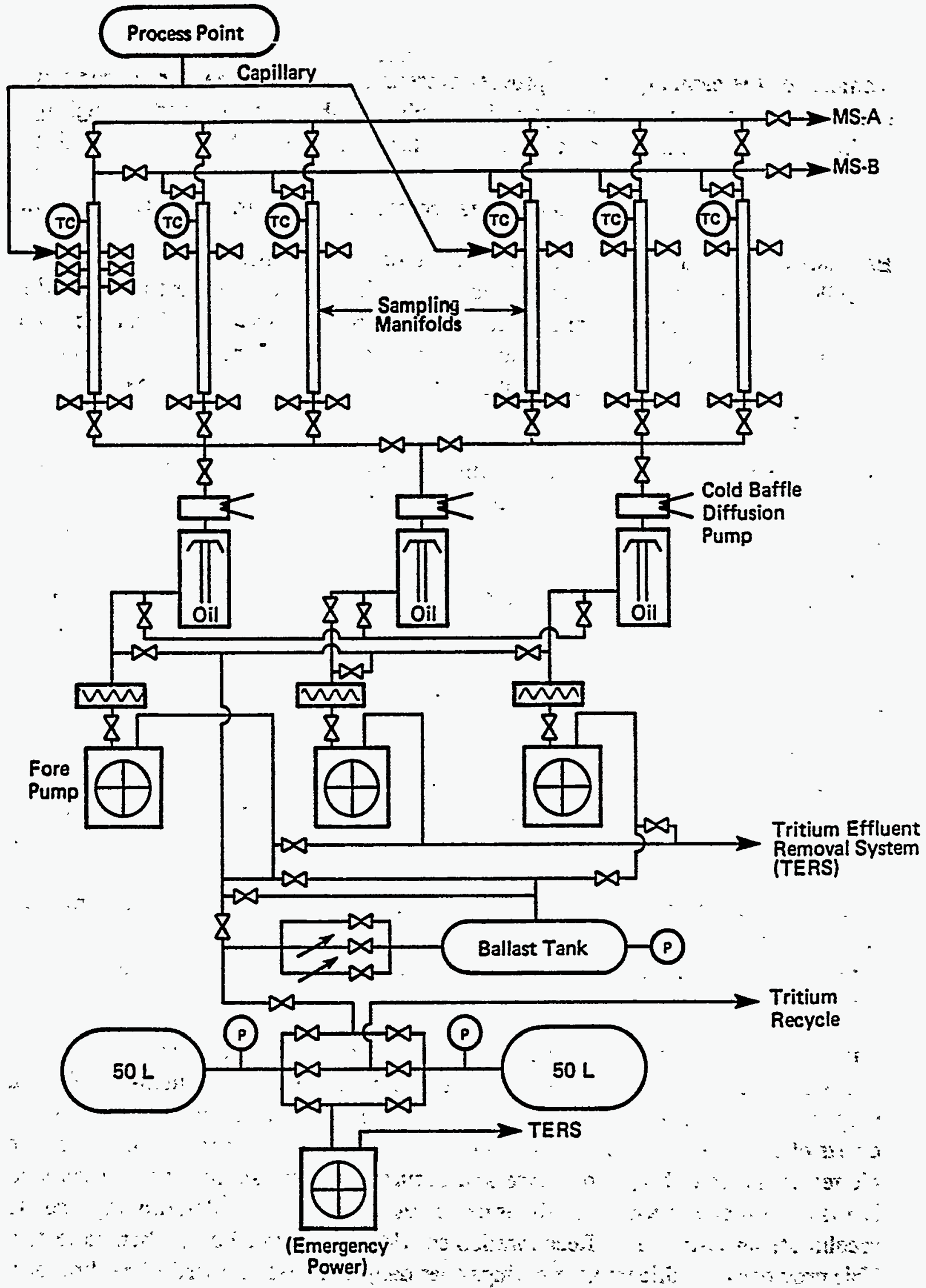

- Figure E.4-Sampling and recovery system. Each of the 6 sampling manifolds has 24 capillary valves (most omitted here for clarity). 
diameter of the capillary and on process pressure. To ensure that a representative sample of the process-gas is obtained, sample gas should be purged through the capillary long enough for three capillary volumes of gas to be swept through to condition the capillary. Then the analytical sample (about $1 \mathrm{~cm}^{3}$ (STP)) can be taken. Most of the gas removed from the process comes out during the purging operation.

Each site must weigh economic and accountability factors when making the decision to build forepump exhaust recovery facilities. In the case of exhaust from the capillary sampling pumps, economic factors are probably favorable. Exhausts from the mass spectrometers and their inlet systems are probably not worth recovering, but the exhaust gases must be scrubbed for tritium before being released to the environment.

Another method for transporting a sample to an analytical instrument is a process bypass flow loop. In such a loop, process gas from the sampling point is piped through a gas chromatograph sample loop, then reintroduced into the system at a point downstream. This method can be applied to a dedicated process monitoring operation and has the advantage of recovering the sample stream. Disadvantages are. the cost of dedication of analytical instrumentation and the potential leakage from the process.

\section{E.3.2.4. Measurement Control Methods}

Mass spectrometers require two calibrations: the mass scale calibration and calibration of the sensitivity of the instrument for different components. The mass scale is determined using a mixture of components of known mass. The known peaks are located, and the instrument parameters that correspond to the measurement of ion current for the peaks are recorded. Usually, a polynomial relationship between mass and instrument parameters can be established. This allows the computer controlling the mass spectrometer to compute the parameters for an arbitrary mass. If necessary, a table can be used to locate peaks of interest. Validation of the mass scale occurs daily by ensuring all peaks in a standard are found.

The sensitivity values for each component are determined by analyzing pure gases and standard mixtures of hydrogen, deuterium, tritium, and helium-3. With a proper set of sensitivities, the bias in analyses of mixtures is minimized. Control charts of the difference between measured and standard values for gas mixtures are plotted to indicate the performance and accuracy of analysis for each instrument. Drifts that produce biases in analyses can be used as criteria for determining when to recalibrate an instrument. Recalibration should be performed only when indicated. This provides a significant time savings over daily"ör wieekly prescribed calibrations. The accuracy achieved by modern mass spectrometers is easily within $1 \%$ of component for major components and is usually within $0.5 \%$. The beta scintillation 
detection instrument has a relative accuracy of $2 \%$ without temperature control of the crystal and phototube, and less than $1 \%$ relative if the unit is temperature stabilized within $0.2^{\circ} \mathrm{C}$ [E.6].

\section{E.4. Process Operation Measurements}

\section{E.4.1. Process Pressure and Vacuum Measurements}

In addition to the pressure transducers on tank volumes, it is usually necessary, or at least desirable, to have pressure transducers on process lines to monitor upstream/downstream pressures on pumps or to determine when a line has been evacuated. For these measurements, the pressures should be measured with transducers equivalent to those chosen for PVT and accountability measurements (see Section E.3.1). In some designs, the process line transducer provides the pressure reading used in PVT data. Calibration of the process line pressure transducer should be a part of the same certification process used to qualify other pressure transducers. This allows meaningful comparisons between tank and process line transducers during appropriate static operation. This process control check ensures that both transducers are working. If they disagree, further comparisons with other transducers should indicate which transducer is in error. Repair or replacement plans can then be made.

Frequently, lines and tanks are emptied to prepare for the next task. Evacuation of lines and tanks is first done using metal getter, vane, or metal bellows pumps to preserve the tritium contained in the gas. In practical operations, this reduces the pressure, which can be read on the strain-gauge pressure transducers to a few torr.

There are times when a more complete evacuation is desired. In these instances, the process is pumped using a forepump or, in rare cases, a turbomolecular or diffusion pump backed by a forepump. To measure pressure in a 0 - to 1-torr range, thermocouple (TC) pressure gauges are useful. To measure the progress of the pumpout of lines and tanks, TC gauges should be located not only near the pump, but also on the lines being pumped at the farthest practical location along the pumping path. Typically, the process system has a low conductance, allowing the reading at the pump to reach a low value rapidly. However, the pressure back in the line can be significantly higher. The equation for determining line pressure is as follows:

$$
\mathrm{P}(\text { Line })=\mathrm{Q} / \mathrm{C}+\mathrm{P}(\mathrm{Pump})
$$

where $Q$ is the flow rate, torr $-\mathrm{L} / \mathrm{s}$,

$\mathrm{C}$ is the conductance, $\mathrm{L} / \mathrm{s}$, and

$\mathrm{P}$ is the pressure, torr. 
In a complete pumpout, $\mathrm{Q}$ is zero and the two TC gauge readings agree with each other. When two or more TC gauges are available, an operational definition of "pumpout completed" can be made. This can be used for checking or setting zero on the strain-gauge pressure transducers. TC pressure gauges have a nonlinear response (easily seen on the display) and are not particularly accurate. However, they are precise and useful in noting changes in pump performance. TC gauges with stainless steel construction and ceramic electrical feedthroughs should be chosen, because many of these units have at least a 50-psi pressure rating. A fitting should be welded onto the gauges for attachment to the tritium process system. This is consistent with the all-metal construction philosophy. The TC gauges attached to process lines should have isolation valves to minimize long-term exposure of the ceramic-to-metal seal to tritium.

TC gauges on storage tanks should have isolation valves and rupture disk protection to minimize exposure and the risk of venting large quantities of tritium. The isolation valves need only be opened for vacuum measurements.

\section{E.4.2. In-Line Tritium Concentration Measurements}

The tritium concentration in gas being processed can be determined by the same methods used for quantitative PVT-MS measurements (see Section E.3.2). Process status can be rapidly evaluated using an in-laboratory method for measuring tritium concentration. A reasonably inexpensive in-line device for tritium measurement uses a commercial beta scintillation detector, a 0 - to 1-torr capacitance manometer, and capillary sampling hardware much like that described in Section E.3.2 [E.6]. The control of sampling and immediate reporting of data give an operator timely results. In-line concentration measurement devices based on ion chambers can be built and calibrated for well-defined processes. One of the problems of the ion chamber approach is the dependence of ion current on gas composition as well as on tritium concentration.

\section{E.4.3. Gas Flow Rate Measurements}

Flow rate measurement for tritium-containing gases requires a tritium-compatible mass flow meter. All stainless steel flow meters based on temperature profile measurements along the heated flow tube work well for low tritium concentrations. For higher concentrations, tritium can permeate through the heated tube and raise glovebox concentrations. Capacitance manometer-based flow meters will also work well, provided the design of the manometer does not expose tritium to the capacitance electrodes.

\section{E.4.4. Process Impurity Measurements}

Common impurities in tritium process gas include helium-3, helium-4, nitrogen, oxygen, argon, carbon dioxide, and all isotopic forms of methanes, water, and 
ammonia. Fresh contamination by hydrocarbons will yield higher mass $\mathrm{C}_{n} \mathrm{H}_{2 \mathrm{n}+\mathrm{x}}$ species until radiolytic decomposition reduces them to methane species. Air leaks first lead to the formation of water vapor as a result of the beta-induced reaction of oxygen with the hydrogen species. Following the conversion of oxygen to water, ammonia begins to form as a result of the beta-induced reaction of nitrogen with the hydrogen species. The permanent, noncondensable gaseous impurities are transported through the capillary sampling lines described in Section E.3.2 for analysis. The condensable impurities, water and ammonia, are not representatively transferred through the capillary lines and thus are typically undermeasured if present in the gas.

In-line measurement devices for these impurities are needed. Currently, reliable, tritium-compatible methods are not available. Hygrometer measurements give an indication of water vapor, but their accuracy is difficult to determine. If a quantitative measure of tritium content in the water and ammonia components of process gas is needed, a trapping procedure followed by calorimetry of the trapped contents is necessary.

\section{E.5. Measurement of Tritium Diffused into Solids}

Autoradiography is another technique for determining the amount and location of low level tritium in exposed materials. This technique is based on the sensitivity of silver halide photographic emulsions to beta radiation from tritium. The technique is used routinely to determine the depth of penetration into container materials and to determine semiquantitatively the amount of tritium present. Additional quantitative determinations can be made for some materials by using specially prepared standards [E.7].

A technique that has evolved from autoradiography is tritium imaging. Secondary electrons resulting from the interaction of tritium beta particles with a solid are imaged by electrostatic lenses onto a multichannel plate detector. The output of the channel plate is projected onto a phosphor-coated fiber-optic screen. Magnification is controlled by lens potentials and varies from 1 to $25 \mathrm{X}$. The secondary electrons are produced from tritium within $200 \mathrm{~nm}$ of the surface. Thus, the image is the surface of the solid.

Another example of measurement of tritium diffused into solids is work on polyethylene [E.8]. Here, laser Raman spectroscopy has been used to monitor protium ingrowth (as $\mathrm{HT}$ and $\mathrm{H}_{2}$ ) in tritium gas exposed to high density polyethylene. Also, laser fluorescence and laser Raman spectra of the polymer surface have been used to monitor the progress of radiation damage [E.9]. 


\section{E.6. Process Glovebox Atmosphere Measurements}

Gloveboxes provide a secondary .tritium containment system that protects the operators and the environment from tritium releases from the primary containment. A real-time measurement of the tritium concentration is needed to know the status of the glovebox. An ionization chamber that samples the glovebox atmosphere by diverting all or a portion of the glovebox exhaust through the ion chamber is recommended for detecting tritium. The ionization chamber electrometer and readout should provide linear response from one microcurie per cubic meter to tens of millicuries per cubic meter. The glovebox monitor can be used to switch to a high purge rate when the box reaches some preset level of contamination. The source of a tritium leak can be isolated by connecting a hose to the exhaust port leading to the ion chamber and sampling with the probe to find the leak in the process. Because of the function of a glovebox, the tritium concentration inside is higher than in the surrounding room. Thus, the glovebox monitor and the room monitor must be separate units.

In some gloveboxes, the oxygen and water.vapor levels must be kept low to protect some process components. The sensing probes for oxygen and water vapor detection can be placed in the exhaust line of the glovebox to monitor the integrated result of leaks anywhere in the glovebox. It is important for the probes to be in a flowing stream. This ensures that the probe responses represent the bulk gas in the glovebox and not some local stagnant atmosphere.

\section{E.7. References}

E.1. American National Standards Institute, Calibration Techniques for the Calorimetric Assay of Plutonium Bearing Solids Applied to Nuclear Material Control, ANSI N15.22-1975.

E.2. S. C. Keeton, Recommended Values for the Tritium Half-Lives and Watts-per-Gram-Number, SCC-TM-720230, March 1972.

E.3. P. Chastagner, Mass Spectrometer for Accurate Hydrogen Isotope Anaysis, DP-1492, Savannah River Laboratory, Savannah, Georgia (August 1978).

E.4. J. T. Gill, W. E. Moddeman and R. E. Ellefson, J. Vac. Sci. Technol., 1 (1983), p. 869-873.

E.5. R. E. Ellefson, F. E. Morgan, and B. E. Anderson, J. .Vac. Sci. Technol. (May-June 1986).

E.6. 'R. E. Ellefson, J. Vac. Sci. Technol., 1 (1983), p. 865 .

E.7. 'G. L. Downs, "A New Technique for Microautoradiography and Tritium

... Profiling," Proceedings of the :Environmental Degradation of Engineering Materials Conference, Blacksburg, VA, September 1981, pp. 425-435. 
E.8. J. T. Gill, J. Vac. Sci. Technol., 3 (May-June 1985), p. 1209.

E.9. ' J. T. Gill, Fusion Technol.; 8 (1985), p. 2318.

\section{E.8. Additional Reading}

W. L. Phillinger, et al., Phys. Rev. (1961), pp. 232-233.

R. E. Ellefson, W. E. Moddeman, and H. F. Dylla, J. Vac. Sci. Technol., 18 (1981), p. 1062.

D. K. Warner, C. Kinard, and D. R. Bohl, Chromatographic Measurements of Isotopic Hydrogen Impurities in Purified Tritium, MLM-2264, Monsanto Research Corporation, Miamisburg, Ohio (October 1975).

R. E. Ellefson, "Tritium Technology in Fission, Fusion and Isotopic Applications," CONF-800427 (1980), pp. 240-244.

T. B. Rhinehammer, T. E. Burgess, and E. L. Spyrou, Fusion Technol., 8 (1985), p. 2095.

A. W. Rogers, Techniques of Autoradiography, Elsevier Publishing Co., Amsterdam, (1967).

M. E. Malinowski, J. Vac. Sci. Technol., 1 (April-June 1983), p. 933. 



\section{Glossary}

Aldehyde - any of various highly reactive compounds typified by acetaldehyde and characterized by the group $\mathrm{CHO}$

Aliphatics - derived from fat: specifically, belonging to a group of organic compounds having an open-chain structure and consisting of the paraffin, olefin, and acetylene hydrocarbons and their derivatives.

Aliquot - contained an exact number of times in something else-used of a divisor or part, as in 5 is an aliquot part of 15

Amines - basic compounds derived from ammonia by replacement of hydrogen by one or more univalent hydrocarbon radicals or a compound containing one or more halogen atoms attached to nitrogen

Annular - forming a ring: ring-like

Anthracene - a crystalline cyclic hydrocarbon $\mathrm{C}_{14} \mathrm{H}_{10}$ obtained from coal-tar distillation

Antineutrino - the antiparticle of the neutrino

Atmosphere - a unit of pressure equal to the air at sea level or approximately 14.7 pounds to the square inch

Austenitic - relating to a solid solution in iron of carbon, and sometimes other solutes, that occurs as a constituent of steel

Beta rays - high energy electrons

Becquerel - 1 disintegration per second

Bremsstrahlung - the electromagnetic radiation produced by the sudden retardation of a charged particle in an intense electric field

Butyl - synthetic rubbers made by polymerizing isobutylene

Chemiluminescense - luminescence that is caused by chemical interaction

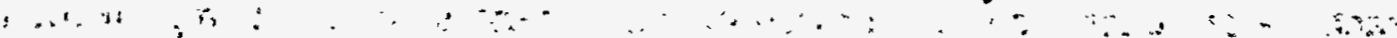

Committed dose rate equivalent $\left(D_{00}\right)$ - a dose of tritium that a person will receive for the rest of his/her life as a result of an uptake of tritium

Cryogenic - relating to very low temperatures

De minimis value - smallest value of any significance 
Desiccant - a drying agent

Deuterium - the second isotope of hydrogen

Dewar - A glass or metal container that has an evacuated space between the walls, is often silvered on the innermost surface to prevent heat transfer, and is used especially as a filter for storing liquefied gasses; also called vacuum bottle.

Diatom - algae with silicified skeleton that form diatomite

Diatomaceous earth - a light, friable, siliceous material derived chiefly from diatom remains and used especially as a filter

Diatomic - consisting of two atoms

Diffusivity - ability to diffuse, or spread out: a measure of the speed that the diffusing species jumps from one solution site to another

Dis $/ \mathrm{min} / \mathrm{cm}^{2}$ - disintegration per minute per cubic centimeter

Endothermic - characterized by or formed with absorption of heat: materials where there is overall repulsive interaction between hydrogen and the material structure Enthalpy - the sum of the internal energy of a body and the product of its volume multiplied by the pressure

Entrain - to draw in and transport by the flow of a fluid

Equilibrate - to come to equilibrium

Esters - a class of often fragrant compounds formed by the reaction between an acid and an alcohol, usually with elimination of water

Exothermic - characterized by or formed with evolution of heat: materials where there is overall attraction between hydrogen and the material structure

Getter - a substance introduced into a vacuum tube or electric lamp to remove traces of gas

Glycol - ethylene glycol: a related alcohol containing two hydroxyl groups

Good Practice - an action, policy, or procedure that enhances the radiation protection program

Halogen - any of the following five elements: fluorine, chlorine, bromine, iodine, and astatine

Halogenated - combined with halogen 
Holdup - tritium is retained in a process system and not removed by the normal pumping or purging method

Hydrate - to cause to take up or combine with water

Hydride - (noun) a compound of hydrogen usually with a more electropositive element: (verb) to form a chemical compound

Hydroxyl - a chemical group or ion that consists of one atom of hydrogen and one atom of oxygen

Hysteresis - a retardation of the effect when the forces acting upon a body are changed, especially a lagging in the values of resulting magnetization in a magnetic material due to a changing magnetizing force

Ion - an atom or group of atoms that carries a positive or negative electric charge as a result of having lost or gained one or more electrons: a free electron or other charged subatomic particle

Ionization chamber - a partially evacuated tube provided with electrodes so that its conductivity, due to the ionization of the residual gas, reveals the presence of ionizing radiation

Ketones - an organic compound (such as acetone) with a carbonyl group attached to two carbon atoms

Labile - exchangeable, as in labile hydrogen sites

Luminescence - an emission of light that is not ascribable directly to incandescence and, therefore, occurs at low temperatures, and that is produced by physiological processes, by chemical action, by friction, or by electrical action

Manifold - a pipe fitting with several lateral outlets for connecting one pipe with others

Martensitic - like the hard constituent that quenched steel is chiefly composed of Miscible - capable of being mixed in any ratio without separation of two phases

Mole - a short form of molecule

Monatomic - consisting of one atom

Neutrino - an uncharged elementary particle that has at least 2 forms, that is believed to be massless, and that interacts very weakly after being created as $\dot{a}$ result of particle decay 
Nitile - an organic cyanide containing the group $\mathrm{CN}$ which on hydrolysis yields an acid with elimination of ammonia

Noble (gases) - chemically inert or inactive

Octahedral - having eight plane faces

Orifice - an opening through which something can pass

Palladiuim - a silver-white, ductile, malleable, metallic element of the platinum group that is used in electrical contacts as a catalyst and in alloys

Permeability - having pores or openings that permit liquids or gasses to pass through

Phosphorescence - luminescence that is caused by the absorption of radiations and continues for a noticeable time after these radiations have stopped: an enduring luminescence without sensible heat

Picoammeter - an instrument that measures tiny amounts of current

-Polyamides - polymeric condensation product of the diamine and a di-acidanhydride

Polystyrene - a rigid transparent thermoplastic of good physical and electric insulating properties used especially in molded products, foams, and sheet materials

Primary Containment - the container that surrounds the tritium to keep it from escaping

Protium - the first isotope of hydrogen

Quenching - extinguishing, cooling by immersion, causing to lose heat, to bring something to an end by dampening, cooling, decreasing, or terminating; to become calm, subside

Radiologic - of or relating to nuclear radiation

Radioluminescent - light given off by a compound that is stimulated by radiation Radiolytic - pertaining to chemical decomposition by the action of radiation

Radiometric - using an instrument to measure the intensity of radiant energy by the torsional twist of suspended vanes that are blackened on one side and exposed to a source of radiant energy

Roentgen - relating to X-rays

Scintillation - a flash of light produced in a phosphor by an ionizing event 
Scintillation counter - a device for detecting and registering individual flashes (as in radioactive emission)

Secondary Containment - the container that surrounds the primary container in case tritium escapes from it

Solute - a dissolved substance

Sorption - the process of taking up and holding by either adsorption or absorption Species - a class of individuals having common attributes and designated by a common name or a particular kind of atomic nucleus, atom, molecule or ion

Ternary - the third of three parts

Tertiary Containment - the container that surrounds the secondary container

Tetahedral - having four plane faces

Torr - a unit of pressure equal to $1 / 760$ of an atmosphere

Transducer - a device that is actuated by power from one system and supplies power, usually in another form to a second system: a converter

Tritides - generic name for any compound of tritium

Trition - the nucleus of tritium 